UNIVERSIDADE DE BRASÍLIA

INSTITUTO DE FÍSICA - IF

PROGRAMA DE PÓS-GRADUAÇÃO EM FÍSICA

TESE DE DOUTORADO

"PROPRIEDADES MAGNÉTICAS DE MEMÓRIA E ENVELHECIMENTO, EXCHANGE BIAS E TREINAMENTO DE NANOPARTÍCULAS DO TIPO CORE-SHELL EM REGIME DE INTERAÇÕES DIPOLARES FRACAS E FORTES"

RODOLPHO CARVALHO LEITE

ORIENTADOR

JÉRÔME DEPEYROT

BRASÍLIA - DF, BRASIL

OUTUBRO, 2016 
“PROPRIEDADES MAGNÉTICAS DE MEMÓRIA E ENVELHECIMENTO, EXCHANGE BIAS E TREINAMENTO DE NANOPARTÍCULAS DO TIPO CORE-SHELL EM REGIME DE INTERAÇÕES DIPOLARES FRACAS E FORTES"

Tese apresentada ao Programa de Pós-graduação em Física do Instituto de Física da UnB, como requisito parcial para obtenção do título de Doutor em Física Experimental da Universidade de Brasília.

COMISSÃO AVALIADORA COMPOSTA POR:

PROF. DR. JÉRÔME DEPEYROT

PROF. DR. FRANCISCO ERONI PAZ DOS SANTOS PROF. DR. MÁRIO ALBERTO SINOMATO ALTOÉ PROF $^{\mathrm{a}}$. DR ${ }^{\mathrm{a}}$. RENATA AQUINO DA SILVA SOUZA PROF. DR. FRANCISCARLOS GOMES DA SILVA PROF. DR. FÁBIO LUIS DE OLIVEIRA PAULA

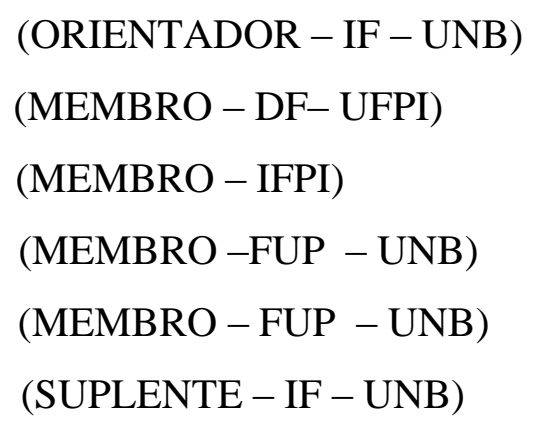


Ficha catalográfica elaborada automaticamente, com os dados fornecidos pelo(a) autor(a)

PROPRIEDADES MAGNÉTICAS DE MEMÓRIA E

ENVELHECIMENTO, EXCHANGE BIAS E TREINAMENTO DE NANOPARTÍCULAS DO TIPO CORE-SHELL EM REGIME DE INTERAÇÕES DIPOLARES FRACAS E FORTES / RODOLPHO CARVALHO LEITE; orientador JÉRÔME DEPEYROT. -Brasilia, 2016. $175 \mathrm{p}$.

Tese (Doutorado - Doutorado em Física) -Universidade de Brasília, 2016.

1. Nanopartículas core-shell. 2. Ferrofluido. 3. Efeito de Memória. 4. Exchange Bias. 5. Efeito de Treinamento. I. DEPEYROT, JÉRÔME, orient. II. Título. 


\section{"Propriedades magnéticas de memória e envelhecimento, exchange bias e treinamento de nanopartículas do tipo core-shell em regime de interações dipolares fracas e fortes."}

\section{Por}

\section{Rodolpho Carvalho Leite}

Tese submetida ao Instituto de Física da Universidade de Brasília como parte dos requisitos para a obtenção do grau de Doutor em Física.

Aprovada por:

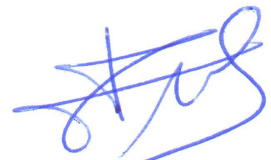

Prof. Jerome Depeyrot

$\mathrm{IF} / \mathrm{UnB}$

$$
\text { Francisco Eroni P. dos Santos }
$$

Prof. Francisco Eroni Paz dos Santos

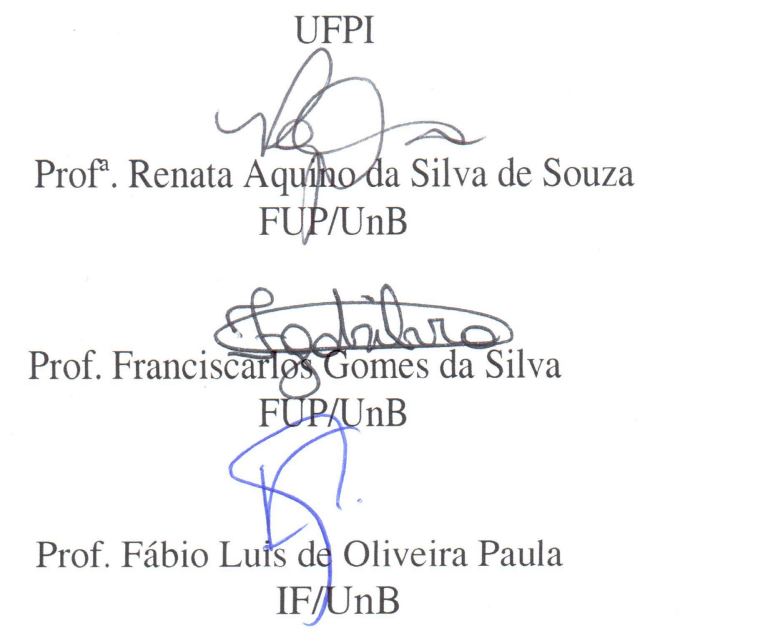

Prof. Dr. Fernando de Oliveira Albuquerque

Coordenador de Pós-Graduação

Instituto de Física 
Posso ter defeitos, viver ansioso e ficar irritado algumas vezes, Mas não esqueço de que minha vida É a maior empresa do mundo...

E que posso evitar que ela vá à falência. Ser feliz é reconhecer que vale a pena viver Apesar de todos os desafios, incompreensões e períodos de crise. Ser feliz é deixar de ser vítima dos problemas e Se tornar um autor da própria história... É atravessar desertos fora de si, mas ser capaz de encontrar Um oásis no recôndito da sua alma... É agradecer a Deus a cada manhã pelo milagre da vida. Ser feliz é não ter medo dos próprios sentimentos. É saber falar de si mesmo. É ter coragem para ouvir um "Não"!!! É ter segurança para receber uma crítica, Mesmo que injusta...

Pedras no caminho? Guardo todas, um dia vou construir um castelo...

Fernando Pessoa 


\section{AgRADECIMENTOS}

Em primeiro lugar agradeço a Deus por ter me guiado pelo caminho do bem, por ter colocado pessoas extraordinárias na minha vida que contribuíram para a formação do meu caráter.

À criança que teve contato com ciências e se apaixonou, que deste momento em diante começou a tentar compreender a Natureza. Sua busca por conhecimento teve como resultado a elaboração desta Tese.

A minha esposa Lara Patrícia, por entender, se preocupar comigo, dar suporte, atenção, carinho, e tempo a mim dedicado, sempre disposta a ajudar e por dividir a vida comigo. Agradeço por você estar ao meu lado.

Aos meus pais Ernandes e Benedita, por tudo que me ensinaram e proporcionaram, educação, carinho, palavras de força e apoio incondicional nesta jornada longe de casa. Aos meus irmãos Ronney, Rosane, Raysa e Rubens pelos debates, brigas, risos e pelo apoio que sempre demonstraram.

Aos familiares tia Isabel, Vilani e Bernadete, Bruno e Mônica e os tios José Cavalcante e Anunciada pela acolhida e apoio durante a passagem por Brasília.

A minha avó Maria José e tia Maria da Luz, meus sogros Ângela e Francisco e demais parentes que sempre me apoiaram e ajudaram. Muito obrigado!

Aos professores de toda uma vida escolar, que me deram uma base para chegar tão longe. Meu eterno agradecimento!

Aos professores do curso de Licenciatura em Física da UESPI Edina, Janete e Memória por transmitir seus conhecimentos e o professor Carlos Alberto por ter me aceitado como aluno de iniciação cientifica e me proporcionar os primeiros passos na vida acadêmica-científica.

Agradeço ao Prof. Dr. Jérôme Depeyrot que me acolheu como aluno desde 2009, pelas orientações, discussões para enriquecimento deste trabalho e orientação desde o mestrado. Muitíssimo obrigado pelos seus conselhos, explicações, dicas, paciência, entusiasmo e vasto conhecimento no assunto! 
A Prof ${ }^{a}$. Dra ${ }^{a}$. Renata Aquino que muito me ensinou, direcionou, ajudou a solucionar diversos problemas científicos e sempre questionou sobre resultados dos experimentos para enriquecimento das pesquisas.

Minha sincera gratidão aos membros do Grupo de Fluidos Complexos (GFC). Ao Prof. Dr. Mikhael Ael pelas primeiras discursões sobre magnetismo, aos professores Dr(s). Fábio Luís, Alex Campos e Leonardo pelas valiosas conversas e bate papos descontraídos. Ao Dr. Francisco Tourinho (in memoriam) por dar início as pesquisas com fluidos complexos no Brasil, momentos de risos, pelas piadas, histórias e esclarecimentos. Aos alunos do GFC, Priscilla Copolla pela elaboração da amostra de ferrofluido nesta Tese e amizade, Danielle, Vanessa, Guilherme, Thiago, Clauber, Fernando, Rafael, Tatiane, Larissa, Cynara, Cleber e Paulo. Pela companhia e trocas de experiências.

Agradeço a professora $\mathrm{Dr}^{\mathrm{a}}$. Regine Perzynski da Universidade UPMC-Sorbonne por ter me recebido em Paris para conclusão dos experimentos de magnetização desta Tese.

Aos amigos de República, Argleydson Leão tivemos muitos momentos de descontração e científicos, tanto em casa como no laboratório. Igo Tôrres sempre vou lembrar das coisas que aconteciam conosco na UnB e das conversas à noite. Rhuiago pelas conversas, brincadeiras e aprendi muito com sua história de vida. Amigos para uma vida toda.

Ao Dr. Clever Stein por compartilhamos das dificuldades e aventuras na chegada em Brasília, das horas de estudo para as disciplinas do mestrado e doutorado e compartilhar as ansiedades pré-defesa.

Ao Dr. Franciscarlos, amigo de república e laboratório, por toda ajuda nos experimentos e pela parceira. Aprendi muito com você, muito obrigado por tudo!

Ao Dr. Rafael Cabreira sempre irei lembrar da frase que você me falou na véspera da defesa de mestrado que mudou minha forma de pensar. "Bah para com isso! Você sabe! Ninguém mais que você sabe do seu trabalho e para de bancar o coitadinho" te agradeço meu amigo!

Aos amigos do Instituto de Física Nádia, Queila, Mônica, Sara, Ana Claudia, Lauriane, Mário, Allison, Edson, Erinaldo, Marcos André, entre tantos. Com vocês a UnB não teria graça.

As instituições de ensino por onde lecionei como professor substituto e muito aprendi. Ao Campus Formosa do Instituto Federal de Educação do Goiás (IFG) e Unidade Universitária da Universidade Estadual do Goiás (UEG). E aos seus diretores e coordenadores que me 
ajudaram organizando os horários para que eu pudesse me dedicar às pesquisas do meu doutorado. Muito obrigado.

Ao Instituto Federal de Educação do Piauí, como professor efetivo, Campus Corrente e agora Oeiras agradeço pela compreensão e liberação todas as vezes que precisei me ausentar para concluir os experimentos e escrita desta Tese.

Aos professores do Instituto de Física da Universidade de Brasília Geraldo José, Ricardo Gargano e demais professores. Muito obrigado!

Aos Funcionários do IF-UnB, em especial Sandra Patrícia por todo auxilio e pelo respeitável trabalho desenvolvido na secretária da Pós-Graduação em Física.

Ao Prof. Dr. Francisco Eroni da Paz dos Santos do Departamento de Física da Universidade Federal do Piauí e Dr. Mário Alberto Sinomato Altoé do Instituto Federal do Piauí por aceitarem participar da comissão avaliadora dessa Tese.

Ao repositório $\mathrm{Sci}-\mathrm{Hub}$ por fornecer acesso livre a artigos, possibilitando a difusão de conhecimento.

Pelo apoio financeiro da Coordenação de Aperfeiçoamento de Pessoal de Nível Superior - CAPES que possibilitou a realização desta pesquisa. 
Cada pessoa deve trabalhar para seu aperfeiçoamento e, ao mesmo tempo, participar da responsabilidade coletiva por toda a humanidade 


\section{RESUMO}

LEITE, R. C. Propriedades magnéticas de memória e envelhecimento, exchange bias e treinamento de nanopartículas do tipo core-shell em regimes de interações dipolares fracas e fortes. 2016 175f. Tese (Doutorado em Física Experimental) - Instituto de Física, Universidade de Brasília - UnB, Brasília, 2016.

Investigamos as propriedades magnéticas de nanopartículas core-shell (NPs-CS) ultrapequenas de $\mathrm{CoFe}_{2} \mathrm{O}_{4} @ \gamma-\mathrm{Fe}_{2} \mathrm{O}_{3}$ com diâmetro médio de $\mathrm{d}_{\mathrm{RX}}=2.7 \mathrm{~nm}$ em amostras de ferrofluido diluído e pó compacto. Utilizamos a abordagem proposta por Thamm e Hesse para definir os dois regimes de interações fracas, para amostra de ferrofluido diluído, e fortes, para amostra pó, presentes a $5 \mathrm{~K}$. A energia de anisotropia magnética, nestes regimes, é sondada pela curva de primeira magnetização, dependência térmica do campo coercivo e curva ZFC-FCW. O congelamento dos spins de superfície em camada desordenada Spins-Glass-Like (SGL) é observado por um desvio da Lei de Bloch em baixas temperaturas que induz uma interface Ferrimagnética/Spins-Glass-Like (FI/SGL) nas NPs-CS. Em baixo campo constatamos a presença do efeito de memória magnética com protocolo de envelhecimento DC, atribuímos aos spins desordenados da superfície como a origem intrínseca do efeito de memória e potencializado pelo comportamento coletivo do estado de Superspins-Glass - SSG (vidros de superspins) da amostra na forma de pó. Os Resultados magnéticos evidenciam que as nanopartículas possuem um núcleo ferrimagnético revestido com uma superfície com spins congelados desordenadamente. Devido essa particularidade em sua formação magnética, quando o sistema é submetido ao congelamento com campo aplicado induz uma anisotropia unidirecional nas NPs-CS gerando um deslocamento do ciclo de histerese magnética, conhecido como Exchange Bias $\left(H_{E X}\right)$. O campo $H_{E X}$ é medido em função do campo de congelamento $\left(H_{c o o l}\right)$, aumentando até um máximo $\left(H_{c o o l}^{M A X}\right)$ de $12 \mathrm{kOe}$ e diminuindo com aumento adicional de $H_{\text {cool. }}$. Com $H_{\text {cool }}^{M A X}$ encontramos um $H_{E X}$ de $42.3 \mathrm{kA} / \mathrm{m}$ para amostra pó e $H_{E X}$ de $18.5 \mathrm{kA} / \mathrm{m}$ para ferrofluido diluído da ordem da metade do campo de anisotropia. A presença de efeitos laços menores (minor loops) sobre as NPs-CS podem ser excluídos porque, para todos os ciclos de histerese, a magnetização de alto campo é bem reversível em uma grande variedade de campo. A análise da variação de $H_{E X}$ com número de ciclos ( $n$ ) sucessivos após o processo de FC com $H_{c o o l}^{M A X}$, em tais sistemas de NPs-CS, revelaram uma diminuição no $H_{E X}$ apontando para a presença do chamado Efeito de Treinamento. Investigamos o Efeito de Treinamento em relação algumas características: regime de interações interpartículas fracas e fortes, relaxamento dos spins não compensados congelados e rodáveis na interface FI/SGL, influência da temperatura e envelhecimento. Os dados experimentais foram ajustados com o modelo Binek, com o qual conseguimos extrair o parâmetro $\gamma$ que nos fornece informações da dinâmica não linear do acoplamento entre as interfaces. O modelo Zheng et al. para observar o vertical Shift (deslocamento vertical) atribuído pelo alinhamento dos spins congelados com campo de congelamento e por fim o modelo de Radu et al. que considera um cenário misto de contribuições, para o efeito de treinamento, de origem nas componentes de spins não compensados congelados e rodáveis na interface. Em suma, as análises feitas nesta Tese confirmam a presença do Efeito de Treinamento em ferrofluidos, ainda se demonstrou que as interações interpartículas, temperatura e envelhecimento influenciam na intensidade do fenômeno.

Palavras Chaves: Nanopartículas core-shell, ferrita de cobalto, efeito de memória, exchange bias, efeito de treinamento. 


\begin{abstract}
LEITE, R. C. Magnetic properties of memory and aging, exchange bias and training of core-shell type in weak and strong dipolar interactions regimes nanoparticles. $2016175 \mathrm{f}$. Thesis (Doctorate in Experimental Physics) - Institute of Physics, Universidade de Brasília UnB, Brasília 2016.

We investigated the magnetic properties of ultrasmall core-shell nanoparticles (NPs-CS) $\mathrm{CoFe}_{2} \mathrm{O}_{4} @ \gamma-\mathrm{Fe}_{2} \mathrm{O}_{3}$ with mean diameter $\mathrm{d}_{\mathrm{RX}}=2.7 \mathrm{~nm}$ in samples diluted ferrofluid and compact powder. We used the approach proposed by Thamm and Hesse to define the two interactions regimes. Weak for diluted ferrofluid sample and strong for powder sample present at $5 \mathrm{~K}$. The magnetic anisotropy energy in these interaction regimes, is probed by the first magnetization curve, temperature dependence of the coercive field and ZFC-FCW curve. The freezing of surface spins in disordered layer Spin-Glass-Like (SGL) is observed by a deviation from Bloch's law at low temperatures, that induces an ferrimagnetic/spin-glass-like (FI/SGL) interface in NPs-CS. At Lowest field we investigate the effect of magnetic memory with DC aging protocol, attribute to the shell as the intrinsic origin of memory effect and potentiated by the collective behavior of the state of Superspins-Glass (SSG) of the sample in powder. Magnetic results show that nanomaterials have a ferrimagnetic core coated with a surface with spins frozen disorderly (SGL). Due to this peculiarity in its magnetic forming, when the system is subjected to freezing with applied field induces a unidirectional anisotropy in NPs that generates a displacement of the magnetic hysteresis loop, known as the exchange bias $\left(H_{E X}\right)$. The $H_{E X}$ field is measured according to the freezing field $\left(H_{c o o l}\right)$. It increases up to a maximum $\left(H_{\substack{\text { cool } \\ \text { caX }}}\right.$ ) of $12 \mathrm{kOe}$ and decreases with further increase in $H_{\text {cool }}$, with $H_{\text {cool }}^{M A X}$ we found $H_{E X} 42.3$ $\mathrm{kA} / \mathrm{m}$ to powder sample and $H_{E X} 18.5 \mathrm{kA} / \mathrm{m}$ to dilute ferrofluid, of the order of half the anisotropy field. The presence of minor loops effects on NPs-CS investigated can be excluded, because for all hysteresis loops, the high magnetizing field is reversible and in a wide variety of field. The analysis of $H_{E X}$ variation with number of successive cycles $(n)$ after the FC process with $H_{\substack{\text { cool } \\ \text { col }}}$, in such systems NPs-CS, revealed a decrease in the $H_{E X}$ pointing out the presence of training effect. Investigated in relation some characteristics: regime of weak and strong interactions interparticle, relaxation of spins uncompensated frozen and rotatable in FI/SGL interface, influence of temperature and aging. The experimental data were adjusted with the Binek model, with which we can extract the $\gamma$ parameter that provides information on the dynamic non-linear coupling between the interfaces. The model Zheng et al. to observe the vertical shift attributed by the alignment of frozen spins with cooling field and finally the model Radu et al. considering a mixed picture of contributions for the purpose of training effect, origin in the spin components uncompensated frozen and rotatable in the interface. In summary, the analyzes made in this thesis confirm the presence of the Training Effect in ferrofluids, it was still demonstrated that interactions interparticle, temperature and aging influence the intensity of the phenomenon.
\end{abstract}

Keywords: core-shell nanoparticles, cobalt ferrite, memory effect, exchange bias, training effect. 


\section{SUMÁRIO}

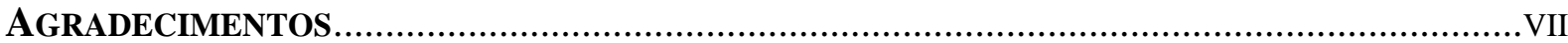

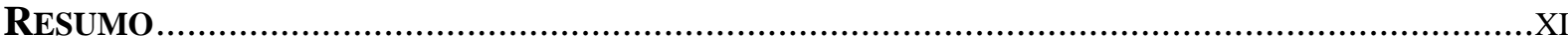

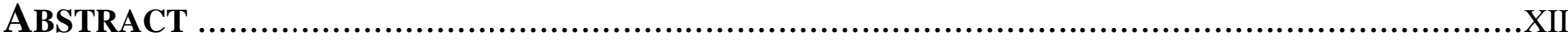

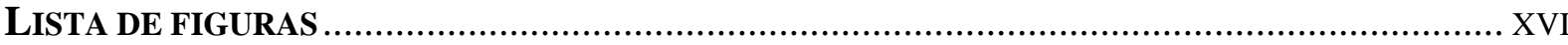

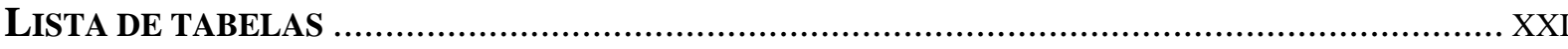

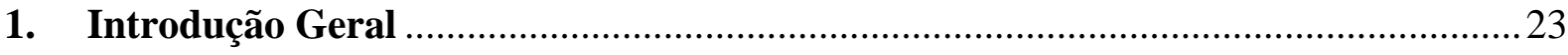

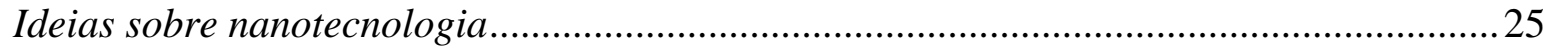

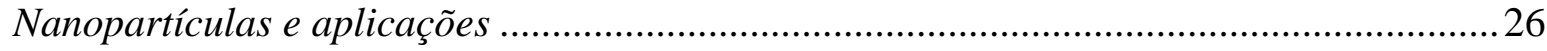

Nanopartículas core-shell e fenômenos magnéticos ..........................................................2 28

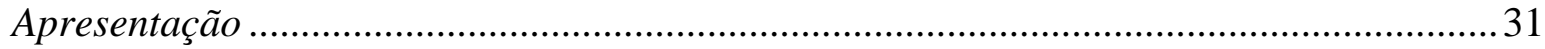

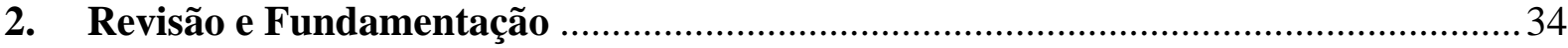

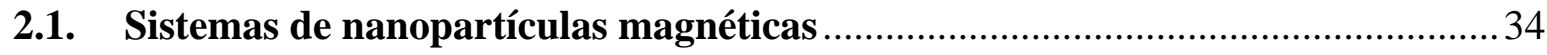

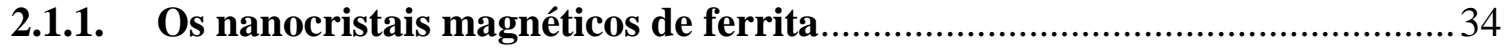

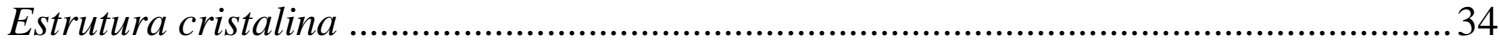

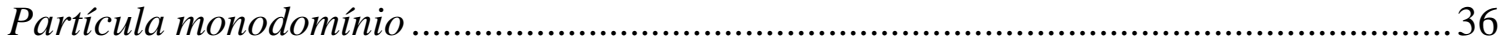

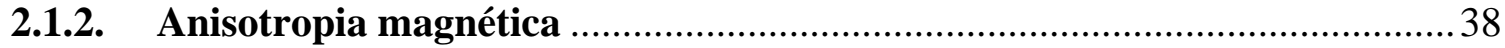

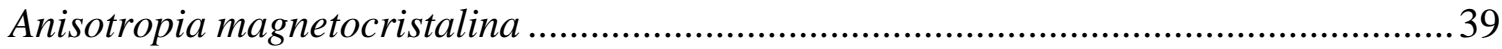

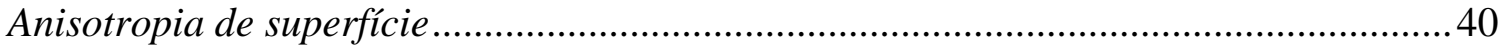

2.1.3. Ciclo de histerese magnética - Modelo de Stoner \& Wohlfarth .................. 40

2.1.4. Superparamagnetismo de Néel e Temperatura de Bloqueio ….................... 43

2.1.5. Interações Interpartículas e Thamm-Hesse Plot ........................................ 44

Energia de Interação dipolar entre as partículas ............................................................ 44

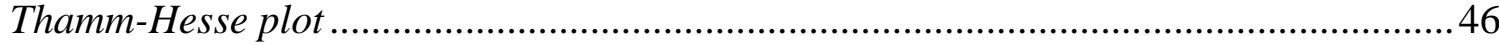

2.1.6. Aleatoriedade e frustração em sistemas de nanopartículas magnéticas...... 48

2.1.7. Efeito de memória magnética com protocolo de envelhecimento DC..........50

2.2. Exchange Bias e Efeito de Treinamento ..........................................................52

2.2.1. Congelamento de spins de superfície em estrutura SGL ...........................52

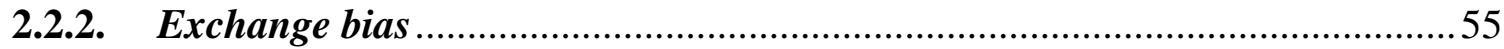

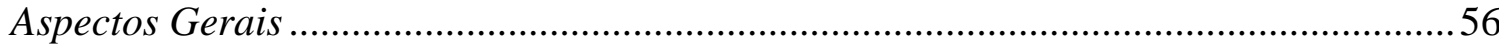

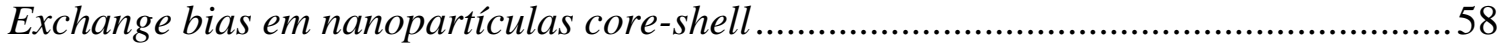

Interações intra/interpartículas e natureza do núcleo ........................................................6 60

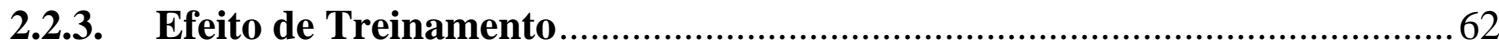


Modelo de Paccard et al.

Modelo de Binek.....

Modelo de Zheng et al.

Modelo de Radu et al.

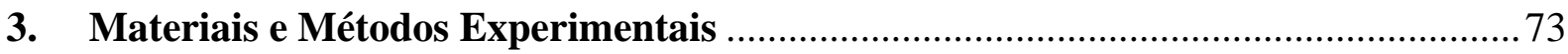

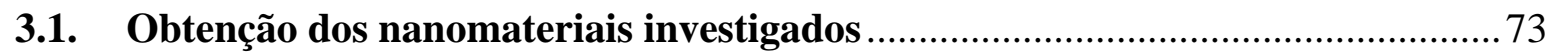

3.1.1. Síntese química de ferrofluidos do tipo EDL-MF ...................................... 73

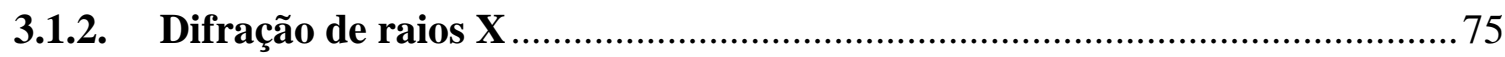

3.1.3. Composição química e fração volumétrica de nanopartículas ...................... 78

3.1.4. Microscopia eletrônica de transmissão .......................................................... 81

3.2. Métodos de investigação das propriedades magnéticas ...................................... 84

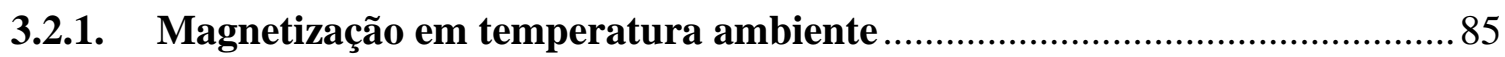

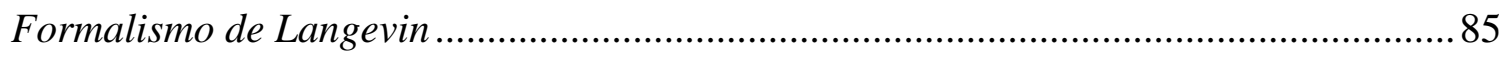

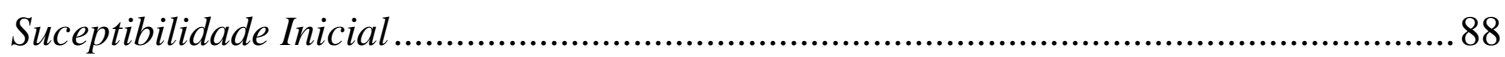

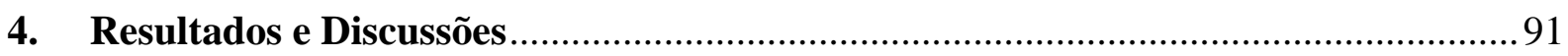

4.1. Ciclos de histerese magnética ZFC e interações interpartículas .......................91

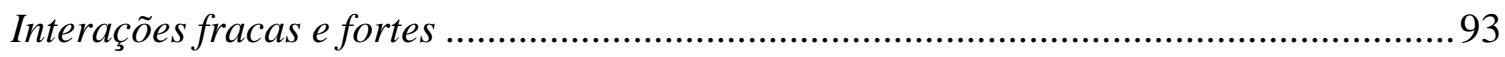

4.2. Anisotropia magnética em regime de interações fracas e fortes........................95

4.2.1. Curva de primeira magnetização ................................................................ 95

4.2.2. Dependência térmica do campo coercivo .................................................. 97

4.2.3. Magnetização versus temperatura em curvas ZFC-FCW ......................... 100

Considerações sobre anisotropia magnética investigada .............................................. 104

4.3. Desordem magnética em sistemas de NPs-CS com interações fracas e fortes.. 105

4.3.1. Dependência térmica da magnetização em alto campo................................ 105

4.3.2. Magnetização DC em baixo campo: memória e envelhecimento …............ 108

4.4. Exchange bias e efeito de treinamento induzido pelo shell ..............................112

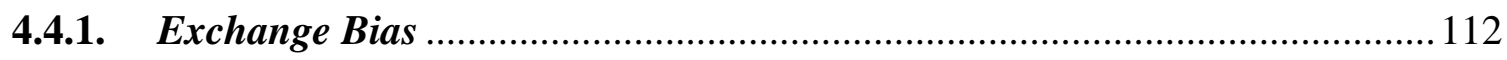

Origem do exchange bias e sua dependência com o campo de cooling......................... 112

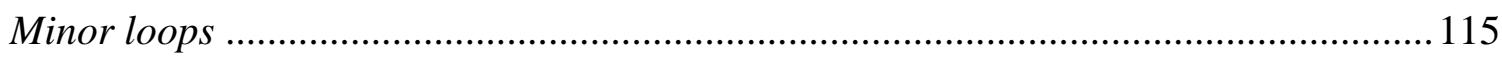

4.4.2. Dinâmica não linear do efeito de treinamento ......................................... 118

Interações fracas e fortes no efeito de treinamento ....................................................... 119

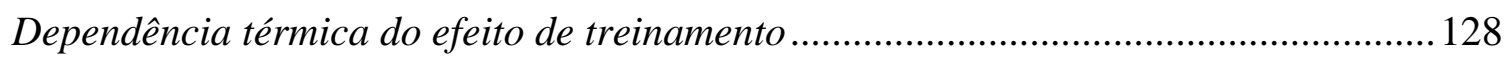

Influencia do envelhecimento do efeito de treinamento ................................................ 132

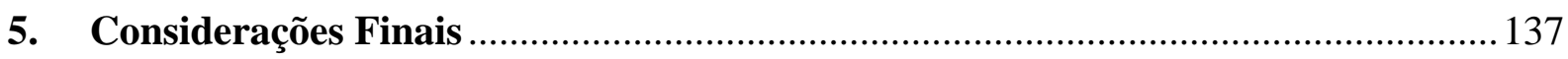

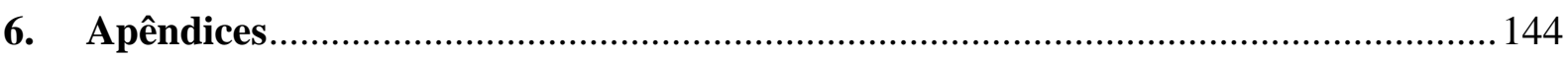




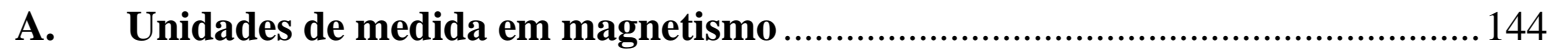

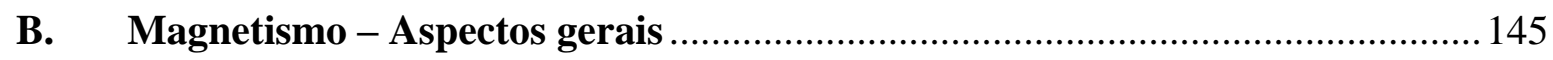

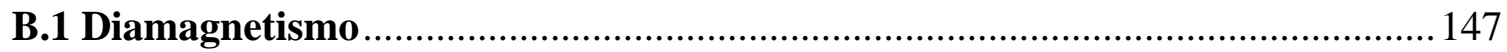

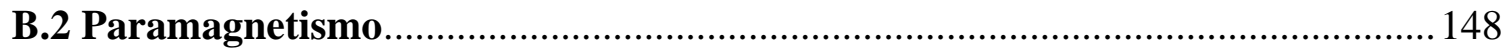

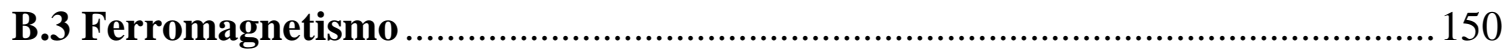

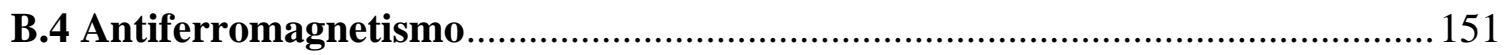

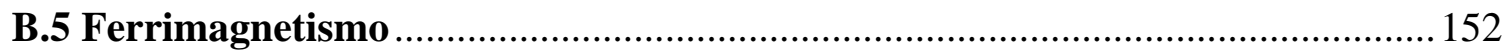

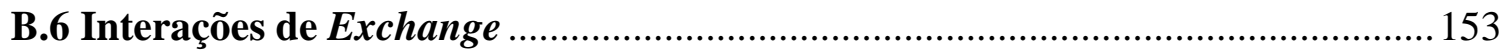

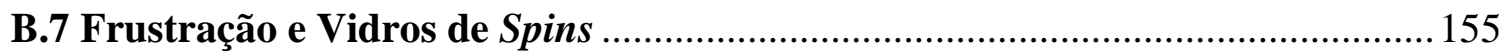

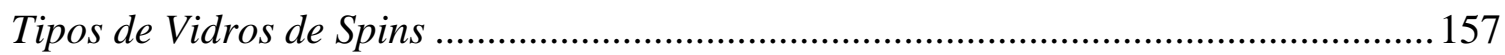

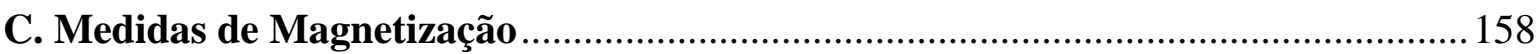

C.1 Protocolos experimentais das medidas magnéticas ............................................ 159

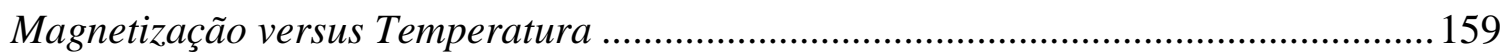

Magnetização versus Campo Magnético Aplicado ....................................................... 161

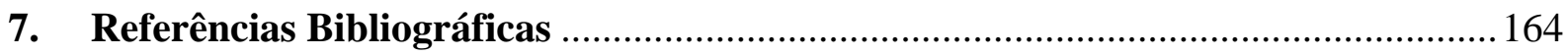




\section{LISTA DE FIGURAS}

Figura 1: a) Separação magnética de bactérias por nanopartículas magnética retirado da referência (LEE et al., 2013). b) Esquema da estrutura e função Nanopartícula hibridada com a sequência de reconhecimento de DNA que contém um fluoróforo (vermelho) (Nanoflare). c) As células cancerosas com genes específicos, brilho em vermelho, uma vez infiltrada por novas nanopartículas (esquerda). As nanopartículas não brilham em células sem o gene (à direita) Adaptado de (HALO et al., 2014) d) Oligômeros fluorescentes beta amiloide (verde), vinculados aos neurônios do hipocampo em cultura, foram detectados com mais de 90 por cento de precisão pela nanoestrutura magnética (vermelho) Adaptado de (VIOLA et al., 2015).... 27

Figura 2: Estrutura cristalina de uma ferrita tipo espinélio.

Figura 3: Representação da distribuição eletrônica dos íons metálicos nos orbitais $3 \mathrm{~d}$ e número de magnétons de Bohr associado.

Figura 4: (a) definição do sistema de eixos para uma partícula fina e (b) Dependência angular da barreira de energia para campo externo zero (linha contínua) e por um valor menor do campo do que o campo coercitivo (linha tracejada) (KNOBEL et al., 2008).

Figura 5: Ciclos de histerese magnética de partículas monodomínios com anisotropia uniaxial. $\phi$ é o ângulo entre o campo externo e o eixo de fácil magnetização retirado da ref. (CULLITY; GRAHAM, 2011)....

Figura 6: O esquema mostra geometricamente dois momentos magnéticos $\mu$ distantes entre si de uma distância $r$, porém próximos o suficiente para interagirem através da interação dipolar.

Figura 7: (a) Explanação das suposições para o cálculo da relação entre $\Delta \mathrm{m}$ e $\Delta \mathrm{m}_{\mathrm{H}}, \mathrm{m}_{\mathrm{vir}}=\mathrm{m}_{\mathrm{ic}}$, $\mathrm{m}_{\text {sup }}=\mathrm{m}_{\text {uc }}$ e $\mathrm{m}_{\text {inf }}=\mathrm{m}_{\mathrm{lc}}$. A curva de primeira magnetização e o laço de histerese são desenhados com linhas sólidas. Os resultados típicos de $m_{d}(H)$ e $m_{r}(H)$ usado para o Henkel plot são mostrados como linhas tracejadas. (b) O resultado do Henkel plot para amostra de ferritas de cobalto em regimes de ferrofluido diluído (representado por F) e pó compacto (representado por P variando a pressão de compactação) de Ferrita de Cobalto com diâmetro similar de 3.15 nm, extraída de (VIEIRA, 2013). c) ciclo de histerese (normalizado) de 2DD de 3,5" material do disco Sony. (d) derivação do $\Delta m$ calculado a partir da fig. (c) figuras extraídas da ref. (THAMM; HESSE, 1996).

Figura 8: (a) MzFC (T) (círculos abertos) e de $\mathrm{MFC}_{\mathrm{FC}}(\mathrm{T})$ (círculos a cheio) de $\left[\mathrm{Co}_{80} \mathrm{Fe}_{20}(\mathrm{TN}=0,9\right.$ $\left.\mathrm{nm}) / \mathrm{Al}_{2} \mathrm{O}_{3}(3 \mathrm{~nm})\right]$ medida com campo de $\mu_{0} \mathrm{H} \approx 0.4 \mathrm{mT}$. O mergulho no $\mathrm{M}_{\mathrm{FC}}$ (seta) é típico de um sistema SSG ou SG; Extraído da ref. (BEDANTA; KLEEMANN, 2009. (b) Dependência da temperatura da magnetização para o resfriamento em ausência de campo (ZFC) ou em presença de campo Field Cooled Cooling (FCC) e aquecimento Field Cooled Warming (FCW). [insert (a)] O mergulho na MFCw está associada com o início do congelamento dos superspins em estrutura SSG $\left(\mathrm{T}_{\mathrm{f}} \sim 50 \mathrm{~K}\right)$ e (b) mostra a diferença $\left(\mathrm{MFCC}_{\mathrm{F}} \mathrm{M}_{\mathrm{FCW}}\right)$ representada graficamente em função da temperatura, em que um aumento acentuado $\left(\mathrm{T}_{\mathrm{g}} \sim 68 \mathrm{~K}\right)$ marcas o início da histerese térmica. Extraído da ref. (CHANDRA et al., 2012).

Figura 9: (a) Efeito de memória na magnetização DC para nanopartículas de permalloy $\left(\mathrm{Ni}_{11} \mathrm{Fe}_{19}\right)$ dispersas num liquido carreador. A linha sólida é medida por aquecimento a uma velocidade constante de $2 \mathrm{~K} / \mathrm{min}$ após FC em 50 Oe (curva de referência). Os quadrados cheios são medidos durante o arrefecimento em 50 Oe à mesma velocidade, mas com paradas de 4 horas de duração, a 70, 50 e $30 \mathrm{~K}$. O campo é cortado durante cada paragem. Os círculos abertos 
são medidos com aquecimento contínuo com a mesma taxa de arrefecimento após o procedimento anterior, extraído da referência (SUN et al., 2003). (b) (Linhas coloridas) susceptibilidade $\mathrm{FC}$ do sistema $\mathrm{Fe}_{3} \mathrm{~N}$ com o mesmo protocolo que o que na fig. 13 (a). A temperatura crítica da amostra é de cerca de $60 \mathrm{~K}$. O campo é cortado durante as paragens intermitentes do arrefecimento a $\mathrm{T}=40$ e $30 \mathrm{~K}$ para $3000 \mathrm{~s}$ a cada temperatura. A taxa de arrefecimento (e reaquecimento) é $\sim 0.01 \mathrm{~K} / \mathrm{s}$. O insert mostra o ZFC e FC susceptibilidades vs temperatura, extraído da referência (SASAKI et al., 2005).

Figura 10: (a) diminuição da camada superficial com campo aplicado e dependência térmica da magnetização para ferrita de níquel fig. extraída de (SOUSA et al., 2009). (b) dependência da magnetização com a temperatura, o insert mostra a contribuição da superfície na magnetização, fig. extraída de (GOMES, 2015). (c) dependência da magnetização com a temperatura para vários diâmetros de partículas de ferrita de manganês, fig. extraída de (SILVA, 2014). ........54

Figura 11: a) ciclos de histerese de partículas Co-CoO tomadas a $77 \mathrm{~K}$. A linha tracejada mostra o ciclo após o arrefecimento no campo zero. A linha sólida representa a curva de histerese medidos após o arrefecimento do sistema de um campo de $10 \mathrm{kOe}$. b) curva de torque para as partículas de Co a $300 \mathrm{~K}$ mostram anisotropia uniaxial. b) curva de torque de partículas de Co$\mathrm{CoO}$ tomadas a $77 \mathrm{~K}$ mostrando a anisotropia unidirecional incomum. d) O magnetômetro de torque. O principal componente é uma mola que mede o torque em função do ângulo $\theta$ quando amostra é colocada na presença de um campo magnético. Fig. extraída da ref. (RADU; ZABEL, 2008a). 56

Figura 12: ciclos de histerese magnética com protocolos: (a) Zero Field Cooling e (b) Field Cooling que apresenta o deslocamento do ciclo de histerese característica do fenômeno de exchange bias. Figura extraída da ref. (GOMES, 2015).

Figura 13: Representação de uma nanopartícula core-shell com interação de superexchange na interface.

Figura 14: Representação gráfica (a) sistemas não interativos quando amostra suficientemente diluída (b) com proximidade entre as partículas, estas interagem de duas formas: a distância pela interação dipolar e quando em contato por pelo exchange.

Figura 15: Efeito de treinamento típico, (a) mostra a contração dos ciclos de histerese magnética (YANG; ZENG; PAN, 2010) e (b) dependência do Hex com o número de ciclos extraído da referência (BINEK, 2004) .

Figura 16: (a) Definição que modifica o modelo de Stoner \& Wohlfarth apresentado por Zheng et. al. (b) resultado experimental utilizando modelo para nanopartículas de $\mathrm{Fe}$ (core) revestidas por $\gamma-\mathrm{Fe}_{2} \mathrm{O}_{3}$ (shell). Figuras extraídas da ref. (ZHENG et al., 2004a). 70

Figura 17: Esquema geral de síntese química (método bottom-up) de fluidos Magnéticos a base de ferrita de cobalto. $\mathrm{Fe}^{3+}$ e $\mathrm{M}^{2+}$ são as soluções de ferro e do metal divalente $\left(\mathrm{Co}^{2+}\right)$, respectivamente.

Figura 18: a) equipamento utilizado para medida instalado no campus Teresina Central do IFPI b) A condição para que ocorra interferência construtiva, raios difratados na direção $2 \theta$, ângulo entre a direção do feixe incidente e a direção de observação é dada pela lei de Bragg.

Figura 19: A linha da cor preta é o difratograma da amostra pó com seus picos indexados e a linha da cor cinza é a o difratograma para ferrita de cobalto maciça extraído da ficha cristalográfica No. 22-1086. 
Figura 20: (a) equipamento utilizado para experimento de AAS. (b) Representação pictórica das nanopartículas de diâmetro d, mostrando o núcleo composto de ferrita estequiométrica recoberta por uma camada de óxido de Ferro com espessura e..............................................78

Figura 21: (a) densímetro instalado no Laboratório do Grupo de Fluidos Complexos da Universidade de Brasília. (b) curva típica de um ferrofluido em função da fração volumétrica de partículas $\phi$.

Figura 22: Microscópio Eletrônico de Transmissão JEM-2100 instalado no LabMic da Universidade Federal do Goiás.

Figura 23: (a) Microscopia Eletrônica de Transmissão da amostra de ferrita de cobalto com escala de $50 \mathrm{~nm}$ e EDS que confirma os elementos químicos da amostra.

Figura 24: (a) Histograma para nanopartículas aqui investigadas e a linha de cor azul é o ajuste com a função log-normal. (b) microscopia que apresenta algumas nanopartículas que apresenta nanopartículas da ordem de $3 \mathrm{~nm}$.

Figura 25: Microscopia Eletrônica de alta Resolução da amostra FPCo2 evidenciando uma nanopartícula. (b) Transformada Rápida de Fourier.

Figura 26: Physical Properties Measurements System - PPMS utilizados nos experimentos desta Tese.

Figura 27: Curva de magnetização a temperatura ambiente com sua resposta diamagnética do solvente subtraída para amostra FPCo2 $\operatorname{com} \phi=0.18 \%$.

Figura 28: (a) curva de magnetização a temperatura de $300 \mathrm{~K}$ a linha sólida é o ajuste com a função de Langevin (b) determinação da magnetização de saturação.

Figura 29: Medida de Susceptibilidade magnética inicial da amostra FPCo2 a $300 \mathrm{~K}$, a linha solida na cor vermelhe é o ajuste linear.

Figura 30: (a) ciclos de histereses magnéticas ( $5 \mathrm{~K}$ ) juntamente com a curva virgem das amostras pó e ferrofluido diluído congelado. No insert (b) visualizamos a magnetização de Saturação (Ms) das amostras e (c) identificamos o campo coercivo e magnetização remanente na região central dos ciclos.

Figura 31: Funções do tipo $\Delta m$ de Thamm-Hesse para as duas amostras estudadas. Todas as curvas são negativas mostrando um regime de interações predominantemente dipolares.......94

Figura 32: Curva de primeira magnetização para as amostras investigadas a $5 \mathrm{~K}$ 96

Figura 33: Ciclos de histerese magnética para amostra de ferrofluido diluído com $\phi=0.18 \%$, observamos uma contração dos ciclos com o aumento da temperatura. 98

Figura 34: Dependência térmica do campo coercivo para as amostras de ferrofluido diluído e pó compacto, a linha solida é o ajuste linear com a Lei de Kneller.

Figura 35: Resultados dos experimentos usando o protocolo ZFC-FCW para as amostras (a) ferrofluido diluído congelado e (b) pó investigadas, a curva sólida vermelha é a $-d\left(M_{F C W}-M_{Z F C}\right) / d T$ versus T.

Figura 36: Magnetização da amostra de ferrofluido diluído congelado com variação de $5 \mathrm{~K}$ até $250 \mathrm{~K}$ com campo aplicado de $90 \mathrm{kOe}$. 106

Figura 37: Variação da magnetização oriunda da camada de spins desordenados. A linha sólida representa o ajuste aplicado pela equação 71 . 
Figura 38: Efeito de memória para amostra de ferrofluido diluído congelado com paradas em 60,40 e $20 \mathrm{~K}$ com tempo de paradas de 2 horas.

Figura 39: Efeito de memória para amostra pó de nanopartículas core-shell de ferrita de cobalto.

Figura 40: ciclos de histerese magnética com protocolo FC e ZFC a 5 K com variação do campo de cooling para amostra pó, as setas mostram a direção do deslocamento do ciclo a seta indica o sentido do deslocamento do exchange bias.

Figura 41: Dependência do campo de cooling de HEx para as amostras de (a) pó e (b) ferrofluido diluído.

Figura 42: (a) Ciclos de histerese magnética medidos em diferentes entre $\pm H_{\max }$ são apresentados. Em (b) região de saturação, onde as setas representam os $\mathrm{H}_{\max }$ utilizados nos experimentos realizados, os ciclos com $\mathrm{H}_{\max }$ de 10,15 e $20 \mathrm{kOe}$ não fecham as setas representam os campos magnéticos máximos utilizados em cada laço de histerese. (c) região central dos ciclos medidos mostrando o deslocamento dos ciclos para o primeiro quadrante com $\mathrm{H}_{\max }$ 116

Figura 43: A figura (a) apresenta a magnetização de saturação dos ciclos obtidos de $30 \mathrm{kOe}$ até $90 \mathrm{kOe}$, abaixo de $30 \mathrm{kOe}$ o início e o final dos ramos superior e inferior dos ciclos não coincidem confirmando que estão abaixo de de $\mathrm{H}_{\mathrm{k}}$. (b) dependência do campo coercivo com $\mathrm{H}_{\max }$ (c) dependência de $\mathrm{H}_{\text {shift }}$ com $\mathrm{H}_{\max }$. (d) Magnetização remanente e deslocamento vertical com dependência do $\mathrm{H}_{\max }$ 118

Figura 44: Ciclos de histerese magnética medidos consecutivos a $5 \mathrm{~K}$ para amostras de (a) pó e (b) ferrofluido diluído, os inserts mostram a região central dos ciclos de histerese.

Figura 45: Dependência do Exchange Bias para amostras (a) pó e (b) ferrofluido diluído. Com o ajuste da curva com a equação 39 encontramos os valores de k e $H_{E X}^{\infty}$ para as amostras de ferrofluidos diluído e pó compacto. Utilizamos o ajuste com $\mathrm{n} \geq 2$ (linha solida vermelha) para servir de input, para $\mathrm{n} \geq 1$ (linha tracejada em preto) o ajuste é insatisfatório.

Figura 46: A figura reuni os dados extraídos dos ciclos de histerese magnética no protocolo FC e HeX vs n (ciclos abertos) obtidos para o ferrofluido diluído (azul) e pó compacto (preto) da amostra de ferrita de cobalto. Quadrados da cor preta são o ajuste recursivo pelo modelo de Binek. 122

Figura 47: Dependência da magnetização reduzida com o exchange bias para as amostras pó e ferrofluido diluído, as linhas tracejadas são apenas guias para os olhos. 125

Figura 48: Efeito de treinamento das amostras aqui investigadas (a) pó e (b) ferrofluido. A linha sólida de cor vermelha é o ajuste com modelo Radu et al. que leva em consideração as contribuições dos spins congelados e rodáveis. 127

Figura 49: (a) apresenta a dependência de $\operatorname{Hex} \times T$, para amostras ultrapequenas de Ferrita de Cobalto normalizados pelo $\mathrm{H}_{0, \mathrm{Ex}}$ quando $\mathrm{H}_{\text {ex }}$ tende $0 \mathrm{~K}$ para pó e dispersão congelada da Co3. O insert apresenta os mesmos dados. As linhas sólidas são os melhores ajustes encontrados pela lei de resfriamento. Os dados da amostra $\mathrm{Co} 3$ foram gentilmente cedidos por R. CabreiraGomes. (b) em (I) apresenta curva Hex $\times$ T para a amostra de ferrofluido diluída Co3 e (II) a segunda derivada da curva, evidenciando pela ponto de inflexão a temperatura em que o exchange bias tem um aumento acentuado.

Figura 50: (a) ciclos de histerese magnética a $30 \mathrm{~K}$ da amostra de ferrofluido diluída. (b) exibe os ramos superiores dos ciclos 1, 2 e 7 que possibilita visualizamos a contração dos ciclos. 131 
Figura 51: Dependência o EB com número de ciclos de histerese para as duas temperaturas, o quadrado sólido é o ajuste recursivo feito em ambas temperaturas.

Figura 52: Efeito de treinamento para amostra pó com tempos de parada diferentes após o primeiro ciclo.

Figura 53: Efeito de treinamento amostra de ferrofluido diluído com parada em $+90 \mathrm{kOe}$ de $6000 \mathrm{~s}$ antes de todos os ciclos de histerese medidos (a) Dependência do exchange bias com número de ciclos medidos. (b) dependência exchange bias com a magnetização reduzida do modelo de Zheng et al.

Figura 54: Efeito de treinamento com protocolo de envelhecimento para amostra diluída com ajuste com modelo de Radu et al. 135

Figura A.1: Comparação simplificada da permeabilidade para: Ferromagnetismo ( $\left.\mu_{\mathrm{FM}}\right)$, Ferrimagnetismo $\left(\mu_{\mathrm{FI}}\right)$, Paramagnetismo $\left(\mu_{\mathrm{P}}\right)$, o vácuo $\left(\mu_{0}\right)$ e Diamagnetismo $\left(\mu_{\mathrm{D}}\right)$.

Figura A.2: (a) Ciclo de histerese a $5 \mathrm{~K}$ com variação de campo aplicado de $\pm 90 \mathrm{kOe}$ e (b) susceptibilidade a baixo campo $300 \mathrm{~K}$ de $\mathrm{H}_{2} \mathrm{O}+\mathrm{HNO}_{3}$ com ph 3 utilizada para subtração da resposta diamagnética do líquido carreador das amostras investigadas nesta Tese. 148

Figura A.3: Representação pictográfica do comportamento das interações (a) exchange direto (b) exchange indireto. (c) curva de Bethe e Slater mostra que o sinal da integral J muda com o raio dos átomos e assim mudando o tipo de acoplamento, $\mathrm{J}$ positivo alinhamento paralelo e $\mathrm{J}$ negativo alinhamento antiparalelo. Figura extraída e adaptada da ref. (CULLITY; GRAHAM, 2011)

Figura A.4: O coeficiente de exchange indireto (RKKY) versus o espaçamento interatômica $r$ extraído de (SENGUPTA; SARKAR, 2015). 154

Figura A.5: Representação do acoplamento de superexchange da magnetita $\left(\mathrm{Fe}_{3} \mathrm{O}_{4}\right)$, as setas representam os spins dos átomos. 155

Figura A.6: (a) rede quadrada de vizinhos mais próximos antiferromagnética não frustrada. (b) rede triangular de vizinhos mais próximos antiferromagnética frustrada extraída de (BEDANTA; KLEEMANN, 2009). 156

Figura A.7: Representação pictográfica do PPMS com opção VSM. 158

Figura A.8: Protocolo de medida do efeito de memória com magnetização DC. (I) linha sólida na cor preta é a medida com aquecimento a uma velocidade constante de $2 \mathrm{~K} / \mathrm{min}$ com protocolo FC e campo de cooling de 50 Oe (curva de referência) $M_{F C W}^{R}$. (II) protocolo de resfriamento com paradas programadas $M_{F C C}^{D o w n}$ e em (III) protocolo de medida com aquecimento $M_{F C W}^{U_{p}}$. (II) e (III) as curvas foram feitas com paradas de 2 horas de duração, a 60, 40 e $20 \mathrm{~K}$. O campo é cortado durante cada paragem. 


\section{LISTA DE TABELAS}

Tabela 1: Cálculo para uma ferrita de cobalto, * magnetização de saturação experimental (CULLITY; GRAHAM, 2011).

Tabela 2: Resultados da amostra diluída FPCo2 de AAS e valores extraídos a partir do modelo de composição química das nanopartículas core-shell.

Tabela 3: Resultados do experimento de densidade feito para amostra de ferrofluido diluído.

Tabela 4: Resultados quantitativos obtidos a partir do espectro de EDS.

Tabela 5: Parâmetros de interação dipolar a $300 \mathrm{~K}$ deduzidos da susceptibilidade magnética inicial da amostra de ferrofluido diluído. * Calculado com valores da magnetização de saturação a $5 \mathrm{~K}$

Tabela 6: Apresenta os resultados extraídos dos ciclos de histereses magnéticas para amostras aqui investigadas para o campo coercivo, magnetização remanente, magnetização de saturação e a razão entre as duas últimas..

Tabela 7: Resultados extraídos da análise do campo de anisotropia das amostras.

Tabela 8: Resultados do ajuste proposto aos dados extraídos dos ciclos de histerese. Os valores das colunas representam o campo coercivo quando $\mathrm{T} \rightarrow 0 \mathrm{~K}$, a temperatura de bloqueio Intrínseca $T_{B i}$, a Energia de anisotropia $E_{a i}$ e o valor da constante de anisotropia cristalina $K_{i}$.

Tabela 9: Os resultados extraídos da análise da curva ZFC-FCW, via $T_{B}^{M A X}$ 102

Tabela 10: Resultados extraídos da análise do pico $-d\left(M_{F C W}-M_{Z F C}\right) / d T$ versus $\mathrm{T}$ das curvas ZFC-FCW.

Tabela 11: Análise da anisotropia magnética deduzida via: campo de anisotropia $5 \mathrm{~K}\left(\mathrm{H}_{\mathrm{k}}\right)$, dependência térmica do campo coercivo ( $\mathrm{H}_{\mathrm{C}} \mathrm{vs} \mathrm{T}$ ), pico da derivada da diferença das curvas FCW-ZFC $\left(-d\left(M_{F C W}-M_{Z F C}\right) / d T\right.$ vs T) e máximo da curva ZFC $\left(T_{B}^{M A X}\right)$......... 104

Tabela 12: A tabela apresenta os valores encontrados nos ajustes, usando as equações (29) e (71). As colunas da tabela representam respectivamente: a fração volumétrica $(\phi)$, a magnetização de saturação (Ms), o expoente crítico $(\alpha)$, a constante de Bloch $(B)$, a temperatura de congelamento $\left(\mathrm{T}_{\mathrm{f}}\right)$ e a constante de proporcionalidade $(\mathrm{A})$. * Resultados extraídos de (CABREIRA-GOMES et al., 2014).

Tabela 13: Resultados dos ajustes de Paccard et al. e Binek para as amostras de ferrofluido diluído e pó com tempo de espera entre os ciclos $t \mathrm{w}=0 \mathrm{~s} . T E_{n}(\%)$ entre o primeiro e segundo ciclo.

Tabela 14: Parâmetros encontrados do ajuste das curvas de efeito de treinamento utilizando o modelo de Radu et al.

Tabela 15: Parâmetros extraídos do modelo de Binek para amostra pó com protocolo de envelhecimento com tempos de parada $\left(\mathrm{t}_{\mathrm{w}}\right)$ diferentes.

Tabela 16: Resultados extraídos dos modelos de Binek e Radu et al. para amostra de ferrofluido diluído com protocolo de envelhecimento. 
Tabela 17: Valores extraídos dos modelos de Binek e Radu et al. as amostras com efeito de envelhecimento antes e após o primeiro ciclo de histerese magnética medido. 136

Tabela 18: Reúne classificação dos materiais com os principais tipos de comportamentos magnéticos conhecidos em relação à susceptibilidade magnética e a permeabilidade magnética

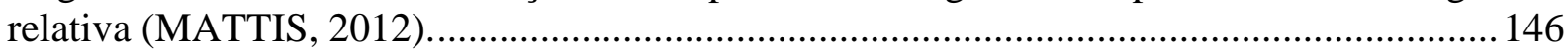




\section{Introdução Geral}

Raramente pensamos a respeito de como os materiais melhoram nossa qualidade de vida. O termo material pode ser amplamente definido como qualquer elemento que ocupa espaço, possui massa ou dispositivo que pode ser usado para atender a uma necessidade da sociedade atual ou futura. Estes podem ser atribuídos diversas aplicações sozinho ou em conjunto. Tomamos como exemplo materiais como o aço, borrachas, vidros, circuitos e etc., componentes na construção de um automóvel, bem necessário para a locomoção em grandes centros. Outros materiais mais complexos como as nanopartículas, nanotubos, ferrofluidos e grafenos podem ainda não ser amplamente utilizados para aplicações específicas, mas poderão tornar-se essenciais para atender demandas futuras. Neste contexto, o design de novos materiais é fator extremamente importante para sociedade moderna. Podemos mencionar os ferrofluidos que são dispersões coloidais de partículas magnéticas de diâmetro nanométrico (ROSENSWEIG, 2013). Suas propriedades resultam da combinação das características do fluido como o estado macroscópico e a ordem local da dispersão, com as características individuais e/ou interativas dos nanocristais magnéticos (SHLIOMIS, 1974; SHLIOMIS et al., 1990; RAIKHER; SHLIOMIS, 1994).

Os materiais magnéticos naturais quando aquecidos perdem suas propriedades magnéticas ao ultrapassar a Temperatura de Curie $\left(T_{C}\right)$ ou Temperatura de Néel $\left(T_{N}\right)$, que é bem inferior ao ponto de fusão do material. Durante a história, inúmeras tentativas foram feitas de produzir líquidos que exibissem propriedades magnéticas. Um dos primeiros trabalhos foi de Benjamin Wilson que publicou no Phil. Trans de 1779 o trabalho "Dr. Knight's method of forming artificial magnetic paste (Método do Dr. Knight's de formação de pasta magnética artificial) (WILSON, 1779; SMEDLEY, 1845). Ele moeu (método top-down) a limalha de ferro até produzir um pó muito fino e misturou com óleo de linhaça para produzir uma pasta firme e macia, produzindo o primeiro coloide magnético não estável que após de cozido e resfriado apresentava sua "virtude magnética" em qualquer direção, produzindo os primeiros ímãs artificiais. Outro trabalho histórico é o de Lars A. Welo em 1927 que compara três métodos de produção de coloides a base de magnetitas com método bottom-up. Investigando suas propriedades magnéticas com ênfase na histerese magnética, discute sobre as propriedades deste materiais para possíveis aplicações, como catalisadores químicos e biológicos (WELO; BAUDISOH, 1927). Francis Bitter investiga irregularidades na magnetização de cristais ferromagnéticos de partículas magnéticas $\mathrm{Fe}_{2} \mathrm{O}_{3}$, utilizando método top-down, com cerca de 1 
$\mu \mathrm{m}$ de diâmetro suspensas em acetato etílico (BITTER, 1932). Em ambos os trabalhos as partículas precipitavam devido a ação da força gravitacional e não havia um controle das forças de atração e repulsão entre as partículas.

Em 1965 a Agência Espacial Norte Americana - NASA (STEPHEN, 1965) patenteou o primeiro método para síntese de um líquido magnético estável. Baseado na moagem do material magnético maciço, principalmente da magnetita $\left(\mathrm{Fe}_{3} \mathrm{O}_{4}\right)$, na presença de surfactantes e de um solvente compatível até dimensões coloidais. Definido como método top-down (de cima para baixo). Este fluido magnético foi utilizado para controlar a vazão de combustível em aeronaves em microgravidade. Tal procedimento era bastante limitado, devido à grande dificuldade de se obter partículas com baixa polidispersão, o que demandava de vários dias de moagem, acarretando altos valores para produção, além da obtenção de nanopartículas, pela moagem, a partir de óxidos magnéticos maciços (bulk) pré-existentes.

No início dos anos 80 René Massart (MASSART, 1981) propôs outro método de síntese de um fluido magnético estável a base de $\mathrm{Fe}_{3} \mathrm{O}_{4}$. O método consistia na peptização de partículas em meio aquoso, por meio da criação de uma densidade superficial de carga experimentalmente ajustável às partículas, que tornou a produção de fluidos magnéticos mais rápida e barata. $\mathrm{O}$ mesmo era baseado em uma metodologia do tipo bottom-up (de baixo para cima, governada pelos processos de nucleação e crescimento cristalino), na qual as nanopartículas são quimicamente sintetizadas e dispersas em um meio aquoso. Tourinho (TOURINHO, 1988; TOURINHO et al., 1989) aprimorou o método de síntese química produzindo ferrofluidos a base de nanopartículas de ferrita de manganês e cobalto revestidas com uma camada superficial de maguemita, trazendo para o Brasil toda uma nova linha de pesquisa.

A fim de obter nanopartículas core-shell (NPs-CS) ultra pequenas, Aquino et al. mudou a solução da base para amônia $\left(\mathrm{NH}_{3}\right)$, e conseguiu sintetizar os primeiros ferrofluidos a base de NPs-CS ultra pequenas da ordem de $3 \mathrm{~nm}$ (AQUINO et al., 2002), possibilitando estudos de fenômenos que surgem quando os efeitos de superfície são aumentados, uma vez que a relação superfície/volume torna-se maior, por exemplo o exchange bias. Silva et al. investigou este fenômeno em fluidos magnéticos com NPs-CS com núcleo ferrita de manganês, magneticamente soft (mole), e observa também a influência das interações em ferrofluidos concentrados (SILVA et al., 2013). Cabreira-Gomes et al. compara os efeitos da natureza do núcleo, observando valores elevados do exchange bias para as nanopartículas com núcleo à base de ferrita de cobalto em relação as NPs-CS com núcleo de ferrita de manganês. Conclui 
que a intensidade visualizada do exchange bias depende da anisotropia magnética do núcleo (CABREIRA-GOMES et al., 2014).

\section{Ideias sobre nanotecnologia}

Voltando um pouco no tempo, observamos que ideias sobre o mundo do muito pequeno já habitavam a mente de grandes cientistas. Michael Faraday, em 1857, proferiu palestra à Royal London Society em que descrevia o comportamento de uma dispersão de partículas nanométricas de ouro e outros metais com a luz. Estas dispersões produziam diferentes cores (FARADAY, 1857), naquela época ele tentou explicar o fenômeno com a teoria ondulatória da luz, os hoje conhecidos como Quantum dots (pontos quânticos). Esse fenômeno só poderia ser explicado pela teoria quântica que nasceria somente no século seguinte. Os Quantum dots são partículas muito pequenas, tão pequenas que suas propriedades ópticas e eletrônicas diferem das partículas maiores. James Cleck Maxwell sugeriu em 1871, a criação de uma entidade microscópica conhecida como "Maxwell's Demon" (O Demônio de Maxwell), que seria capaz de manejar moléculas individuais. Conseguiria observar o estado microscópico de um sistema físico e aproveitar a ocorrência de flutuações favoráveis para diminuir a entropia do sistema. David Leigh em 2007, inspirado pelo Demônio de Maxwell, conseguiu criar uma molécula sintética, chamada de Rotaxane, capaz de mover e classificar partículas alimentada por uma fonte de luz externa (SERRELI et al., 2007). Outro momento histórico aconteceu em 1959, quando Richard Feynman proferiu palestra intitulada "There's Plenty of Room at the Bottom" (Há muito espaço lá embaixo), onde abordou questões de escala de tamanho nanométrica que gerariam mudanças significativas na magnitude de vários fenômenos físicos. A gravidade se tornaria menos importante, a tensão superficial e atração Van der Waals se tornaria mais importante e pela primeira vez cunhou o termo Nanotecnologia (FEYNMAN, 1960). Sua visão arrojada e persistente inspirou toda uma nova geração de pesquisadores, direcionando-os para uma das últimas fronteiras instituídas pelas leis físicas.

A emergência da nanotecnologia na década de 1980 ocorreu-se devido à convergência de avanços experimentais, como a invenção do microscópio de varredura de tunelamento em 1981, que permite obter imagens de átomos e moléculas ao nível atômico, baseado no conceito de tunelamento quântico ${ }^{1}$. Esta técnica de caracterização de materiais utiliza uma ponta, de

\footnotetext{
${ }^{1}$ Fenômeno da mecânica quântica no qual partículas podem transpor um estado de energia classicamente proibido. Isto é, uma partícula pode escapar de regiões cercadas por barreiras potenciais mesmo se sua energia cinética for menor que a energia potencial da barreira.
} 
forma análoga à agulha, que foi usada uma vez em fonógrafos, para criar imagens da topologia de superfície de uma amostra. Juntamente com a técnica de Microscopia Eletrônica de Transmissão (MET), o primeiro equipamento MET, construído em 1931, usa um feixe de elétrons acelerados por uma $d d p$ da ordem de centenas de quilovolts $(\mathrm{kV})$, para criar uma resolução da ordem de alguns Angstrons $(\AA)$, uma vez que a luz visível varia o comprimento de luz entre o violeta a $400 \mathrm{~nm}$ e o vermelho a $700 \mathrm{~nm}$ e o limite de resolução teórico será entre 0.14 e $0.25 \mu \mathrm{m}$. Por exemplo um potencial de $100 \mathrm{kV}$ rende um $\lambda=3.7 \times 10^{-3} \mathrm{~nm}$, muito menor que o comprimento de onda da luz e também dos raios $X$, só assim materiais em nanoescala se tornam evidentes.

Nanotecnologia é a manipulação da matéria em escala atômica, molecular e supramolecular. Englobando a compreensão da física fundamental, química, biologia e tecnologia de objetos em escala nanométrica $\left(10^{-9} \mathrm{~m}\right)$. Esta ordem de comprimento é bem interessante por apresentar fenômenos quânticos e clássicos. The National Nanotechnology Initiative (A Iniciativa Nacional de Nanotecnologia) criada pelo governo dos EUA para financiar esse novo ramo da ciência, define a nanotecnologia como a manipulação da matéria (“nanoobjetos") com pelo menos uma dimensão de tamanho de 1 a 100 nanômetros. Esses aprimoram as novas propriedades, onde os fenômenos únicos permitem novas aplicações não viáveis quando se trabalha com materiais naturais na forma "bulk” (maciços) ou mesmo com átomos individuais ou moléculas. Usando técnicas e ferramentas que estão sendo aprimoradas para produzir produtos com novas perspectivas e propriedades com alto desempenho (ROCO, 2011).

Nanopartículas e aplicações

Dentro de uma infinidade de nanomateriais as nanopartículas magnéticas (NPs) se destacam. Recentemente, tem sido empregadas em ampla variedade de aplicações devido suas propriedades magnéticas exóticas, que fazem com que esses sistemas sejam atraentes para novas aplicações biomédicas e tecnológicas. Entre elas podemos citar: Biofluidos magnéticos formados por NPs, que tem sido utilizados para a separação magnética de bactérias no sangue (LEE et al., 2013); Nanoflares ${ }^{2}$, que se ligam à células cancerosas individuais numa amostra de sangue e, em seguida, brilham permitindo que as células cancerosas possam ser detectadas e

\footnotetext{
2 Nanoflares são nanopartículas funcionalizadas que contém uma monocamada de DNA anti-sentido (sequência de reconhecimento) adsorvida a superfície de nanopartículas esféricas de ouro, que permitem a detecção de células vivas de ARNm intracelular.
} 
classificadas com a ajuda de um laser. A análise de células tumorais circulantes pelo sangue (CTCs) podem prever oportunidades sem precedentes para a avaliação de risco metastático (HALO et al., 2014).

Destacam-se ainda a Distribuição local de fármacos utilizando implantes magnéticos (FERNÁNDEZ-PACHECO et al., 2007); a Fabricação de nanosondas magnéticas para orientação de anticorpos (LIN et al., 2009); e como Método de detecção precoce da doença de Alzheimer, a partir do uso de nanopartículas interligadas com anticorpos que se ligam a toxina oligômero beta amiloide no cérebro responsável pelo aparecimento da doença, permitindo sua visualização por Imagem de Ressonância Magnética (IRM) (VIOLA et al., 2015). A Figura 1 exibe algumas destas aplicações.
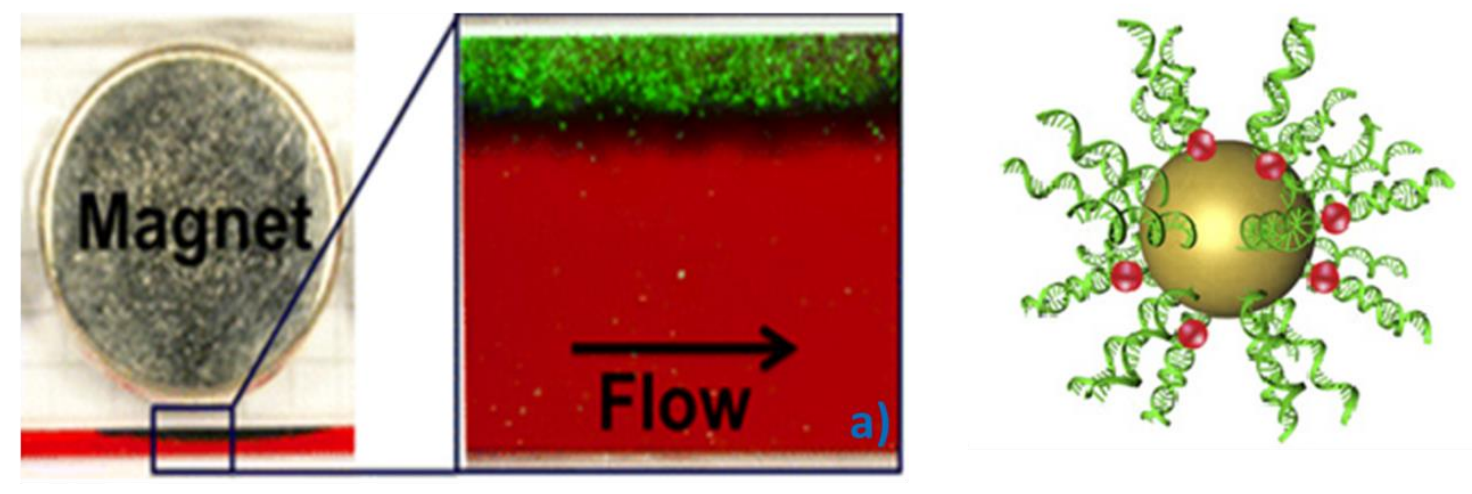

b)
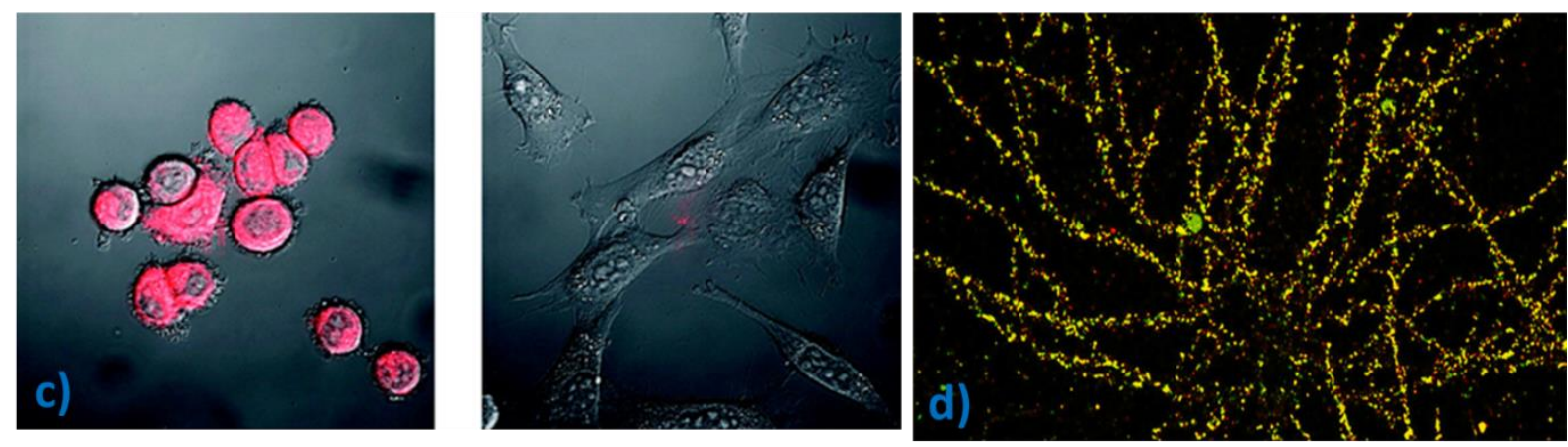

Figura 1: a) Separação magnética de bactérias por nanopartículas magnética retirado da referência (LEE et al., 2013). b) Esquema da estrutura e função Nanopartícula hibridada com a sequência de reconhecimento de DNA que contém um fluoróforo ${ }^{3}$ (vermelho) (Nanoflare). c) As células cancerosas com genes específicos, brilho em vermelho, uma vez infiltrada por novas nanopartículas (esquerda). As nanopartículas não brilham em células sem o gene (à direita) Adaptado de (HALO et al., 2014) d) Oligômeros fluorescentes beta amiloide (verde), vinculados aos neurônios do hipocampo em cultura, foram detectados com mais de 90 por cento de precisão pela nanoestrutura magnética (vermelho) Adaptado de (VIOLA et al., 2015).

Dentre os diversos materiais para síntese de nanopartículas magnéticas, a classe das ferritas se destaca por possuírem uma grande diversidade de aplicações, principalmente nas suas propriedades magnéticas como: Coercividade, remanência magnética e magnetização de

\footnotetext{
${ }^{3}$ Componente de uma molécula que faz com que esta seja fluorescente.
} 
saturação moderadas, assim como uma ótima estabilidade química (CARTA et al., 2010); Grande candidato para aplicações biotecnológicas para IRM (TROMSDORF et al., 2007; YANG et al., 2010a); Agente de contraste para imagiologia do fígado (LU et al., 2009); Eficiente agentes para rotulagem magnética e rastreamento via IRM de células estaminais humanas (YANG et al., 2010b); Utilizadas em catalisadores magnéticos com intuito de degradar os poluentes por causa do desempenho catalítico de decomposição do peróxido de hidrogénio em radicais hidroxila (MAHMOODI, 2015); Remoção de solúvel em água azo corante (WU; QU, 2005). NPs de ferrita são extremamente versáteis para o design de novas aplicações para resolver problemas de nanoengenharia.

Com a redução do tamanho da partícula, o número de spins que se comportam de forma cooperativa dentro da NPs diminui, os efeitos de superfície e de interface estão relacionados com a falta de arranjo dos íons, que induz a quebra de ligações e resulta na frustração e desordem de spins na superfície. Assim os efeitos se manifestam de diferentes maneiras: não continuidade das interações de troca entre spins individuais que existem na superfície; diferentes estruturas internas, forma e competição entre o núcleo e a superfície (YANES et al., 2007); e dependência com a temperatura devido ao aumento das flutuações dos spins (YANES et al., 2010b). Estes efeitos agem mutuamente para definir o conceito fenomenológico de anisotropia de superfície e juntos influenciam as propriedades dos ciclos de histerese magnética como o aumento da coercividade e campos de irreversibilidade (IGLESIAS; LABARTA, 2005).

\section{Nanopartículas core-shell e fenômenos magnéticos}

As Nanopartículas do tipo núcleo-casca ou core-shell (NPs-CS) são formadas por camadas de materiais diferentes, e essa pertence a categoria de nanomateriais que recebe grande atenção, devido suas propriedades e ampla variedade de aplicações, uma vez que supera algumas das limitações dos materiais naturais monocamadas. Suas propriedades mistas mostram grandes mudanças nas propriedades físicas e químicas desses materiais formados por bicamadas, acarretando capacidades multifuncionais. Isso ocasiona um aumento gradual na investigação de NPs-CS devido a demanda por mais avanços em materiais, alimentados pelas exigências da evolução tecnológica para suprir a necessidade (GAWANDE et al., 2015). O design destas NPs-CS depende da função a qual é destinada, sendo que as novas propriedades irão depender da interação entre o núcleo e casca e/ou da combinação de materiais do tipo 
inorgânico/inorgânico, inorgânico/orgânico, orgânico/inorgânico e orgânico/orgânico (CHAUDHURI; PARIA, 2012).

Nanopartículas com diâmetros menores que $50 \mathrm{~nm}$ apresentam o comportamento magnético do Superparamagnetismo (BEAN; LIVINGSTON, 1959), se as partículas são suficientemente pequenas considera-se que os momentos magnéticos no interior de uma partícula movam-se de maneira regular, ou seja, o momento magnético total pode ser representado por um único vetor clássico chamada de superspins. E a energia de anisotropia $\left(E_{a}\right)$ pode ser comparada à energia térmica $k_{B} T$. Essas NPs apresentam magnetização apenas na presença de um campo magnético externo. Na ausência de campo os superspins giram em direções aleatórias sob a influência da temperatura. O estado magnético das nanopartículas (superparamagnético ou bloqueado) depende do tempo de medição $\left(\tau_{m}\right)$ e o tempo entre dois giros é o tempo de relaxamento de Néel $\left(\tau_{N}\right)$ (NÉEL, 1948). Se $\tau_{m} \gg \tau_{N}$ a magnetização da NPs irá girar várias vezes durante a medição e depois da medida a magnetização será a média igual a zero, apresentado o estado superparamagnético. E se $\tau_{m} \ll<\tau_{N}$ a magnetização não irá girar durante a medição de modo que a magnetização medida será a magnetização instantânea do início da medição apresentado o estado bloqueado.

A transição entre os dois casos ocorre no momento em que $\tau_{m} \approx \tau_{N}$, podemos observar essa situação no comportamento típico de uma curva Zero Field Cooling - ZFC (ausência de campo aplicado) que mostra bem esta transição e indica uma média da Temperatura Bloqueio $\left(T_{B}\right)$. Nessa situação o tempo de medição é mantido constante, mas a temperatura é variada de modo que a transição entre o superparamagnetismo e o estado bloqueado é visto como uma função da temperatura, caracterizada por um máximo e definida por uma Temperatura de Bloqueio. Abaixo de $T_{B}$ existe um aumento gradual do congelamento de superspins (estado bloqueado) com a diminuição da temperatura. Nessa região é interessante estudar a dinâmica lenta que se apresenta, quando os superspins possuem algum tipo de característica de spins glass (vidros de spins). Em NPs-CS, em regime sem interações, a desordem de superfície exibe um estado de spins-glass-like - SGL (tipo vidros de spins) na casca e num regime de fortes interações o comportamento coletivo das NPs-CS induz ao estado de superspins-glass - SSG (vidro de superspins). Sistemas com característica de vidros de spins exibem efeito de memória.

O Efeito de Memória se manifesta em estados com tais propriedades em temperaturas abaixo da temperatura de formação do estado de vidro de spins $\left(T_{g}\right)$, sendo que $T_{g}$ é ligeiramente menor que $T_{B}$. Em baixas temperaturas, se pausado o resfriamento, e o campo aplicado é desligado, observamos que após um determinado tempo de espera vai existir uma queda da 
magnetização. Em seguida com o religamento do resfriamento e do campo aplicado o sistema tende a voltar ao seu estado inicial de magnetização (curva de referência), em outras palavras o sistema memorizou informação. A queda na magnetização em todos as paradas de tempo $\left(t_{w}\right)$ é a característica principal do efeito de memória, dependendo do estado magnético das NPs e só cessa quando o sistema entra em equilíbrio. Após um tempo de espera $t_{w}$, quando o campo está ligado, a recuperação na magnetização depende de quão rápido as nanopartículas se realinham com campo aplicado. Em temperaturas menores que $T_{g}$ o sistema apresenta uma queda da magnetização acentuada, a queda da magnetização é relativamente menor em temperaturas muito baixas devido a dinâmica lenta.

Nesse trabalho, objetivamos a investigação do efeito de memória magnética em nanopartículas magnéticas com regime de interações interpartículas fracas (ferrofluido diluído) e fortes (pó compacto). Esperamos observá-lo, uma vez que nossas nanopartículas possuem uma estrutura magnética formada por núcleo ordenado de ferrita de cobalto e uma camada de ferro extremamente desordenada de $S G L$. Quando investigamos amostras extremamente diluídas, estamos sondando as propriedades individuais da partícula, observamos o efeito de memória induzido pela casca $(S G L)$. No regime de fortes interações, amostra de pó de partículas, iremos ter duas contribuições para o efeito de memória uma intrínseca da partícula induzida pela casca e outra extrínseca do comportamento coletivo das nanopartículas que geram o estado SSG.

Outro fenômeno estudado nessa Tese é o acoplamento de troca que ocorre na interface de materiais magnéticos em contato conhecido como Exchange Bias (EB). Atribuído à anisotropia de troca induzida na interface de um sistema heterogêneo. Primeiramente investigado por Meiklejohn e Bean, em 1956, numa estrutura formada de partículas núcleo (core) de Co ferromagnético (FM) recoberta por uma casca de óxido de cobalto $\mathrm{CoO}$ antiferromagnético (AFM) FM/AFM (MEIKLEJOHN; BEAN, 1956). Desde então foram observados em muitos sistemas com diferentes interfaces de FM/AFM; Filmes FM com cristais individuais AFM (NOGUÉS; SCHULLER, 1999); Sistemas formados por materiais heterogêneos Ferromagnético e Spin Glass FM/SG, Antiferromagnético e Ferrimagnético AFM/FI, Ferrimagnético e Antiferromagnético FI/AFM, Ferrimagnético e Ferrimagnético FI/FI (NOGUÉS et al., 2005b).

D. Paccard, em 1966, publicou resultados sobre um novo fenômeno com título The New Property of Ferromagnetic-Antiferromagnetic Coupling (PACCARD et al., 1966; SCHLENKER; PACCARD, 1967), nele observa a degradação do exchange bias com 
sucessivos ciclos e esse novo fenômeno auxilia a esclarecer o mecanismo de acoplamento microscópico que induz o efeito de exchange bias chamado de Training Effect - TE (efeito de treinamento) devido aos ciclos consecutivos. O efeito de Treinamento é atribuído à variação do acoplamento magnético entre materiais, rearranjo da configuração dos spins na interface que modifica as interações magnéticas entre as regiões de forma diferente, juntamente com cada ciclo. A nova propriedade mostra uma dependência do exchange bias medido dos laços de histerese em função do índice $(n)$ de ciclos consecutivos.

Por fim, a presente Tese objetiva averiguar o efeito de treinamento do exchange bias em nanopartículas core-shell em regimes de interação fracas e fortes. Vários modelos tentam explicar a dinâmica não linear do efeito do ciclismo ${ }^{4}$ no exchange bias, escolhemos alguns para embasar a nossa investigação. O modelo básico de Cristian Binek explica que a contração do ciclo de histerese é devido a variação de energia da interface entre os materiais (BINEK, 2004); Zheng et al. modificaram o modelo de Stoner \& Wohlfarth de um ciclo de histerese magnética para explicar a diminuição dos spins frozen (congelados) na interface com ciclos consecutivos (ZHENG et al., 2004a). Por fim, o modelo de Radu et al. mostra a existência de duas contribuições para o efeito de treinamento que surgem com os spins rotatables (rodáveis) e congelados na interface (RADU; ZABEL, 2008a).

\section{Apresentação}

O ferrofluido e amostra pó aqui investigados são compostos de Nanopartículas Magnéticas Core-Shell (NPs-CS) com uma estrutura composta de um núcleo ordenado e uma superfície desordenada. As pesquisas desenvolvidas para elaboração da Tese foram feitas no Laboratório do Grupo de Fluidos Complexos (GFC) do Instituto de Física da Universidade de Brasília e laboratórios parceiros sobre orientação do Professor Doutor Jérôme Depeyrot. Este trabalho tem como objetivo:

- Examinar as propriedades magnéticas de nanopartículas core-shell NPs-CS ultrapequenas em regimes de interação dipolares fracas e fortes (Ferrofluido diluído e Pó compacto);

- Caracterizar as interações magnéticas interpartículas e a anisotropia nos dois regimes;

\footnotetext{
${ }^{4}$ Ciclos de histereses consecutivos numa determinada temperatura.
} 
- Investigar os efeitos de memória com protocolo de envelhecimento DC em regimes de interação diferentes; e

- Compreender os mecanismos de comportamento dos spins desordenados na interface entre o núcleo e a casca no efeito de Treinamento do Exchange bias (regime de interações, temperatura e envelhecimento).

Esta Tese está organizada da seguinte maneira:

Revisão e Fundamentação: Apresentamos uma revisão bibliográfica no sentido de fornecer uma visão geral sobre os materiais pesquisados para a elaboração desta Tese. Uma breve introdução sobre os conceitos fundamentais de magnetismo, as estruturas magnéticas e o sistema de nanopartículas é apresentado. O efeito de memória induzido pelo shell desordenado, Exchange Bias fenomenologicamente atribuído à interface de acoplamento em baixas temperaturas, o efeito de treinamento, atribuído às flutuações do acoplamento entre as interfaces FI/SGL, são abordados e suas principais características são expostas.

Materiais e Métodos Experimentais: O método de síntese química de ferrofluidos é apresentado e as várias técnicas experimentais utilizadas nesta Tese são expostas. Por espectroscopia de absorção atômica (AAS) determinamos a composição química e a fração volumétrica de partículas utilizando o modelo core-shell de composição química, com o pó de partículas analisamos a cristalinidade, deduzimos o tamanho médio das nanopartículas por difração de Raios X. A fim de investigar a morfologia e distribuição de tamanhos usamos a técnica de Microscopia Eletrônica de Transmissão. Por curvas de magnetização em temperatura ambiente achamos uma polidispersão e um diâmetro médio pelo formalismo de Langevin e da análise de baixo campo conseguimos calcular um parâmetro de interação para a amostra de ferrofluido diluído.

Resultados e Discussões: Incialmente analisamos os ciclos de histerese com protocolo ZFC e a partir deles conseguimos definir os dois sistemas de interações investigados, após fazemos um estudo da anisotropia magnética das nanopartículas nos regimes de interação fraca e forte por diversas técnicas. Em seguida observamos a dependência da magnetização com a temperatura em alto e baixo campo. Em alto campo conseguimos observar um acréscimo na magnetização em baixas temperaturas atribuída à casca, com esses resultados podemos definir 
a interface FI/SGL das NPs-CS em baixas temperaturas, em regime de baixo campo aplicado investigamos o efeito de memória com protocolo de envelhecimento DC. Por fim fazemos um estudo minuciosos do exchange bias e do efeito de treinamento.

Considerações Finais: Fazemos um esboço final dos principais resultados obtidos nesta Tese, bem como propostas para trabalhos futuros. 


\section{Revisão e Fundamentação}

\subsection{Sistemas de nanopartículas magnéticas}

\subsubsection{Os nanocristais magnéticos de ferrita}

\section{Estrutura cristalina}

Os Ferrofluidos à base de nanopartículas de Ferrita de Cobalto objeto desse trabalho são compostos de nanopartículas que apresentam uma estrutura cristalina do tipo espinélio (ASKELAND; PHULÉ, 2003), assim designada por ser análoga a estrutura do "mineral espinélio" $\mathrm{MgAl}_{2} \mathrm{O}_{4}$. Quando um dos cátions metálicos é o ferro trivalente, esses materiais são denominados de ferritas. A Figura 2 ilustra o arranjo de uma estrutura espinélio.

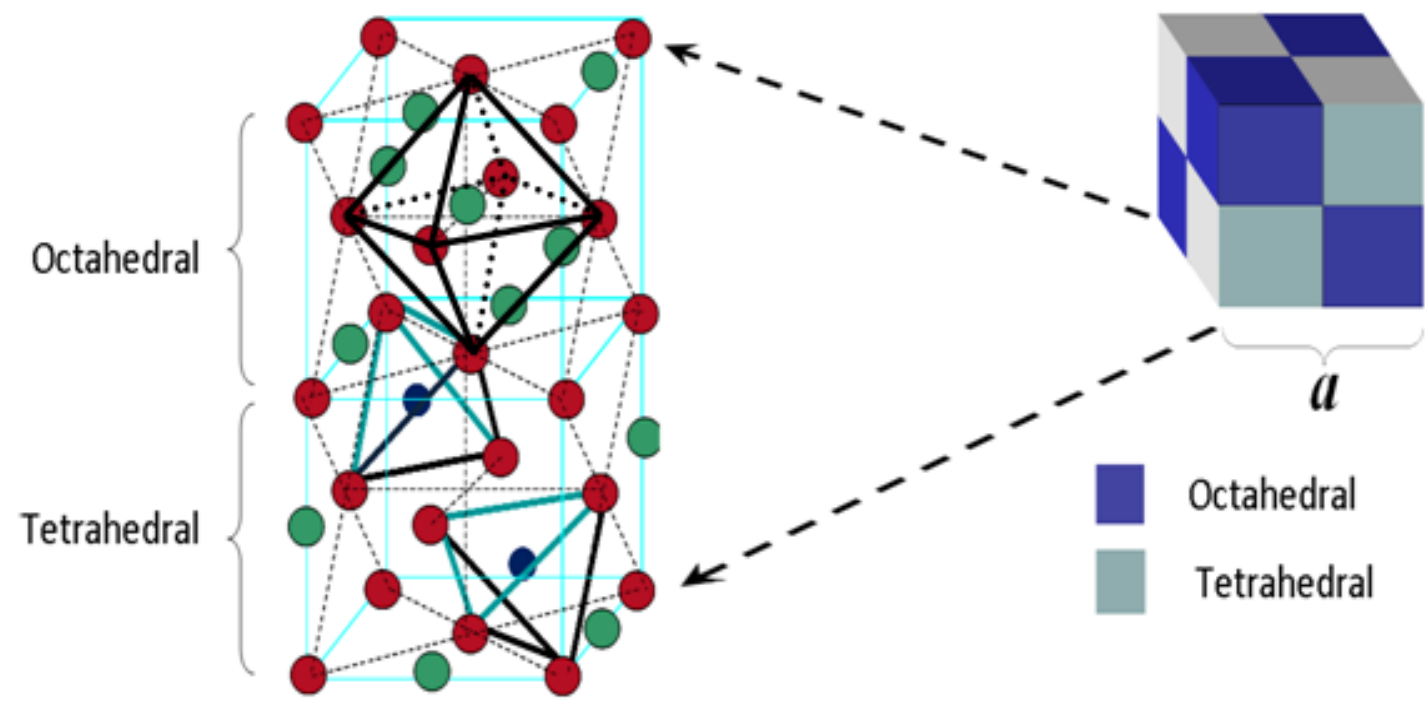

Figura 2: Estrutura cristalina de uma ferrita tipo espinélio.

As ferritas do tipo espinélio têm fórmula química geral $\mathrm{MFe}_{2} \mathrm{O}_{4}$, onde $\mathrm{M}$ é um metal geralmente do período do ferro ou combinação destes (por exemplo, $\mathrm{Fe}^{2+}, \mathrm{Co}^{2+}, \mathrm{Ni}^{2+}, \mathrm{Cu}^{2+}$, $\left.\mathrm{Zn}^{2+} \mathrm{e} \mathrm{Mn}^{2+}\right)$. Esse arranjo é constituído por um empacotamento cúbico compacto de 32 átomos de oxigênio, formando 64 interstícios de simetria tetraédrica (sítios A) e 32 interstícios de simetria octaédrica (sítios B). Esses sítios são parcialmente ocupados com 1/8 dos sítios 
tetraédricos e $1 / 2$ dos sítios octaédricos preenchidos por cátions metálicos como visualizamos na figura 1.6 (CULLITY; GRAHAM, 2011).

Os espinélios podem ser classificados como diretos, inversos e mistos de acordo com a disposição dos cátions nos interstícios. Nesse sentido, a distribuição dos cátions nos interstícios é dada através da representação cristalográfica:

$$
\left[M_{(1-x)}^{2+} F e_{x}^{3+}\right]_{A}\left[F e_{(2-x)}^{3+} M_{x}^{2+}\right]_{B} O_{4}^{2-}
$$

onde $x$ é o parâmetro de ocupação dos sítios pelos íons metálicos.

Quando existem somente os íons divalentes $\mathrm{M}^{2+}$ nos sítios tetraédricos e os íons $\mathrm{Fe}^{3+}$ nos sítios octaédricos $(x=0)$, o espinélio é chamado de normal ou direto e sua fórmula pode ser representada por $\left[\mathrm{M}^{2+}\right]_{A}\left[\mathrm{Fe}_{2}^{3+}\right]_{B} \mathrm{O}_{4}$. Quando os íons de $\mathrm{Fe}^{3+}$ são igualmente distribuídos entre os sítios A e B e os íons de metais divalentes são repartidos nos sítios B restantes $(x=1)$, o espinélio é classificado como inverso, podendo ser representado por $\left[\mathrm{Fe}^{3+}\right]_{A}\left[\mathrm{Fe}^{3+} \mathrm{M}^{2+}\right]_{B} \mathrm{O}_{4}$ As duas estruturas, normal e inversa representam os casos extremos e quando a distribuição catiônica é intermediária a ferrita é dita mista.

A cristalização em um tipo de estrutura espinélio é governada pela energia de estabilização, que resulta da influência do campo cristalino. Dependendo da configuração eletrônica dos íons o ambiente mais favorável será tetraédrico ou octaédrico. No caso das ferritas estudadas aqui, o metal trivalente é o ferro, de configuração $\mathrm{d}^{5}$, que não tem preferência entre os sítios A e B. Se o metal divalente tem uma configuração $\mathrm{d}^{6}, \mathrm{~d}^{7}, \mathrm{~d}^{8}$ ou d $\mathrm{d}^{9}$, a estrutura inversa é preferida e se a configuração é $\mathrm{d}^{10}$, a estrutura normal é privilegiada.

O desemparelhamento de elétrons no orbital $3 d$ origina as propriedades magnéticas nas ferritas. Em uma ferrita do tipo espinélio, os íons metálicos ocupando os sítios tetraédricos e octaédricos, formam duas sub-redes magnéticas com um alinhamento antiparalelo de momentos de spin. Entretanto, devido principalmente à diferença entre o número de sítios preenchidos $\mathrm{A}$ e $\mathrm{B}$, essas duas sub-redes em alinhamento antiferromagnético induzem uma contribuição magnética não nula e o ordenamento magnético resultante é ferrimagnético (CULLITY; GRAHAM, 2011).

Sabendo como os íons metálicos são distribuídos nos sítios A e B e o momento magnético de cada íon, é possível determinar a magnetização de saturação de qualquer ferrita. Somando as contribuições de todos os sítios A e B a magnetização de saturação é dada por:

$$
m_{0}=\frac{N \rho}{M_{M}}\left|\sum_{B} n_{B, B}-\sum_{A} n_{B, A}\right| \mu_{B},
$$


onde $n_{B, i}$ é o número de magnétons de Bohr $\mu_{B}$ associado ao sítio $i$ por malha elementar, $M_{M}$ a massa molar da ferrita, $\rho$ a densidade e $N$ é o número de Avogadro.

A Figura 3 apresenta a configuração eletrônica dos íons de $\mathrm{Fe}^{3+} \mathrm{e} \mathrm{Co}^{2+}$ nos orbitais $3 d$ assim como o número de magnétons de Bohr associado. Podemos então calcular o valor da magnetização em $0 \mathrm{~K}$ de $1 \mathrm{~mol}$ de ferrita de cobalto utilizando a contribuição de cada íon e a distribuição catiônica ideal $(\mathrm{x}=1)$. Os resultados são apresentados na Tabela 1.

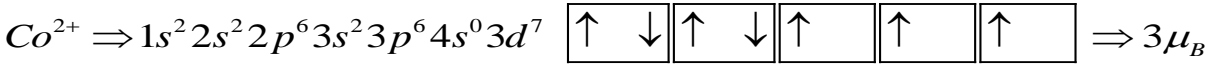

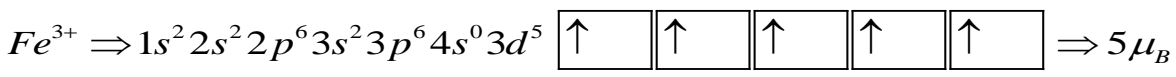

Figura 3: Representação da distribuição eletrônica dos íons metálicos nos orbitais $3 d$ e número de magnétons de Bohr associado.

Tabela 1: Cálculo para uma ferrita de cobalto, * magnetização de saturação experimental (CULLITY; GRAHAM, 2011).

\begin{tabular}{|c|c|c|c|c|c|c|c|c|}
\hline \multirow{2}{*}{ Valência } & \multirow{2}{*}{ Estrutura } & \multirow{2}{*}{\multicolumn{2}{|c|}{$\begin{array}{c}\text { Sitio }(A) \\
\rightarrow\end{array}$}} & \multirow{2}{*}{\multicolumn{2}{|c|}{$\begin{array}{c}\text { Sitio }(B) \\
\leftarrow\end{array}$}} & \multirow{2}{*}{$\begin{array}{c}\mu_{B} / \text { malha } \\
\text { Cal. }\end{array}$} & \multicolumn{2}{|c|}{$m_{0}(k A / m)$} \\
\hline & & & & & & & Cal. & Exp.* \\
\hline \multirow{3}{*}{$2+$} & \multirow{3}{*}{$\begin{array}{l}\text { Mista } \\
\mathrm{x}=0.8\end{array}$} & 0.2 & 0.8 & 1.2 & 0.8 & \multirow{3}{*}{30.4} & \multirow{3}{*}{475} & \multirow{3}{*}{475} \\
\hline & & $\mathrm{Co}^{2+}$ & $F e^{3+}$ & $F e^{3+}$ & $\mathrm{Co}^{2+}$ & & & \\
\hline & & $0.6 \mu_{B}$ & $4 \mu_{B}$ & $6 \mu_{B}$ & $2.4 \mu_{B}$ & & & \\
\hline
\end{tabular}

A condição de equilíbrio de um sistema magnético é sempre o estado cuja energia total é a menor, assim o conceito de domínios magnéticos surge da necessidade em explicar o porquê materiais magnéticos podem estar desmagnetizados, mesmo possuindo localmente uma magnetização espontânea não nula. A energia total, que determina a estrutura magnética de materiais, geralmente inclui a energia de exchange, energia magnetostática (proporcional ao volume do material), energia da parede de domínio (proporcional à área de superfície), energia de anisotropia e energia Zeeman. Mediante redução de tamanho à escala nanométrica, pode surgir uma situação em que a formação de domínios pode tornar-se energeticamente desfavorável devido à energia da parede de domínio.

\section{Partícula monodomínio}

Um material bulk é dividido em domínios separados por paredes de domínio para minimizar a energia total. Existem basicamente dois tipos de paredes que separam os domínios 
magnéticos: paredes de Bloch e de Néel. Em uma parede de Bloch o vetor magnetização gira e sempre permanece paralelo ao plano da parede, todavia, em uma parede de Néel o vetor magnetização gira e permanece perpendicular ao plano da parede. A energia da parede de domínio também participa da energia total do material, o equilíbrio das diferentes energias determina as configurações dos domínios. Por exemplo: dois domínios que se encontrarem em direções diferentes, eles podem permanecer na mesma direção devido à interação de troca entre eles, portanto a diminuição da energia total é causada pelo cancelamento dos momentos entre domínios.

Com a miniaturização do material as estruturas magnéticas serão alteradas imediatamente, uma nova condição de equilíbrio das diferentes energias será alcançada. A energia resultante da parede de domínio torna-se maior do que a redução da energia total, devido à formação de uma estrutura de múltiplos domínios, no momento em que se diminui o tamanho de uma partícula, a fração de spins localizados nas paredes entre domínios aumenta no material magnético beneficiando a formação do único domínio. A partícula magnética que é formada por apenas um domínio é chamado de partículas monodomínio, que desempenha um papel central no design de materiais magnéticos. Para a partícula ser monodomínio ela deve possuir um diâmetro crítico, abaixo do qual a partícula magnética favorece o domínio único, em vez do estado de múltiplos domínios. Para uma partícula esférica de anisotropia uniaxial, o raio crítico $r_{c}$ é dado por (BLUNDELL; THOULESS, 2001; BEDANTA; KLEEMANN, 2009):

$$
r_{c}=9 \frac{(K A)^{1 / 2}}{\mu_{0} M_{S}^{2}}
$$

$K, A$ e $M_{S}$ são a constante de anisotropia magnetocristalina, constante da rigidez de troca exchange stiffness e magnetização de saturação da nanopartícula. O tamanho do domínio único crítica será grande no material com $K$ e $A$, grande e pequena com M. Dentro desta perspectiva, se as partículas são suficientemente pequenas considera-se que os momentos magnéticos no interior de uma partícula movam-se de maneira regular, ou seja, o momento magnético total pode ser representado por um único vetor clássico de magnitude $\vec{\mu}=\vec{\mu}_{a t} N$, $\vec{\mu}_{a t}$ é o momento magnético atômico e $\mathrm{N}$ é o número de átomos magnéticos na partícula. No caso das nanopartículas de ferrofluidos, $\mu=m_{s} V, m_{s}$ é a magnetização espontânea da partícula de ferrita de volume $V$ e o momento magnético é da ordem de $10^{3}-10^{4} \mu_{B}$.

A magnetização de uma partícula ferrimagnética de monodomínio único é geralmente restrita por estar orientada paralelamente ou antiparalelamente em uma direção particular, 
chamada direção de fácil magnetização. Essa direção do momento magnético é caracterizada por uma energia de anisotropia, tema que nós abordaremos na seção seguinte.

\subsubsection{Anisotropia magnética}

A anisotropia magnética é o termo usado para descrever a dependência da energia interna na direção da magnetização espontânea dentro do material, criando direções fáceis e difíceis de magnetização. Ao observarmos a resposta magnética de um sistema, em geral estamos interessados na projeção de sua magnetização em um determinado eixo, normalmente é o do campo externo aplicado, que pode mudar de maneira drástica conforme a direção do campo magnético aplicado. A magnetização total do sistema selecionará o estado de menor energia e ficará ao longo do eixo fácil. A diferença energética entre os eixos fáceis e difíceis resulta de duas interações microscópicas: a interação spin-órbita e outra a longa distância de acoplamento dipolar de momentos magnéticos (BEDANTA; KLEEMANN, 2009). A representação gráfica do eixo fácil de magnetização é exibida na Figura 4(a).

A energia de anisotropia surge da interação spin-órbita e do aniquilamento parcial do momento angular. $\mathrm{O}$ acoplamento spin-órbita é responsável pela anisotropia magnetocistalina intrínseca, anisotropia de forma, anisotropia superfície e magnetoestricção, enquanto a anisotropia dipolar é uma contribuição assumindo uma distribuição uniforme dos dipolos magnéticos entre as superfícies.

Para alguns materiais, o comportamento observado pode variar em função da direção analisada e depende basicamente (YANES et al., 2010a):

- Intensidade dos momentos magnéticos associados aos átomos ou íons vizinhos;

- Distância entre os íons vizinhos;

- Simetria da rede cristalina;

- Forma;

- Stress interno;

- Temperatura.

As propriedades magnéticas da maioria dos materiais ferromagnéticos são dependentes da direção, estes são conhecidos como materiais magneticamente anisotrópicos e diz que exibem uma anisotropia magnética. 
Em materiais maciços (bulk) a energia magnetocristalina e magnetostática são a principal fonte de anisotropia. Enquanto em nanopartículas, filmes finos e nanoestruturas diversas outras anisotropias são mais acentuadas, a energia de anisotropia inclui as contribuições de anisotropia magnetocristalina, anisotropia de forma, anisotropia superfície, anisotropia troca e anisotropia rodável. A seguir apresentamos a principal fonte de anisotropia magnética para nanopartículas, em particular para aqueles à base de óxidos de ferro como, por exemplo, as ferritas do tipo espinélio.

\section{Anisotropia magnetocristalina}

A ordem magnética observada em um cristal ferrimagnético origina-se na energia de superexchange, via orbitais $p$ do oxigênio no caso das ferritas, o que favorece o alinhamento de spins mais próximos. Existe em geral, outra energia, muito menor, que tende a orientar a direção dos spins em direções cristalinas particulares, chamadas direções de fácil magnetização.

Essa energia de anisotropia magnetocristalina é provavelmente decorrente do acoplamento spin-órbita que tende a acoplar o spin eletrônico ao estado eletrônico orbital, esse último estando fortemente relacionado com a estrutura cristalina. $\mathrm{O}$ acoplamento entre os elétrons de um íon das camadas magnéticas e o campo elétrico irradiado pelos íons vizinhos (campo cristalino) conduz a uma orientação preferencial da distribuição eletrônica e do momento orbital associado (CULLITY; GRAHAM, 2011). Pelo acoplamento spin-órbita, o movimento de spins acompanha o movimento orbital. É, portanto o momento magnético global que se orienta paralelamente a uma direção cristalográfica peculiar.

Em cristais bulk a simetria cristalina que determina as propriedades relativas ao volume, determina também a anisotropia magnética de volume. Se considerarmos um cristal de simetria cúbica, a energia magneto-cristalina deve ser escrita como sendo uma função simétrica dos cosenos diretores $\alpha_{1,2,3}$ dos três eixos diretores do cubo:

$$
E_{\text {crist }}=K_{1}\left(\alpha_{1}^{2} \alpha_{2}^{2}+\alpha_{2}^{2} \alpha_{3}^{2}+\alpha_{3}^{2} \alpha_{1}^{2}\right)+K_{2} \alpha_{1}^{2} \alpha_{2}^{2} \alpha_{3}^{2}+\ldots,
$$

onde $K_{1}$ e $K_{2}$ representam as densidades de energia magneto-cristalina ou comumente chamadas de constantes de anisotropia ${ }^{5}$. Seus valores variam de acordo com o tipo de material e com a temperatura. Os diferentes valores e sinais relativos que podem ser obtidos conduzem às diferentes famílias de anisotropia cúbica.

\footnotetext{
${ }^{5}$ Unidade de medida no SI é $\mathrm{J} / \mathrm{m}^{3}$ e no $\mathrm{cgs}$ de $\mathrm{erg} / \mathrm{cm}^{3} .1 \mathrm{erg} / \mathrm{cm}^{3}$ equivale a $0.1 \mathrm{~J} / \mathrm{m}^{3}$
} 
A anisotropia de origem superficial introduzida por Néel (NÉEL et al., 1954) é de fundamental importância para compreensão do comportamento magnético e dos processos e funcionalização de nanopartículas para potenciais aplicações. Com a redução do tamanho das partículas, as contribuições magnéticas da superfície tornam-se mais importante do que aquelas a partir do volume da partícula, e, por conseguinte, a energia de anisotropia de superfície irá dominar sobre a anisotropia magnetocristalina e energia magnetostática. Por conseguinte, a mudança de simetria de átomos na superfície de uma partícula fina tem um impacto sobre a anisotropia magnética e a direção de fácil magnetização.

A energia de anisotropia magnética da partícula é escrita como a soma de contribuições do material maciço e de superfície (BØDKER; MØRUP; LINDEROTH, 1994):

$$
E_{a}=E_{a}^{\text {bulk }}+E_{a}^{\text {superficie }} .
$$

Cada termo é calculado considerando uma partícula esférica de diâmetro $d$, portanto:

$$
E_{a}^{\text {bulk }}=\frac{\pi K_{V} d^{3}}{6} \text { e } E_{a}^{\text {superficie }}=\pi K_{S} d^{2}
$$

Explicitando-se a equação (5) a partir de (6), é possível determinar uma constante de anisotropia efetiva por unidade de volume caracterizada por $K$ (KACHKACHI et al., 2000; FIORANI, 2005):

$$
K=K_{V}+\frac{6}{d} K_{S}
$$

Nesse caso, a dependência do campo de anisotropia com o tamanho da partícula é dado por:

$$
H_{a}^{e f}=\frac{2 K_{V}}{m_{S}}+\frac{12 K_{S}}{m_{S} d} .
$$

\subsubsection{Ciclo de histerese magnética - Modelo de Stoner \& Wohlfarth}

Este modelo foi proposto em 1948 por Stoner \& Wohlfarth para compreensão de um ciclo de histerese ${ }^{6}$ magnética de um sistema de partículas (STONER; WOHLFARTH, 1948). Considera o caso de uma partícula monodomínio com anisotropia uniaxial (NÉEL et al., 1954)

\footnotetext{
${ }^{6}$ Derivado do termo grego hysterein que significa "estar atrasado" ela mostra que o fluxo magnético B está sempre atrasado em relação à força magnetizante $\mathrm{H}$.
} 
em presença de um campo magnético $H$ formando um ângulo $\alpha$ com à direção de fácil magnetização (ver Figura 4 (a)). A energia da partícula se escreve pela contribuição das energias de anisotropia e Zeeman:

$$
E=E_{a} \operatorname{sen}^{2} \theta-\mu_{0} \mu H \cos (\alpha-\theta)
$$

onde $\theta$ é o ângulo entre o momento magnético $\vec{\mu}$ e a direção de fácil magnetização e $E_{a}=K V$.

(a)

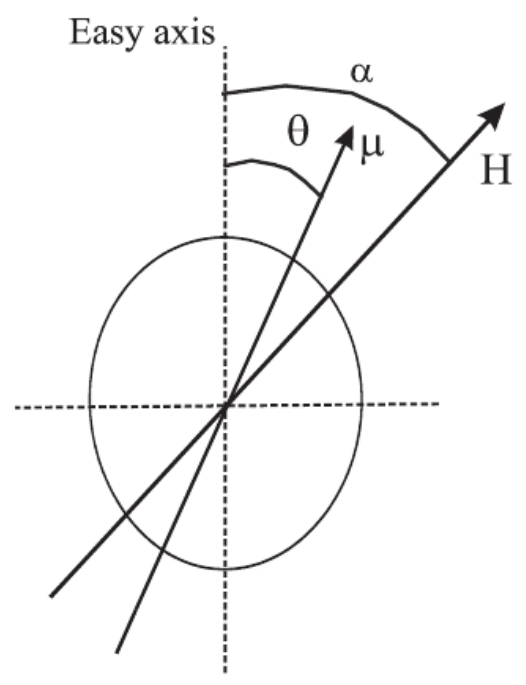

(b)

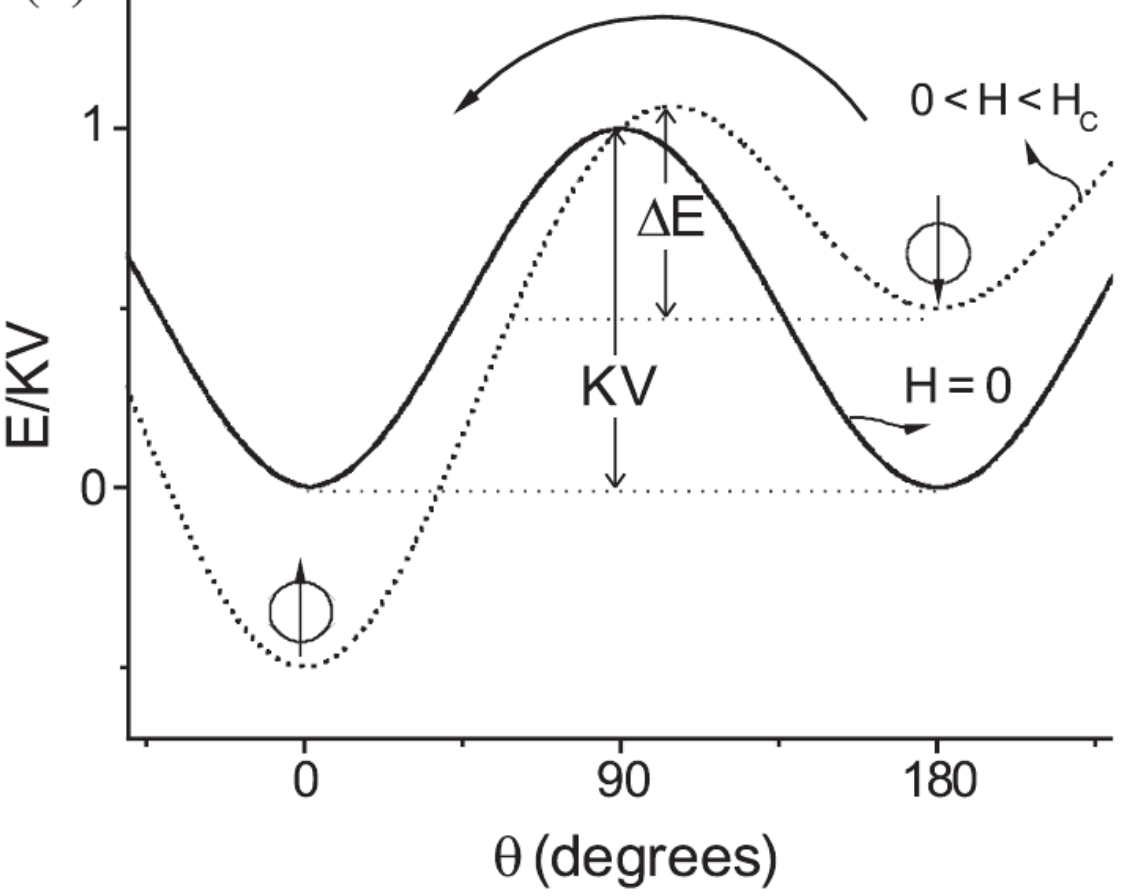

Figura 4: (a) definição do sistema de eixos para uma partícula fina e (b) Dependência angular da barreira de energia para campo externo zero (linha contínua) e por um valor menor do campo do que o campo coercitivo (linha tracejada) (KNOBEL et al., 2008).

A posição de equilíbrio é dada por:

$$
\frac{d E}{d \theta}=2 K \operatorname{sen} \theta \cos \theta-\mu_{0} H M_{S} \operatorname{sen}(\alpha-\theta)=0
$$

e a componente da magnetização na direção do campo é $m=m_{S} \cos (\alpha-\theta)$. Se o campo é normal ao eixo de fácil magnetização $\left(\alpha=90^{\circ}\right)$, a magnetização reduzida escreve-se:

$$
m^{*}=\frac{m}{M_{S}}=\frac{\mu_{0} H M_{S}}{2 K} .
$$

Portanto a magnetização é proporcional a $H$, sem histerese. A saturação é atingida quando $H=H_{a}=2 K / \mu_{0} M_{S}$, campo de anisotropia (Figura 5). Utilizando o campo reduzido $h=H / H_{a}=\mu_{0} H M_{S} / 2 K$, então $m=h$ quando $\alpha=90^{\circ}$. 


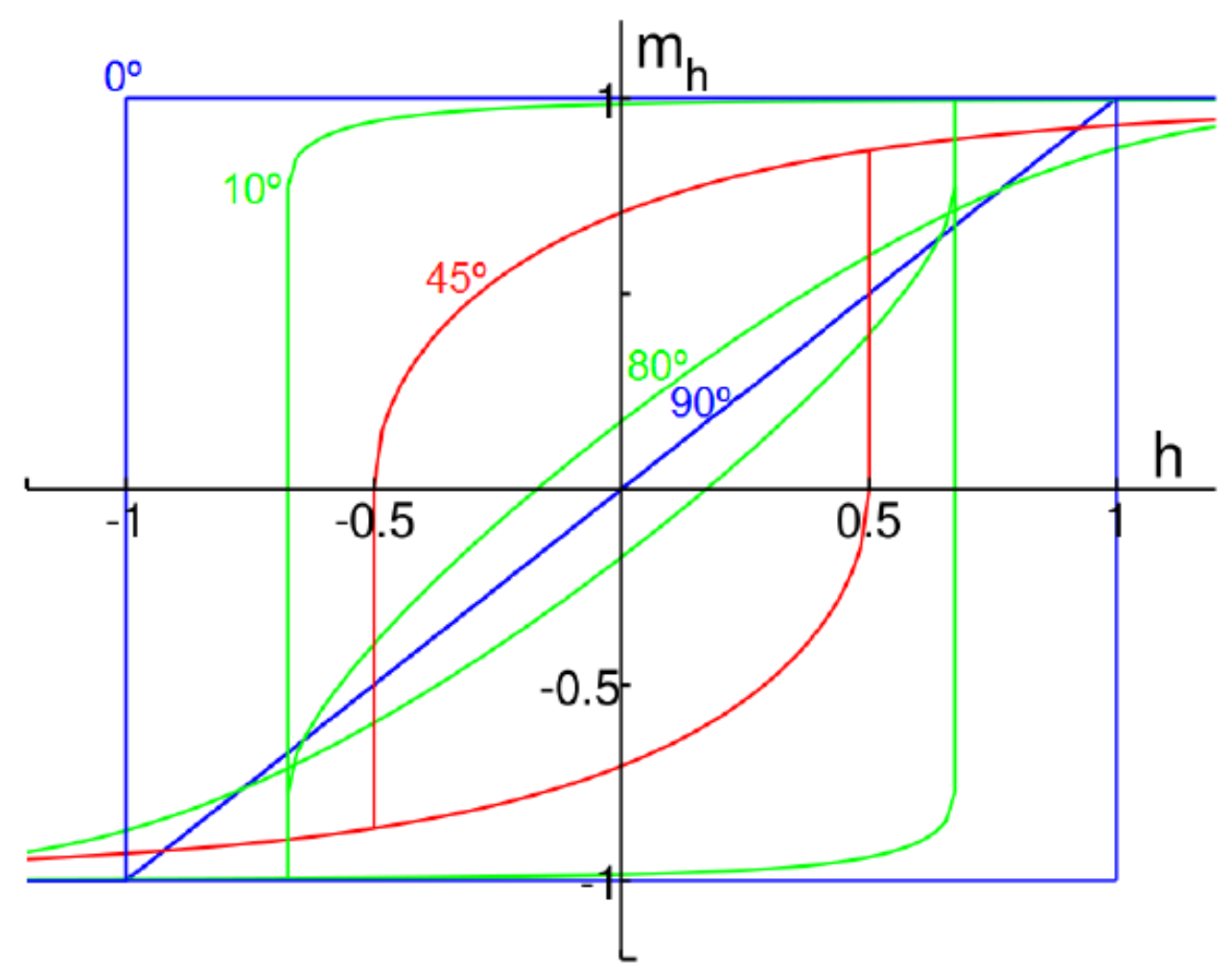

Figura 5: Ciclos de histerese magnética de partículas monodomínios com anisotropia uniaxial. $\phi$ é o ângulo entre o campo externo e o eixo de fácil magnetização retirado da ref. (CULLITY; GRAHAM, 2011)

Consideremos agora o campo aplicado paralelamente ao eixo fácil $\left(\alpha=0^{\circ}\right)$ e $\vec{H}$ e $\vec{\mu}$ apontando no sentido positivo desse eixo. Em seguida, reduzimos $\mathrm{H}$ a zero e na mesma sequência aumentamos $\mathrm{H}$ em sentido negativo $\left(\alpha=180^{\circ}\right)$. Apesar de $\vec{H}$ e $\vec{\mu}$ estarem agora em sentido contrário e o campo não criar nenhum torque sobre o momento, a posição $\theta=0^{\circ}$ se torna instável e o momento inverte sua orientação, para $\theta=180^{\circ}$, quando h atinge um valor suficientemente significativo no sentido negativo. Esse valor crítico pode ser determinado escrevendo $d^{2} E / d \theta^{2}=0$. Tanto o campo crítico $h_{c}$, quanto o ângulo crítico $\theta_{c}$, valores para os quais o momento inverte seu sentido, podem ser calculados:

$$
\tan ^{3} \theta_{c}=-\tan \alpha \quad \text { e } \quad h_{c}^{2}=1-\frac{3}{4} \operatorname{sen}^{2} 2 \theta_{c} .
$$

Quando $\alpha=180^{\circ}, \theta_{c}=0^{\circ}$ e $h_{c}=1$ ou $H_{c}=H_{a}$. O ciclo de histerese é retangular.

A Figura 5 mostra ciclos de histerese calculados para vários valores de $\alpha$. O valor crítico de campo reduzido $h_{c}$, no qual o vetor de magnetização muda de uma orientação para outra, diminui de 1 para $\alpha=0$, até um mínimo de 0.5 quando $\alpha=45^{\circ}$, e aumenta de novo para 1 quando $\alpha$ se aproxima de $90^{\circ}$. 


\subsubsection{Superparamagnetismo de Néel e Temperatura de Bloqueio}

Esse estado magnético ocorre em nanopartículas ferromagnéticas e ferrimagnéticos que são monodomínio com diâmetro inferior a $50 \mathrm{~nm}$, em que a energia de anisotropia $E_{a}$ pode ser comparada à energia térmica $k_{B} T$. (BEAN; LIVINGSTON, 1959; DORMANN, 1981). Nesta condição, considera-se que a magnetização da nanopartícula é um único momento magnético gigante, resultado da soma de todos os momentos magnéticos individuais dos spins da nanopartícula "superspin". Sem campo magnético externo aplicado a direção do momento magnético do monodomínio estará ao longo do eixo fácil, e pode ser determinada pela energia de anisotropia como podemos observar na Figura 4 (a).

Devido à anisotropia magnética, o momento magnético tem normalmente apenas duas orientações estáveis antiparalelas, separadas por uma barreira de energia. As orientações estáveis definem o eixo fácil de magnetização das nanopartículas. À temperatura finita há uma probabilidade finita para a magnetização inverter e reverter a sua direção. Neste caso, a probabilidade da passagem dos spins de uma direção de fácil magnetização a outra não é mais nula, em outras palavras, o sistema de spins vai relaxar com um certo período de tempo $\tau$ entre as direções de fácil magnetização que pode ser verificado na Figura 4 (b). Este tempo de relaxação, introduzido por Néel em 1949 (NÉEL, 1949) é definido como sendo o tempo médio para reverter o momento magnético de um estado de equilíbrio até outro. A barreira de energia $E_{a}=K V$ do momento magnético é determinada pela energia de anisotropia, e pode ser alterada por um campo aplicado, visualizado pela linha pontilhada na Figura 4 (b). O tempo do momento magnético chamado de reverso do $\tau_{N}$ tempo de relaxação, é regido pela lei de Néel-Arrhenius (NÉEL, 1949):

$$
\tau_{N}=\tau_{0} \exp \left(\frac{K V}{k_{B} T}\right),
$$

onde $\tau_{0}$ é um tempo característico dependente do material que varia de $10^{-13}-10^{-9} s, k_{B}$ é a constante de Boltzmann ${ }^{7}$ e T a temperatura em Kelvin.

Se o tempo de medida $\tau_{m}$ for $\tau_{m}>>\tau$, o equilíbrio termodinâmico é atingido durante a medida e o estado observado é desordenado, caracterizando um comportamento superparamagnético. Se $\tau_{m}<\tau$, os momentos magnéticos não têm tempo de relaxar e o sistema apresenta o fenômeno de histerese, característico de um regime bloqueado. A partir da equação

\footnotetext{
${ }^{7}$ Constante de Boltzmann no SI $1.38064852 \times 10^{-23} \mathrm{~m}^{2} \mathrm{~kg} \mathrm{~s}^{-2} \mathrm{~K}^{-1}$
} 
13 o tempo de relaxamento é determinado pelo expoente $E_{a} / k_{B} T$ e podemos tirar algumas conclusões. À medida que o volume da partícula diminui $E_{a}$ também diminuirá. Quando $E_{a}$ é menor do que um certo valor, o tempo de relaxamento satisfará a condição $\tau<\tau_{m}$ e as partículas irão mostrar comportamento superparamagnético.

O tempo de relaxação é também dependente da temperatura, como pode ser visto na equação 13 para uma dada a partículas, $\tau$ irá aumentar com a diminuição da temperatura $T$. Assim, deve haver uma temperatura crítica, acima da qual, $\tau<\tau_{m}$ e a partícula é superparamagnético, e abaixo do qual, $\tau>\tau_{m}$ e o comportamento superparamagnético é bloqueado. Esta temperatura crítica é a assim chamada a temperatura superparamagnética de bloqueio $T_{B}$, em que $\tau \approx \tau_{\mathrm{m}}$. $E_{a}$ e $T_{B}$ são relacionados por:

$$
E_{a}=k_{B} T_{B} \ln \left(\tau_{m} / \tau_{0}\right) .
$$

Experimentalmente, a existência de um máximo na curva de magnetização DC com protocolo zero-field-cooling caracteriza a passagem de um sistema de partículas bloqueadas para um estado superparamagnético.

As técnicas de magnetometria permitem uma investigação dos fenômenos durante um tempo típico da ordem de $100 \mathrm{~s}$. Então, $\ln \left(\tau_{m} / \tau_{0}\right)$ é de cerca 25 . Sob esta aproximação, equação 14 pode ser simplificada como:

$$
E_{a} \approx 25 k_{B} T_{B}
$$

\subsubsection{Interações Interpartículas e Thamm-Hesse Plot}

\section{Energia de Interação dipolar entre as partículas}

Cada nanopartícula possui um momento magnético intrínseco que se origina no momento de spin dos elétrons. No entanto, existe uma interação entre os momentos das partículas através de seus campos magnéticos dipolares. Essas interações podem ser fortes ou insignificantes dependendo da concentração volumétrica de partículas e podem também mudar de natureza individual. Se, por exemplo, nanopartículas estão isoladas, isto é, distantes umas das outras, as propriedades magnéticas são intrínsecas, governadas principalmente pelas anisotropias magnetocristalina, de superfície e eventualmente magnetoestáticas (MARTINEZ-HUERTA et al., 2013). Por outro lado, se esta condição não for satisfeita, como por exemplo amostras em pó, que possui interações dipolares e exchange entre os spins de superfície de curto alcance, e ferrofluidos concentrados, somente interações dipolares de longo alcance, as propriedades 
individuais das partículas serão modificadas pela interação de campo produzida pelas outras partículas(LUO et al., 1991; GARCÍA-OTERO et al., 2000).

Considerando o caso ideal de duas partículas como sendo dois dipolos permanentes $\vec{\mu}_{1}$ e $\vec{\mu}_{2}$, cada partícula é submetida à indução magnética criada pela outra e a energia de interação dipolar é expressa por e ilustrada na figura 6:

$$
E_{D}=-\vec{\mu}_{1} \vec{B}_{12}=-\vec{\mu}_{2} \vec{B}_{21}=-\frac{\left(\vec{\mu}_{1} \vec{B}_{12}+\vec{\mu}_{2} \vec{B}_{21}\right)}{2},
$$

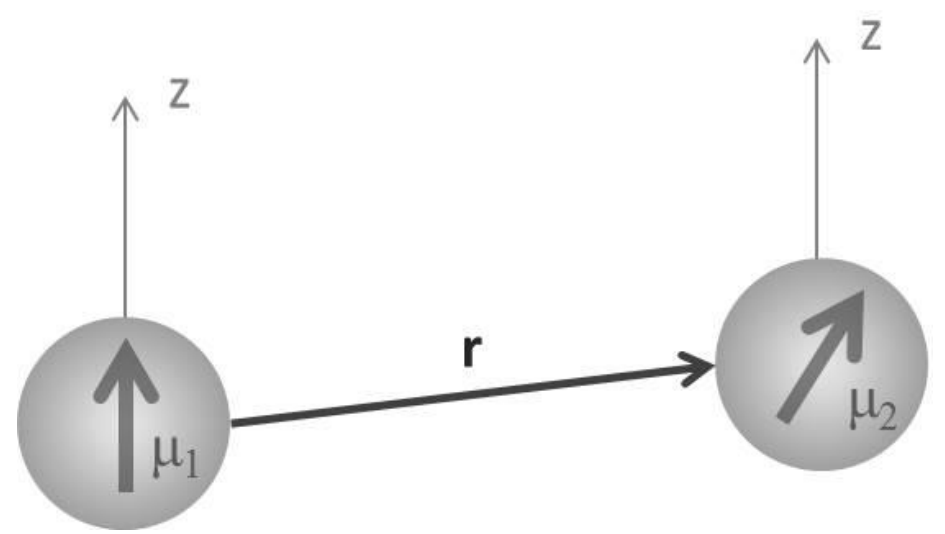

Figura 6: $\mathrm{O}$ esquema mostra geometricamente dois momentos magnéticos $\mu$ distantes entre si de uma distância r, porém próximos o suficiente para interagirem através da interação dipolar.

onde $\vec{B}_{12}$ e $\vec{B}_{21}$ são as induções criadas por $\vec{\mu}_{2}$ e $\vec{\mu}_{1}$ respectivamente, o campo magnético associado é $\vec{H}_{i j}=\vec{B}_{i j} / \mu_{0}$. Utilizando a expressão da interação magnética criada a grande distância(KECHRAKOS; TROHIDOU, 1998), a equação acima se escreve no caso de duas partículas esféricas idênticas separadas de uma distância $r$ (distância centro a centro):

$$
E_{D}=\frac{\mu_{0}}{4 \pi}\left[\frac{\vec{\mu}_{1} \vec{\mu}_{2}}{r^{3}}-\frac{3\left(\vec{\mu}_{1} \cdot \vec{r}\right)\left(\vec{\mu}_{2} \cdot \vec{r}\right)}{r^{5}}\right]
$$

e a energia é frequentemente expressa em função do parâmetro de interação dipolar $\lambda$, que representa a razão entre a energia de interação dipolar e a energia térmica no caso de dois dipolos alinhados, caracterizando assim o acoplamento magnético entre eles(GAZEAU et al., 2002).

Considerando agora um conjunto de muitas partículas, cada partícula é submetida a um campo adicional criado pelo conjunto dos dipolos magnéticos vizinhos. Neste caso, a expressão da energia de interação não é simples e depende do arranjo geométrico das partículas. Se as partículas são muito dispersas, a energia de interação será desprezível, ao contrário, se as partículas são compactas, a contribuição devido à interação dipolar pode se tornar significativa. 
Por outro lado, a existência de uma distribuição de tamanhos vem ainda complicar o problema, já que resulta em uma distribuição de barreira de energia e tempo de relaxação.

As interações dipolares magnéticas podem ser quantificadas por um parâmetro de referência $\Psi_{d d}$, característico do material e independente da fração volumétrica $(\phi)$ da amostra como observamos na expressão (MÉRIGUET et al., 2012):

$$
\Psi_{d d}=\frac{\mu_{0} M_{S}^{2} \pi d^{3}}{6 k_{B} T},
$$

onde $M_{S}$ é a magnetização de saturação das nanopartículas. Nós obtemos então o parâmetro de interação dipolar que está associado a um conjunto de partículas de fração volumétrica $\phi$, pela expressão:

$$
\lambda=\frac{\Psi_{d d} \phi}{4 \pi} .
$$

Thamm-Hesse plot

Para observar o comportamento das interações presentes nas amostras investigadas empregamos a abordagem proposta por Thamm e Hesse (THAMM; HESSE, 1996, 1998) que desenvolvem um método alternativo ao Henkel Plot (HENKEL, 1964) utilizando as propriedades de Stoner \& Wohlfarth para um ciclo de histerese magnética. Usam o artifício que uma única partícula $\mathrm{S} W$ não possui curva de magnetização inicial explícita, essa aparecendo apenas em um conjunto de partículas $S W$. Apresentamos o modelo de Henkel e sua analogia com Thamm e Hesse Plot. E como o $\Delta m$ (do modelo de Thamm e Hesse) com $\Delta m_{H}$ (do modelo de Henkel) se relacionam para um sistema de simples partículas não interagentes.

Em 1964, Henkel apresenta seu método (Henkel plot) para verificar a validade da relação proposta pela teoria de Stoner \& Wohlfarth do ciclo de histerese para sistemas de partículas não interagentes:

$$
M_{d}(H)=M_{r}(H \rightarrow \infty)-2 M_{r}(H),
$$

onde $M_{d}$ é remanência de desmagnetização dc e $M_{r}$ a remanência isotérmica, após normalização com relação ao valor da saturação da remanência, $\mathrm{M}_{\mathrm{r}}(\mathrm{H} \rightarrow \infty)$ a equação 20 torna-se:

$$
m_{d}(H)=1-2 m_{r}(H),
$$

onde, $m_{d}(H)=M_{d}(H) / M_{r}(\infty) \mathrm{e} m_{r}(H)=M_{r}(H) / M_{r}(\infty)$, apresentadas na Figura 7 (a). O efeito das interações pode ser examinado a partir do gráfico de $\Delta m_{H}(\mathrm{H}$ de Henkel) em função do campo $\mathrm{H}:$

$$
\Delta m_{H}(H)=m_{d}(H)-\left(1-2 m_{r}(H)\right) .
$$




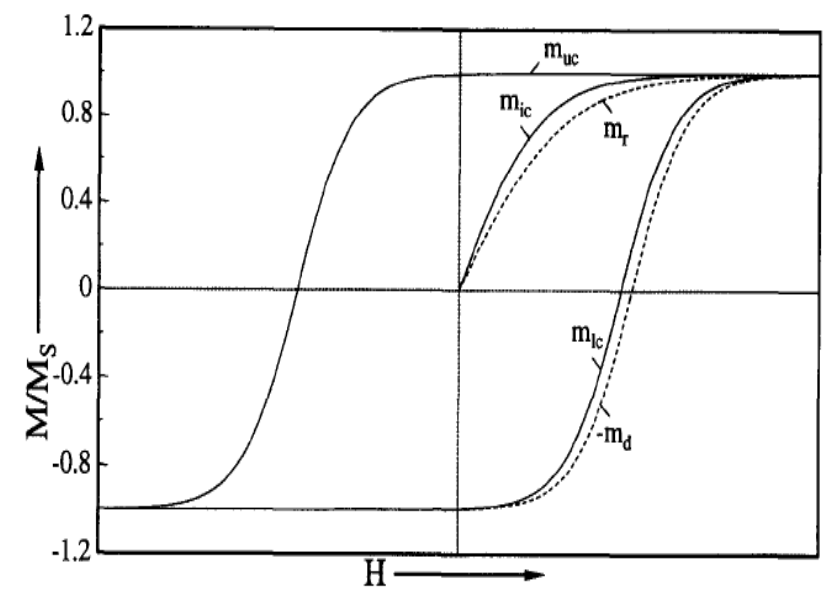

(a) ciclo de histerese e curva típica do Henkel plot

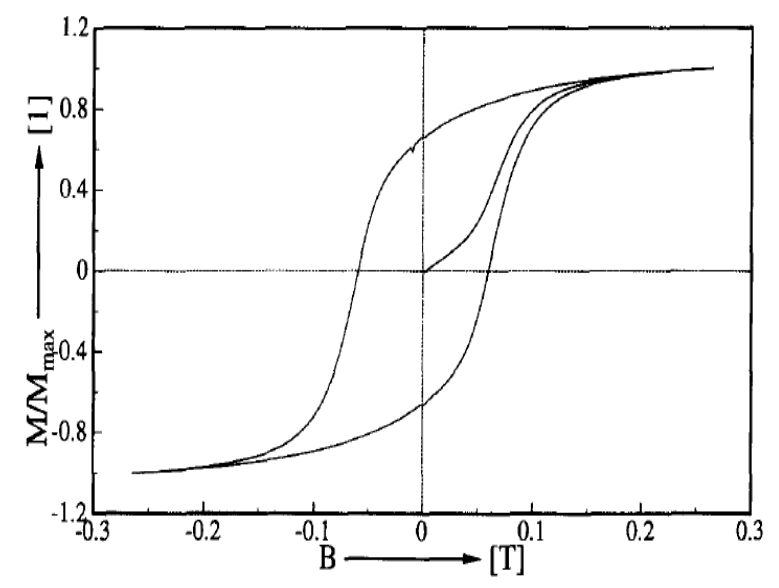

(c) ciclo de histerese magnética experimental

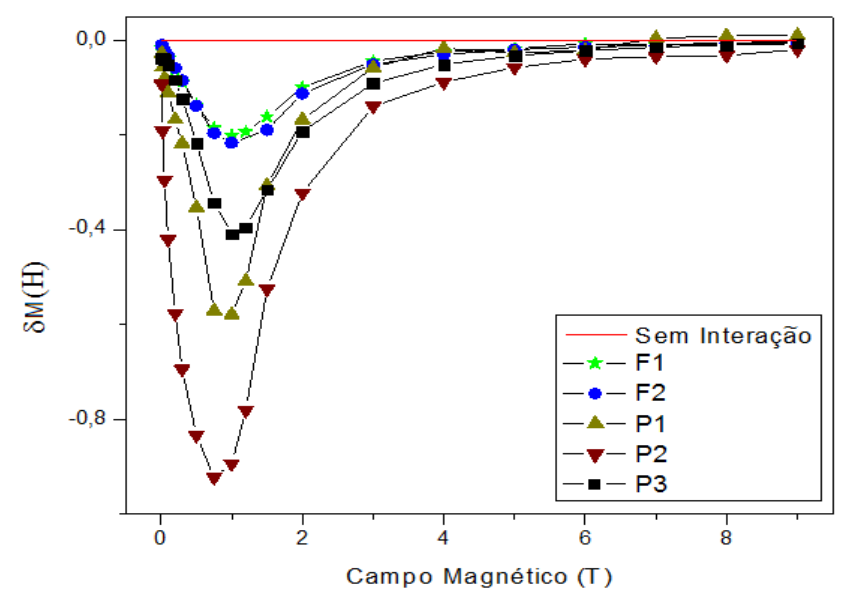

(b) Henkel plot $\left(\Delta M_{H}\right)$

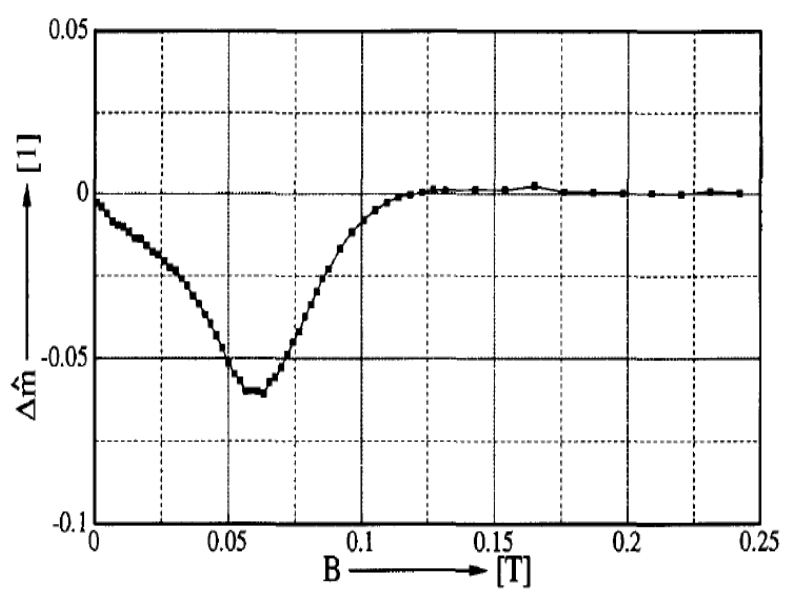

(d) Thamm e Hesse plot ( $\Delta m$ )extraído da fig. (c)

Figura 7: (a) Explanação das suposições para o cálculo da relação entre $\Delta m$ e $\Delta m_{H}, m_{v i r}=m_{i c}, m_{\text {sup }}=m_{u c}$ e $m_{\text {inf }}=m_{l c}$. A curva de primeira magnetização e o laço de histerese são desenhados com linhas sólidas. Os resultados típicos de $m_{d}(H)$ e $m_{r}(H)$ usado para o Henkel plot são mostrados como linhas tracejadas. (b) O resultado do Henkel plot para amostra de ferritas de cobalto em regimes de ferrofluido diluído (representado por F) e pó compacto (representado por P variando a pressão de compactação) de Ferrita de Cobalto com diâmetro similar de $3.15 \mathrm{~nm}$, extraída de (VIEIRA, 2013). c) ciclo de histerese (normalizado) de 2DD de 3,5" material do disco Sony. (d) derivação do $\Delta m$ calculado a partir da fig. (c) figuras extraídas da ref. (THAMM; HESSE, 1996).

Um desvio do zero em $\Delta m_{H}$ geralmente indica a existência de interações interpartículas como exibido na Figura 7 (b) para um sistema de nanopartículas à base de ferrita de cobalto. Neste caso, a intensidade do pico aumenta com as interações interpartículas que se tornam mais importantes com o aumento da fração volumétrica ou da compactação no caso de pó comprimido. Entretanto, quando a compactação é máxima devem também ser consideradas as interações de super trocas entre partículas diferentes. Um sistema de partículas magnéticas pode ser desmagnetizado por um processo que conduza a uma configuração na qual a probabilidade de uma partícula ter magnetização ao longo de qualquer direção é igual a probabilidade de encontrar a magnetização na direção oposta. Em um sistema sem interações, 
a curva de primeira magnetização $\left(m_{v i r}\right)$ fica exatamente na média entre o ramo superior do ciclo de histerese ( $\left.m_{\text {sup }}\right)$ e o ramo inferior $\left(m_{\text {inf }}\right)$, apresentadas na Figura 7 (a) $\Delta m$ se escreve:

$$
\Delta m=m_{\text {vir }}-\frac{1}{2}\left(m_{\text {sup }}-m_{\text {inf }}\right) .
$$

Quando $\Delta m$ é igual à zero a amostra é constituída por partículas ideais de $S W$ (STONER; WOHLFARTH, 1948). Em presença de interações interpartículas, irá haver um desvio na magnetização $\Delta m$ negativo, e este desvio é uma medida da intensidade das interações. $\Delta m$ de Thamm Hesse é extraída da curva Figura 7 (c) e apresentado na Figura 7 (d).

Assumimos (Figura 7 (a)) que após a normalização para o valor máximo de $H$ o ramo superior tenha um valor constante, a curva virgem é idêntica para $\mathrm{m}_{\mathrm{r}}$ (este é o caso para as partículas com o eixo fácil paralelo ao campo externo). Além disso, o ramo menor e $-m_{d}$ deve ter a mesma dependência com campo. Essas suposições levam:

$$
\begin{gathered}
m_{v i r}(H)=m_{r}(H) \\
m_{\text {sup }}=1 \\
m_{\text {inf }}=-m_{d}(H)
\end{gathered}
$$

e são exibidos na Figura 7 (a). A partir das equações (24), (25) e (26) podemos expressar a magnetização média por:

$$
m=\frac{1}{2}\left(m_{\text {sup }}+m_{\text {inf }}\right)=\frac{1}{2}\left(1-m_{d}\right) .
$$

Por fim, encontramos a relação entre $\Delta m$ e $\Delta m_{H}$ que unifica as duas abordagens de Henkel e Thamm e Hesse:

$$
\Delta m=\underbrace{m_{\text {vir }}-\frac{1}{2}\left(m_{\text {sup }}+m_{\text {inf }}\right)}_{\text {Thanm }- \text { Hesse Plot }}=\underbrace{m_{r}-\frac{1}{2}\left(1-m_{d}\right)}_{\text {Henkel Plot }}=\frac{1}{2} \Delta m_{H}
$$

\subsubsection{Aleatoriedade e frustração em sistemas de nanopartículas magnéticas}

Com o confinamento espacial na escala nanométrica os fenômenos de interface (superfície), ou seja, quebra de simetria no limite da partícula e defeitos de coordenação, criam o estado spin-glass-like que corresponde a uma estrutura magnética desordenada nas superfícies das partículas. O comportamento coletivo dos spins no interior das NPs resulta num momento magnético total associado a um monodomínio, denominado de "superspin". Ao considerarmos um conjunto de muitas partículas observamos que é impossível de arranjá-las numa rede periódica e tridimensional para criar um "cristal perfeito de superspins". Isto é principalmente devido à aleatoriedade nas direções dos momentos magnéticos e dos eixos de anisotropia, bem 
como à polidispersão de tamanhos que impedem a construção de um cristal coloidal. A existência desse tipo de frustração induz a obtenção de um estado desordenado de superspins, chamado de Superspin-Glass SGG (vidros de superspins).

O estado $S G G$ é observado em vários sistemas, por exemplo de nanopartículas coreshell a base de $\mathrm{Fe} / \gamma-\mathrm{Fe}_{2} \mathrm{O}_{3}$ (CHANDRA et al., 2012), de nanopartículas de $\gamma-\mathrm{Fe}_{2} \mathrm{O}_{3}$ recobertas por coroa de sílica e é, em geral, proveniente da interação dipolar entre superspins com distância interpartículas controlada (HIROI; KOMATSU; SATO, 2011). Fiorani e Peddis investigam a dinâmica de nanopartículas magnéticas interagentes a partir do regime de interação fraca para o estado SSG para compreender a formação desse estado (FIORANI; PEDDIS, 2014).

Nakamae et al. (NAKAMAE et al., 2010a) investigaram o estado SSG em ferrofluidos congelados à base de nanopartículas de $\gamma-\mathrm{Fe}_{2} \mathrm{O}_{3}$ dispersas em glicerina com fração volumétrica de $\sim 15 \%$ e observam as propriedades dinâmicas do SSG quando texturizado (resfriado em presença de campo) e não texturizado (resfriado em ausência de campo). Na mesma amostra, pesquisam também (NAKAMAE et al., 2010b) o efeito do alinhamento do eixo de anisotropia magnética nos estados superparamagnético (SPM) e vidro de superspins (SSG). Experimentos de magnetização e simulações ainda indicam o aumento do comprimento de correlação observado na dinâmica dos vidros de superspins (NAKAMAE et al., 2012).

Semelhante ao regime SPM, o experimento de dependência térmica da magnetização em baixo campo (curva ZFC e FC) é o método mais usual para estudar sistemas SSG. A dependência da susceptibilidade magnética com a temperatura no protocolo ZFC é caracterizado por um máximo da susceptibilidade (ZFC) enquanto a susceptibilidade com protocolo FC apresenta um pequeno acréscimo seguido de um platô com o decréscimo da temperatura (BEDANTA; KLEEMANN, 2009; CHANDRA et al., 2012). Esse comportamento é consequência do comportamento coletivo dos núcleos (o congelamento dos spins da superfície em estrutura SG ocorre em temperaturas mais baixas). A Figura 8 (a) e (b) exemplifica a região de platô abaixo do pico de $T_{B}$ na curva FC. Dependendo do regime das interações entre as partículas, um conjunto de superspins pode apresentar diferentes estados magnéticos: o Superspin glass (SSG) devido as forças de interação e o Superparamagnetismo (SPM) para o caso de nenhuma interação, para os materiais que se comportam como SSG a temperaturas baixas e a temperaturas mais elevadas SPM (CHEN et al., 2004; FIORANI; PEDDIS, 2014).

As propriedades dinâmicas abaixo de $T_{g}$, no SSG, são caracterizadas por efeitos de memória e envelhecimento, são a manifestação de um estado fora de equilíbrio associados ao aparecimento de um estado aleatório coletivo de superspins. Isto reflete a evolução lenta do 
sistema no sentido de uma configuração de equilíbrio durante o envelhecimento começando no momento do arrefecimento rápido abaixo de $T_{g}$.
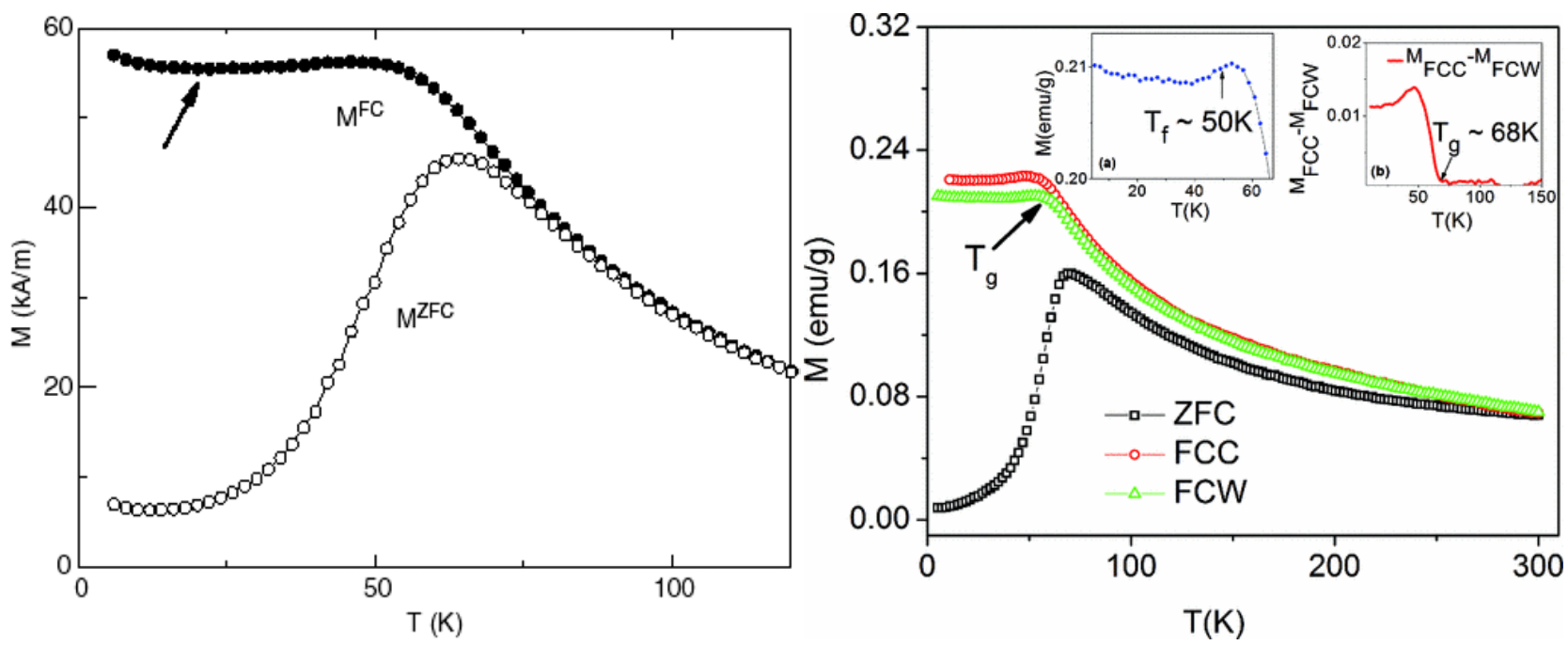

Figura 8: (a) $\mathrm{M}_{\mathrm{ZFC}}(\mathrm{T})$ (círculos abertos) e de $\mathrm{M}_{\mathrm{FC}}(\mathrm{T})$ (círculos a cheio) de $\left[\mathrm{Co}_{80} \mathrm{Fe}_{20}(\mathrm{TN}=0,9 \mathrm{~nm}) / \mathrm{Al}_{2} \mathrm{O}_{3}(3\right.$ $\mathrm{nm}$ )] medida com campo de $\mu_{0} \mathrm{H} \approx 0.4 \mathrm{mT}$. O mergulho no $\mathrm{M}_{\mathrm{FC}}$ (seta) é típico de um sistema SSG ou SG; Extraído da ref. (BEDANTA; KLEEMANN, 2009. (b) Dependência da temperatura da magnetização para o resfriamento em ausência de campo (ZFC) ou em presença de campo Field Cooled Cooling (FCC) e aquecimento Field Cooled Warming (FCW). [insert (a)] $\mathrm{O}$ mergulho na $\mathrm{M}_{\mathrm{FCW}}$ está associada com o início do congelamento dos superspins

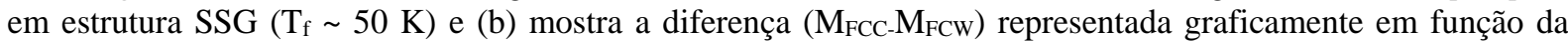
temperatura, em que um aumento acentuado $\left(\mathrm{T}_{\mathrm{g}} \sim 68 \mathrm{~K}\right)$ marcas o início da histerese térmica. Extraído da ref. (CHANDRA et al., 2012).

\subsubsection{Efeito de memória magnética com protocolo de envelhecimento DC}

Os fenômenos de envelhecimento e de memória são ideais para investigar as características típicas da dinâmica de vidros de spins. Vários trabalhos observaram estas características em susceptibilidade de baixa frequência AC ou medidas de magnetização de baixo campo em ferrofluidos congelados (JONSSON et al., 1995; JONSSON; SVEDLINDH; HANSEN, 1998; MAMIYA; NAKATANI; FURUBAYASHI, 1999; JÖNSSON; HANSEN; NORDBLAD, 2000). Eles discutem sobre a existência de comportamento coletivo e da existência de uma fase de spin-glass em baixa temperatura com magnetização AC. O principal argumento sugere a existência de uma fase de vidros de spins. No entanto, existem algumas diferenças entre esses sistemas: Para um estado de spin glass o tempo de giro dos momentos magnéticos individuais é da ordem de $10^{-13} \mathrm{~s}$ e independente da temperatura, ao mesmo tempo que pode variar para escalas de tempo de nanosegundos num sistema de partículas magnéticas, de acordo com o tempo de relaxação, $\tau=\tau_{0} \exp \left(K V / k_{B} T\right)$, onde $\tau_{0} \sim 10^{-12}-10^{-9} \mathrm{~s}$. Uma vez que todos os sistemas de partículas estão mais ou menos polidispersos, acarreta-se uma distribuição de energias de anisotropia que implica numa distribuição dos tempos de giros individuais dos 
momentos magnéticos. Além disso, a interação entre os momentos magnéticos no spin glass é na maior parte por interações de exchange de curto alcance ou do tipo RKKY de longo alcance, Esses fenômenos também são encontrados em sistemas de partículas magnéticas com interação dipolo-dipolo e quando em contato de superexchange entre os spins de superfície. (JONSSON; SVEDLINDH; HANSEN, 1998).

Efeito de Memória (EM) no protocolo de envelhecimento com magnetização DC, primeiramente reportadas por Sun et al. (SUN et al., 2003) obtém resultados interessantes para um conjunto de nanopartículas interagentes de um "ferrofluido" congelado. Demonstram efeitos marcantes na magnetização DC e o relaxamento magnético que confirmam a existência de uma fase de spin-glass neste sistema, a Figura 9 (a) mostra a curva do experimento de Sun et al. Sasaki et al. realizam experimentos e simulações que demonstram que Sun et al. é qualitativamente reprodutível em materiais superparamagnéticos, a Figura 9 (b) mostra a curva feita para um sistema de partículas em pó (SASAKI et al., 2005). Zheng et al. demonstra executando os mesmos protocolos de medidas que em sistema de partículas não interagentes com uma distribuição de tamanho, o efeito de memória pode ser observado (ZHENG; GU; ZHANG, 2004).

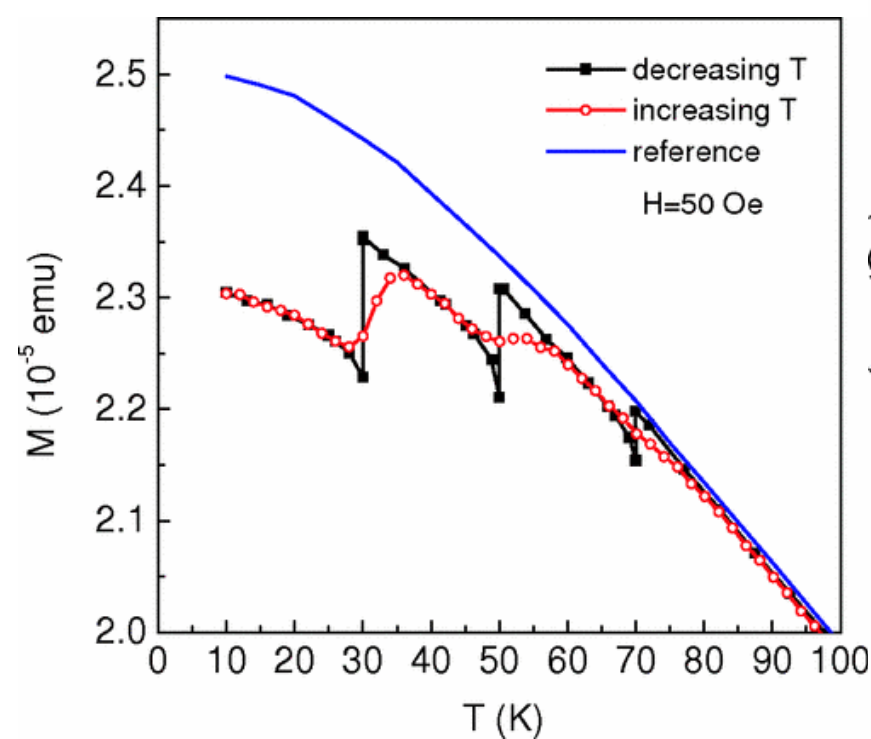

(a) EM em sistema com regime de Interações Fracas

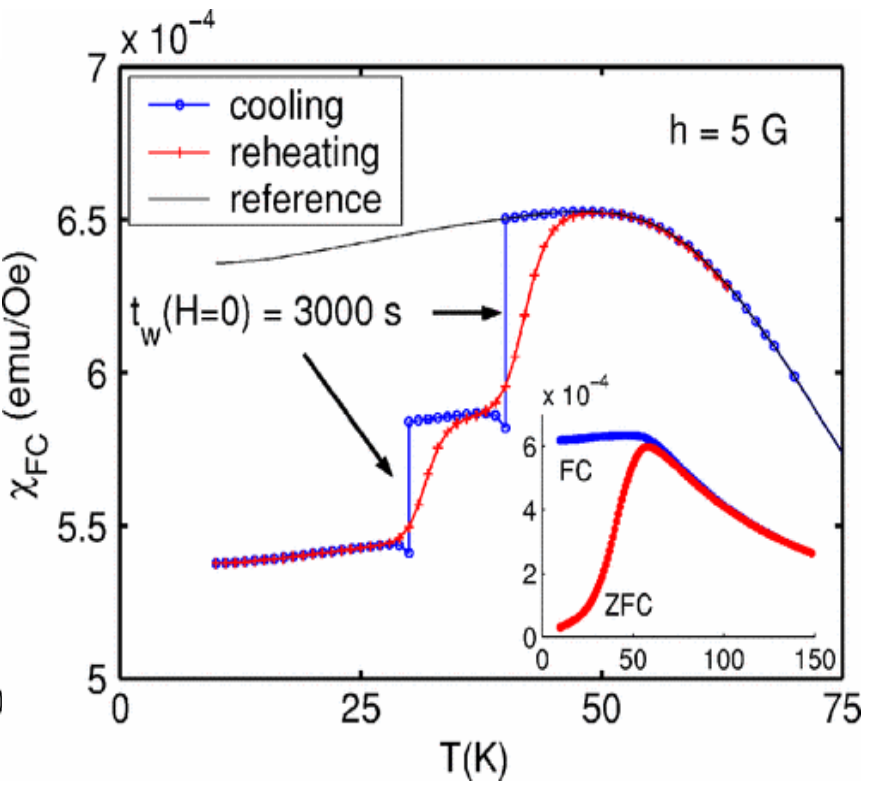

(b) EM em sistema com regime de Interações Fortes

Figura 9: (a) Efeito de memória na magnetização DC para nanopartículas de permalloy $\left(\mathrm{Ni}_{81} \mathrm{Fe}_{19}\right)$ dispersas num liquido carreador. A linha sólida é medida por aquecimento a uma velocidade constante de $2 \mathrm{~K} / \mathrm{min}$ após FC em 50 Oe (curva de referência). Os quadrados cheios são medidos durante o arrefecimento em 50 Oe à mesma velocidade, mas com paradas de 4 horas de duração, a 70, 50 e $30 \mathrm{~K}$. O campo é cortado durante cada paragem. Os círculos abertos são medidos com aquecimento contínuo com a mesma taxa de arrefecimento após o procedimento anterior, extraído da referência (SUN et al., 2003). (b) (Linhas coloridas) susceptibilidade FC do sistema $\mathrm{Fe}_{3} \mathrm{~N}$ com o mesmo protocolo que o que na fig. 13 (a). A temperatura crítica da amostra é de cerca de $60 \mathrm{~K}$. $\mathrm{O}$ campo é cortado durante as paragens intermitentes do arrefecimento a $\mathrm{T}=40$ e $30 \mathrm{~K}$ para 3000 s a cada temperatura. A taxa de arrefecimento (e reaquecimento) é $\sim 0.01 \mathrm{~K} / \mathrm{s}$. O insert mostra o ZFC e FC susceptibilidades vs temperatura, extraído da referência (SASAKI et al., 2005). 
No pó de nanopartículas existe uma forte interação interpartículas que induz uma estrutura SSG. Torna-se significativa de modo que não pode ser desprezada, em comparação com a energia de anisotropia de cada partícula magnética (HIROI; KOMATSU; SATO, 2011). O efeito de memória magnética é interpretado como uma inscrição magnética do sistema e este é associado ao estado de SG (ZHENG et al., 2005) em baixas temperaturas a magnetização é rigorosamente idêntica. Se pausado o resfriamento e desligado o campo e após um determinado tempo de espera vai existir uma queda da magnetização, após, caso aconteça o religamento do resfriamento e do campo aplicado, o sistema tenta voltar ao seu estado de inicial magnetização (curva de referência), em outras palavras o sistema memorizou informação, recuperando sua história térmica quando a temperatura é devolvida.

Este procedimento produz uma curva de resfriamento com steplikes (degraus), Estes degraus são a assinatura do efeito de memória e pode ser usado como uma boa medida para determinar se o sistema está Superparamagnético ou spin glass. A curva com degraus exibe uma diminuição da magnetização em comparação com a curva de referência. Este comportamento é normalmente atribuído a estruturas SG. A queda na magnetização em todos as paradas de tempo $t_{w}$ é a característica principal do efeito de memória e depende do estado magnético das NPs e só cessa quando o sistema entra em equilíbrio. Após um tempo de espera $t_{w}$, quando o campo está ligado, a recuperação na magnetização depende de quão rápido as nanopartículas se realinham com campo aplicado. Em temperaturas menores que $T_{g}$ o sistema apresenta uma queda da magnetização acentuada, a queda da magnetização é relativamente menor em temperatura muito baixas devido a dinâmica lenta. Em amostras extremamente diluídas de nanopartículas magnéticas é observado superparamagnetismo, enquanto em muitos sistemas de nanopartículas densas o estado de superspin glass (SSG) é observado (VASILAKAKI et al., 2013). Em contraste, um sistema de partículas não interagentes mostra o SPM e o comportamento da magnetização é crescente com a diminuição da temperatura (SASAKI et al., 2005).

\subsection{Exchange Bias e Efeito de Treinamento}

\subsubsection{Congelamento de spins de superfície em estrutura SGL}

Sistemas magnéticos ordenados, em temperaturas abaixo de $T_{C}$, a dependência da magnetização com a temperatura é impulsionada por excitações de ondas de spins, suas energias possíveis são quantizadas da mesma forma que fótons e outras excitações elementares, em que 
o estado associado a uma onda de um spin corresponde às vibrações elementares de baixa energia de um sistema de spins, esse comportamento é descrito pela Lei de Bloch. A dependência da magnetização deve se comportar de acordo com a Lei Bloch:

$$
M(T)=M_{S}(0)\left(1-B T^{\alpha}\right) .
$$

esta dependência é bem descrita pelo modelo das ondas de spins para materiais bulk.

As características magnéticas são fortemente afetadas com a redução do tamanho das partículas à escala manométrica, devido à influência da energia térmica através da ordenação do momento magnético, originando o superparamagnetismo. A magnetização de nanopartículas e sua dependência térmica estão diretamente relacionados a dois tipos de fenômenos que são reforçadas conforme a relação superfície/volume torna-se maior. Alguns trabalhos mostram que a redução produz uma contribuição superficial nas propriedades magnéticas que conduz a uma interação complexa entre dois tipos de fenômenos: diâmetro finito e efeitos de interface que mostram grandes diferenças em relação ao bulk (KODAMA et al., 1996, 1997; KODAMA, 1999; BATLLE; LABARTA, 2002). Os efeitos de tamanho finito do núcleo magnético estão relacionados com o baixo número de spins ligados que se comportam de forma cooperativa no interior do núcleo da nanopartícula. Experimento de Espectroscopia Mössbauer feito em nanopartículas de maguemita, explica a redução da magnetização de saturação de ferritas em escala manométrica. Coey considera uma configuração de spins que difere do tipo encontrado por Néel para o bulk. Ele propôs que os spins estão inclinados (canted) na superfície das nanopartículas. Isto é, os íons da camada de superfície estão inclinados em ângulos diferentes em relação à direção do momento rede. Desta forma, a magnetização da partícula não pode ser vista como uniforme para nanopartículas e sim resultado de um núcleo ordenado magnética, e uma casca circundante de spins desordenadas (COEY, 1971).

Kodama et al. estudaram nanopartículas de ferrita de níquel com diâmetro médio 6.5 nm, mostraram que os resultados são consistentes com spin canting sugerido por Coey. Eles propuseram um modelo em que os spins estão inclinados na camada de superfície e se congelam, devido a frustração, numa fase de spin-glass-like em temperaturas inferiores a $50 \mathrm{~K}$. Em consequência, os spins da casca têm configurações múltiplas para qualquer orientação da magnetização do núcleo. Eles também discutiram várias razões para esperar a desordem dos spins de superfície em nanopartículas de ferrita e o principal motivo é a redução da coordenação efetiva dos cátions magnéticos na superfície (KODAMA et al., 1996).

A mudança de uma coordenação efetiva dos cátions magnéticos da superfície com a miniaturização modifica as interações de superexchange, resultando numa distribuição de 
campos de exchange na rede cristalina, positivas e negativas com relação a sub-rede de um cátion. As ligações de exchange estão quebradas se um íon de oxigênio estiver faltando na superfície ou se moléculas orgânicas são ligadas à superfície (KODAMA et al., 1997). Além disso, o superexchange é muito sensível aos ângulos de ligação e comprimentos de correlação, o que provavelmente modifica as interações na superfície (VÁZQUEZ-VÁZQUEZ et al., 2011).O congelamento da camada superficial em estrutura spins-glass-like tem sido bastante discutido na literatura, relatamos aqui alguns trabalhos publicados pelo GFC-UnB que corroboram para confirmação deste fenômeno. Aquino et al. ao investigar a dependência térmica da magnetização de saturação em regime diluído, sonda as propriedades individuais, de nanopartículas de ferritas de Manganês e Cobre com tamanho variando $3.3-10.4 \mathrm{~nm}$. Mostram que em temperaturas extremamente baixas, a estrutura das nanopartículas pode ser visto como sendo feitas de um superspin ordenado (núcleo) e uma superfície de spins desordenados (casca). A camada flutua livremente em altas temperaturas não influenciando na magnetização.
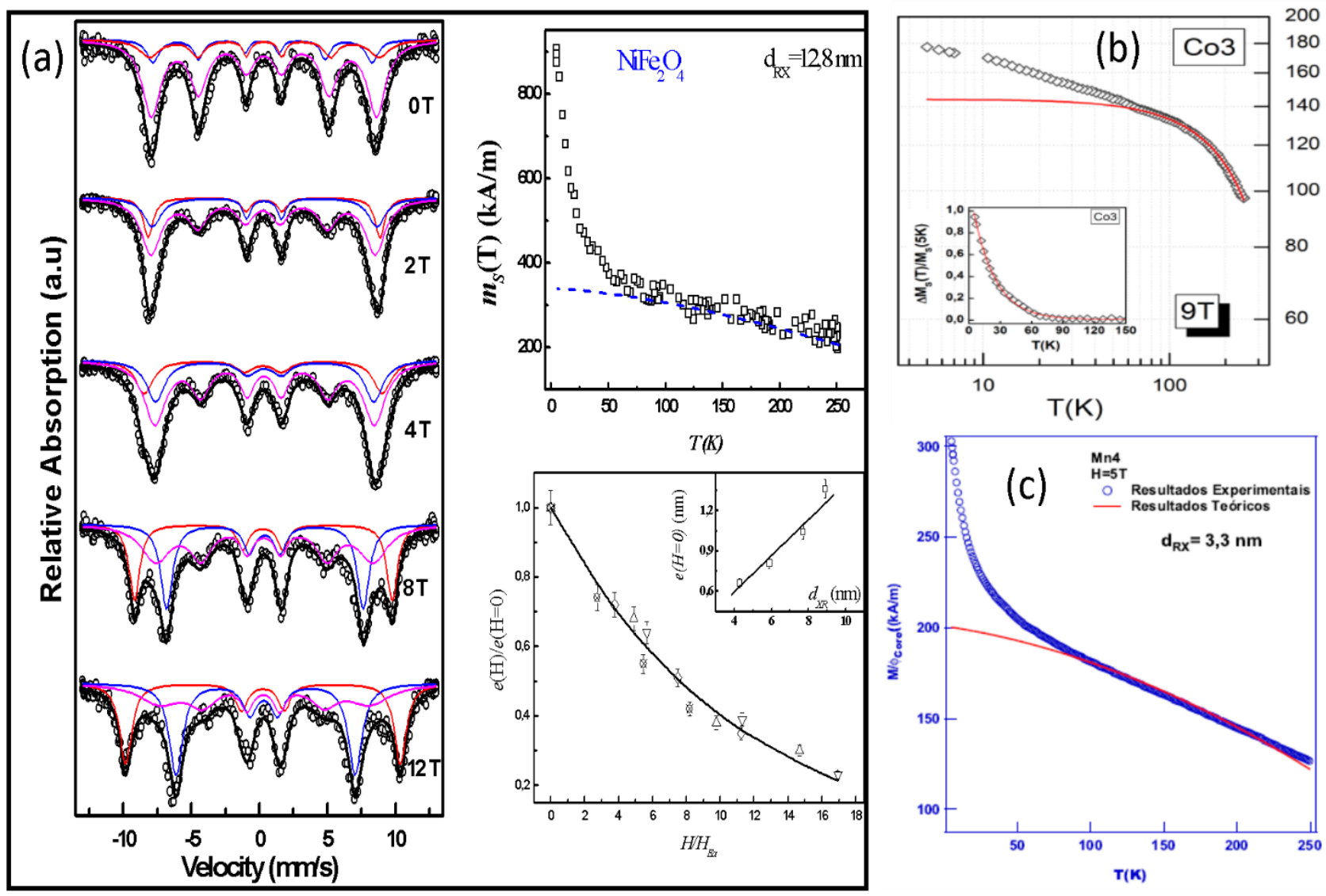

Figura 10: (a) diminuição da camada superficial com campo aplicado e dependência térmica da magnetização para ferrita de níquel fig. extraída de (SOUSA et al., 2009). (b) dependência da magnetização com a temperatura, o insert mostra a contribuição da superfície na magnetização, fig. extraída de (GOMES, 2015). (c) dependência da magnetização com a temperatura para vários diâmetros de partículas de ferrita de manganês, fig. extraída de (SILVA, 2014). 
Observa-se um aumento significativo da magnetização de saturação que é evidenciada a baixa temperatura por um desvio da lei de $\operatorname{Bloch}\left(\Delta M_{S}\right)$, mais marcante à medida que o tamanho diminui, visualizamos na Figura 10 nas curvas $\mathrm{M}(\mathrm{T})$, sugerindo que esse desvio é fortemente dependente da temperatura e escrito da seguinte forma (AQUINO et al., 2005).

$$
M(T)=M_{S}(0)\left(1-B T^{\alpha}\right)+\Delta M_{S}(T),
$$

$\mathrm{Ms}_{s}(0)$ magnetização de saturação do núcleo quando a temperatura tende a zero, B a constante de Bloch e $\alpha$ expoente que caracteriza o material, o valor de $\alpha$ são $3 / 2$ e geralmente para material bulk. Sousa et al. utilizando a Espectroscopia Mössbauer sob campo magnético em conjunto com medidas de dependência térmica de magnetização $\mathrm{M}(\mathrm{T})$ em nanopartículas de ferritas de Níquel com diâmetro variando de $4-13 \mathrm{~nm}$. Observam que umas das contribuições para o comportamento magnético é referente a camada de spins congelados, outra verificação importante é a contração da camada de spins desordenados com aumento do campo aplicado.

$\mathrm{O}$ resultado indica que alguns spins conseguem se desprender e rotacionam, como podemos observar na Figura 10 (a), consequentemente alinham-se com o campo magnético aplicado, aumentando o volume de spins alinhados as custas do volume de spins rotatables (rodáveis) desordenados (SOUSA et al., 2009). Corroborando com esses resultados Silva et al. observa, por medidas de magnetometria, para ferritas de Manganês ultrapequena que a contribuição da superfície não depende somente da distribuição em tamanho das nanopartículas e da temperatura, mas que depende também do campo aplicado. Magneticamente, esses efeitos de superfície se expressam impedindo a saturação magnética. Medidas em campos intensos (H $>52 \mathrm{~T}$ ) foram realizados nessas amostras ultrapequenas e os resultados confirmam a suposição de não saturação magnética desses sistemas (SILVA, 2014). Cabreira-Gomes et al. também investigaram nanopartículas ultrapequenas de Ferrita de Cobalto e observa a influência dos efeitos de superfície na magnetização como visualizado na Figura 10 (b) (GOMES, 2015).

O surgimento dessa camada desordenada em nossos sistemas deve ser investigado, uma vez que irá surgir um acoplamento por troca entre spins do núcleo e da casca. Permitindo definir a interface FI/SGL das nanopartículas aqui investigadas, que induz no protocolo field cooling uma anisotropia unidirecional amplamente conhecida como exchange bias.

\subsubsection{Exchange bias}

Esta anisotropia foi descoberta em 1956 por Meiklejohn e Bean quando investigavam partículas Co metálico em uma matriz de seu óxido natural $(\mathrm{CoO})$, formando uma estrutura com 
núcleo de Co ferromagnético (FM) incorporado no seu óxido (casca) $\mathrm{CoO}$ antiferromagnético (AFM) criando a interface FM/AFM. Desde então muitos sistemas com interfaces diferentes foram investigados. Filmes FM com cristais individuais AFM (NOGUÉS; SCHULLER, 1999); materiais heterogêneo com camadas Ferromagnético e Spin Glass FM/SG, Antiferromagnético e Ferrimagnético AFM/FI, Ferrimagnético e Antiferromagnético FI/AFM, Ferrimagnético e Ferrimagnético FI/FI e recentemente nanopartículas com núcleo Ferrimagnético e casca com spins-glass-like FI/SGL (SILVA et al., 2013). A Figura 11 exibe as curvas do experimento de Meiklejohn e Bean e o magnetômetro de torque que foi utilizado.
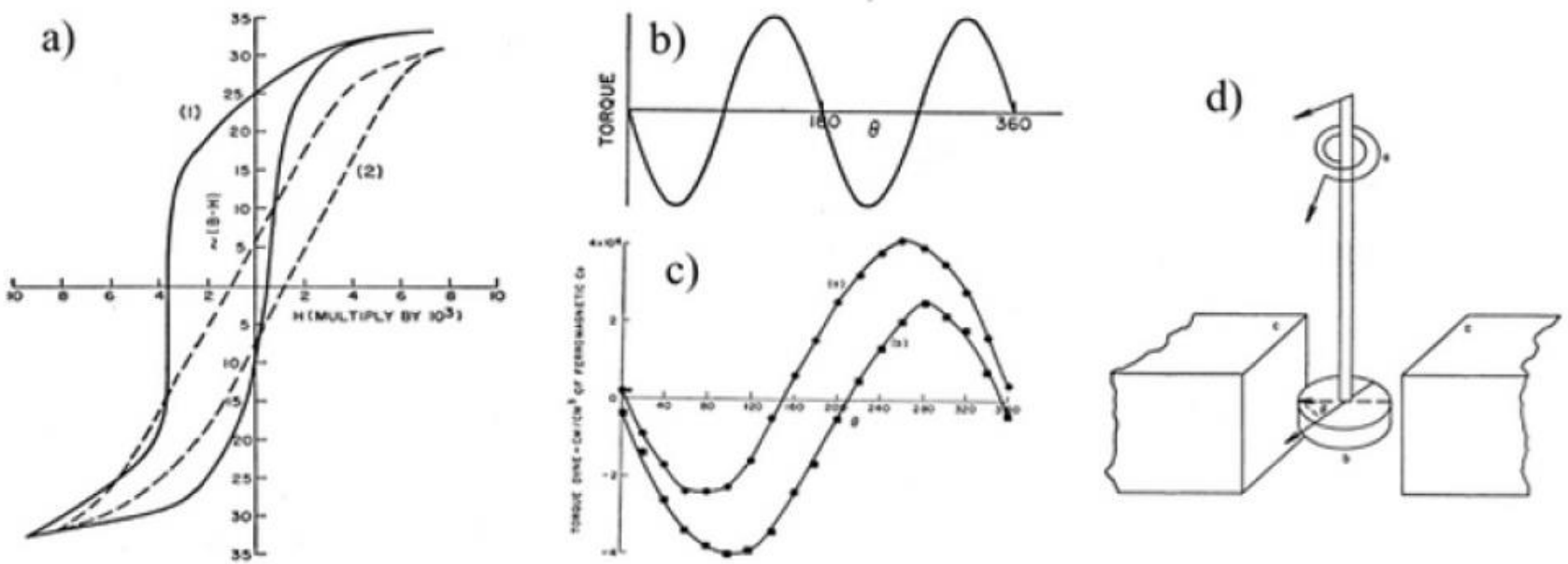

Figura 11: a) ciclos de histerese de partículas Co-CoO tomadas a $77 \mathrm{~K}$. A linha tracejada mostra o ciclo após o arrefecimento no campo zero. A linha sólida representa a curva de histerese medidos após o arrefecimento do sistema de um campo de $10 \mathrm{kOe}$. b) curva de torque para as partículas de Co a $300 \mathrm{~K}$ mostram anisotropia uniaxial. b) curva de torque de partículas de $\mathrm{Co}-\mathrm{CoO}$ tomadas a $77 \mathrm{~K}$ mostrando a anisotropia unidirecional incomum. d) $\mathrm{O}$ magnetômetro de torque. O principal componente é uma mola que mede o torque em função do ângulo $\theta$ quando amostra é colocada na presença de um campo magnético. Fig. extraída da ref. (RADU; ZABEL, 2008a).

A desordem estrutural e magnética na interface é fundamental para surgimento do exchange bias (EB). Na interface pode existir parâmetros de rede diferentes, deformações e defeitos. Além disso, a estrutura magnética na vizinhança da interface é diferente da ordenação magnética dos materiais em contato (LEDERMAN; NOGUÉS; SCHULLER, 1997).

\section{Aspectos Gerais}

Fenomenologicamente o Exchange bias é a observação macroscópica do deslocamento do ciclo de histerese magnética devido à anisotropia unidirecional de um material formado por bicamada FM/AFM. Qualitativamente compreendido através da análise microscópica do estado magnético da interface em comum entre as camadas Ferromagnética em contato com uma Antiferromagnética. $\mathrm{O}$ ciclo de histerese obtido com processo de resfriamento do par com 
campo aplicado estático $\left(H_{c o o l}\right)$ apresenta um deslocado ao longo do eixo, geralmente na direção campo negativo, ou seja, o valor absoluto do campo coercivo diminui e aumenta na presença de um campo de resfriamento diferente.

As temperaturas críticas dos materiais das camadas FM/AFM devem satisfazer duas condições. $\mathrm{T}_{\mathrm{C}}>\mathrm{T}_{\mathrm{N}}$; E temperatura de medida do ciclos de histerese maior do que a temperatura de Néel e inferior à temperatura de Curie $\left(\mathrm{T}_{\mathrm{N}}<\mathrm{T}<\mathrm{T}_{\mathrm{C}}\right)$. Nessa região os spins da camada Ferromagnética se alinham ao longo da direção do campo aplicado, ao passo que os spins da camada AFM permanecem orientados randomicamente em um estado "paramagnético", observamos nas configurações (1), (2), (3), e (4) da Figura 12 (a). A curva de histerese do ferromagneto obtida está centrada em torno zero dos eixos, $H_{E X}=\left(\left|H_{C 1}\right|-\left|H_{C 2}\right|\right) / 2=0$, não sendo afetadas pela proximidade da camada de AFM.

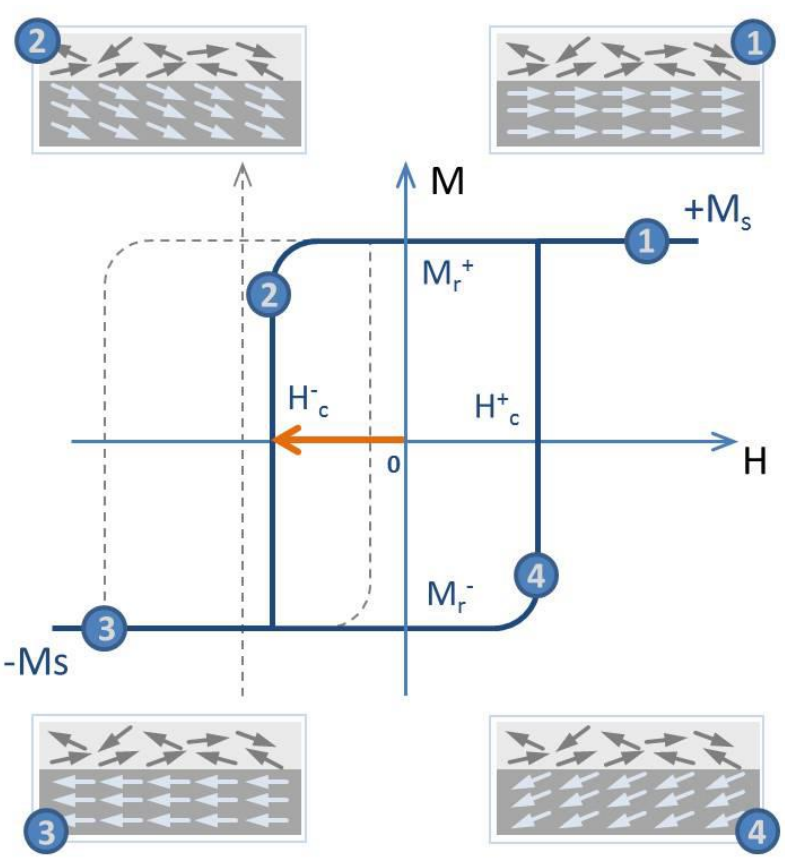

(a) $Z F C\left(T_{N}<T<T c\right)$
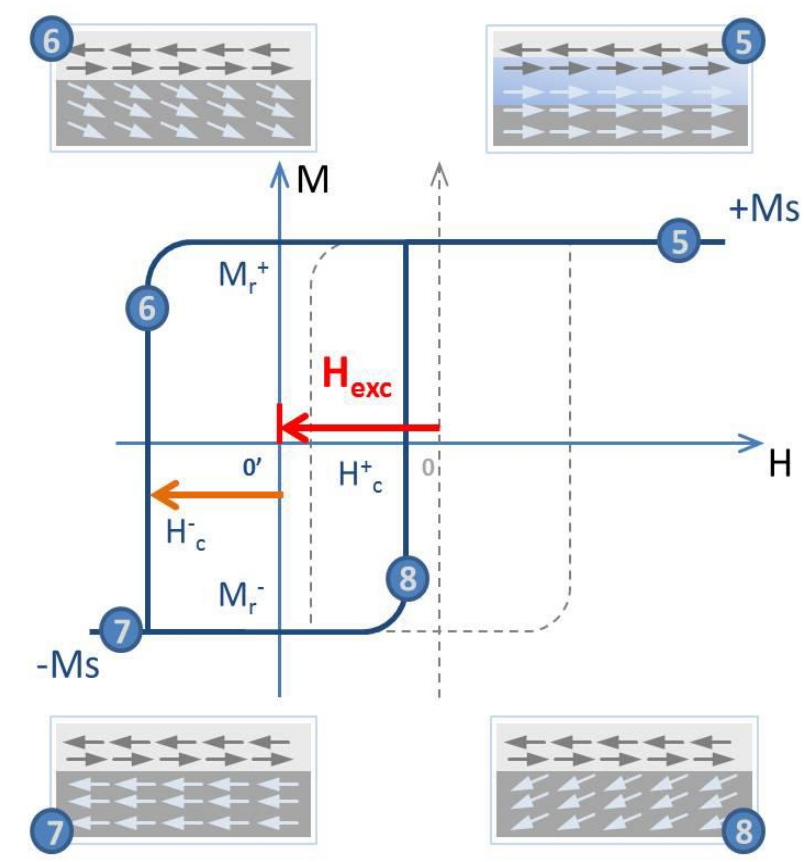

(b) $F C\left(T<T_{N}\right)$

Figura 12: ciclos de histerese magnética com protocolos: (a) Zero Field Cooling e (b) Field Cooling que apresenta o deslocamento do ciclo de histerese característica do fenômeno de exchange bias. Figura extraída da ref. (GOMES, 2015).

A Figura 12 (b) apresenta uma situação em que o fenômeno de exchange bias aparece. Inicialmente, saturando o antiferromagneto pela aplicação de um campo externo suficientemente alto e em seguida sem alterar a intensidade e direção do campo aplicado, a temperatura é diminuída para um valor menor que $T_{N}$ (procedimento de arrefecimento com campo Field-Cooling - FC). Depois do arrefecimento do sistema com o campo, devido à 
interação de troca na interface da primeira monocamada AFM irá alinhar paralelamente (ou antiparalelo) aos spins do FM.

No caminho de volta da saturação negativa para valores de campos positivos (Figura 12 (b) configuração (7) e (8), os spins FM exigem uma força externa menor (campo coercivo), a fim de girar no sentido contrário, visto Figura 12 (b) configuração (8) na direção original. Um torque está operando nos spins do FM para todos os outros ângulos, exceto a direção estável, que é ao longo da direção do campo de arrefecimento (anisotropia unidirecional). Como resultado a curva de magnetização é deslocada para valores negativos do campo aplicado. Esse deslocamento do centro do ciclo de histerese é chamado campo de exchange bias, e é negativo em relação à orientação dos spins da camada FM após arrefecimento com campo (polarização negativa de troca). Deve notar-se que nesta simples descrição a camada de spins AFM fixa a magnetização na direção de campo de cooling durante todo o processo de reversão. Embora o mecanismo de exchange bias não sendo totalmente compreendido, acreditava-se que se origina a partir dos spins da camada AFM estáveis e descompensados na interface FM/AFM, que exercem uma força de exchange unidirecional sobre a camada FM. Uma das possíveis explicações seria que a densidade de momentos interfaciais da AFM não compensada poderia determinar a magnitude do campo de EB, sugerindo que o EB pode ser ajustado pela mudança dessa densidade de momentos (YANG; ZENG; PAN, 2010).

Exchange bias em nanopartículas core-shell

Em nanopartículas são normalmente expostas ao ambiente e são facilmente oxidadas resultando em estruturas core-shell (IGLESIAS; LABARTA; BATLLE, 2008) ou podem ser produzidas por síntese química controlada (GOMES et al., 2008), nestas, quando suficientemente pequenas, apresentam o exchange bias (SILVA et al., 2013; CABREIRAGOMES et al., 2014).

A composição de nanopartículas core-shell NPs-CS resulta de uma combinação formada de núcleo magneticamente ordenado, geralmente ferromagnético, rodeado por um shell, comumente antiferromagnético (normalmente um óxido). $\mathrm{O}$ aumento da coercividade (HC) após resfriamento com campo aplicado e em temperatura abaixo $\mathrm{T}_{\mathrm{N}}$ é observado no exchange bias, o que está relacionado com a anisotropia unidirecional induzida no core FM pelo processo de arrefecimento campo. Este aumento deve aparecer apenas quando a anisotropia da casca AFM é pequena em relação à energia de interação do acoplamento de troca com o core FM. Durante o ciclo de histerese com protocolo FC alguns spins são arrastados pelo 
núcleo FM, neste caso, é esperado um aumento do HC (IGLESIAS; BATLLE; LABARTA, 2005). A Figura 13 mostra uma representação pictográfica de uma partícula com FI/SGL, núcleo ferrimagnético ordenado e uma casca com estrutura spins-glass-like. A região de interface, apresentada na região aumentada, mostra a interação superexchange entre o núcleo e a casca.

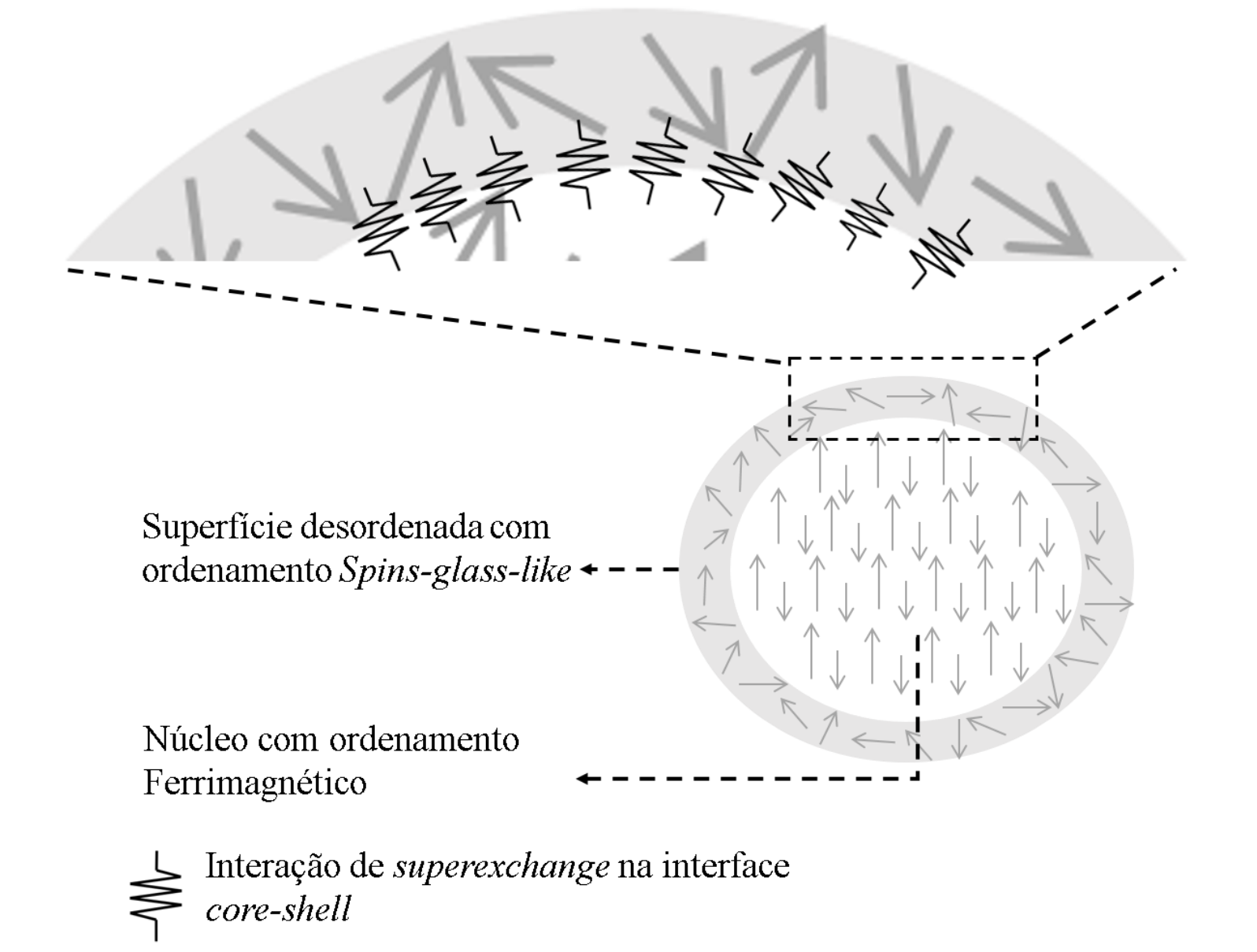

Figura 13: Representação de uma nanopartícula core-shell com interação de superexchange na interface.

Vários parâmetros envolvidos têm se mostrado importantes no exchange bias em sistema nanopartículados, tais como a influência da espessura das camadas, a rugosidade interfacial, a cristalinidade e tamanho de grãos, dentre outros. Observação de EB em nanopartículas tem sido relatado para uma ampla variedade de materiais e morfologias que pode ser dividida em três categorias (IGLESIAS; LABARTA; BATLLE, 2008):

- Fase única do tipo óxido FI ou AFM;

- Nanopartículas incorporadas em uma matriz AFM; e

- Nanopartículas com estrutura core-shell. 
$\mathrm{Na}$ primeira classe temos nanopartículas de ferritas, manganitas e partículas ferromagnéticas. As origens do EB não são bem estabelecidas nesse caso, já que não existe uma interação de troca entre as camadas FM/AFM. Entretanto, o EB é comumente associado, nesse tipo de material, ao congelamento de uma camada superficial de spins numa estrutura spinsglass-like, nestes casos, é devido à existência de interações fortes na interface do núcleo e de uma superfície desordenada induzida em temperaturas abaixo da temperatura de fronzen (IGLESIAS; BATLLE; LABARTA, 2005; IGLESIAS; LABARTA; BATLLE, 2008; NADEEM; KRENN; SZABÓ, 2015; NOGUÉS et al., 2005). Na segunda classe podemos citar o trabalho pioneiro de Meiklejohn e Bean ao investigar partículas de Co em seu óxido e alguns trabalhos de Del Bianco et al. que estudam exchange bias nanopartículas Fe em uma matriz de seu oxido natural (DEL BIANCO et al., 2003, 2004; DEL BIANCO; FIORANI; TESTA, 2007). Por fim, exemplificamos o trabalho de Chandra et al. que investiga nanopartículas com estrutura Fe@ $\gamma-\mathrm{Fe}_{2} \mathrm{O}_{3}$ FM/SGL (CHANDRA et al., 2012) e alguns trabalhos feitos no GFC Silva et. al (SILVA et al., 2013) que estudam nanopartículas de $\mathrm{MnFe}_{2} \mathrm{O}_{4} @ \gamma-\mathrm{Fe}_{2} \mathrm{O}_{3}$ FI/SGL e o papel das interações interpartículas no EB; e Cabreira-Gomes et al. Que compara NPs de $\mathrm{MnFe}_{2} \mathrm{O}_{4} @ \gamma-\mathrm{Fe}_{2} \mathrm{O}_{3}$ e $\mathrm{CoFe}_{2} \mathrm{O}_{4} @ \gamma-\mathrm{Fe}_{2} \mathrm{O}_{3}$ na tentativa de observar se a dureza magnética do núcleo influencia na intensidade do exchange bias (CABREIRA-GOMES et al., 2014). Faremos uma breve explanação sobre estas características.

\section{Interações intra/interpartículas e natureza do núcleo}

Em NPs-CS, da mesma natureza das aqui investigadas, a fonte principal do exchange bias é o acoplamento dos spins ordenados do núcleo de ferrita e os spins desordenados da superfície de maguemita $\left(\gamma-\mathrm{Fe}_{2} \mathrm{O}_{3}\right)$ FI/SGL. No momento em que as interações interpartículas podem ser desprezadas, e então nesse caso, podemos considerar que $H_{E X}$ tenha uma origem puramente intrínseca por interação de troca interpartículas, isso acontece sempre que a amostra está suficientemente diluída. Grande distância entre partículas leva a uma energia dipolar desprezível.

Silva et al. propõem o estudo dos efeitos de interação em amostras com frações volumétrica de $\mathrm{NPs} \mathrm{MnFe}_{2} \mathrm{O}_{4} @ \gamma-\mathrm{Fe}_{2} \mathrm{O}_{3}$ variando 0,4\% até 13,9\% e amostra pó. Observa-se que as interações interpartículas perturbam e desordenam a interface, resultando numa degradação do $H_{E X}$. Essa desordem está associada à natureza anisotrópica dos campos magnéticos dipolodipolo de natureza desmagnetizante, e o EB intrínseco da NPs é diminuído pela interação dipolar interpartículas. Para amostra pó o exchange bias é consideravelmente maior do que nas 
dispersões mais diluídas, ou seja, bem maior do que o $H_{E X}$ intrínseco, acarretado pelo o contato direto entre as partículas que organiza uma "supercasca" com efeito coletivo, multiplicador, nos núcleos FI incorporados. Como o acoplamento de troca de curto alcance entre as partículas é muito maior do que o acoplamento magnético dipolar, o efeito da troca interpartículas em contato certamente supera a ação redutora da interação dipolo-dipolo. A Figura 14 exemplifica esse tipo de comportamento intra/interpartículas.
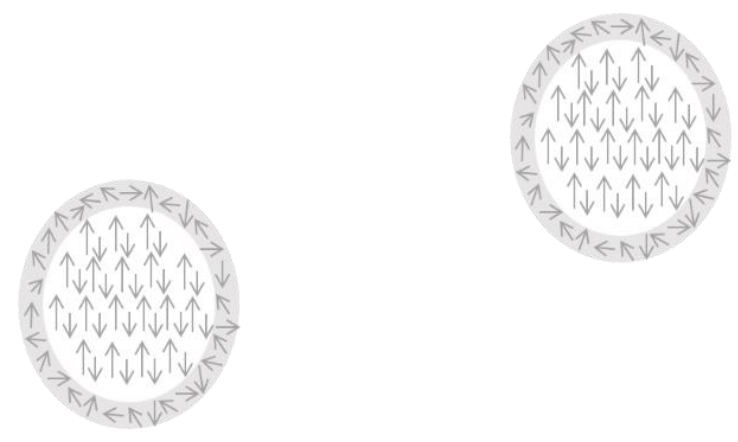

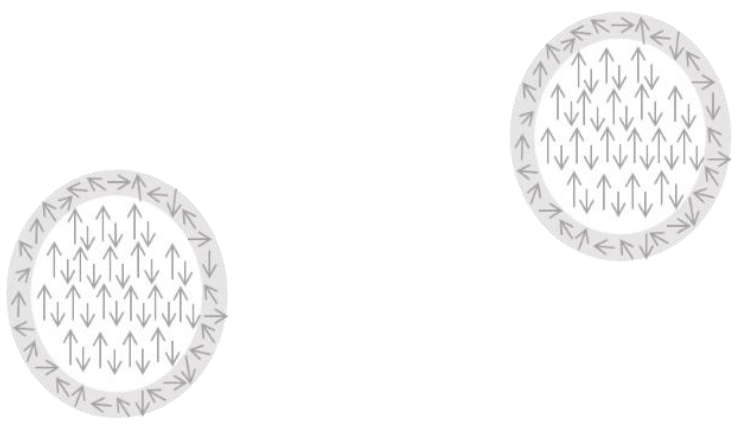

(a) Sistema não interativo

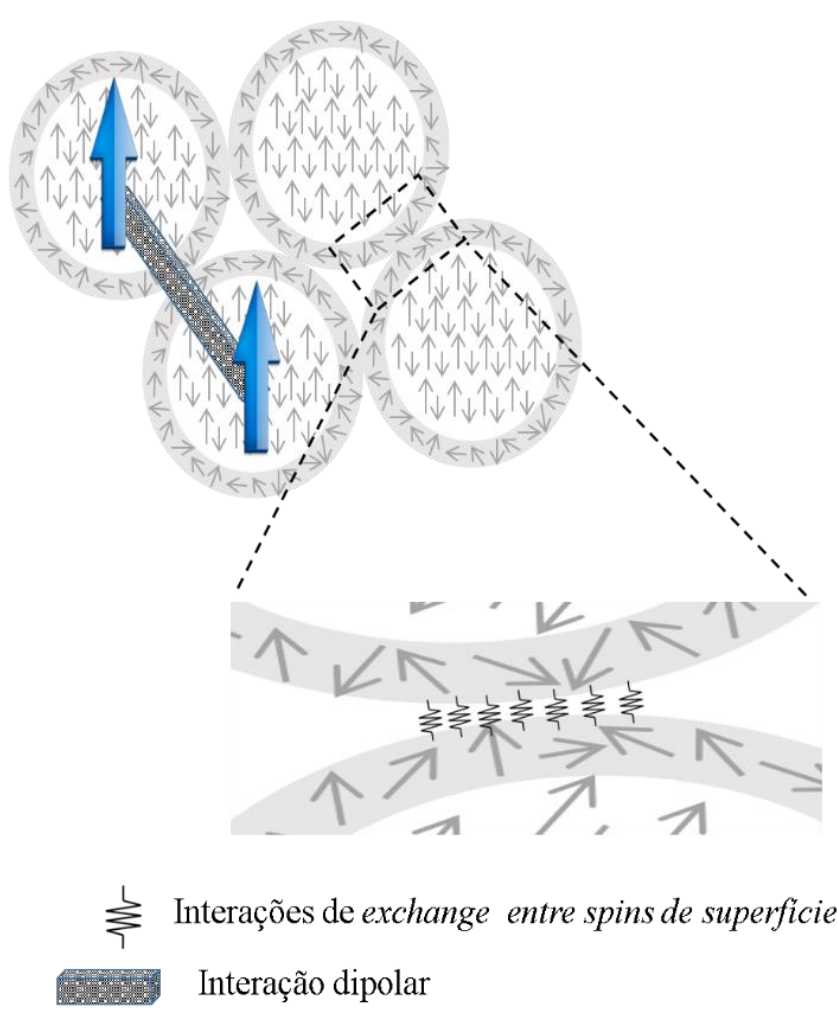

(b) Sistema Interativo

Figura 14: Representação gráfica (a) sistemas não interativos quando amostra suficientemente diluída (b) com proximidade entre as partículas, estas interagem de duas formas: a distância pela interação dipolar e quando em contato por pelo exchange.

No caso do estudo amostras de ferrofluido diluído formada por NPs-CS com núcleos de dureza magnética diferentes, Cabreira-Gomes et al. observam que a natureza do núcleo influencia o exchange bias, encontram que o $H_{E X}$ é superior para amostras com núcleo de $\mathrm{CoFe}_{2} \mathrm{O}_{4}$ (hard) quando comparado com a $\mathrm{MnFe}_{2} \mathrm{O}_{4}$ (soft) de diâmetros na mesma ordem e mesma fração volumétrica de partículas. Esse resultado indica que os spins da camada SGL alinham-se mais facilmente quando o núcleo é composto de $\mathrm{CoFe}_{2} \mathrm{O}_{4}$. Portanto, o aprisionamento dos spins da superfície na interface depende da dureza magnética do núcleo. Tal comportamento pode ser atribuído ao contraste da anisotropia entre o núcleo e a casca, aliado a rugosidade interfacial FI/SGL. Outra influência da dureza magnética do núcleo das 
ferritas é o que faz $H_{E X}$ menos sensitivo a interações de exchange interpartículas, fazendo a camada superficial menos desordenada para Co que para o Mn.

\subsubsection{Efeito de Treinamento}

O Efeito de Treinamento, do inglês Training Effect é atribuído às flutuações do acoplamento entre as interfaces entre os materiais, que modificam as interações magnéticas entre as regiões de maneira diferente juntamente com cada inversão do campo magnético aplicado. A mudança no ciclo de histerese é perfeitamente visualizada na Figura 15, observando que existe uma variação das propriedades do ciclo. Exibe uma diminuição do exchange bias, do campo coercitivo após consecutivos ciclos de histerese medidos a temperatura constante

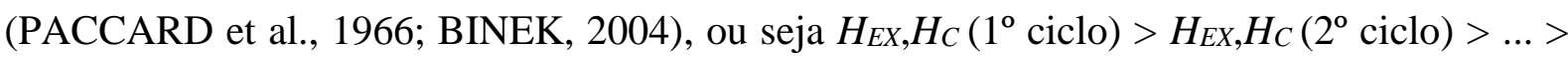
$H_{E X}, H_{C}$ (enésimo ciclo).
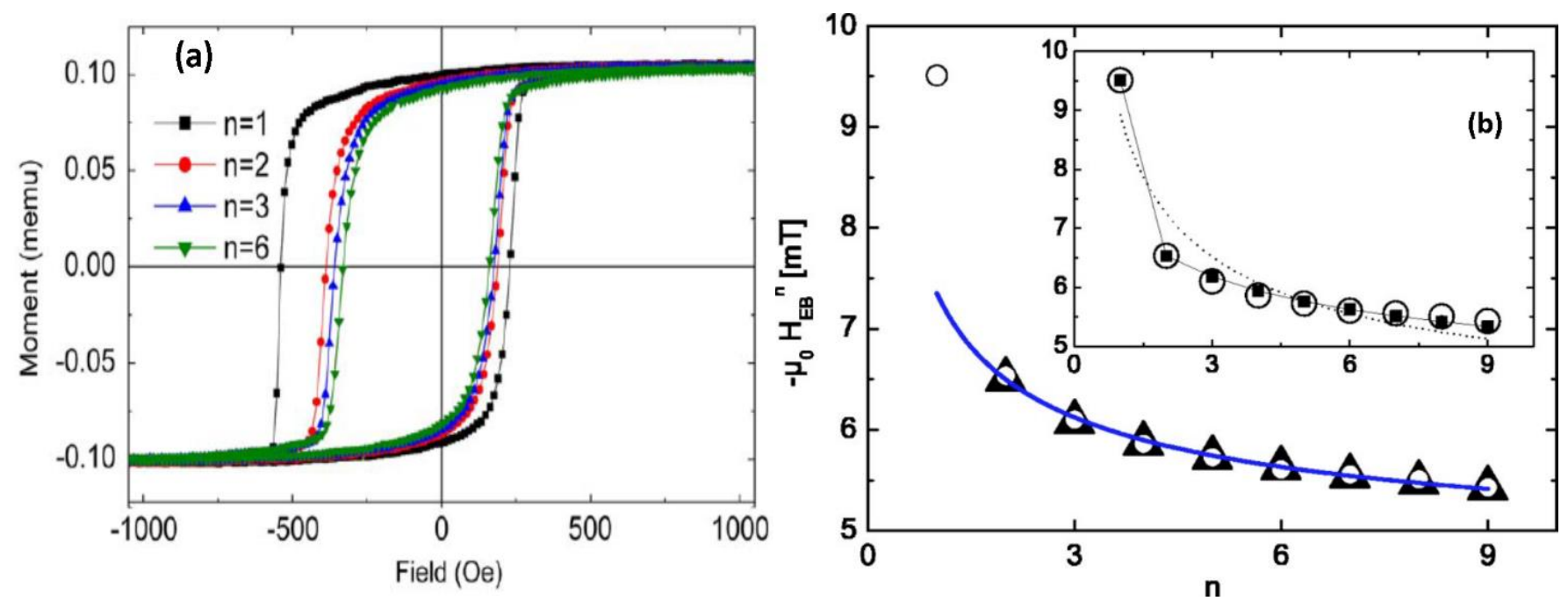

Figura 15: Efeito de treinamento típico, (a) mostra a contração dos ciclos de histerese magnética (YANG; ZENG; PAN, 2010) e (b) dependência do $H_{E X}$ com o número de ciclos extraído da referência (BINEK, 2004) .

A fim de interpretar essas descobertas experimentais em inúmeras interfaces, um enorme número de modelos foram criados para descrever o efeito de treinamento (FULCOMER; CHARAP, 1972; BINEK, 2004; HOFFMANN, 2004; ZHENG et al., 2004a; SAHOO et al., 2007a; RADU; ZABEL, 2008a). Experimentalmente, além disso, verificou-se que existem dois tipos distintos de efeito de treinamento. Um entre o primeiro e segundo ciclo, chamado de treinamento atérmico, Hoffman explica que é devido a alterações irreversíveis na microestrutura magnética da camada de pinning AFM através de um modelo de simples rotação coerente de Stoner \& Wohlfarth. Um segundo para $\mathrm{n} \geq 2$ que abrange um número maior de 
ciclos de histerese, envolve um HC continuamente decrescente com o aumento do número de ciclos suportado por muitos resultados experimentais. Um acoplamento é estabelecido na interface entre as camadas FM e AFM durante processo de formação da configuração do sistema. O acoplamento é superado na primeira ocasião em que a camada FM tem sua magnetização invertida levando a uma coercividade reduzida em comparação com o observado no primeiro ciclo (HOFFMANN, 2004). Isto acontece devido ao fato da configuração inicial não poder ser restaurada.

Harres e Geshev propõem um modelo para o efeito de treinamento atérmico em curvas de magnetização estáticas com bicamadas FM/AFM com uma interface granular possuindo spins não compensados (uncompensated spins) (UCS). Eles dividem os grãos em duas categorias estáveis e instáveis. Grãos estáveis poderiam ser divididos em mais duas subcategorias: (i) grãos com o UCS (set) ao longo da direção do campo magnético presente durante o processo de preparação ou de pós-tratamento da amostra e (ii) grãos (unset) com UCS apontando em direções aleatórias. Os grãos instáveis podem ser divididos em mais duas subcategorias: (a) que podem rodar com spins que giram de modo irreversível sobre a magnetização de comutação FM e (b) os superparamagnéticos. O último e os grãos unset não contribuem para $H_{E X}$ ou para a coercividade, mas os grãos set são responsáveis pelo exchange bias e os rotativos adicionam o aumento da coercividade quando congelados (HARRES; GESHEV, 2011).

O Deslocamento Vertical Magnético - $\delta \mathrm{M}$ (Vertical Shift) está intimamente ligado com a diminuição da fração de spins fixados e não compensados sobre ciclismo de campo (ZHENG et al., 2004a, 2004b). Nesta situação, o $\delta \mathrm{M}$ e $H_{E X}$ estão estreitamente relacionadas e têm a mesma origem. Assim, $\delta \mathrm{M}$ mostra uma tendência muito semelhante ao $H_{E X}$ durante todo o processo de formação. Observa-se, quando aplicados os ciclos de histerese magnética de forma contínua, que alguns dos spins estão presos e não compensados e alteraram seus sentidos e caem em configurações metaestáveis. Em outras palavras, a fração de spins fixados não compensados na camada AFM diminui com o campo de ciclismo. Como uma das consequências, esta reconfiguração resulta na diminuição $\delta \mathrm{M}$. Por outro lado, ele minimiza a interação de troca na interface da ligação entre as camadas que leva para a redução da $H_{E X}$.

Com o modelo macroscópico proposto por Harres e Geshev para um conjunto de partículas incorporadas numa matriz, podemos fazer um comparativo com o que acontece dentro de uma nanopartícula core-shell. As NPs-CS possuem um núcleo organizado e uma casca que se congela numa camada de spins desordenados, esses podem se congelar em spins 
pinned ou frozen (presos), devido a frustação das interações criando a anisotropia unidirecional, e os rotatables (rodáveis) que contribuem para o acréscimo do $H_{E X}$ quando congelados.

Antes de apresentarmos os resultados experimentais obtidos neste trabalho, é interessante expor os modelos teóricos utilizados para extrair alguns parâmetros das curvas de magnetização para compreensão do efeito de treinamento do exchange bias investigado nesta tese para amostras de nanopartículas core-shell.

\section{Modelo de Paccard et al.}

D. Paccard, em 1966, publica o estudo "The New Property of FerromagneticAntiferromagnetic Coupling" (PACCARD et al., 1966) para filmes finos de Co/CoO, $\mathrm{NiFe} / \mathrm{NiFeMn}$ e $\mathrm{NiFe} / \mathrm{Cr}_{2} \mathrm{O}_{3}$ neste artigo reporta que uma nova propriedade de tais sistemas é encontrada. Isto é, uma concentração de laços de histerese em função do números de ciclo de histerese $H_{E X} \propto 1 / \sqrt{n}$ (SCHLENKER; PACCARD, 1967). As propriedades características deste fenômeno abrangem:

- Um ciclo de histerese deslocado ao longo do eixo do campo;

- Uma componente unidirecional na curva de torque; e

- Histerese rotacional persistindo para campos elevados.

Estas são características básicas do exchange bias que primeiramente foi visualizado 10 anos antes por Meiklejohn, William H., e Charles P. Bean (MEIKLEJOHN; BEAN, 1956). Paccard et al. demonstram a existência deste novo fenômeno em sistemas exibindo acoplamento Ferromagnético/Antiferromagnético, que resulta na contração dos ciclos de histerese com sucessivos ciclos medidos. Mesmo não compreendendo a sua origem, o novo fenômeno mostra-se relacionado com o ciclismo ${ }^{8}$ da histerese magnética. Acreditavam que este efeito parecia estar presente em grande número de sistemas com efeito de exchange bias, o que estavam corretos, e mostram que é importante para uma compreensão de tais sistemas, em geral.

O Novo fenômeno auxilia a esclarecer o mecanismo de acoplamento microscópico do efeito de exchange bias. Este é atribuído à variação de acoplamento entre os materiais, devido ao rearranjo da configuração dos spins na interface que modificam as interações magnéticas entre as regiões de forma diferente, juntamente com cada reversão. Isso implica que os dois

\footnotetext{
${ }^{8}$ Ciclos de histereses consecutivos numa determinada temperatura.
} 
materiais podem ter respostas separadas às mudanças de temperatura e campo magnético. Depois chamado de Training Effect (Efeito de treinamento) refere-se à mudança dramática do ciclo de histerese quando varrendo consecutivamente o campo magnético aplicado de um sistema que está em um estado de exchange bias.

Paccard et al. sugerem uma expressão empírica, lei de potência simples, para o efeito de treinamento que vem da dependência do campo coercivo e do campo de exchange bias em função do índice de ciclo de $n$ :

$$
H_{E X}-H_{E X}^{\infty}=\frac{k}{\sqrt{n}}
$$

onde $n$ o número de ciclos, $H_{E X}^{\infty}$ é o campo de exchange bias quando o número de ciclos tende ao infinito (equilíbrio) e $k$ uma constante que depende do sistema. Neste modelo as curvas experimentais mostram ajuste satisfatório para $\mathrm{n} \geq 2$ como visto na linha sólida azul na Figura 15 (b). No entanto, quando o primeiro ponto é incluído para o ajuste não se consegue explicar o relaxamento abrupto para $\mathrm{n}=1$, esse comportamento é visualizado no insert da Figura 15 (b) pela linha pontilhada.

\section{Modelo de Binek}

Christian Binek (BINEK, 2004) a partir do conceito mais simples do exchange bias, que descreve o fenômeno quantativamente correlacionando o campo $H_{E X}$ com espessura da camada $t_{F M}$ e magnetização da camada Ferromagnética $M_{F M}$, com a magnetização da interface Antiferromagnética $S_{A F}$ e Interface Ferromagnética $S_{F M}$. Essas acopladas por uma integral de troca $J$ constante, expressa por:

$$
H_{E X}=-\frac{J S_{A F} S_{F M}}{M_{F M} t_{F M}} .
$$

Esta expressão é utilizada para descrever o exchange bias em materiais formadas por multicamadas, partículas Core-Shell, nanopartículas FM incorporadas em matriz AFM e nanocompósitos, não abordando diretamente o fenômeno de treinamento do exchange bias (NOGUÉS et al., 2005a). Antiferromagnetos e interações antiferromagnéticas são utilizadas para fixar a magnetização de camadas ferromagnéticas em estruturas multicamadas no exchange bias. A magnetização da interface da camada AFM, $S_{A F}$, muda durante a aplicação de sucessivos ciclos de histereses ( $n)$ da camada FM de tal forma que $S_{A F}=S_{A F}(n)$ dá origem a $n$ dependência do $H_{E X}$ segundo $H_{E B}(n)=\sigma S_{A F}(n), \sigma$ é independente do índice de loop $n$ expresso por $\sigma=-J S_{F M} / M_{F M} t_{F M}$. 
Christian Binek mapeia o efeito de treinamento do exchange bias observando a dependência do exchange bias com a magnetização da interface $S_{A F}, H_{E B}(n)=\sigma S_{A F}(n)$. Do ponto de vista fenomenológico $S_{A F}$ tem a sua própria correspondência microscópica na mudança das configurações dos spins da camada de pinning, a partir de uma configuração de não-equilíbrio para um estado de quase-equilíbrio. O processo é de fato acionado pelos consecutivos ciclos de histerese magnética da camada fixada (FM) e a mudança da configuração na camada de pinning pode acontecer de duas formas. Localmente envolvendo giros dos spins individuais não correlacionados ou podem também envolver rearranjos de domínio mesoscópicos coletivos. Geralmente, a camada de pinning é a AFM, e camada FM a fixada para um sistema EB regular. No entanto, o conceito de treinamento tem aplicabilidade muito mais amplo; portanto, as camadas pinning pode incluir, spin-glass, spin-glass-like ou ferromagneto magneticamente duros para citar apenas alguns exemplos.

A Teoria de Landau-Devonshire (L-D) é a teoria fenomenológica da aproximação do campo médio e se concentra na diferença de energia livre entre as fases ordenadas e desordenadas. A dinâmica não linear de L-D é descrita por uma equação diferencial parcial com o nome de equação de Landau-Khalatnikov (L-K) baseada na tendência do relaxamento do sistema ir para equilíbrio (VIZDRIK et al., 2003), a expressão de L-K é

$$
\xi \dot{S}_{A F}=-\frac{\delta \Delta F}{\delta S_{A F}}
$$

a expressão proporciona observar o relaxamento na camada de pinning para o seu estado de equilíbrio. Aqui $\xi$ é uma constante fenomenológica de amortecimento, $\dot{S}_{A F}$ é a derivada em função do tempo de magnetização de interface de $S_{A F}$ e $\Delta F$ é a variação da energia livre da camada de pinning. $S_{A F}$ é alterada apenas quando há uma reversão da magnetização do ferromagneto. O relaxamento no antiferromagneto no intervalo de tempo entre dois consecutivos ciclos de histerese do ferromagneto é insignificante em comparação com a alteração no $S_{A F}$ durante a inversão do ferromagneto. Portanto, tem-se para discretizar $\dot{S}_{A F}$ de modo:

$$
\dot{S}_{A F}=\frac{S_{A F}(n+1)-S_{A F}(n)}{\tau},
$$

$S_{A F}(n)$ e $S_{A F}(n+1)$ são as magnetizações da interface AF de sucessivos $n$ e de $n+1$ ciclos de histerese do ferromagneto e $\tau$ é o tempo característico levado para medir um ciclo de histerese completo. Observando que a energia livre final é sempre menor que a inicial podemos assumir que $\Delta F\left(\delta S_{A F}\right)=\Delta F\left(-\delta S_{A F}\right)$, fazendo uma expansão em série de $\Delta \mathrm{F}$ até quarta ordem em $\delta S_{n}$ 


$$
\Delta F=\frac{1}{2} a \delta S_{n}^{2}+\frac{1}{4} b \delta S_{n}^{4}+\mathrm{O}\left(\delta S_{n}^{6}\right)
$$

em que $\delta S_{n}=S_{A F}(n)-S_{A F}^{e}$ e $\quad$ o $S_{A F}^{e}=\lim _{n \rightarrow \infty} S_{A F}(n)$. O último termo descreve magnetização da interface no estado de quase-equilíbrio do antiferromagneto após um número infinito de reversões magnéticas da camada pinned. Em geral $\mathrm{O}\left(\delta S_{n}^{6}\right)$ são insignificantes aqui devido ao valor muito pequeno de $\left|\delta S_{n}\right|$.

A partir da Eq. (33), (34) e (35) pode-se escrever:

$$
\xi^{\prime}\left(S_{A F}(n+1)-S_{A F}(n)\right)=-\delta S_{n}\left(a+b \delta S_{n}^{2}\right),
$$

onde $\xi^{\prime}=\xi / \tau$. Quando existe uma redução estritamente monótona de $\left|S_{A F}(n)\right|$, a $>0$ gera necessariamente uma deterioração assintótica do tipo $S_{A F}(n) \propto e^{-a n}$ no limite $n \rightarrow \infty$. $\delta S_{n} \gg \delta S_{n}^{3}$ teremos um relaxamento exponencial, que é de forma genérica mais rápido do que qualquer decaimento potencial, se observa tipicamente, quando a correlação de spin se torna insignificante. Mas no caso do exchange bias uma grande correlação de spins AFM é essencial, a fim de fixar a camada FM durante a sua reversão da magnetização. Exchange bias e o efeito do treinamento desaparecem apenas acima da Temperatura de Bloqueio $\left(T_{B}\right)$ onde a correlação dos spins do antiferromagneto torna-se insignificate, assim espera-se o relaxamento nãoexponencial acima da temperatura de bloqueio. Por conseguinte, esta condição dá origem um a $=0$ (BINEK; HE; POLISETTY, 2005).

A descrição acima prevê a ausência do termo de segunda ordem na dependência da energia livre (a partir da equação 35) em $S_{A F}$ usando a observação experimental como uma entrada. Entretanto, este argumento pode ser derivado, empregando abordagem de campo médio. Quando $\mathrm{T}<\mathrm{T}_{\mathrm{N}}$, a energia livre $\Delta F$ da camada de fixação tem dois mínimos pronunciada $\eta \pm \eta_{e}$, onde $\eta=\left(m_{1}-m_{2}\right) / 2$ descreve o parâmetro de primeira ordem do antiferromagnético, enquanto que a magnetização $m=\left(m_{1}+m_{2}\right) / 2$ descreve o parâmetro de ordem secundária. Nisto $\mathrm{m}_{1,2}$ são a magnetização da sub-rede normalizada. Devido a estes dois mínimos $\pm \eta_{e}, \Delta F$ da camada de fixação pode ser expandido em aproximação harmônica, isto é,

$$
\Delta F=\alpha(T)\left(\eta-\eta_{e}\right)^{2}
$$

com $\alpha(T)$ é o coeficiente de expansão dependente da temperatura. Por outro lado, a teoria de campo médio fornece a relação entre os parâmetros de ordem primária e secundária. A partir da teoria de campo médio obtém-se $\eta$, uma função par de $m$, na vizinhança do valor de equilíbrio $m=0$, onde se lê 


$$
\eta=\eta_{e}+\left.\frac{1}{2} \frac{\partial^{2} \eta}{\partial m^{2}}\right|_{m=0} m^{2}+\ldots,
$$

substituindo a expressão 37 em 36 e a partir da proporcionalidade $\delta S_{A F} \propto m$ encontramos,

$$
\Delta F \propto \alpha(T)\left(\left.\frac{\partial^{2} \eta}{\partial m^{2}}\right|_{m=0}\right)^{2}\left(\delta S_{A F}\right)^{4} .
$$

Isto é, $\Delta F \propto\left(\delta S_{A F}\right)^{4}$, que é exatamente consistente com a definição acima referida, aparência apenas de dependência de quarta ordem da energia livre em $\mathrm{S}_{\mathrm{AF}}$ dando origem a $\mathrm{a}=$ 0 na equação 36 .

Portanto, Equação 36 simplificada,

$$
S_{A F}(n+1)-S_{A F}(n)=-\frac{b}{\xi^{\prime}} \delta S_{n}^{3} .
$$

A expressão (48) tem estreita analogia com o fenômeno de abrandamento crítico. Podese especular que a estreita analogia entre o abrandamento crítica para baixo e o efeito do treinamento se origina a partir da física de grandes flutuações de spins, que desempenham um papel importante no caso de ambos os fenômenos.

Agora, a substituição de $\delta S_{n}=S_{A F}(n)-S_{A F}^{e}$ e $H_{E B}(n)=\sigma S_{A F}(n)$ na equação 39, dar origem a uma equação implícita:

$$
H_{E X}(n+1)-H_{E X}(n)=-\gamma\left(H_{E X}(n)-H_{E X}^{\infty}\right)^{3}
$$

onde $\gamma=b / \sigma^{2} \xi^{\prime}$, a equação 40 representa a expressão fenomenológica do efeito do treinamento em bicamadas FM/AFM. Os parâmetros de ajuste e $\gamma$ e $H_{E X}^{\infty}$ são os resultados de ajustes envolvidos equação 40 para os dados experimentais.

A força absoluta do efeito do treinamento é quantificada de acordo com $H_{E X}(n=$ const $)-H_{E X}^{\infty}$. Torna-se óbvio quando reorganizando os termos da equação $40 \mathrm{em}$,

$$
\gamma=\frac{H_{E X}(n)-H_{E X}(n+1)}{\left(H_{E X}(n)-H_{E X}^{\infty}\right)^{3}}
$$

Um grande valor da $\gamma$ requer um pequeno valor do denominador, o que significam pequenos desvios do campo $H_{E X}$ equilíbrio. Em outras palavras, a intensidade do efeito de treinamento é mais fraca para grande valor de $\gamma$. No entanto atingindo $T_{B}$, o efeito de treinamento absoluta tem de se tornar igual a zero quando o efeito exchange bias é zero para todos os $\mathrm{n}$. Por outro lado, pequenos valores de $\gamma$ correspondem a grandes efeitos do treinamento absoluto que são, no entanto, distribuídos por um maior número de ciclos. O valor limite de $\gamma=0$ em $\mathrm{T}=0$ é um caso especial onde $\left(H_{E X}(n)-H_{E X}^{\infty}\right)$ permanece finito e mesmo para 
todo $\mathrm{n}$, o que significa que o sistema está congelado, onde $\left(H_{E X}(n)-H_{E X}(n+1)\right)=0$. Isto faz todo o sentido, devido à falta de excitações térmicas, a nenhuma mudança do campo de EB, que é termicamente assistida, e o sistema é incapaz de alcançar o valor de equilíbrio e $H_{E X}^{\infty}$ em laços de histerese consecutivos $(n)$. No entanto, note que isso não significa que o campo EB é zero.

\section{Modelo de Zheng et al.}

Zheng et al. consideram que o exchange bias e efeito de treinamento surge dentro de uma partícula core-shell e observa que o Vertical Shift $(\delta \mathrm{M})$ está intimamente ligado com a diminuição da fração de spins pinneds e não compensados sobre o ciclismo campo (ZHENG et al., 2004a). Eles estudaram nanopartículas de Fe (núcleo) revestidas por uma camada superficial de $\gamma-\mathrm{Fe}_{2} \mathrm{O}_{3}$ (casca) que apresenta um comportamento spin-glass-like. Sua amostra possui uma composição química parecida com as investigadas nesta Tese, mostrando que o modelo proposto possa ser usado em nossa investigação. Nesse tipo de sistema a superfície desordenada das NPs-CS têm um papel muito importante, são responsáveis por ambos os deslocamentos horizontais e verticais dos ciclos de histerese com campo de cooling.

Para compreender o exchange bias Zheng et al. modificaram o modelo Stoner $\&$ Wohlfarth, adicionando um termo referente a energia de anisotropia unidirecional na energia total. Verificou que os efeitos de exchange bias $e$ treinamento em nanopartículas podem ser bem interpretados dentro do modelo modificado proposto.

As definições de vetores e de ângulo estão apresentadas na Figura 16 (a). $N_{F}$ e $N_{R}$ denotam os números de spins congelados e rodáveis, $\vec{S}_{F}$ e $\vec{S}_{R}$ spins por unidade de volume de uma partícula, respectivamente. Uma vez que a inversão de magnetização no modelo Stoner \& Wohlfarth é por rotação coerente, todos os spins reversíveis deverão ter a mesma direção que a magnetização reversível $\vec{S}_{R} \| \vec{M}_{R}$. Mas as direções dos $S_{\mathrm{F}}$ depende da história térmica e de campo. A energia total do modelo original Stoner \& Wohlfarth deverá ter dois termos. O primeiro termo é a energia de anisotropia uniaxial, $E_{a}$ incluirá as contribuições de todas as anisotropias, exceto a anisotropia unidirecional do exchange bias. O segundo termo é a energia Zeeman $-\mu_{0} \vec{H} \cdot \overrightarrow{M_{R}}$ 


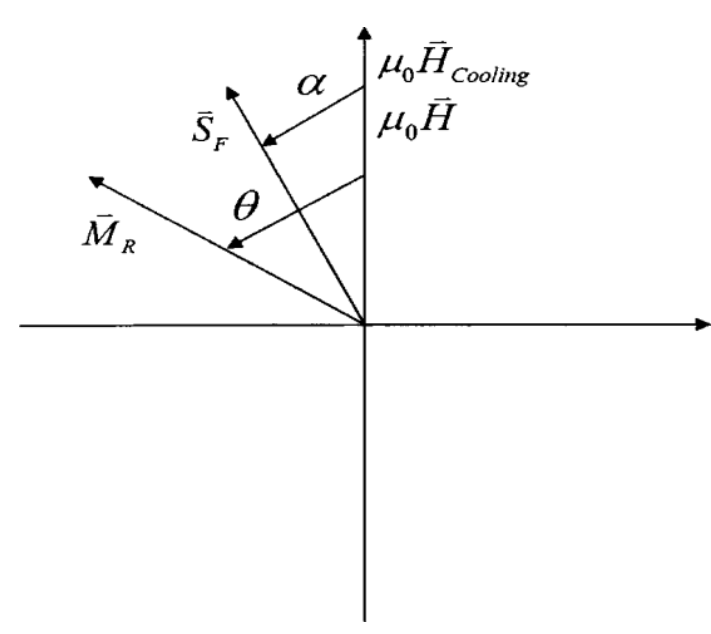

(a) definições de vetores e de ângulo

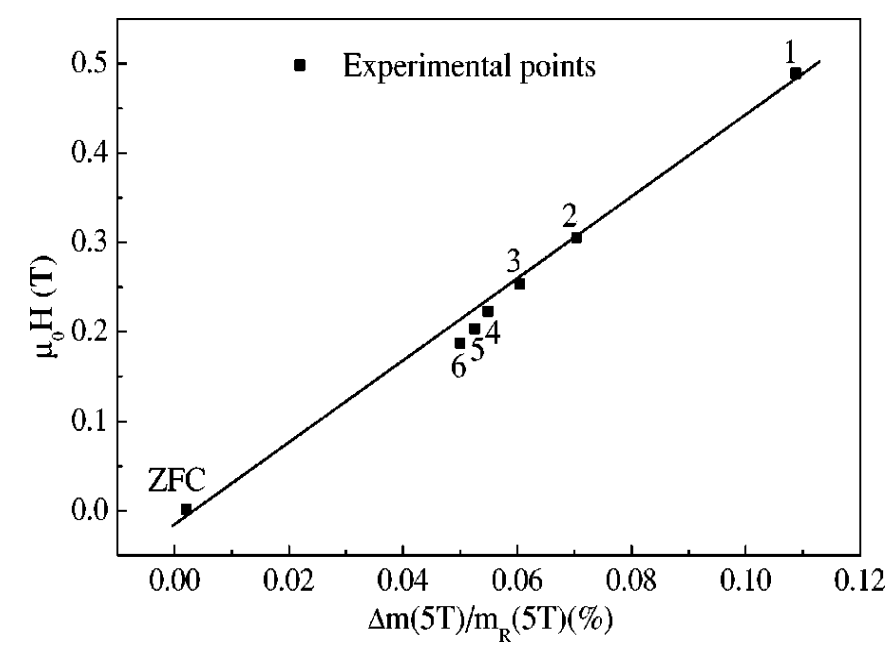

(b) resultado experimental do modelo

Figura 16: (a) Definição que modifica o modelo de Stoner \& Wohlfarth apresentado por Zheng et. al. (b) resultado experimental utilizando modelo para nanopartículas de $\mathrm{Fe}$ (core) revestidas por $\gamma-\mathrm{Fe}_{2} \mathrm{O}_{3}$ (shell). Figuras extraídas da ref. (ZHENG et al., 2004a).

Para um sistema com exchange bias, a energia fixação leva ao surgimento de uma anisotropia unidirecional $\left(K_{U D}\right)$ que será adicionado na energia total. Por simplicidade, o modelo assume que o exchange de acoplamento efetivo fornecidos por um spin congelado é

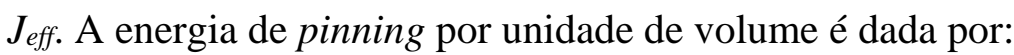

$$
E_{p}=-\sum_{i=1}^{N_{F}} J_{e f f} \cos \left(\alpha_{i}-\theta\right)
$$

Assim, a energia total por unidade de volume de uma partícula com exchange bias é escrita como:

$$
E=E_{a n}-\mu_{0} \vec{H} \cdot \vec{M}_{R}-\sum_{i=1}^{N_{F}} J_{e f f} \cos \left(\alpha_{i}-\theta\right) .
$$

Na situação de ZFC, as direções dos spins congelados numa partícula são paralelas à magnetização da partícula, porque a interação de trocas entre os spins congelados e reversíveis está bem estabelecida, devido ao fato de que a $T_{B}$ ser superior à $T_{f}$ neste sistema. Uma vez que os eixos fáceis das partículas estão distribuídos aleatoriamente no espaço (distribuição aleatória de $\theta$ ), a anisotropia unidirecional resultante da troca também deve ser distribuída aleatoriamente. Neste caso, o efeito de anisotropia unidirecional de cada partícula será cancelado uns aos outros, levando a um ciclo de histerese simétrico. Na situação de FC, as direções dos spins congelados alinham na direção do campo de cooling que geram uma energia de pinning eficaz. Seja $N_{F}^{\text {net }}$ o número dos spins congelados da rede (net) por unidade de volume, a energia de pinning pode ser escrita $\operatorname{como} N_{F}^{n e t} J \cos \theta$, ou sob a forma de anisotropia unidirecional $K_{U D} \cos \theta=N_{F}^{\text {net }} J_{\text {eff }} \cos \theta$. O exchange bias é determinada por: 


$$
H_{E X}=K_{U D} / \mu_{0} M_{R}=N_{F}^{n e t} J_{e f f} / \mu_{0} M_{R} .
$$

Para o campo $\vec{H}$ medido paralelo ao campo de cooling $\left(H_{\text {cool }}\right)$, a energia total é escrita no forma:

$$
E=E_{a n}-\mu_{0}\left(|\vec{H}|+H_{E X}\right) M_{R} \cos \theta
$$

Para o campo de medição $\vec{H}$ antiparalelo ao campo de cooling $\left(H_{\text {cool }}\right)$, a energia total é

$$
E=E_{a n}-\mu_{0}\left(-|\vec{H}|+H_{E X}\right) M_{R} \cos .
$$

Como é bem conhecido, o ciclo de histerese é determinado pela minimização da energia total. O coercividade na direção do campo de cooling é reduzida por $H_{E X}$ a partir da equação (45); a coercitividade na direção oposta do campo de refrigeração é aumentada por $H_{E X}$ a partir da equação (46). Em outras palavras, a anisotropia unidirecional desloca horizontalmente o ciclo FC para a direção oposta do campo de cooling por $H_{E X}$. A quantidade de spins congelados da rede $N_{F}^{\text {net }}$ é proporcional à diferença na magnetização medida no intervalo 9 e $-9 \mathrm{~T}$, o campo aqui expressão é utilizado em nossos experimentos:

$$
N_{F}^{\text {net }} \propto \Delta M(9 T)=M(9 T)+M(-9 T) .
$$

$\mathrm{O}$ efeito do treinamento pode ser bem interpretados dentro desse modelo. Como é bem sabido, uma das características dos vidros de spins é a sua configuração múltipla de estados. Alguns dos spins congelados, os quais foram inicialmente alinhadas na direção do campo de cooling, pode alterar as suas direções e dividem-se em outras configurações metastáveis durante a medidas de histerese. Em outras palavras, $N_{F}^{\text {net }}$ diminui com o ciclismo do campo aplicado.

Esta característica do spins-glass-like influencia os comportamentos do exchange bias do sistema, e uma das consequências da reconfiguração dos spins congelados alinhados é a diminuição da diferença momento magnético $\Delta M(9 T)$ de acordo com a equação 47 . Um outro é a diminuição de $H_{E X}$ de acordo com a equação 44. Se as diferenças de Jeff para diferentes spins congelados são ignoradas, pode-se expressar por uma variação da magnetização $\Delta \mathrm{M}$, escrita $\mathrm{a}$ partir das equações 45 - 47:

$$
H_{E X} \propto \Delta M(9 T) / M_{R} .
$$

\section{Modelo de Radu et al.}

Mais recentemente, a equação do modelo de Binek foi redefinida com a discretização da equação 49. Conseguida através da substituição da mudança temporal contínua do $\dot{S}_{A F}$ da 
interface AFM de magnetização, de acordo com uma média temporal e estendendo a expansão da energia livre $\Delta F$. Essa foi adaptada para levar em conta a ordenação dos spins da camada de pinning AFM. A nova equação para efeito de treinamento (SAHOO et al., 2007b):

$$
H_{E X}(n+1)-H_{E X}(n)=-\gamma_{b}\left(H_{E X}(n)-H_{E X}^{\infty}\right)^{3}-\gamma_{c}\left(H_{E X}(n)-H_{E X}^{\infty}\right)^{5},
$$

onde os novos parâmetros $\gamma_{c}$ resultam da expansão de ordem superior da energia livre, portanto, $\gamma_{b}<<\gamma_{c}$. O parâmetro $\gamma_{b}$ é semelhante ao $\gamma$ da eq. 49. Ambos os parâmetros $\gamma_{c}$ e $\gamma_{b}$ apresentam uma dependência exponencial (taxa de varrimento) para a medição do ciclo de histerese. Radu et al. sugerem que ambas as componentes dos spins congelados e rodáveis são afetadas pelas inversões de magnetização da camada ordenada FM. Além disso, existem componentes misturadas das camadas ferromagnéticas e antiferromagnéticas acopladas que contribuirão distintamente, através de diferentes taxas de relaxamento, para o efeito do treinamento (RADU; ZABEL, 2008b; MISHRA et al., 2009). Eles sugerem outro tipo de expressão que reproduz a dependência do campo de exchange bias e do campo coercivo em função do índice de loop (n) para diferentes temperaturas. Com cada ciclo, a desordem de spins diminuirá ligeiramente, amortecendo o campo de exchange bias. Ambas as contribuições causam uma diminuição gradual do exchange bias em função do ciclo $n$, podendo ser tratadas probabilisticamente. Radu et al. sugere a seguinte expressão para simular a diminuição da EB em função do índice n:

$$
H_{E X}(n)=H_{E X}^{\infty}+A_{f} \exp \left(-n / P_{f}\right)+A_{i} \exp \left(-n / P_{i}\right),
$$

$H_{E X}^{\infty}$ é o exchange bias do ciclo de histerese enésimo, $A_{f}$ e $P_{F}$ são parâmetros relacionados com a mudança dos spins congelados, $A_{i}$ e $P_{i}$ são os parâmetros relacionados com a evolução da desordem interfacial. Os parâmetros A têm dimensão de Oersted, enquanto os parâmetros $P$ são adimensionais e semelhantes a um tempo de relaxamento, onde a variável "tempo" é contínua substituída por uma variável discreta $n$. Radu et al. observa que a contribuição interfacial entre camada FM/AFM diminui fortemente $\operatorname{com} n$, a anisotropia dos spins interfaciais é reduzida (baixa anisotropia dos spins AFM), enquanto a contribuição dos spins congelados AFM pertencentes aos domínios AFM (spins não compensados congelados) aparecem como uma longa cauda diminuindo à medida que são intimamente incorporados pelo ambiente muito mais duro. 


\section{Materiais e Métodos Experimentais}

$\mathrm{O}$ método de síntese química das nanopartículas ultrapequenas de $\mathrm{CoFe}_{2} \mathrm{O}_{4} @ \gamma-\mathrm{Fe}_{2} \mathrm{O}_{3}$ investigadas e as principais técnicas experimentais utilizadas no decorrer do trabalho serão apresentadas e seus princípios de funcionamento discutidos.

\subsection{Obtenção dos nanomateriais investigados}

\subsubsection{Síntese química de ferrofluidos do tipo EDL-MF}

As nanopartículas ultrapequenas aqui investigadas foram sintetizadas por P. Coppola e F. G. da Silva, através do método coprecipitação hidrotérmica de fluidos magnéticos com dupla camada elétrica - EDL-MF (TOURINHO ET AL., 1989; TOURINHO; FRANCK; MASSART, 1990; GOMES ET AL., 2008). Este método de síntese química depende principalmente de parâmetros tais como a temperatura da reação, o pH da suspensão, a concentração molar inicial, agitação, entre outras. O processo de elaboração de ferrofluidos geral é ilustrado na figura 17 e composto por 2 etapas: obtenção de nanopartículas (etapa 1), tratamento de superfície (etapas 1a e 1 b) e finalmente, peptização das nanopartículas (etapa 2) em um meio aquoso de pH ácido.

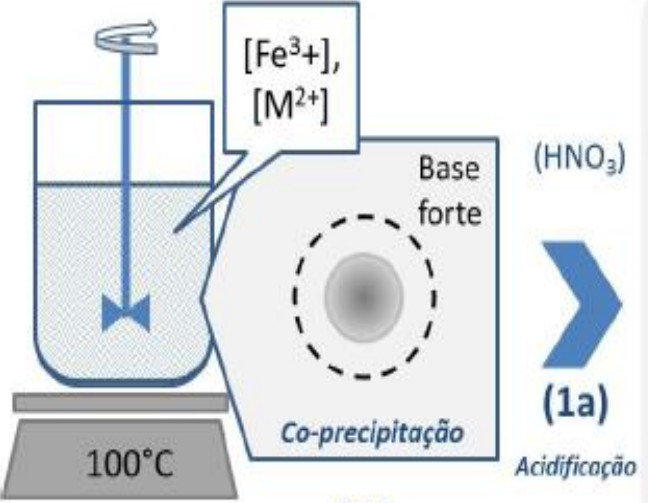

(1)

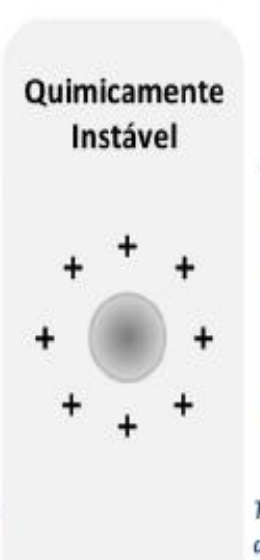

da superficie

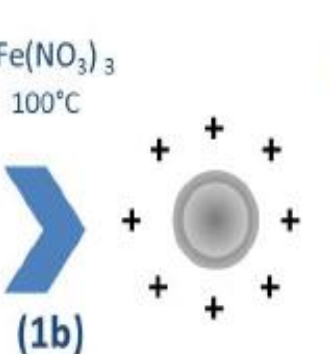

peptizaçōo

(2)

Figura 17: Esquema geral de síntese química (método bottom-up) de fluidos Magnéticos a base de ferrita de cobalto. $\mathrm{Fe}^{3+}$ e $\mathrm{M}^{2+}$ são as soluções de ferro e do metal divalente $\left(\mathrm{Co}^{2+}\right)$, respectivamente.

Na etapa 1 de síntese uma mistura estequiométrica de soluções de metais divalentes $\mathrm{Co}^{2+}$ e trivalentes $\mathrm{Fe}^{3+}$ é utilizada com adição rápida das soluções na base forte, para cada parte de Nitrato de Cobalto $\left(\mathrm{Co}\left[\mathrm{NO}_{3}\right]_{2}\right)$ são adicionadas duas de solução de Cloreto de Ferro $\left(\mathrm{FeCl}_{3}\right)$ 
em meio alcalino sob agitação (1000 rpm) a $100^{\circ} \mathrm{C}$ (ilustrado em (1)). A fim de obter partículas ultra pequenas foi utilizado uma solução base de amônia $\left(\mathrm{NH}_{3}\right) \operatorname{com}$ pH 11 (AQUINO et al., 2002). As nanopartículas resultantes desta etapa estão na forma de um precipitado, obtidas em meio fortemente alcalino e por consequência estão carregadas negativamente. Entretanto, nessa etapa sua estabilização ainda não é possível devido à alta força iônica presente no seio da dispersão. O precipitado é adicionado de água ultrapura após a decantação magnética, suga-se o sobrenadante e este processo é repetido várias vezes. Após, o precipitado é tratado hidrotermicamente com uma solução de nitrato férrico $0.5 \mathrm{M}\left(\mathrm{Fe}\left[\mathrm{NO}_{3}\right]_{3}\right)$ a $100{ }^{\circ} \mathrm{C}$ por aproximadamente 15 minutos para ajustar a estabilidade química das partículas. Essa etapa intermediária promove um enriquecimento da superfície com ferro criando uma camada de ferro oxidada, fortemente estável em meio ácido e carregada positivamente(GOMES et al., 2008).

Finalmente, para obtermos soluções coloidais estáveis, é preciso realizar sucessivas lavagens para diminuir a força iônica. As partículas são agitadas dentro de uma mistura água/acetona, em seguida decantadas sobre uma placa magnética antes da aspiração do sobrenadante. Depois de vários tratamentos desse tipo, a força iônica é suficientemente pequena para permitir a dispersão dos nanogrãos dentro de uma solução de pH aproximadamente 3, a uma força iónica $10^{-3} \mathrm{~mol} / \mathrm{l}$. As partículas são colocadas em suspensão e caracterizadas por sua carga superficial, a qual, por meio das repulsões eletrostáticas, controla a estabilidade coloidal dos ferrofluidos, prevenindo a aglomeração das mesmas. O produto desta síntese resulta em nanopartículas de ferrita de cobalto $\left(\mathrm{CoFe}_{2} \mathrm{O}_{4}\right)$ coberta por uma fina camada desordenada de maguemita $\left(\gamma-\mathrm{Fe}_{2} \mathrm{O}_{3}\right), \mathrm{CoFe}_{2} \mathrm{O}_{4} @ \gamma-\mathrm{Fe}_{2} \mathrm{O}_{3}$, fruto do tratamento de nitrato de ferro de superfície.

A amostra sintetizada foi denominada de FPCo2 e nesse trabalho utilizamos duas amostras fruto daquela. Da amostra sintetizada fizemos uma diluição afim de observamos as propriedades intrínsecas das partículas num regime de interações fracas. E amostra pó, após a evaporação do líquido carreador a $60^{\circ} \mathrm{C}$ por 24 horas, em que as interações influenciam nas propriedades magnéticas das nanopartículas.

Faz-se necessário um estudo da composição química, estrutural e morfológica das nanopartículas obtidas, realizadas por Espectroscopia de Absorção Atômica (AAS), Difração de Raios X (DRX) e Microscopia Eletrônica de Transmissão (MET). Finalmente, medições de magnetização a 300 e $5 \mathrm{~K}$ são realizadas a fim de investigar as propriedades magnéticas da NPs-CS sintetizadas. 


\subsubsection{Difração de raios $X$}

Difração de raios $X$ (DRX) é a interação da radiação de raios $X$ com a estrutura cristalina dos materiais, uma vez que raios $X$ possui o comprimento de onda $(\lambda)$ próximo de alguns Angstrons ( $\mathrm{A})$. Laue sugeriu em 1912 que o espaçamento entre os planos de átomos no cristal é comparável ao comprimento de onda dos raios $\mathrm{X}$, com distâncias da ordem de $\sim 10^{-10}$ m. A inspiração de Laue culminou com os experimentos realizados por Walter Friedrich e Paul Knipping no Instituto Sommerfeld que conseguiram obter o primeiro diagrama de difração e Laue também formulou a primeira teoria de difração de raios X para cristais (FRIEDRICH; KNIPPING; LAUE, 1913). As descobertas que se seguiram de W. H. Bragg e seu filho W. L. Bragg (BRAGG; BRAGG, 1913) ajudaram a esclarecer o fenômeno e desenvolveram uma nova teoria simplificada de difração de raios X. Em seus experimentos, investigaram a formação de uma interferência construtiva por parte das ondas espalhadas, observaram que o feixe de raios $\mathrm{X}$ incidente normal ao plano de difração produzia um feixe difratado, que é obrigatoriamente coplanar e que o ângulo entre o feixe difratado e o transmitido é duas vezes o ângulo incidente normal à superfície. Espalhamentos múltiplos acontecem reforçando o fenômeno que tem dependência basicamente na distância interplanar $\mathrm{d}_{h k l}$. Ambos pesquisadores receberam prêmio Nobel em 1914-1915 e poucas outras descobertas receberam um rápido reconhecimento e elogios generalizados (ECKERT, 2012).

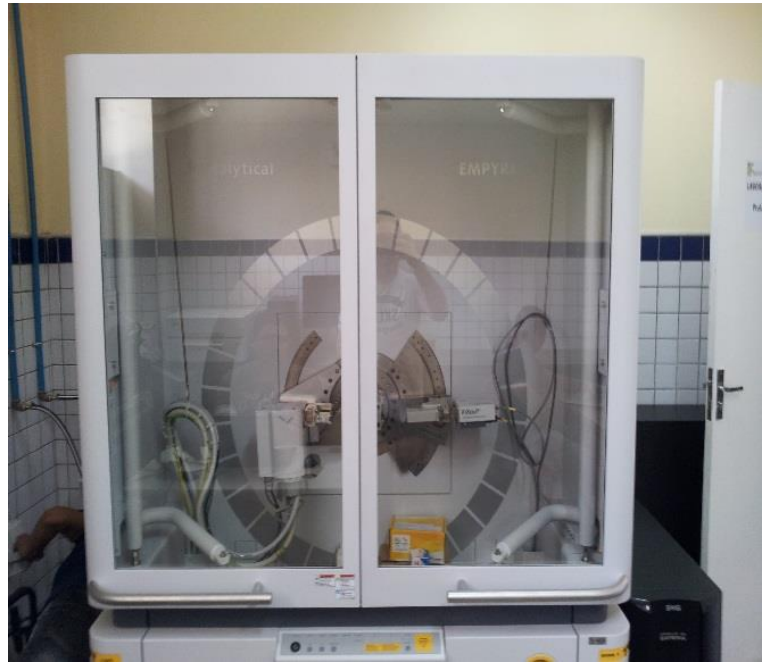

(a) Difratômetro Empyrean da PANalytical ${ }^{\circledR}$

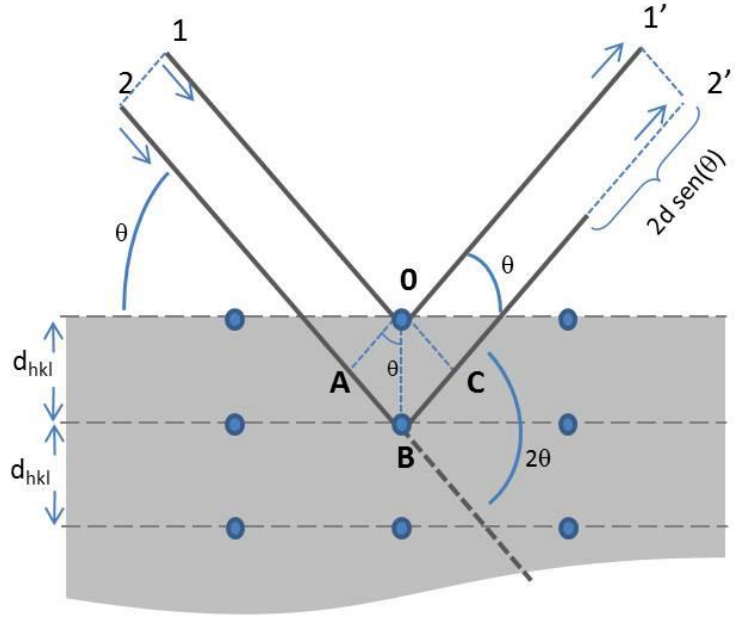

(b) fenômeno de difração de raios $\mathrm{X}$ em cristais

Figura 18: a) equipamento utilizado para medida instalado no campus Teresina Central do IFPI b) A condição para que ocorra interferência construtiva, raios difratados na direção $2 \theta$, ângulo entre a direção do feixe incidente e a direção de observação é dada pela lei de Bragg. 
A Figura 18 (a) mostra equipamento utilizado, instalado no Laboratório do Programa de Pós-Graduação em Engenharia de Materiais do Instituto Federal do Piauí Campus Teresina Central e a Figura 18 (b) exemplifica a difração de raios X em cristais sugerido pelos Braggs. A técnica de caracterização empregada para identificar as fases cristalográficas de uma amostra, permite a investigação do arranjo ordenado dos sólidos (simetria cristalina, parâmetros de rede, distâncias interplanares, defeitos estruturais e etc.). O princípio básico de difração de raios X é baseada na Lei de Bragg (BRAGG; BRAGG, 1913) como mostrado na expressão:

$$
2 d_{h k l} \sin \theta=n \lambda
$$

onde $d_{h k l}$ é o espaçamento de rede de plano $(h k l), \lambda$ é o comprimento de onda do raios $\mathrm{X}, \theta$ é a ângulo de dispersão (incidência), $n$ e é um número inteiro chamado de ordem de reflexão. Os picos observados correspondem à reflexão de Bragg que pertence a uma família particular de planos. Em cristais de estrutura cúbica, caso da estrutura das ferritas do tipo espinélio, a distância interplanar é dada por (CULLITY, 2001):

$$
d_{h k l}=\frac{a}{\sqrt{h^{2}+k^{2}+l^{2}}},
$$

onde $a$ é o parâmetro de malha e $h, k$ e $l$ são os índices de Miller.

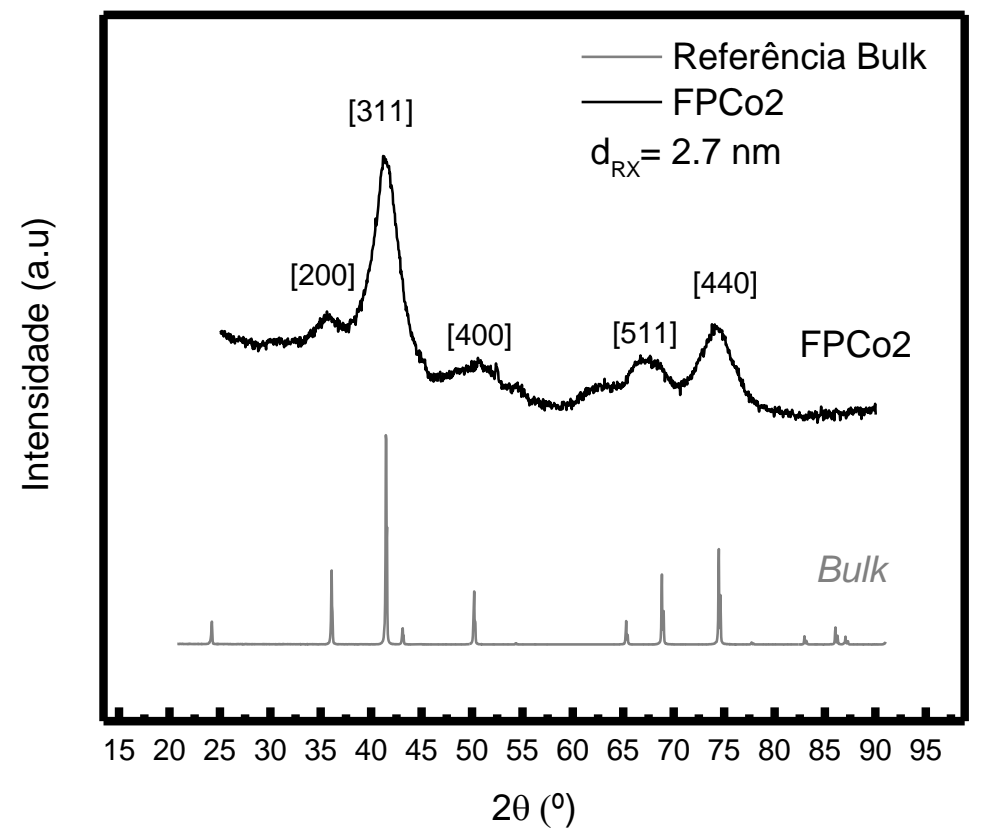

Figura 19: A linha da cor preta é o difratograma da amostra pó com seus picos indexados e a linha da cor cinza é a o difratograma para ferrita de cobalto maciça extraído da ficha cristalográfica No. 22-1086. 
A medida de DRX foi realizada no difratômetro Empyrean da PANalytical ${ }^{\circledR}$ com fonte de Co K $\alpha$ correspondente a um comprimento de onda $1.7906 \AA$, para analisar a natureza cristalinidade da amostra sintetizada. Um padrão de difração de raios $\mathrm{X}$ experimental para amostra FPCo2 é mostrado na Figura 19, o intervalo do ângulo explorado está entre $20^{\circ} \leq 2 \theta \leq 90^{\circ}$ com passo angular de $0.052^{\circ}$, os picos são indexados: (220), (311), (400), (511) e (440). Os perfis do pico de difração experimental são modelados por um ajuste pseudo-Voigt. O tamanho cristalino médio $\left(d_{R X}\right)$ é deduzida pelo formalismo de Scherrer que observou uma relação da largura à meia altura do pico com o tamanho cristalino.

Um cristal perfeito é constituído pela repetição infinita e periódica de uma base utilizando-se as operações de simetria de posição e translação. Nesse caso, a intensidade difratada corresponde a uma linha infinitamente fina (pico de Dirac) como observamos da referência do bulk linha de cor cinza na Figura 19. Usando o software HighScore X'Pert da PANalytical ${ }^{\circledR}$ associado com um banco de dados Powder Diffraction File 2 - PDF-2 da The International Centre for Diffraction Data - ICDD, comparamos nosso difratograma com os cartões da (ICDD) e encontramos o uma correspondência com o cartão No. 22-1086 para $\mathrm{CoFe}_{2} \mathrm{O}_{4}$ que confirma que a estrutura do cristal é o tipo espinélio e pertencente ao grupo espacial $F d 3 m$. A redução da dimensão do cristal conduz a um alargamento do pico de difração, visualizado no difratograma em cor preta na Figura 19, o alargamento do pico está diretamente com o diâmetro ligado pela expressão (SCHERRER, 1912, 1918; CULLITY, 2001):

$$
d_{R X}=\frac{K \lambda}{\beta \cos \theta}
$$

Na fórmula de Scherrer, o parâmetro de forma é introduzido por $K$ em que o fator de correção $(0.7 \leq K \leq 1.7)$ depende da forma da partícula. No caso de nanopartículas aproximadamente esféricas, o valor usado da constante (WARREN, 1969) é 0.9. O parâmetro $\beta$ é a largura a meia altura do pico de Bragg (em radianos) retirado do ajuste do pico pela função pseudo-Voigt aplicado no pico de maior intensidade [311]. Nós encontramos um diâmetro médio de $2.7 \mathrm{~nm}$ com o formalismo da Scherrer para NPS e levamos em consideração as contribuições do material e a largura instrumental para amostra e o parâmetro de malha (a) de $8.36 \AA ̊$ é deduzido a partir da expressão 53.

A análise do padrão de DRX é de vital importância, dado que a aresta da malha cúbica elementar da rede de um material é muito sensível ao tamanho de uma nanopartícula e muda drasticamente. A redução do tamanho ocasiona um alagamento dos picos de difração como observamos no difratograma da amostra FPCo2 pó (HAMMOND; HAMMOND, 2009). 


\subsubsection{Composição química e fração volumétrica de nanopartículas}

Após a etapa $1 \mathrm{~b}$ de tratamento de superfície no processo de síntese, as nanopartículas são protegidas contra a dissolução em meio ácido. Contudo, com essa estratégia, estas não apresentam mais uma composição química homogênea já que o tratamento induz a criação de uma camada superficial rica em ferro $\left(\gamma-\mathrm{Fe}_{2} \mathrm{O}_{3}\right)$. Consequentemente, a fração molar em metal divalente $\left(\chi_{M}=\left[\mathrm{M}^{2+}\right] /\left[\mathrm{M}^{2+}\right]+\left[\mathrm{Fe}^{3+}\right]\right)$ passa de 0.33 após a etapa de coprecipitação, para valores inferiores, após a etapa de tratamento (GOMES et al., 2008). Diluímos a amostra sintetizada para obter uma dispersão de partículas com regime de interação fracas e a partir dessa amostra dosamos a quantidade de metais.

Para determinar quantitativamente a presença de metais nas partículas afim de calcular a fração molar em metal divalente, utilizamos a técnica de Espectrometria de Absorção Atômica (AAS). O Método consiste em determinar a presença e quantidade de um determinado metal em uma solução. Utilizamos o Thermo Scientific ${ }^{\circledR}$ modelo Spectrometer AA S Series instalado no GFC-UnB (Figura 20 (a)). Escolhemos as linhas específicas para cada metal da amostra, ferro $(372.0 \mathrm{~nm})$ e cobalto $(240.7 \mathrm{~nm})$, a fim de evitar os efeitos de interferência.

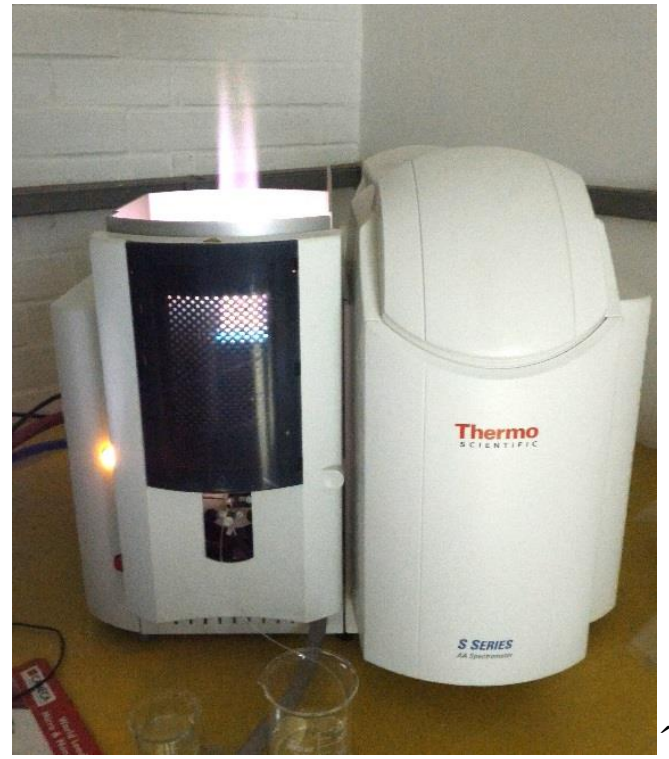

(a) Espectrômetro de Absorção Atômica

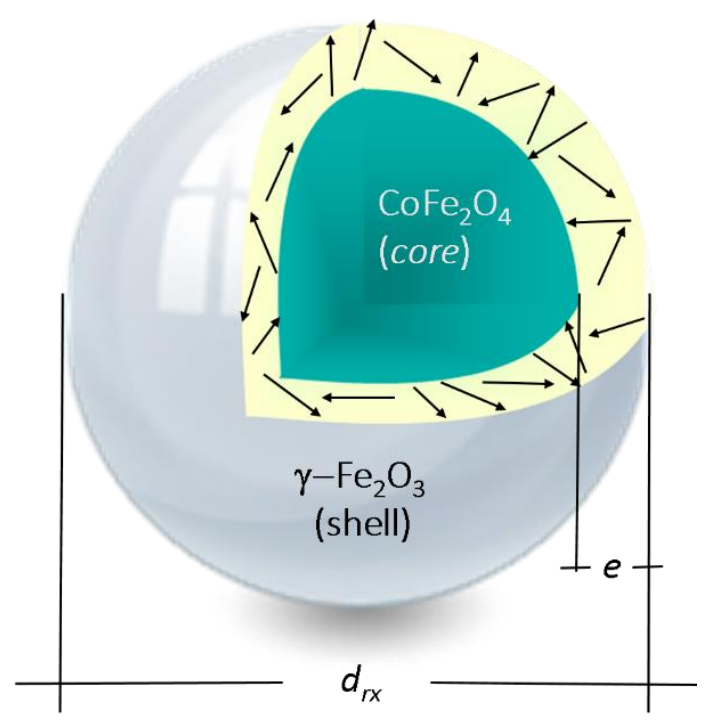

(b) Modelo core-shell para nanopartículas

Figura 20: (a) equipamento utilizado para experimento de AAS. (b) Representação pictórica das nanopartículas de diâmetro d, mostrando o núcleo composto de ferrita estequiométrica recoberta por uma camada de óxido de Ferro com espessura $e$.

A fim de levar em conta está heterogeneidade causada pelo enriquecimento de ferro das superfície das nanopartículas magnéticas core-shell (NPs-CS), utilizamos o modelo de 
determinação das fases químicas proposto por Gomes et al. (GOMES et al., 2008) para uma partícula core-shell, visualizamos uma representação na Figura 20 (b). O modelo considera que a nanopartícula é composta por um núcleo de ferrita estequiométrica, envolvido por uma camada superficial de maguemita $\left(\gamma-\mathrm{Fe}_{2} \mathrm{O}_{3}\right)$. Esse permite a determinação da fração volumétrica de nanopartículas, que é usualmente utilizada para expressar a concentração do fluido magnético. No modelo core-shell de composição química, a fração volumétrica do ferrofluido será a soma das frações volumétricas do núcleo e da camada superficial.

$$
\phi_{\text {Partícula }}=\phi_{\text {Core }}+\phi_{\text {Shell }}
$$

A fração volumétrica do núcleo é proporcional ao teor de metal divalente $\left[\mathrm{M}^{2+}\right]$, enquanto a fração volumétrica da camada superficial é proporcional à concentração de ferro da casca da partícula, assim:

$$
\phi_{C}=\left[M^{2+}\right] V_{M}^{C} ; \quad \phi_{S}=\frac{\left[F e^{3+}\right]-2\left[M^{2+}\right]}{2} V_{M}^{S}
$$

onde $V_{M}^{C}$ e $V_{M}^{S}$ são os volumes molares da ferrita de cobalto e da maguemita $V_{M}^{C} \quad 4.35 \times 10^{-02}$ l/mol e $V_{M}^{S} 3.15 \times 10^{-02} \mathrm{l} / \mathrm{mol}$, respectivamente (SCHWERTMANN; CORNELL, 2008). Podemos calcular a espessura da camada de maguemita e levando em conta a razão $\phi_{C} / \phi_{P}$, o número de íons por malha no core $n_{\text {core }}=24$, o número de íons por malha na superfície $n_{\text {shell }}$ $=21.3$ (GOMES et al., 2008). Uusando a expressão abaixo:

$$
e(n m)=\frac{d_{R X}}{2}\left\{1-\left[\left(\frac{1}{\phi_{C} / \phi_{P}}-1\right) \frac{n_{\text {Core }}}{n_{\text {Shell }}}+1\right]^{-1 / 3}\right\}
$$

Os resultados encontrados por AAS e valores deduzidos com o modelo core-shell de composição química está reunido na Tabela 2.

Tabela 2: Resultados da amostra diluída FPCo2 de AAS e valores extraídos a partir do modelo de composição química das nanopartículas core-shell.

\begin{tabular}{cccccccccc}
\hline \multirow{2}{*}{ Amostra } & $\begin{array}{c}d_{r x} \\
(\mathrm{~nm})\end{array}$ & $\begin{array}{c}{\left[\mathrm{Co}^{+2}\right]} \\
(\mathrm{mol} / \mathrm{l})\end{array}$ & $\begin{array}{c}{\left[\mathrm{Fe}^{+3}\right]} \\
(\mathrm{mol} / \mathrm{l})\end{array}$ & $\chi_{\mathrm{M}}$ & $\begin{array}{c}\phi_{\mathrm{c}} \\
(\%)\end{array}$ & $\begin{array}{c}\phi_{\mathrm{s}} \\
(\%)\end{array}$ & $\begin{array}{c}\phi_{\mathrm{p}} \\
(\%)\end{array}$ & $\begin{array}{l}\phi_{c} / \phi_{P} \\
\phi_{s} / \phi_{P}\end{array}$ & $\begin{array}{c}e \\
(\mathrm{~nm})\end{array}$ \\
\hline \hline
\end{tabular}

$\begin{array}{lllllllllll}\text { FPCo2 } & 2.7 & 0.02 & 0.1 & 0.16 & 0.087 & 0.0945 & 0.182 & 0.48 & 0.52 & 0.27\end{array}$

Encontramos $\chi_{m}$ inferior a 0.33 mostrando que houve um enriquecimento superficial com ferro e um $\phi$ de partículas $0.18 \%$. Desses resultados também observa-se um $\chi_{m}$ 
relativamente pequeno quando comparados com partículas de cobalto obtidas pelo mesmo método de síntese. Isso se deve ao fato de que com a diminuição do diâmetro, a razão $\phi_{s} / \phi_{P}$ da partícula aumenta substancialmente para partícula maior. Marinho et al. encontra para uma partícula de $12.9 \mathrm{~nm}$ um $\phi_{s} / \phi_{P}$ de 0.75 (MARINHO, 2011); ou seja, para partículas menores o enriquecimento de ferro na superfície acaba sendo destacado e portanto a fração de metal divalente acaba por ser minimizada. Para nossas NPs encontramos uma proporção significativa de $52 \%$ que equivale a uma espessura de $0.27 \mathrm{~nm}$ da casca.

Para enriquecer nossos resultados medimos a densidade do ferrofluido, para determinação da fração volumétrica. Neste trabalho foi utilizado um densímetro digital de bancada DMA 38 ANTON PAAR (Figura 21 (a)) para medir a densidade das amostras na fase líquida.

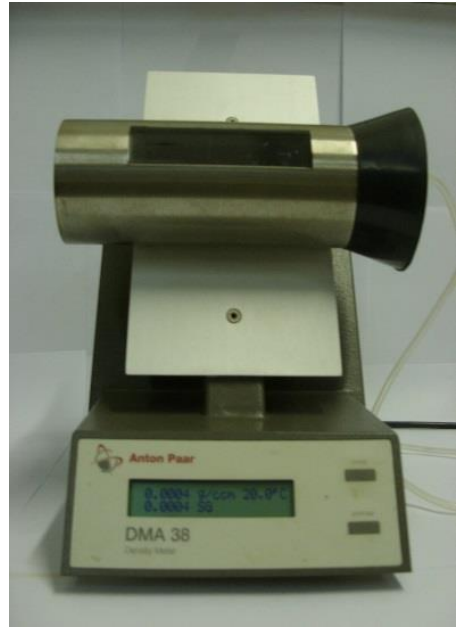

(a) Densímetro DMA 38 ANTON PAAR

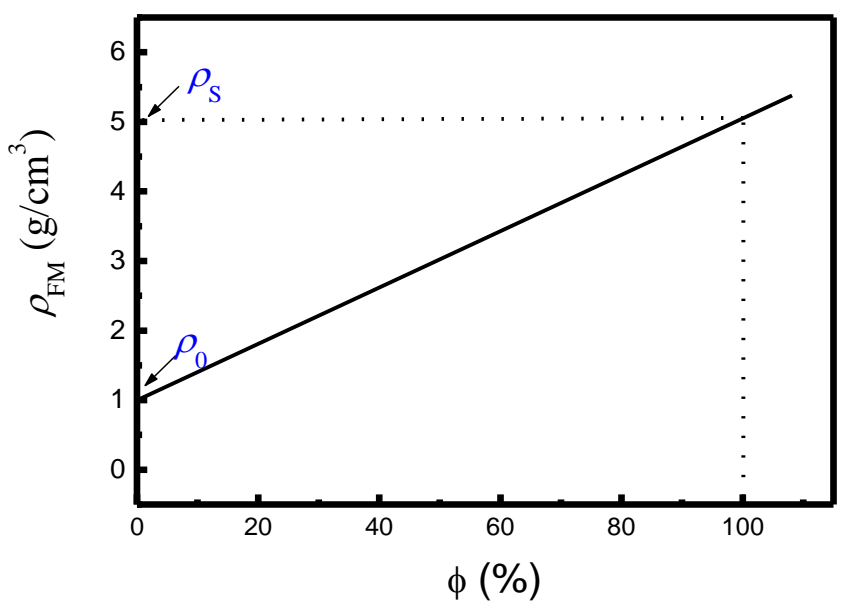

(b) dependência de $\rho$ versus $\phi$ típica de um ferrofluido

Figura 21: (a) densímetro instalado no Laboratório do Grupo de Fluidos Complexos da Universidade de Brasília. (b) curva típica de um ferrofluido em função da fração volumétrica de partículas $\phi$.

Na Figura 21 (b) temos o comportamento esquemático da densidade do fluido $\rho_{F F}$, a densidade do solido é representado por $\rho_{S}$ e $\rho_{0}$ a densidade do líquido carreador. Escrevendo $\phi$ de uma amostra de um ferrofluido em função destes parâmetros temos (GOMES et al., 2008):

$$
\phi_{p}=\frac{\rho_{F F}-\rho_{0}}{\rho_{S}-\rho_{0}} .
$$

Rearranjando a expressão acima, temos:

$$
\rho_{F F}=\rho_{S} \phi_{p}+\rho_{0}\left(1-\phi_{p}\right),
$$

que relaciona a densidade medida do ferrofluido $\phi_{p}$ e a densidade da nanopartícula. 
Inicialmente é medido a densidade de uma solução de $\mathrm{H}_{2} \mathrm{O}+\mathrm{HNO}_{3} \mathrm{com}$ pH igual ao ferrofluido de 2.5 , valor encontrado é de $0.9973 \mathrm{~g} / \mathrm{cm}^{3}$ a uma temperatura de $20^{\circ} \mathrm{C}$, em seguida são inseridos por volta de $1 \mathrm{ml}$ de ferrofluido por uma seringa na célula de medição de densidade e encontramos um valor de $1.0051 \mathrm{~g} / \mathrm{cm}^{3}$.

Tabela 3: Resultados do experimento de densidade feito para amostra de ferrofluido diluído.

\begin{tabular}{ccccc}
\hline Amostra & $\begin{array}{c}\rho_{\left(\mathrm{COFe}_{2} \mathrm{O}_{4}\right)} \\
\mathrm{g} / \mathrm{cm}^{3}\end{array}$ & $\begin{array}{c}\rho_{\left(\mathrm{HNO}_{3}\right)} \\
\mathrm{g} / \mathrm{cm}^{3}\end{array}$ & $\begin{array}{c}\rho_{\mathrm{FF}} \\
\mathrm{g} / \mathrm{cm}^{3}\end{array}$ & $\begin{array}{c}\phi_{p} \\
(\%)\end{array}$ \\
\hline \hline FPCo2 & 5.29 & $0.9973 \pm 0.0001$ & $1.0051 \pm 0.0001$ & 0.1817 \\
\hline
\end{tabular}

A Tabela 3 reúne os valores das densidades do Bulk, do líquido carreador e da amostra diluída de ferrofluido aqui investigada. Com esses resultados podemos deduzir o valor da concentração de partículas $\phi_{p}$ utilizando a expressão 57 e encontramos um valor de $0.1817 \%$, em total concordância com o resultado da dosagem química feita por Espectroscopia de Absorção Atômica.

\subsubsection{Microscopia eletrônica de transmissão}

Para investigar a morfologia e avaliar a distribuição de tamanho das nanopartículas utilizou-se a técnica de Microscopia Eletrônica de Transmissão (MET). As imagens foram feitas no microscópio JEOL mod. JEM- $2100^{\odot}$ operando em $100 \mathrm{keV}$ com $\lambda$ de $3.7 \times 10^{-3} \mathrm{~nm}$, equipado com EDS da Thermo scientific ${ }^{\circledR}$ do Laboratório Multiusuário de Microscopia de alta Resolução - LabMic do Instituto de Física da Universidade Federal do Goiás. A Figura 22 apresenta a imagem do equipamento. Análises foram feitas com ajuda das técnicas auxiliares do microscópio, Microscopia Eletrônica de Transmissão em Alta Resolução - HRTEM (High Resolution Transmission Electron Microscopy) e para ajudar na determinação da composição foi feita espectroscopia de dispersão de energia de raios X - EDS (Energy Dispersive X ray Spectroscopy).

Uma gota da amostra de ferrofluido é depositada num eppendorf e diluída em álcool até ficar quase transparente e o eppendorf passou por um banho de ultrassom com frequência ultrassônica de $40 \mathrm{kHz}$ para ajudar a dispersar as partículas na solução. Antes do experimento uma gota da amostra é depositada sobre uma tela de cobre de 400 mesh com área de aproximadamente $3 \mathrm{~mm}^{2}$, após a evaporação do solvente a amostra é submetida ao experimento de microscopia. 


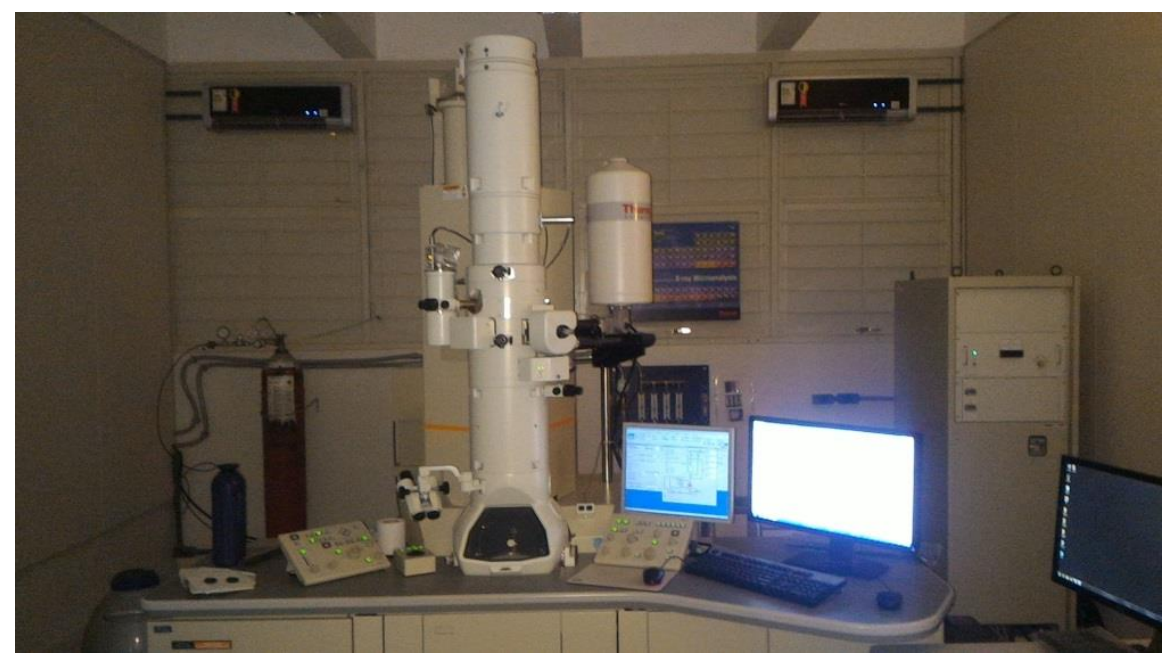

Figura 22: Microscópio Eletrônico de Transmissão JEM-2100 instalado no LabMic da Universidade Federal do Goiás.

Foram feitas um conjunto de imagens de TEM da amostra FPCo2 diluída e escolhemos a imagem apresentada na Figura 23 (a) para fazer o EDS. Figura 23 (a) apresenta alguns aglomerados de partículas, escolhemos o aglomerado na região central da microscopia para checar a composição química por EDS. Deste modo foi possível construir o espectro relativo ao número de contagens em função da energia, em keV, possibilitando assim identificar os elementos presentes na amostra, Figura 23 (b). Os picos detectados no espectro indicam os elementos presentes Fe e Co da amostra FPCo 2 e $\mathrm{Cu}$ da tela de Cobre, a tabela 4 reuni os valores das porcentagens dos metais presentes na amostra.

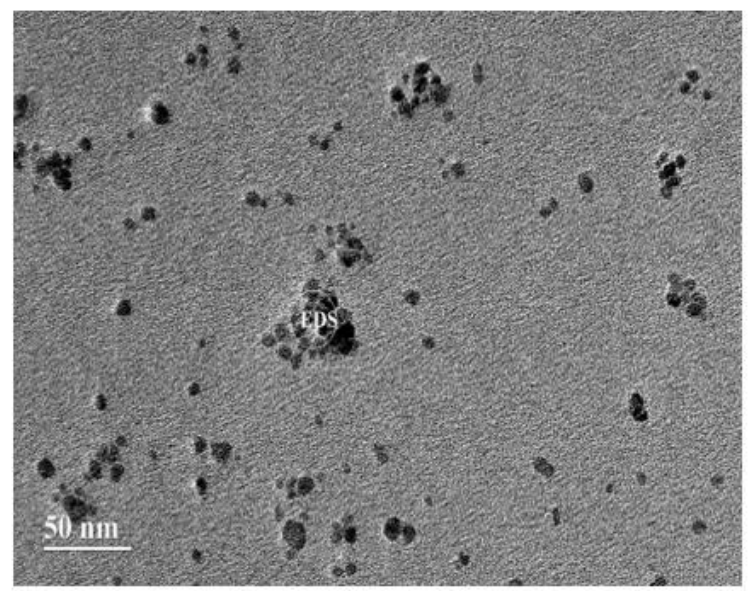

(a) MET da amostras FPCo2

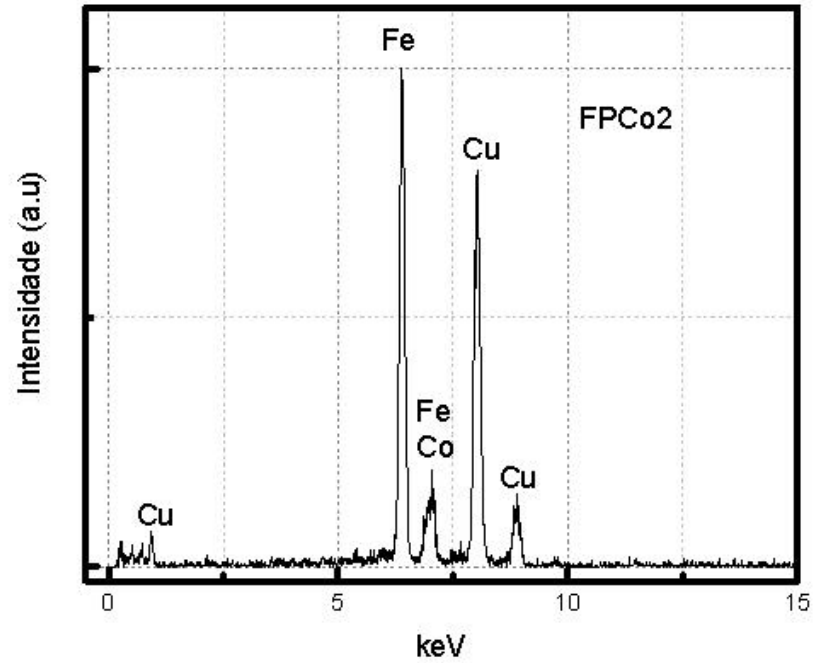

(b) Espectro relativo de EDS da região central

Figura 23: (a) Microscopia Eletrônica de Transmissão da amostra de ferrita de cobalto com escala de $50 \mathrm{~nm}$ e EDS que confirma os elementos químicos da amostra. 
Tabela 4: Resultados quantitativos obtidos a partir do espectro de EDS.

\begin{tabular}{cccc}
\hline Amostra & $\begin{array}{c}\text { Linha do } \\
\text { Elemento }\end{array}$ & Atom\% & $\begin{array}{c}\text { Atom\% } \\
\text { Error }\end{array}$ \\
\hline \hline \multirow{3}{*}{ FPCo2 } & Fe K & 68.86 & $+/-2.79$ \\
\cline { 2 - 4 } & Co K & 31.14 & $+/-2.53$ \\
\cline { 2 - 4 } & Total & 100 & \\
\hline
\end{tabular}

O histograma de distribuição de tamanho foi obtido através da contagem individual de aproximadamente 500 nanopartículas utilizando o programa ImageJ ${ }^{\odot}$, apresentado na Figura 24 (a), este normalizado pelo número de partículas contadas. O histograma de tamanho foi ajustado por uma lei de distribuição do tipo log-normal

$$
P(d)=\frac{1}{\sqrt{2 \pi} \sigma d} \exp \left[-\frac{1}{2 \sigma^{2}}\left(\ln \frac{d}{d_{0}}\right)^{2}\right],
$$

onde $d_{0}$ é o diâmetro característico e $\sigma$ corresponde a largura característica da polidispersão associada à distribuição de tamanhos. Pelo ajuste do histograma com a função log-normal encontramos um diâmetro médio de $2.67 \mathrm{~nm}$, ligeiramente menor que o obtido pelo formalismo de Sherrer, e uma polidispersão $\sigma=0.26$. A Figura 24 (b) foi selecionada por ser a mais representativa do conjunto de imagens da amostra, podemos observar que as partículas são arredondadas e mais uniformes com relação à forma e distribuição de tamanho.

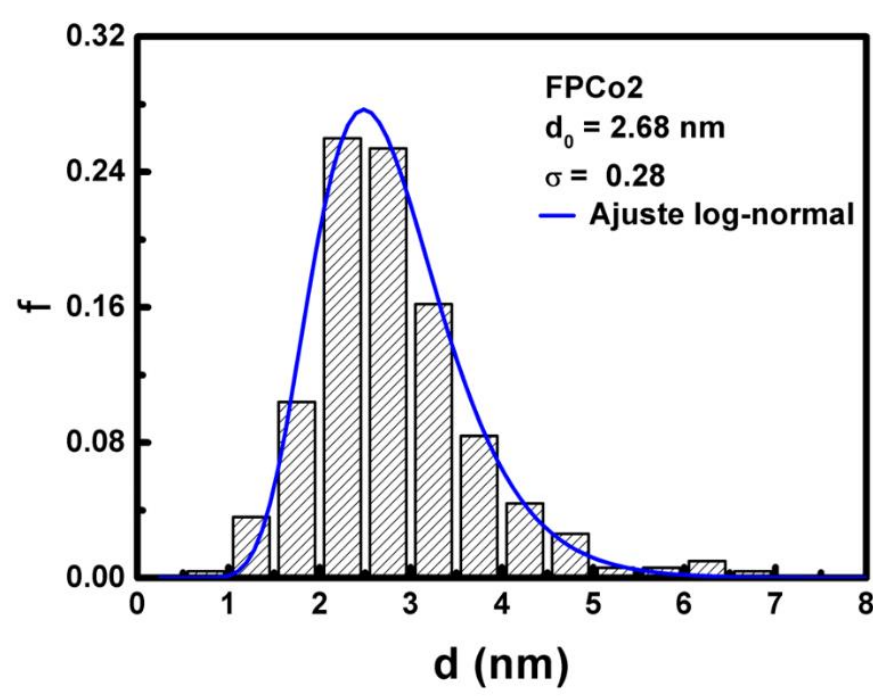

(a) Histograma da amostra FPCo2

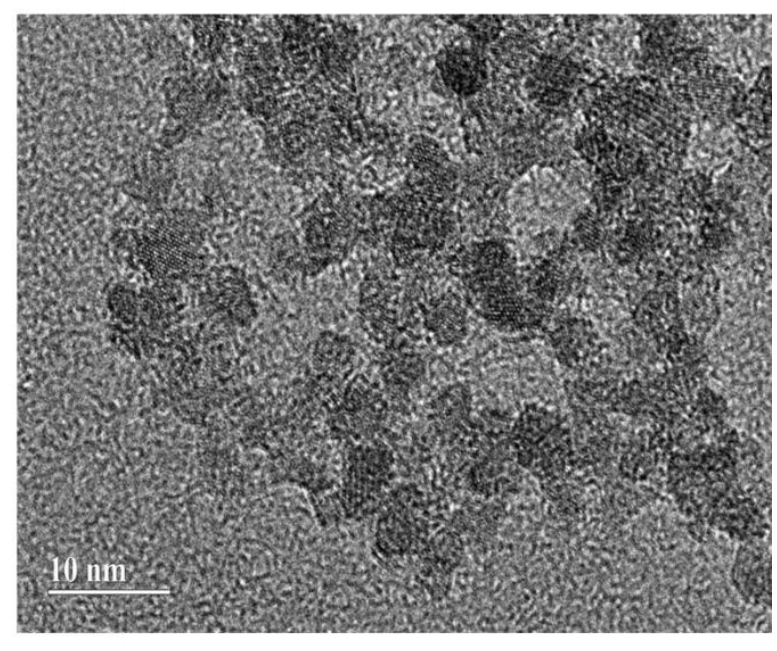

(b) MET com escala de $10 \mathrm{~nm}$

Figura 24: (a) Histograma para nanopartículas aqui investigadas e a linha de cor azul é o ajuste com a função lognormal. (b) microscopia que apresenta algumas nanopartículas que apresenta nanopartículas da ordem de $3 \mathrm{~nm}$.

Na Figura 25 (a) apresentamos uma imagem de HRTEM de uma nanopartícula selecionada do conjunto de imagens da amostra, onde a linha branca tracejada é apenas uma 
guia para os olhos. Essa imagem evidencia alta cristalinidade das NPs (monocristalinas) de onde podemos visualizar os planos atômicos que possibilitam medir a distância interplanar.

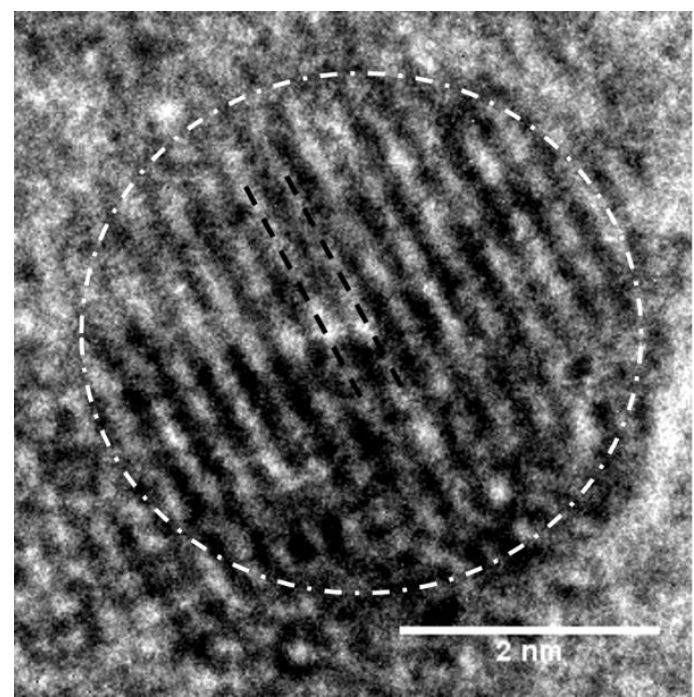

(a) HRTEM da amostra FPCo2

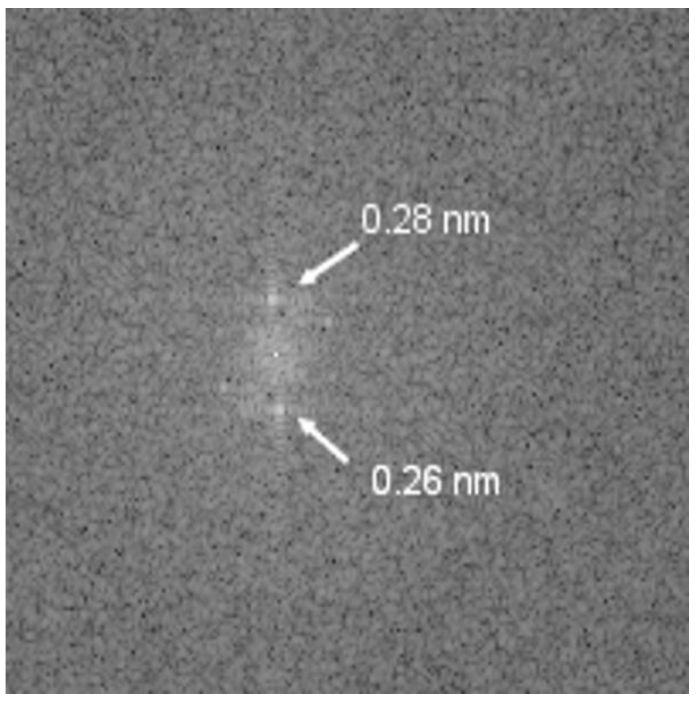

(b) FFT da imagem da esquerda

Figura 25: Microscopia Eletrônica de alta Resolução da amostra FPCo2 evidenciando uma nanopartícula. (b) Transformada Rápida de Fourier.

Encontramos um valor da ordem de 2.6 A correspondente ao índice de Miller [311] para a ferrita de cobalto, destacamos o plano atômico mais intenso [311] da ferrita de cobalto com a linha tracejada na cor preta. Em conjunto com um a Fast Forier Transform - FFT (Transformada Rápida de Fourier) exibida na Figura 25 (b) os pontos brilhantes correspondem as distâncias interplanares, o ponto $0.28 \mathrm{~nm}$ corresponde ao índice de Miller [220] e o ponto $0.26 \mathrm{~nm}$ corresponde ao índice [311]. Nossos valores encontrados estão de bom acordo com os valores da ficha cristalográfica No. 22-1086 da ICDD [220] $0.296 \mathrm{~nm}$ e para [311] $0.253 \mathrm{~nm}$.

\subsection{Métodos de investigação das propriedades magnéticas}

Um dos processos de medição magnetização são os métodos que detectam uma corrente ou tensão induzida no circuito colocado perto de um material magnético em movimento. Nesta categoria se enquadra o chamado magnetômetro de amostra vibrante (VSM) que foi utilizado na caracterização magnética. O sistema utilizado para todos os experimentos é um Physical Properties Measurements System PPMS ${ }^{\circledR}$ da Quantum desing (Sistema de Propriedades Físicas de Medida), que contém, entre outros módulos uma opção de VSM. Nesta Tese utilizamos dois equipamentos exibidos na figura 26 instalados na UPMC-Sorbonne e outro no Instituto de Física da UnB. 


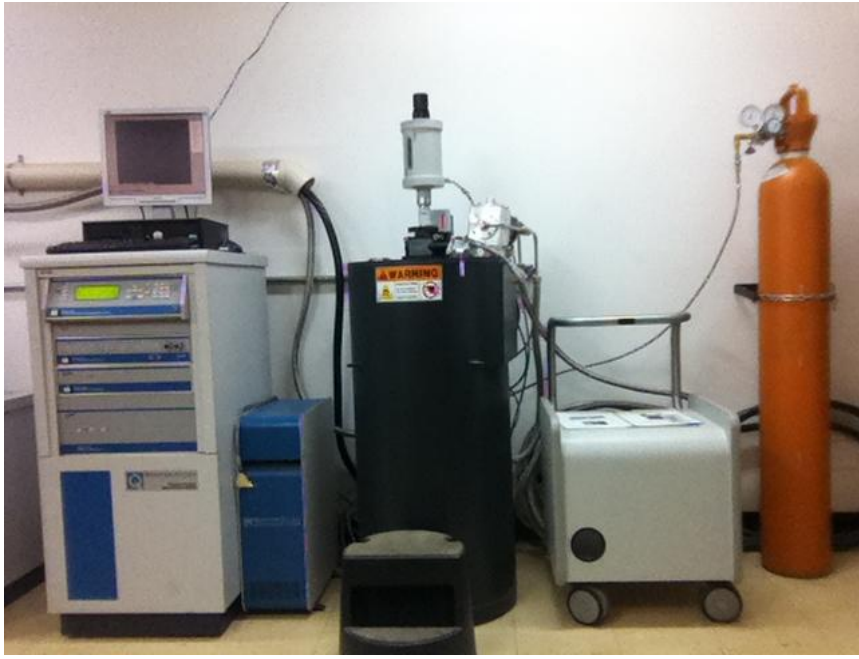

(a) PPMS do Instituto de Física UnB - Brasília

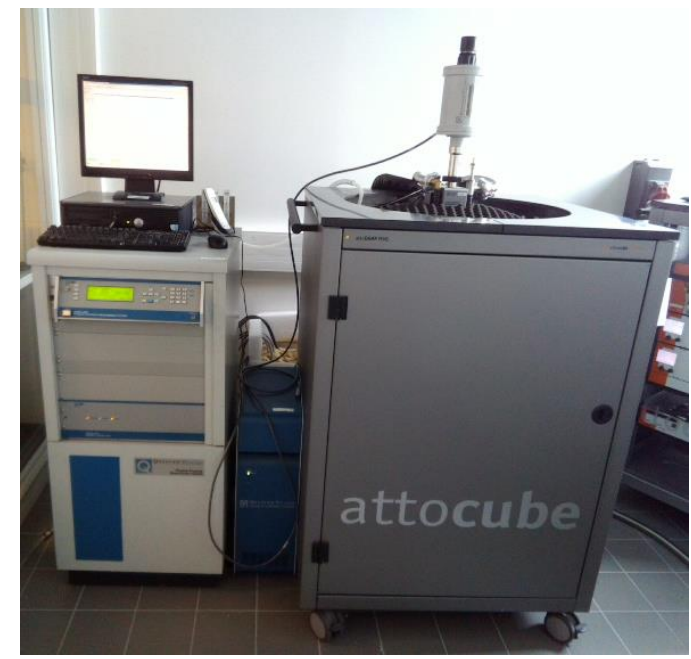

(b) PPMS da UPMC Sorbonne - Paris

Figura 26: Physical Properties Measurements System - PPMS utilizados nos experimentos desta Tese.

\subsubsection{Magnetização em temperatura ambiente}

Nesta seção discutimos as curvas de magnetização em função do campo em temperatura ambiente, para amostra de ferrofluido diluído $\operatorname{com} \phi=0.18 \%$, em regime de alto e baixo campo aplicado. A partir destas curvas podemos extrair alguns paramentos como polidispersão das nanopartículas dispersas no líquido carreador, diâmetro médio e saturação em regime de alto campo e baixo campo o paramento de interação entre as partículas.

\section{Formalismo de Langevin}

Um dos atributos dos ferrofluidos é sua resposta a aplicação de um campo magnético que o torna interessante para aplicações. As nanopartículas dispersas no líquido carreador tem a tendência de se alinhar na direção do campo aplicado. Com a mobilidade das partículas no seio do líquido o movimento browniano das partículas é decorrente do processo de colisão caótica das moléculas do solvente com as partículas. Nesses sistemas com o aumento da temperatura tende aumentar a desordem, fazendo com que os momentos magnéticos se desorganizarem, anulando-se mutuamente.

O formalismo de Langevin considera um conjunto de partículas monodomínios magnéticas, cada um com um momento magnético e anisotropia negligenciável (KNOBEL et al., 2008). O tratamento estatístico deste sistema pode seguir a mesma formulação clássica do paramagnetismo, considerando o momento magnético resultante das partículas (tipicamente de 
milhares de magnetons Bohr) "superspins". Para investigar a magnetização, consideramos aqui um modelo simplificado, válido a temperatura ambiente e dispersões diluídas de ferrofluidos em que as interações dipolares magnéticas interpartículas são desprezíveis (SHLIOMIS, 1974). A distribuição de orientação dos momentos $\vec{\mu}$ resulta da competição entre a energia térmica $k_{B} T$ e a energia magnética $E_{\text {mag }}=-\mu_{0} \vec{\mu} \vec{H}$. No caso de um sistema monodisperso, esta é dada, no equilíbrio termodinâmico, por uma distribuição de Boltzmann do tipo (ROSENSWEIG, 2013):

$$
\frac{\langle M\rangle}{M_{S}}=\frac{\int \frac{\mu_{0} \mu H}{k_{B} T} \exp \left(-\frac{\mu_{0} \mu H}{k_{B} T}\right) d \Omega}{\int \exp \left(\frac{\mu_{0} \mu H}{k_{B} T}\right) d \Omega}=L_{1}(\xi)
$$

onde $d \Omega$ é o ângulo sólido entre $\vec{\mu}$ e $\vec{H}$. Considerando que as partículas estão livres para girar mecanicamente em qualquer direção, a energia Zeeman aparece como termo dominante sobre o comportamento magnético, orientando os superspins progressivamente na direção do campo magnético aplicado. Portanto, a magnetização do fluido magnético de fração volumétrica $\phi$ é dada por:

$$
\langle M\rangle=M_{S} L_{1}(\xi)
$$

$M_{S}=m_{S} \phi$ sendo a magnetização de saturação da solução, onde $\xi=\mu_{0} \mu H / k_{B} T$ é o parâmetro de Langevin e $L_{1}(\xi)=\operatorname{coth} \xi-1 / \xi$ é a primeira função de Langevin. Assim, a magnetização depende dessa competição energética, e é retratada matematicamente pela primeira função de Langevin.

$$
L_{1}(\xi)=\operatorname{coth} \xi-1 / \xi ; \quad \xi=\mu_{0} \mu H / k_{B} T .
$$

No caso de um ferrofluido verdadeiro, deve-se introduzir uma função de distribuição de tamanhos, a magnetização da solução coloidal magnética é então a soma ponderada das diversas contribuições de cada partícula de tamanho $d$ e escreve-se:

$$
\frac{\langle M\rangle}{m_{S} \phi}=\frac{\int d^{3} L_{1}[\xi(d, \sigma)] P(d) d d}{\int d^{3} P(d) d d} .
$$

A polidispersão das partículas é melhor ajustada por uma distribuição do tipo lognormal apresentada na seção 3.1.4. A expressão que descreve o formalismo de Langevin para um sistema polidisperso de nanopartículas não interagentes tem algumas implicações nos regimes de baixo e alto campo que permitem obter informações acerca da amostra estudada. 
Para campo magnéticos fracos $\xi \ll<1$ a função de Langevin tende a $L_{1}(\xi) \approx \xi / 3$ e a equação (63) torna-se:

$$
\langle M\rangle=\underbrace{\frac{\mu_{0} m_{S}^{2} \pi}{18 k_{B} T} \frac{\left\langle d^{6}\right\rangle}{\left\langle d^{3}\right\rangle} \phi}_{\chi_{0}} H
$$

em que $\langle M\rangle=\chi_{0} H, \chi_{0}$ é a susceptibilidade magnética inicial da dispersão de nanopartículas de uma fração volumétrica $(\phi)$. Para região de campo magnético muito intenso o parâmetro de langevin é $\xi>>1$ e a função de Langevin torna-se $L_{1}(\xi) \approx \xi-1 / \xi$, aplicando essas condições na equação 63 teremos:

$$
\frac{M}{\phi}=m_{S}-\frac{6 \mu_{0} k_{B} T}{\pi\left\langle d^{3}\right\rangle} \frac{1}{H} .
$$

Encontramos a equação que descreve o comportamento em regime de alto campo da magnetização. Do gráfico $M / \phi v s 1 / H$ (na região a alto campo) observa-se uma dependência linear, que possibilita encontrar a magnetização de saturação $m_{S}$ quando $1 / H \rightarrow 0$.

A curva de magnetização à temperatura ambiente foi obtida utilizando um magnetômetro do tipo PPMS instalado na Laboratoire de Réactivité de Surface - LRS na UPMC (Paris/FR). A Figura 27 apresenta a curva de magnetização obtida na temperatura ambiente para a amostra de ferrofluido diluído após a subtração da resposta diamagnética do líquido carreador. Qualitativamente podemos ver que a magnetização é zero na ausência de um campo magnético externo, a curva é simétrica em ambas das direções do campo aplicado e uma função crescente do campo aplicado devido ao seu tamanho reduzido que tem a tendência de não saturação.

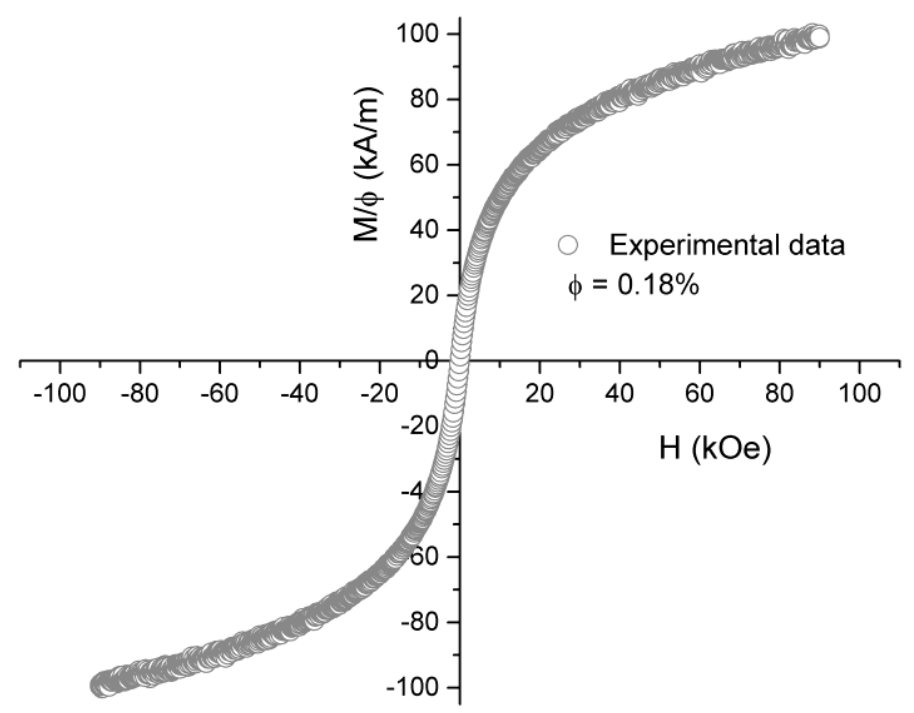

Figura 27: Curva de magnetização a temperatura ambiente com sua resposta diamagnética do solvente subtraída para amostra $\mathrm{FPCo} 2 \operatorname{com} \phi=0.18 \%$. 
A função de Langevin, equação 63, mostra que a magnetização da amostra de ferrofluido depende dos parâmetros d, $M_{S}$ e $\sigma$. A Figura 28 (a) exibe a curva experimental na escala $\log _{10^{-}}$ $\log _{10}$ e a linha sólida é o ajuste com o formalismo de Langevin, obtém-se um diâmetro médio das partículas de $3 \mathrm{~nm}$ e uma polidispersão $\sigma=0.35$. A amostra não está totalmente saturada a um campo acima de $40 \mathrm{kOe}$, assim a magnetização de saturação $m s$ é obtida da aproximação a alto campo, exibido na Figura 28 (b), então a magnetização $\mathrm{M}(\mathrm{H})$ se reduz a uma função somente dos parâmetros da distribuição em tamanho do ajuste na região de linearidade da curva mostrado pela linha sólida quando extrapolado $1 / H \rightarrow 0$, encontramos um $m s$ de $115 \mathrm{kA} / \mathrm{m}$.

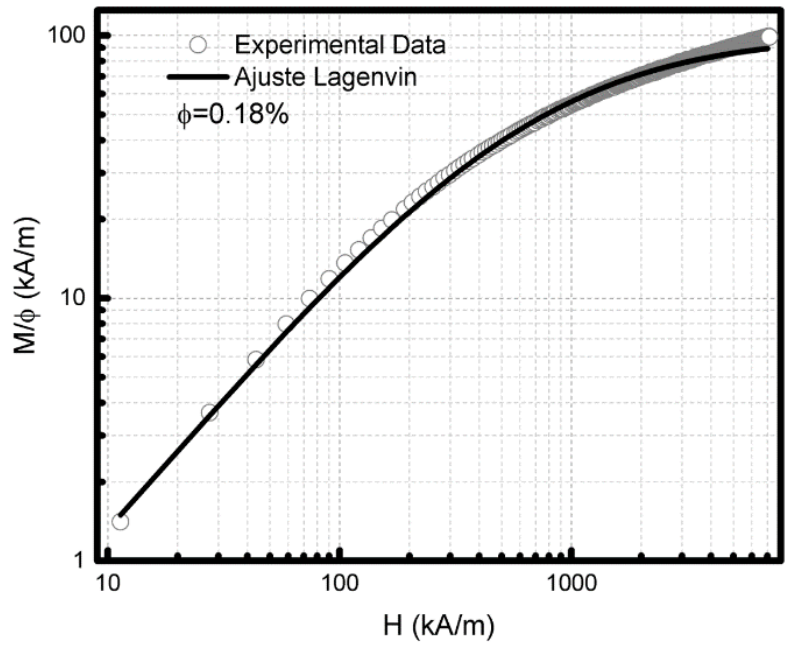

(a) curva magnetização $300 \mathrm{~K}$ em escala $\log _{10}-\log _{10}$

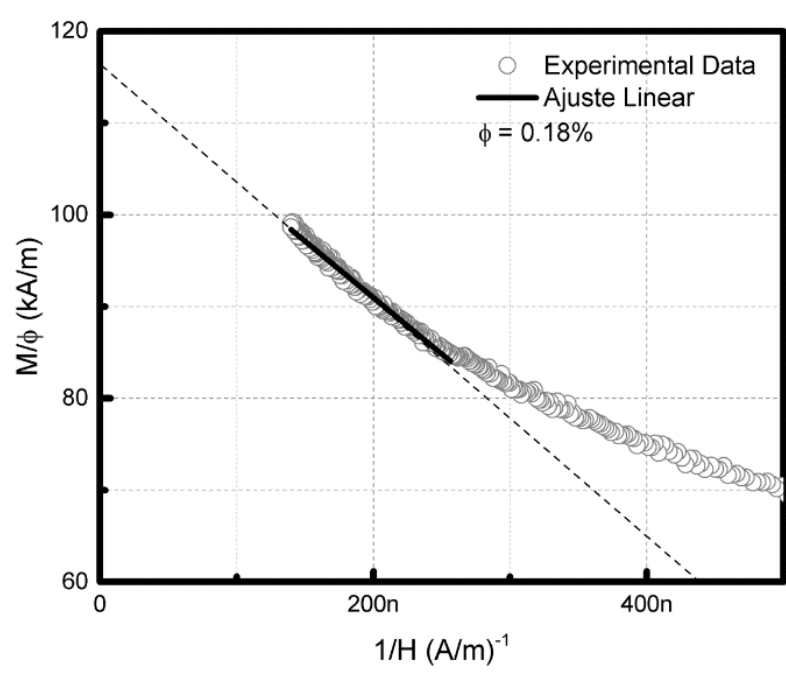

(b) determinação da magnetização de saturação

Figura 28: (a) curva de magnetização a temperatura de $300 \mathrm{~K}$ a linha sólida é o ajuste com a função de Langevin (b) determinação da magnetização de saturação.

\section{Suceptibilidade Inicial}

Para quantificar as interações dipolares magnéticas efetuamos medidas de susceptibilidade magnética a 300 K, gráfico visualizado na Figura 29, da amostra FPCo2 de ferrofluido diluído para encontrar o parâmetro de referência $\Psi_{d d}$, usando as expressões 18 e 19. O parâmetro $\Psi_{d d}$ pode ser facilmente determinado medindo-se a susceptibilidade magnética inicial $\chi_{0}$ em frações volumétricas pequenas de em uma amostra não agregada, na qual o formalismo de Langevin pode ser aplicado com $M(H)=\chi_{0} H=\frac{\phi \Psi_{d d}}{3} H$.

A Figura 29 apresenta a curva experimental de magnetização em baixo campo a $300 \mathrm{~K}$ da amostra diluída com $\phi=0.18 \%$. A magnetização $\mathrm{M}$ depende linearmente com $\mathrm{H}$ até $\mathrm{H} \sim 60$ $\mathrm{kA} / \mathrm{m}$. A susceptibilidade inicial, é então determinada a partir da inclinação da curva a baixo 
campo. O ajuste linear permite obter um valor de $\chi_{0}$ e deduzir o valor de referência $\Psi_{d d}$ a 300 K e a partir dele calcular o parâmetro de interação dipolar $\lambda$ para a amostra de ferrofluido diluído. Os valores de $\lambda$ a $5 \mathrm{~K}$ foram calculado levando em conta a variação térmica da magnetização (AQUINO et al., 2005).

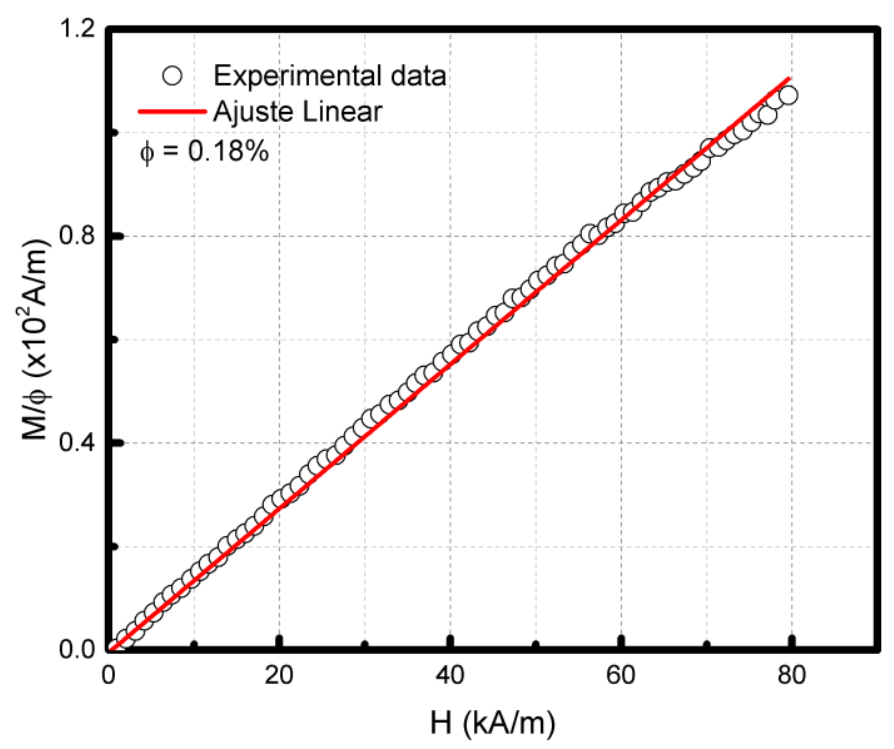

Figura 29: Medida de Susceptibilidade magnética inicial da amostra FPCo2 a $300 \mathrm{~K}$, a linha solida na cor vermelhe é o ajuste linear.

Calculamos o valor de $\lambda$ para a temperatura de $5 \mathrm{~K}$ reorganizando as equações (26) e (27) utilizamos os valores da magnetização de saturação dos ciclos a $5 \mathrm{~K}$ que iremos ver na seção 4.1 e organizamos os valores na bTabela 5. Para a amostra pó a evaporação a $60^{\circ} \mathrm{C}$ não consegue retirar toda água da amostra, restando algumas moléculas ligadas nas superfícies das partículas, diminuído a porcentagem de partículas na amostra. A título de curiosidade calculamos o valor de interação para o pó a $5 \mathrm{~K}$ considerando que $\phi$ seja $100 \%$, para compararmos com os valores encontrados para amostra de ferrofluido diluído.

bTabela 5: Parâmetros de interação dipolar a $300 \mathrm{~K}$ deduzidos da susceptibilidade magnética inicial da amostra de ferrofluido diluído. * Calculado com valores da magnetização de saturação a $5 \mathrm{~K}$.

\begin{tabular}{cccccc}
\hline Amostra & $\begin{array}{c}\phi \\
(\%)\end{array}$ & $\chi_{0}$ & $\Psi_{d d}$ & $\begin{array}{c}\lambda \\
(300 \mathrm{~K})\end{array}$ & $\begin{array}{c}\lambda^{*} \\
(5 \mathrm{~K})\end{array}$ \\
\hline \hline \multirow{2}{*}{ FPCo2 } & 0.18 & $1.394 \times 10^{-3}$ & 2.323 & $3.32 \times 10^{-4}$ & $69.54 \times 10^{-4}$ \\
& 100 & - & - & - & 2.5 \\
\hline
\end{tabular}


A bTabela 5 mostra que a interação dipolares podem ser desprezadas a $300 \mathrm{~K}$ para amostra de ferrofluido diluído, uma vez que $\lambda \ll 1$ caracteriza um regime sem interações (MÉRIGUET et al., 2012). Em $5 \mathrm{~K}$ elas possuem um papel não desprezível para amostra de ferrofluido diluído e um regime de fortes interações para amostra pó. Caracterizando as interações fracas e fortes nos regimes estudados em baixas temperaturas. 


\section{Resultados e Discussões}

Os Resultados obtidos para a amostra de ferrofluido diluído (regime de interações fracas) e do pó (interações fortes) em baixas temperaturas no trabalho é apresentado nessa seção. A discussão se inicia com as propriedades magnéticas a $5 \mathrm{~K}$, imediatamente uma análise anisotropia magnética por várias técnicas é feita em regimes de interação diferentes. Após definirmos a interface FI/SGL para as nanopartículas aqui investigadas, observamos a dinâmica do efeito de memória induzido pela casca e potencializado pelo comportamento coletivo induzindo um estado SSG. Em seguida investigamos o exchange bias induzido pela interface, quando congelado em presença de um campo magnético aplicado. Procuramos a máxima resposta do exchange bias com campo de congelamento e em seguida buscamos observar sua estabilidade. Por fim investigamos a dinâmica não linear do ciclismo imposto ao exchange bias, conhecido como efeito de treinamento e procuramos observar a dependência da temperatura e envelhecimento deste fenômeno.

\subsection{Ciclos de histerese magnética ZFC e interações interpartículas}

Utilizando o protocolo zero field cooling (ZFC) foi medido ciclo de histerese magnética a 5 K, apresentado no apêndice C.1. Foram realizadas medidas na amostra pó e ferrofluido diluído não texturizado. Ambas as amostras mostram um comportamento totalmente bloqueado, numa temperatura muito abaixo da Temperatura de Bloqueio $\left(T_{B}\right)$. O campo coercivo $\left(H_{C}\right)$ é quantificado pela expressão:

$$
H_{C}=\frac{1}{2}\left(H_{C}^{+}-H_{C}^{-}\right)
$$

$H_{C}^{+}$e $H_{C}^{-}$são os pontos onde os ramos superior e inferior do ciclo intercepta o eixo do campo magnético quando a magnetização é zero. A magnetização remanente $\left(M_{R}\right)$ é do mesmo modo quantificada de acordo com:

$$
M_{R}=\frac{1}{2}\left(M_{R}^{+}-M_{R}^{-}\right),
$$

em que $M_{R}^{+}$e $M_{R}^{-}$são, respectivamente, as magnetizações remanentes positivas e negativas dos ramos do ciclo de histerese. A Figura 30 apresenta os ciclos de histereses magnéticos em temperatura medidos em $5 \mathrm{~K}$ com protocolo $Z F C$, nota-se grande diferença entre os comportamentos magnéticos das duas amostras. Entretanto o que mais chama atenção é a não saturação magnética $\left(M_{S}\right)$ em ambas, melhor visualizado no insert (b). Este efeito é devido ao 
seu tamanho reduzido de $2.7 \mathrm{~nm}$ das NPs-CS, trabalhos anteriores mostram a não saturação magnética em nanopartículas de diâmetros similares (SILVA, 2014).

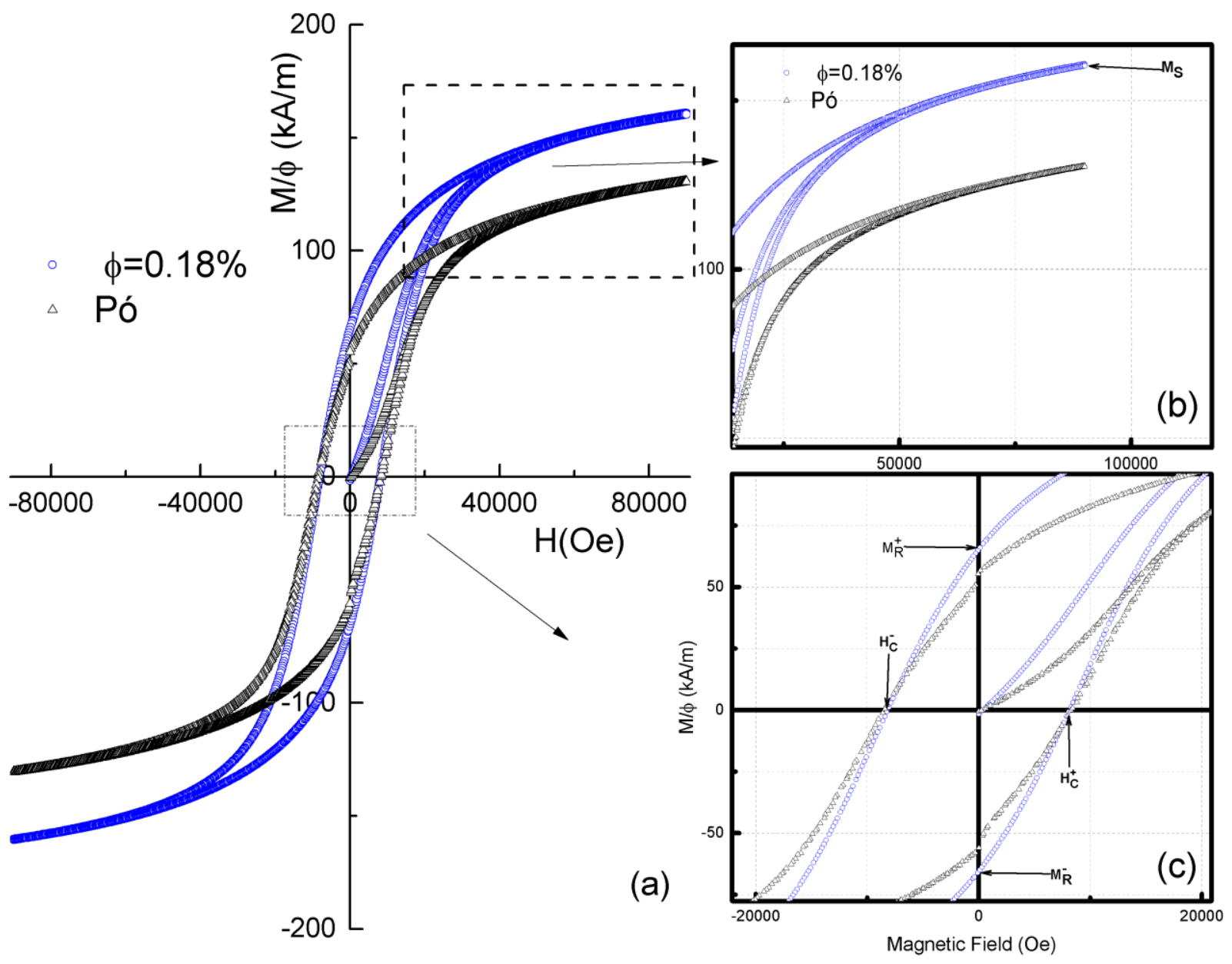

Figura 30: (a) ciclos de histereses magnéticas $(5 \mathrm{~K})$ juntamente com a curva virgem das amostras pó e ferrofluido diluído congelado. No insert (b) visualizamos a magnetização de Saturação $\left(\mathrm{M}_{\mathrm{S}}\right)$ das amostras e (c) identificamos o campo coercivo e magnetização remanente na região central dos ciclos.

O campo coercivo $\left(H_{C}\right)$ tem um acréscimo da amostra pó em comparação com o ferrofluido diluído congelado, devido as interações dipolares e dos spins de superfície em contato que aumentam a dificuldade de reduzir a zero a magnetização remanente. A magnetização remanente tem uma diminuição devido ao aumento das interações dipolares que são altamente desmagnetizantes. Os resultados extraídos estão organizados na Tabela 6.

Tabela 6: Apresenta os resultados extraídos dos ciclos de histereses magnéticas para amostras aqui investigadas para o campo coercivo, magnetização remanente, magnetização de saturação e a razão entre as duas últimas.

\begin{tabular}{ccccc}
\hline Amostra & $\begin{array}{c}\mathrm{H}_{\mathrm{C}} \\
(\mathrm{kA} / \mathrm{m})\end{array}$ & $\begin{array}{c}\mathrm{M}_{\mathrm{R}} / \phi \\
(\mathrm{kA} / \mathrm{m})\end{array}$ & $\begin{array}{c}\mathrm{M}_{\mathrm{s}}\left[\mathrm{H}_{\mathrm{MAx}}\right] / \phi \\
(\mathrm{kA} / \mathrm{m})\end{array}$ & $\mathrm{M}_{\mathrm{R}} / \mathrm{Ms}_{\mathrm{s}}$ \\
\hline \hline Ferrofluido & 648.61 & 65.38 & 160.83 & 0.406 \\
Pó & 666.12 & 51.91 & 130.59 & 0.397 \\
\hline
\end{tabular}


Um alto campo coercivo confirma a presença de um material magneticamente hard na composição das amostras e a presença de uma energia de anisotropia uniaxial distribuída randomicamente visualizado na Figura 30 (c). Podemos fazer esta análise comparando o campo coercivo encontrado para amostra de ferrofluido diluído com valor encontrado para nanopartículas de ferrita de manganês (soft) com diâmetro similar que apresentam valor 63.72 $\mathrm{kA} / \mathrm{m} \operatorname{com} \phi=0.6 \%$ (LEITE, 2011).

Em uma primeira aproximação os ciclos de histereses nos permitiram determinar a razão $\mathrm{M}_{\mathrm{r}}(5 \mathrm{~K}) / \mathrm{Ms}_{\mathrm{s}}(5 \mathrm{~K})$ para ambas as amostras, esta razão tende a 0.5 , valor esperado da literatura para o caso de partículas com anisotropia uniaxial, o valor de $m_{R}(T) / m_{S}(T)$ é sempre inferior a 0.5 , valor assintótico quanto $T \rightarrow 0$ para um conjunto desordenado de partículas magnéticas uniaxiais SW. Isto significa que a temperatura mínima $(5 \mathrm{~K})$ dos experimentos realizados não permite atingir este valor limite. Entretanto esses resultados experimentais corroboram a hipótese de uma simetria uniaxial já que no caso de nanopartículas de diâmetros similares e simetria cúbica conduziria os valores de $m_{R}(T) / m_{S}(T)$ que tenderiam a 0.8 (BACRI; PERZYNSKI; SALIN, 1988).

\section{Interações fracas e fortes}

Para observar o comportamento das interações presentes nas amostras investigadas, resolvemos utilizar a abordagem proposta por Thamm e Hesse (THAMM; HESSE, 1996, 1998). Para isso, precisamos medir apenas a curva de magnetização inicial até atingir a magnetização de saturação e um ciclo de histerese completo deve ser medido do sistema (o que já fizemos previamente). Normalmente, isso é mais fácil do que medir os desvios do método Henkel Plot (HENKEL, 1964), porque, na prática, a amostra precisa ser desmagnetizada apenas uma vez, em vez de muitas vezes como exigido no método Henkel Plot.

O ramo superior $\left(m_{\text {sup }}\right)$, o inferior $\left(m_{\text {inf }}\right)$ e a curva de primeira magnetização $\left(m_{\text {vir }}\right)$ do primeiro quadrante devem ser utilizados para a avaliação, visualizado na Figura 30 (a). Em seguida, qualquer desvio $\Delta m$, dado pela equação 23 , do comportamento SW que é obtido simplesmente através da representação gráfica $\Delta m$ versus $\mathrm{H}$. Quando $\Delta m$ é igual à zero a amostra é constituída por partículas ideais de $S W$. Por outro lado vai existir um desvio na magnetização quando a amostra possuir interações e este desvio é uma medida da intensidade das interações ou violação dos critérios para uma partícula $S W$. Apresentamos os resultados obtidos pelo método alternativo de Thamm-Hesse para as amostras de ferrofluido diluído 
representado pela linha sólida azul e pó pela linha sólida da cor preta. A linha vermelha exemplifica o caso de um sistema ideal de SW sem interações, apresentada na figura 31.

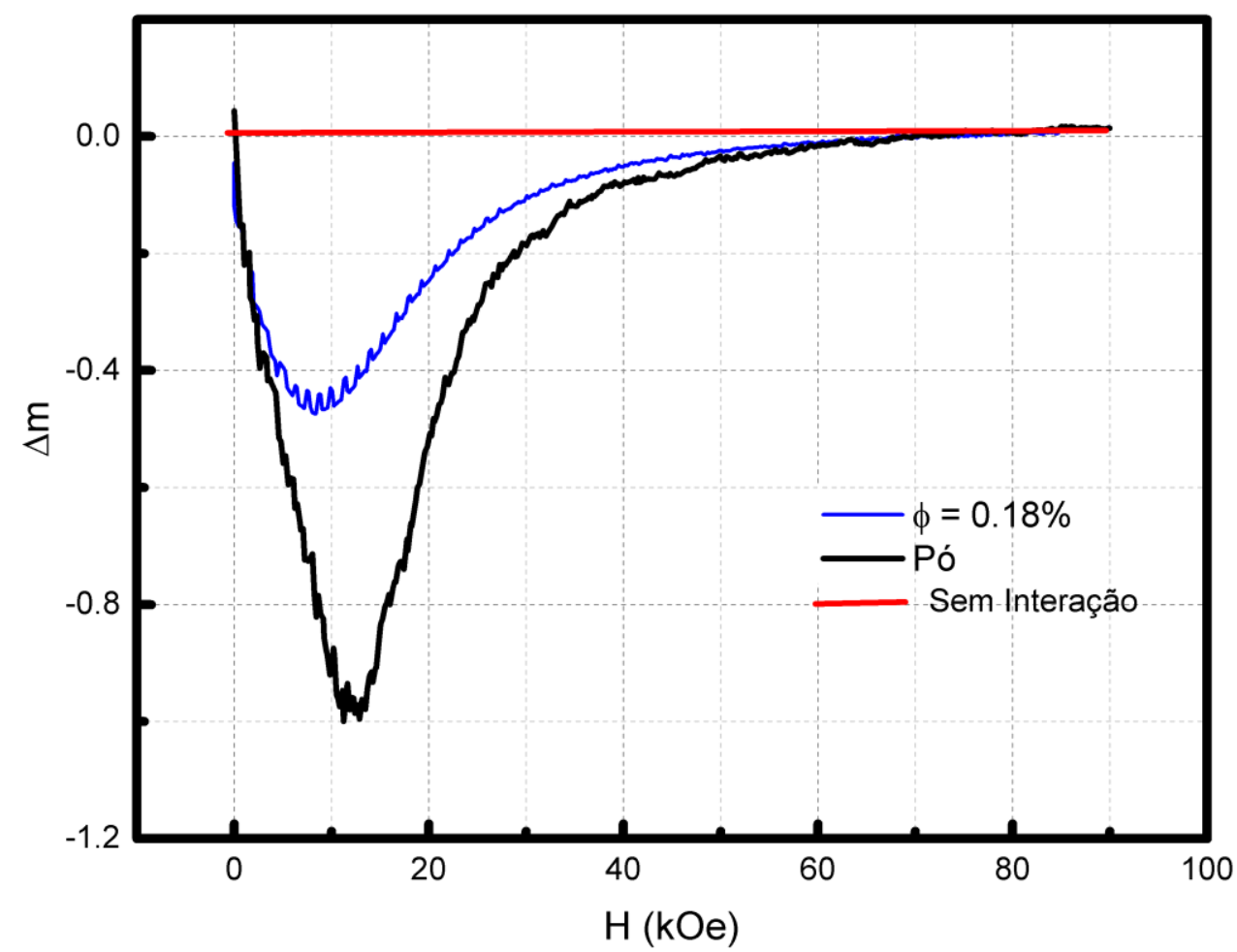

Figura 31: Funções do tipo $\Delta m$ de Thamm-Hesse para as duas amostras estudadas. Todas as curvas são negativas mostrando um regime de interações predominantemente dipolares.

As curvas de $\Delta m$ averiguam o comportamento global das interações para o pó e a amostra de ferrofluido diluído, ambas possuem um desvio negativo revelando que a interação dipolar é predominante. Para a amostra de ferrofluido diluído observamos que existe um regime de interação fraca em relação a amostra pó, que além das interações dipolares apresenta interações entre os spins de superfície. Potencializando o efeito e levando para um regime de fortes interações.

As curvas de $\Delta m$ pelo método Thamm-Hesse de nossas amostras apresentam um perfil semelhante com outras amostras estudas no GFC-UnB pelo método de Henkel Plot. Gomide et al. investiga ferritas mistas $\mathrm{MnZnFe}_{2} \mathrm{O}_{4}$ e encontram a posição do picos variando de 500 a 850 Oe com o aumento do teor de zinco, constataram que a posição do pico muda com a natureza do núcleo (GOMIDE, 2013). Vieira et al. ao investigar ferrita de cobalto com diâmetro similar ao investigado nesta Tese, da ordem de $3 \mathrm{~nm}$, encontra a posição do pico por volta de $10 \mathrm{kOe}$, visualizado na Figura 7 (d) (VIEIRA, 2013). Para nossas amostras encontramos uma posição do pico de $\sim 10 \mathrm{kOe}$ em consonância com os resultados obtidos pelo método de Henkel Plot. Também observamos uma pequena variação entre as curvas $\Delta m$ para o ferrofluido diluído e o 
pó, isto é, devido ao efeito das interações na anisotropia das partículas. Gao et al. observa que a mudança na posição do pico é devido ao aumento nas interações que gera uma alteração na anisotropia (GAO et al., 2001). O rápido retorno da curva $\Delta m$ para zero da amostra de ferrofluido nos mostra que a energia fornecida pelo campo ultrapassa rapidamente a energia dipolar quando comparamos com a amostra pó.

Devemos fazer algumas considerações sobre estas duas técnicas. No Henkel plot devese medir o $M_{R}$ para após obter a normalização, enquanto no Thamm-Hesse plot não há nenhuma necessidade para a normalização. Por conveniência, utilizamos a magnetização normalizada. Um ponto crítico em ambas as técnicas é que no Henkel e Thamm-Hesse plot o experimento deve começar com um sistema de partículas exibindo o estado de magnetização inicial zero. $\mathrm{O}$ que normalmente é muito difícil de se obter. Muitas vezes, esse estado é fornecido em uma amostra preparada na hora. Para o caso de ferrofluidos isso não se aplica, sendo ideal para tais medições (MICHELE; HESSE; BREMERS, 2006), visto que pode ser derretido ou congelado com campo magnético externo zero (ZFC) que permite atingir um estado de magnetização completamente nula.

A abordagem de Thamm-Hesse serve para uma rápida avaliação para observação das interações. Não substituindo o Henkel Plot, mas complementado a investigação das interações em sistemas nanoparticulados.

\subsection{Anisotropia magnética em regime de interações fracas e fortes}

\subsubsection{Curva de primeira magnetização}

O comportamento da curva de primeira magnetização nos fornece parâmetros importantes para avaliar as amostras investigadas. $\mathrm{O}$ formato da curva indica a estabilidade do sistema de nanopartículas com a aplicação do campo magnético. A diminuição da susceptibilidade na região de baixo campo é devido ao aumento das interações intrapartículas (FIORANI et al., 2002). O formato curvado no início da curva (forma de S) é relacionado com a fixação aleatória real dos momentos magnéticos das partículas dentro da amostra quando não texturizada. A forma de S é mais marcante com a interação das partículas, podemos observar isso na Figura 32. Isto é devido à presença de interação de curto (exchange entre os spins de superfície) e longo alcance (interação dipolar). Em baixas temperaturas os spins de superfície estão congelados diminuindo suas flutuações, contribuindo para a resposta magnética da 
partícula. Então na temperatura de $5 \mathrm{~K}$ a superfície irá contribuir para anisotropia da partícula. Apresentamos as curvas de primeira magnetização obtidas até o campo magnético aplicado de +90 kOe com temperatura de $5 \mathrm{~K}$ para as amostras de ferrofluido diluído (círculos da cor azul) e pó compacto (círculos da cor preta).

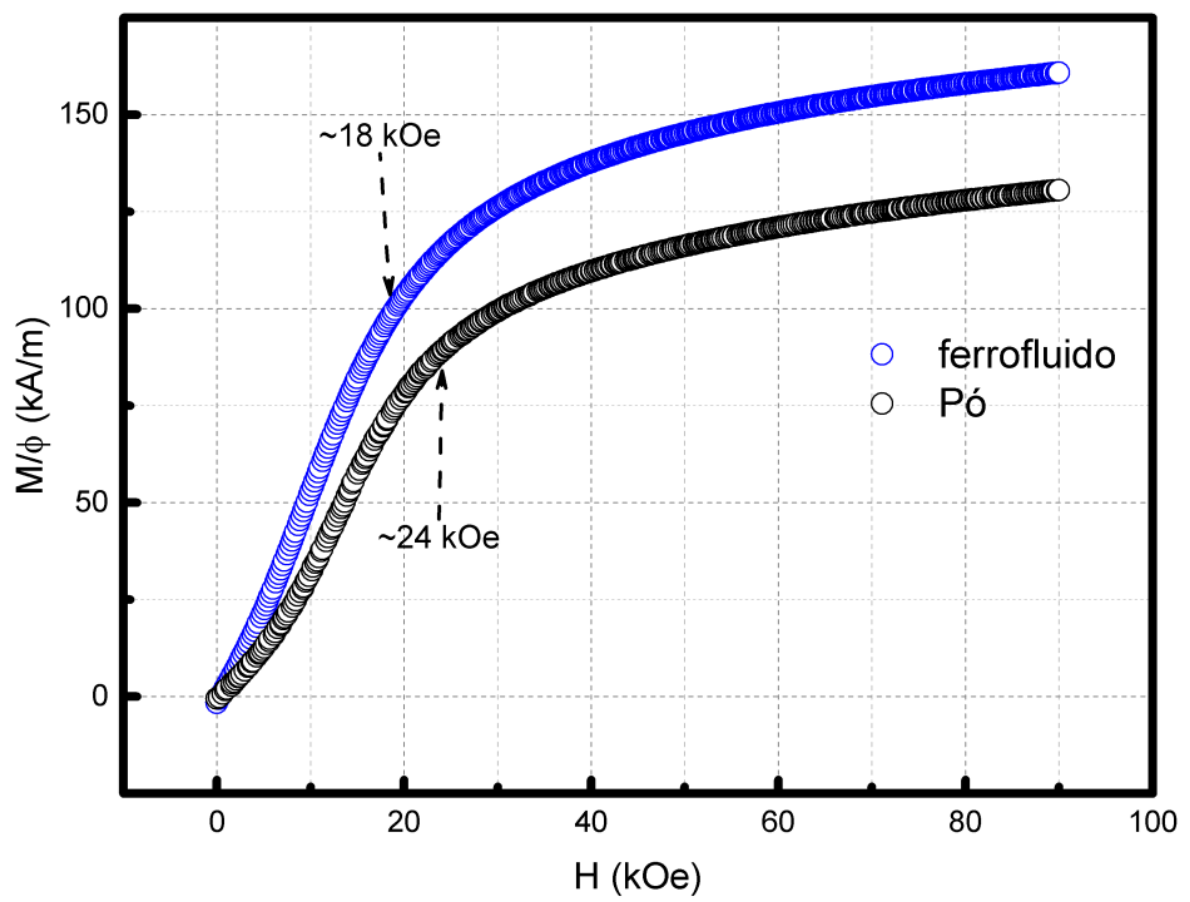

Figura 32: Curva de primeira magnetização para as amostras investigadas a $5 \mathrm{~K}$.

Analisando o regime de interações do ferrofluido diluído e pó da amostra FPCo2 observamos uma mudança da forma de S na Figura 32, mais marcante para amostra pó devido as fortes interações. Da análise da curva de primeira magnetização podemos estimar o valor da anisotropia magnética das NPs quando estas estão totalmente bloqueadas e com sua contribuição superficial, uma vez que todos os spins de superfície estão congelados. A posição do ponto de inflexão da curva nos fornece o campo de anisotropia $\left(H_{k}\right)$ da amostra (CABREIRA-GOMES et al., 2014), a figura exibe o $H_{k}$ deduzido para nossas amostras. $\mathrm{O}$ valor de $H_{k}$ para amostra ferrofluido diluído é um pouco inferior em relação ao pó. Mostrando que a anisotropia é influenciada pelas interações intrapartículas, para a ferrita de cobalto (ferrita dura) as interações não influenciam tanto a posição do ponto de inflexão da curva. Utilizamos a expressão a seguir para deduzir a energia de anisotropia para nossas amostras:

$$
H_{k}=\frac{2 K_{b}}{M_{S}},
$$


$K_{b}$ é a constante de anisotropia quando todas as partículas estão bloqueadas e $M_{S}$ magnetização de saturação. A energia de anisotropia é descrita como $E_{b}=K_{b} V$, em que $\mathrm{V}$ é o volume da partícula. Apresentamos os valores extraídos do campo de anisotropia na Tabela 7.

Tabela 7: Resultados extraídos da análise do campo de anisotropia das amostras.

\begin{tabular}{ccccc}
\hline Amostra & $\begin{array}{c}H_{k} \\
(\mathrm{kOe})\end{array}$ & $\begin{array}{c}M_{S} / \phi \\
(\mathrm{kA} / \mathrm{m})\end{array}$ & $\begin{array}{c}K_{b} \\
\left(\times 10^{5} \mathrm{~J} / \mathrm{m}^{3}\right)\end{array}$ & $\begin{array}{c}E_{b} \\
\left(\times 10^{-21} \mathrm{~J}\right)\end{array}$ \\
\hline \hline Ferrofluido & $\sim 18$ & 160.80 & 1.44 & 1.48 \\
Pó & $\sim 24$ & 130.50 & 1.56 & 1.6 \\
\hline
\end{tabular}

Os valores aproximados do campo de anisotropia corroboram com a análise da dependência do campo de cooling do exchange bias, encontramos um campo de cooling máximo $\left(H_{c o o l}^{M A X}\right)$ de para amostra pó de $12 \mathrm{kOe}$, satisfazendo a expressão $H_{\text {cool }}^{M A X} \sim H_{k} / 2$ (CABREIRA-GOMES et al., 2014) que veremos na seção 4.4.1.

No estudo da estabilidade do exchange bias, via minor loops seção 4.4.1, observamos que quando $H_{\max }$ é inferior ao campo de anisotropia o sistema não atinge a saturação magnética (o ciclo não fecha na extremidade superior) como podemos observar na Figura 42. Acima de $H_{k}$ os ramos ascendente e descendente dos ciclos de histereses coincidem podendo ser considerada efetivamente saturada. Esses resultados corroboram a análise do campo de anisotropia feita aqui.

\subsubsection{Dependência térmica do campo coercivo}

Realizamos o estudo da dependência térmica do campo coercivo $\left(H_{c}\right)$ para nossas amostras. Estudos anteriores em NPs-CS de ferrita de Manganês (LEITE, 2011) e de Cobalto (GOMES, 2015) com diâmetros médio de $3 \mathrm{~nm}$, mostram que a dependência térmica linear de $\mathrm{H}_{\mathrm{C}}$ finda por volta de $25 \mathrm{~K}$ para amostras de ferrofluido com $\phi \sim 0.6 \%$. Em vista disso medimos ciclos de histereses magnéticas com o protocolo ZFC, exibido no apêndice C.1, num intervalo de temperatura $2 \mathrm{~K}$ até $15 \mathrm{~K}$ para o pó compactado e de $5 \mathrm{~K}$ até $25 \mathrm{~K}$ para o ferrofluido diluído, na região de linearidade. A Figura 33 apresenta os ciclos medidos normalizados da amostra de ferrofluido diluído para determinadas temperaturas. 

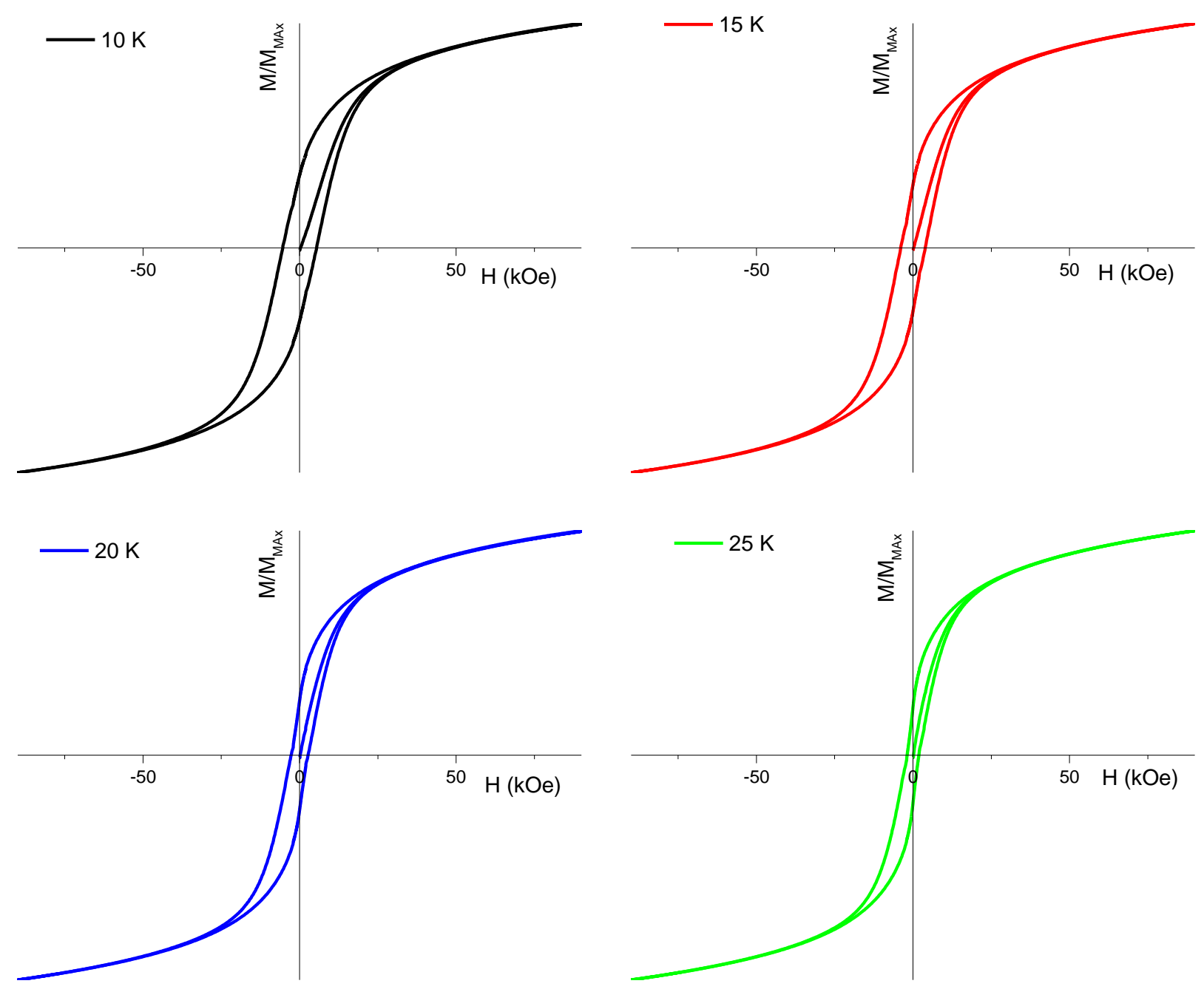

Figura 33: Ciclos de histerese magnética para amostra de ferrofluido diluído com $\phi=0.18 \%$, observamos uma contração dos ciclos com o aumento da temperatura.

A curva a $25 \mathrm{~K}$ apresenta uma grande diminuição do campo coercivo em relação à curva medida em 5 K (ver Figura 30 (a)). Consideramos que as NPs-CS possuem anisotropia uniaxial confirmado por $M_{R} / M_{S}$ (Tabela 6), volume (V), distribuição randômica de eixos fáceis e um processo de inversão coerentes dos momentos magnéticos das NPs-CS. Assim a dependência térmica reescrita em função da Temperatura de Bloqueio intrínseca e expressa pela Lei de Kneller (KNELLER; LUBORSKY, 1963):

$$
H_{C}=H_{C}(0)\left[1-\left(\frac{T}{T_{B i}}\right)^{1 / 2}\right] .
$$


Cabe ressaltar que o regime de validade da aplicação desta equação limita-se a região de baixas temperaturas onde o sistema está totalmente bloqueado (KNOBEL et al., 2008). $T_{B i}$ é definido como temperatura de bloqueio intrínseca, $H_{C}(0)$ é o campo coercivo intrínseco da partícula quando $T$ tende a zero e definido como campo de anisotropia.

Assim o comportamento das propriedades de histerese é dominado pela grande população de NPs-CS cujos momentos estão bloqueados ao longo do eixo de fácil magnetização. Para $T \approx E_{a} / 25 k_{B}$ o campo coercivo aproxima-se de zero, devido à relaxação superparamagnética dos momentos.

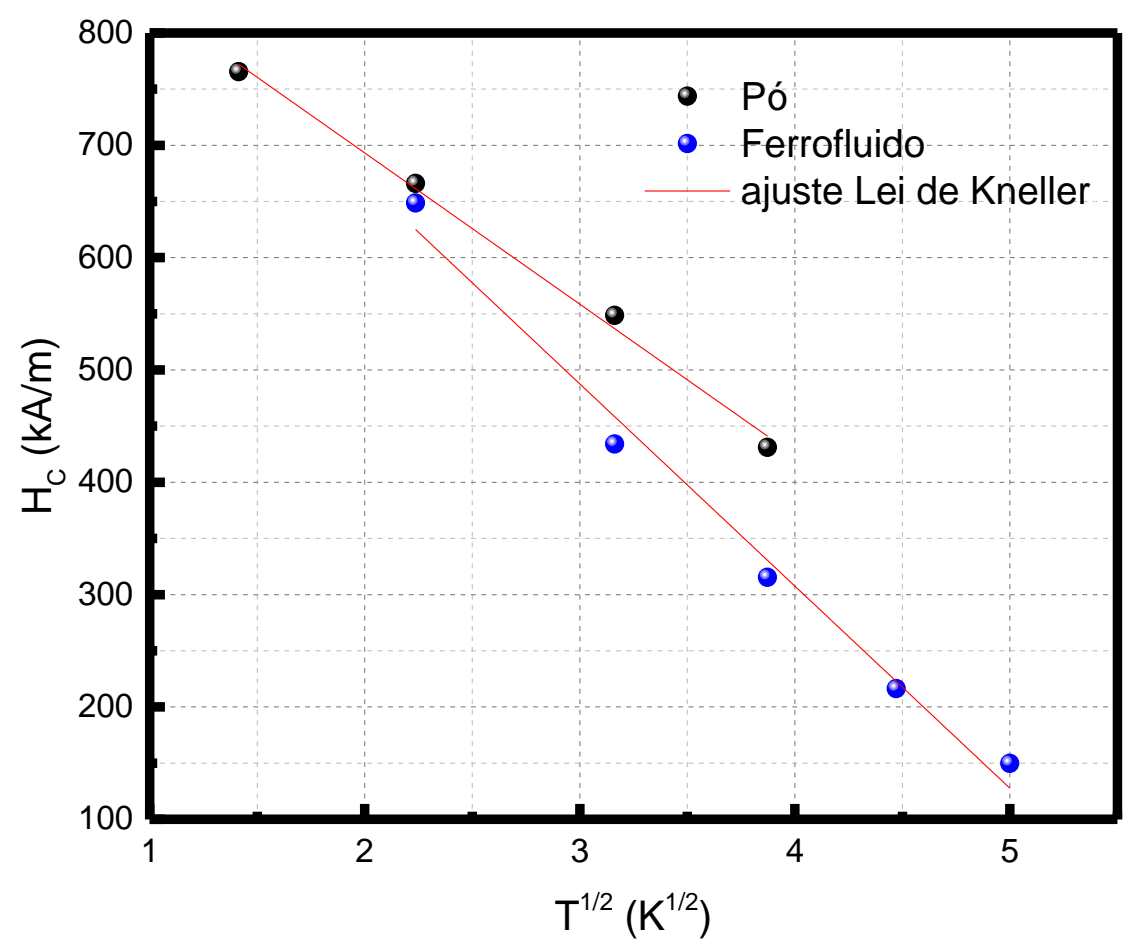

Figura 34: Dependência térmica do campo coercivo para as amostras de ferrofluido diluído e pó compacto, a linha solida é o ajuste linear com a Lei de Kneller.

Das histereses magnéticas medidas em várias temperaturas, foram extraídos os valores de $H_{C}$ para construção das curvas apresentadas na Figura 34, possibilitando determinar o valor de $T_{B i}$ e $H_{C}(0)$ a partir do ajuste da curva $H_{C}$ versus $T$. Na região de baixa temperatura as duas amostras apresentam um comportamento linear com $T$, podendo ser ajustadas com a Lei de Kneller. Observa-se que o valor do campo coercivo é maior para temperaturas menores, este resultado está ligado a uma contribuição de superfície para a barreira de anisotropia. A Tabela 8 apresenta os resultados extraídos do ajuste para ambas amostras. 
Tabela 8: Resultados do ajuste proposto aos dados extraídos dos ciclos de histerese. Os valores das colunas representam o campo coercivo quando $\mathrm{T} \rightarrow 0 \mathrm{~K}$, a temperatura de bloqueio Intrínseca $T_{B i}$, a Energia de anisotropia $E_{a i}$ e o valor da constante de anisotropia cristalina $K_{i}$.

\begin{tabular}{ccccc}
\hline Amostra & $\begin{array}{c}H_{C}(0) \\
(\mathrm{kA} / \mathrm{m})\end{array}$ & $\begin{array}{c}T_{B i} \\
(\mathrm{~K})\end{array}$ & $\begin{array}{c}E_{a i} \\
\left(\times 10^{-20} \mathrm{~J}\right)\end{array}$ & $\begin{array}{c}K_{i} \\
\left(\times 10^{5} \mathrm{~J} / \mathrm{m}^{3}\right)\end{array}$ \\
\hline \hline Ferrofluido & 1027.57 & 32.57 & 1.12 & 10.87 \\
Pó & 962.51 & 51.09 & 1.76 & 17.08 \\
\hline
\end{tabular}

Do ajuste linear das curvas apresentadas na Figura 34 obtivemos o valor da Temperatura de Bloqueio Intrínseca das partículas $T_{B i}$. Assim considerando $E_{a i}=K_{i} V$, determinamos o valor das constantes de anisotropia a partir da dependência térmica do campo coercivo.

\subsubsection{Magnetização versus temperatura em curvas ZFC-FCW}

Utilizamos o protocolo de medida exposto no apêndice C.1 para medir as curvas Zero Field Cooling (ZFC) e Field Cooling Warming (FCW) com um campo aplicado de 50 Oe. Nesses experimentos, a separação entre as curvas ZFC e FCW em uma dada temperatura, juntamente com um pico na curva ZFC (normalmente definida como temperatura de bloqueio $\left(T_{B}\right)$ ) são a assinatura da anisotropia magnética das partículas. Este pico corresponde à transição de um estado bloqueado para estado superparamagnético. Essas medidas são amplamente utilizadas, pois fornecem informações sobre a energia anisotropia magnética de nanopartículas. Podemos distinguir três temperaturas características, a temperatura de bloqueio $T_{B}^{M A X}$ no ponto máximo da curva $\mathrm{ZFC}$, este pico esquematicamente corresponde à transição de um estado bloqueado para estado superparamagnético. A temperatura de irreversibilidade $\mathrm{T}_{\text {irr }}$ que é a temperatura onde a curva de magnetização MzFC afasta-se da curva $M_{F C w}$. O pico da curva $-d\left(M_{F C W}-M_{Z F C}\right) / d T$ versus $T$ que pode estimar a distribuição de temperaturas de bloqueio $f\left(T_{B}\right)$ (NUNES et al., 2005; KNOBEL et al., 2008). A Temperatura de Bloqueio Média $\left\langle T_{B}\right\rangle$ corresponde à mudança mais rápida na separação de ZFC a partir da curva $F C W$, que, por sua vez, está relacionado com o número máximo de nanopartículas que desbloqueiam no momento em que a temperatura aumenta e é uma assinatura da anisotropia magnética das partícula (DENARDIN et al., 2002; CHANDRA et al., 2012). A Figura 35 apresenta os resultados das medidas usando o protocolo ZFC-FCW ambas as curvas foram normalizadas pelo valor das curvas FCW a $5 \mathrm{~K}$. 

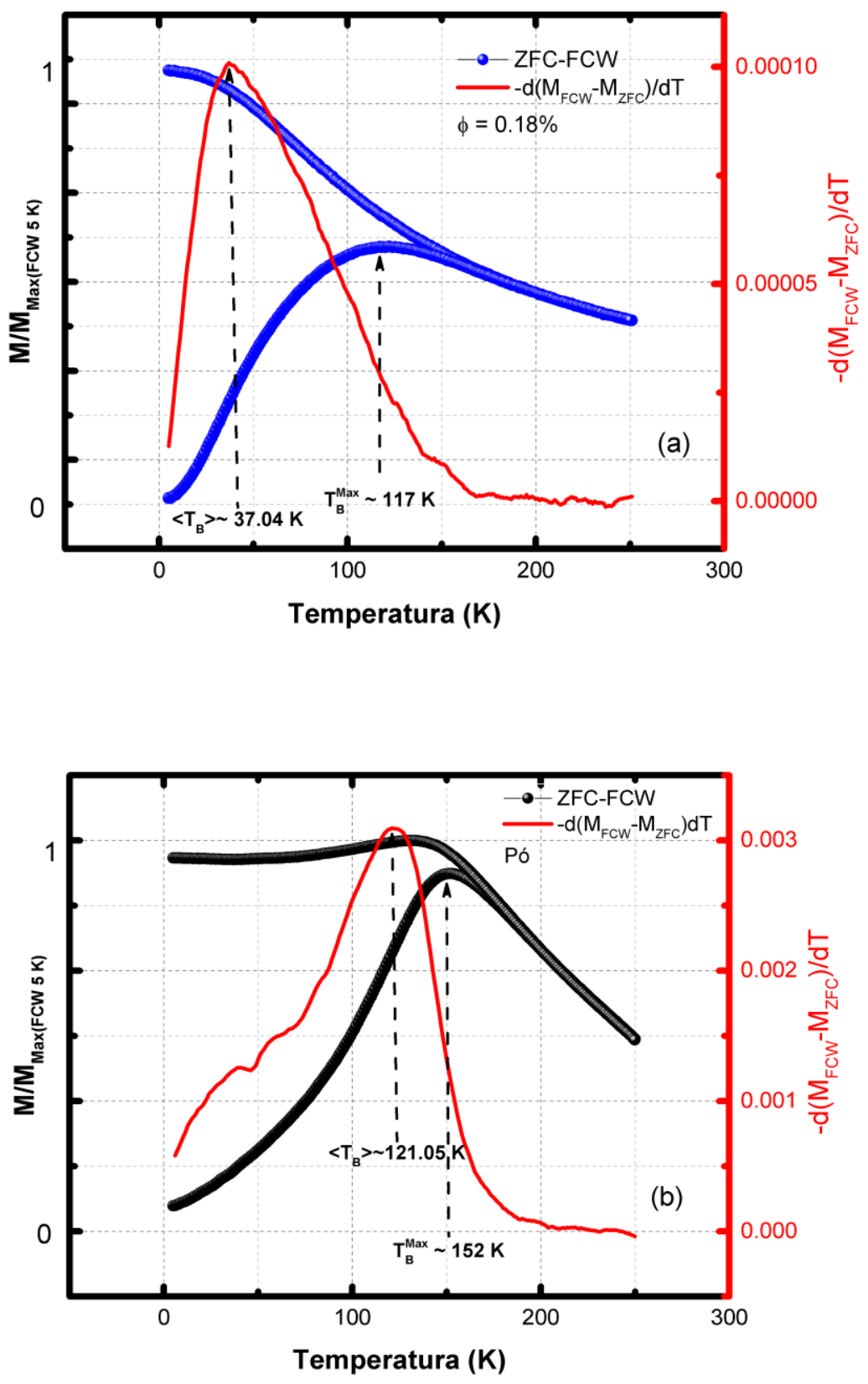

Figura 35: Resultados dos experimentos usando o protocolo ZFC-FCW para as amostras (a) ferrofluido diluído congelado e (b) pó investigadas, a curva sólida vermelha é a $-d\left(M_{F C W}-M_{Z F C}\right) / d T$ versus $T$.

No caso das nanopartículas com distribuição de tamanhos, existe sempre um efeito precursor associado com a desobstrução das partículas menores em temperaturas inferiores a Temperatura de Bloqueio da partícula $T_{B}^{M A x}$. Além disso, a presença de interações interpartículas e a formação de aglomerados deslocam $T_{B}^{M A X}$ a uma temperatura mais elevada, o que é observado em amostras concentradas/pó. A Tabela 9 apresenta os resultados extraídos da análise das curvas ZFC-FCW das amostras. Ambas amostras exibem uma diferença entre as duas análises. 
Tabela 9: Os resultados extraídos da análise da curva ZFC-FCW, via $T_{B}^{M A X}$

\begin{tabular}{cccccc}
\hline Amostra & $\begin{array}{c}\phi \\
(\%)\end{array}$ & $\begin{array}{c}T_{B}^{M A X} \\
(\mathrm{~K})\end{array}$ & $\begin{array}{c}\mathrm{T}_{\text {irr }} \\
(\mathrm{K})\end{array}$ & $\begin{array}{c}\mathrm{E}_{a} \\
\left(\times 10^{-20} \mathrm{~J}\right)\end{array}$ & $\begin{array}{c}\mathrm{K} \\
\left(\times 10^{5} \mathrm{~J} / \mathrm{m}^{3}\right)\end{array}$ \\
\hline \hline Ferrofluido & 0.18 & 117 & 139.96 & 4.04 & 39.22 \\
Pó & 100 & 152 & 197 & 5.24 & 50.87 \\
\hline
\end{tabular}

Note-se que as curvas ZFC-FCW bifurcam a uma temperatura ( $\left.\mathrm{T}_{\text {irr }}\right)$ muito próxima da posição do pico para ambas as amostras, este comportamento é devido a uma distribuição estreita de temperaturas de bloqueio, e, imediatamente, de tamanhos das nanopartículas (CHANDRA et al., 2012). Observamos que existe uma diferença no comportamento entre as medidas MzFC e $M_{F C W}$, na curva $M_{F C W}$ é observado um acréscimo da magnetização na região de baixas temperaturas para amostra de ferrofluido diluído, enquanto para a amostra de pó existe um platô de magnetização que é um comportamento típico de estruturas SSG, devido ao comportamento coletivo dos núcleos, uma vez que nessa temperatura os spins da superfície estão flutuando, mostrando que as interações dipolares interpartículas desempenham papel importante no comportamento magnético global das amostras (FIORANI; PEDDIS, 2014).

Para amostra de ferrofluido diluído visualizado na Figura 35 (a) a interação dipolar interpartículas é fraca, o que proporciona um acréscimo do direcionamento dos momentos magnéticos das NPs-CS com a ação do campo magnético externo aplicado, enquanto a temperatura diminui. Esse comportamento na curva de magnetização $M_{F C W}$ é relacionado com o número máximo de nanopartículas que desbloqueiam quando a temperatura aumenta (CHANDRA et al., 2012). Para a amostra em pó, Figura 35 (b), as nanopartículas maiores bloqueadas magneticamente criam um campo dipolar magnético efetivo, que auxilia na indução de outras partículas e disfarçando os efeitos das NPs-CS menores, surgindo o platô de magnetização na curva $M_{F C W}$.

Foi obtido $\left\langle T_{B}\right\rangle$ pelo máximo da $-d\left(M_{F C W}-M_{Z F C}\right) / d T$ versus $\mathrm{T}$ para ambas as amostras e apresentadas na Figura 35 pela linha sólida de cor vermelha que possibilitou deduzir os valores da energia de anisotropia e constante de anisotropia reunidos na Tabela 10

Tabela 10: Resultados extraídos da análise do pico $-d\left(M_{F C W}-M_{Z F C}\right) / d T$ versus $\mathrm{T}$ das curvas ZFC-FCW.

\begin{tabular}{cccc}
\hline Amostra & $\begin{array}{c}\left\langle T_{B}\right\rangle \\
(\mathrm{K})\end{array}$ & $\begin{array}{c}\mathrm{E}_{\mathrm{ai}} \\
\left(\times 10^{-20} \mathrm{~J}\right)\end{array}$ & $\begin{array}{c}\mathrm{K}_{e f} \\
\left(\times 10^{5} \mathrm{~J} / \mathrm{m}^{3}\right)\end{array}$ \\
\hline \hline Ferrofluido & 37.04 & 1.27 & 12.32 \\
Pó & 121.05 & 4.17 & 39.99 \\
\hline
\end{tabular}


No que diz respeito a análise da temperatura de bloqueio existe uma discrepância dos valores aqui encontrados, já relatadas anteriormente para a conjunto aleatório da nanopartículas sem interação (GITTLEMAN; ABELES; BOZOWSKI, 1974; MØRUP et al., 1995; ZYSLER et al., 2005; PEDDIS et al., 2008).

$$
T_{B}^{M A X}=\beta\left\langle T_{B}\right\rangle \cdot
$$

Estudo com ferritas de cobalto via Espectroscopia Mössbauer e de magnetização possuem significativamente diferentes escalas de tempo de medida e por isso as temperaturas bloqueio estimadas pelas duas técnicas são consideravelmente diferentes (PEDDIS et al., 2008). Nele, por exemplo, verifica-se que a proporção entre as duas temperaturas $T_{B}^{\text {Moss }} / T_{B}^{m}\left(T_{B}^{\text {Moss }}\right.$ temperatura de bloqueio deduzida por Espectroscopia Mössbauer e $T_{B}^{m}$ temperatura de bloqueio via curva termoremanente TRM) deve estar entre $3-7$. Considerando o valor de $T_{B}^{M A X}$ em experimentos de magnetização ZFC e $T_{B}^{m}$ a proporção entre as duas temperaturas varia de 1.5 - 2.5. A proporção entre $T_{B}^{\text {Moss }} / T_{B}^{\text {MAX }}$ varia de $2-7$ (MØRUP et al., 1995; CANNAS et al., 2006).

Encontramos uma discrepância de valores para a temperatura de bloqueio pelos três métodos. Para amostra de ferrofluido encontramos valores de $\left\langle T_{B}\right\rangle$ de $37 \mathrm{~K}$, da dependência do campo coercivo com a temperatura de bloqueio $T_{B i}$ de $32.5 \mathrm{~K}$ e comparamos ambas com a $T_{B}^{M A X}$ de $117 \mathrm{~K}$ (via ZFC). Substituímos estes valores na equação 70 entramos um $\beta$ de 3.16 quando comparamos as duas analises relacionadas com a curva ZFC-FC, $T_{B}^{M A X} /\left\langle T_{B}\right\rangle$. No momento em que comparamos as análises do Hc versus $T$ com o máximo da curva ZFC calculamos um valor de $\beta$ de 3.6, $T_{B}^{M A X} / T_{B i}$. Encontramos valores razoáveis entre as análises feitas quando comparando com os valores encontrados em outras técnicas. Para amostra pó encontramos um $T_{B}^{M A X}$ de $152 \mathrm{~K}$, um $\left\langle T_{B}\right\rangle$ de $121 \mathrm{~K}$ e $T_{B i}$ de $51 \mathrm{~K}$, pela proporção entre $T_{B}^{M A X} /\left\langle T_{B}\right\rangle$ achamos um $\beta$ de 1.25 e para $T_{B}^{M A X} / T_{B i}$ calculamos um valor de 2.98 valores muito diferentes.

Não é fácil de distinguir entre o superparamagnetismo e o estado de spin-glass em sistemas com interações. Mørup, S. et al. (MØRUP et al., 1995) mostram que existe uma diminuição nas relações $T_{B}^{M O s s} / T_{B}^{m}$ e $T_{B}^{\text {MOss }} / T_{B}^{M A X}$ com o aumento das interações. Observam isso pela a temperatura de bloqueio deduzida via espectroscopia Mössbauer e por medição da magnetização ao encontrar valores quase idênticos, uma transição de estado superparamagnético a um estado semelhante ao estado spin-glass-like é fortemente sugerido. Os valores de $\beta$ encontrados para amostra pó nos indica que pode existir um estado de spins glass em temperatura abaixo de transição vítrea $\left(T_{g}\right)$ que merece uma investigação mais detalhada para confirmar esse efeito. 


\section{Considerações sobre anisotropia magnética investigada}

Investigamos a energia de anisotropia dessas nanopartículas por medidas de magnetometria em baixas temperaturas em dois regimes de interação. Quatro análises distintas foram feitas anteriormente e reunimos todos os valores da energia de anisotropia, constante de anisotropia efetiva e temperatura de bloqueio deduzidas na Tabela 11.

Do campo de anisotropia $\left(H_{k}\right)$, extraído da curva de primeira magnetização, podemos estimar o valor da anisotropia das nanopartículas em regimes de interação diferentes. Os valores a $5 \mathrm{~K}$ nos indica que a anisotropia nos dois regimes possui um aumento diminuto em relação as interações, isso é atribuído a dureza magnética da ferrita de cobalto em temperaturas extremamente baixas, nesta temperatura todos os spins de superfície contribuem para anisotropia, uma vez que estão todos congelados.

Tabela 11: Análise da anisotropia magnética deduzida via: campo de anisotropia $5 \mathrm{~K}\left(H_{k}\right)$, dependência térmica do campo coercivo $\left(H_{C} v s T\right)$, pico da derivada da diferença das curvas FCW-ZFC $\left(-d\left(M_{F C W}-M_{Z F C}\right) / d T\right.$ vs $\left.T\right)$ e máximo da curva ZFC $\left(T_{B}^{M A X}\right)$.

\begin{tabular}{lccccccccccc}
\hline \multirow{2}{*}{ Amostra } & $\begin{array}{c}E_{b} \\
\times 10^{-20} \mathrm{~J}\end{array}$ & $\begin{array}{c}K_{b} \\
\times 10^{5} \mathrm{~J} / \mathrm{m}^{3}\end{array}$ & $\begin{array}{c}T_{B i} \\
\mathrm{~K}\end{array}$ & $\begin{array}{c}E_{a i} \\
\times 10^{-20} \mathrm{~J}\end{array}$ & $\begin{array}{c}K_{i} \\
\times 10^{5} \mathrm{~J} / \mathrm{m}^{3}\end{array}$ & $\begin{array}{c}\left\langle T_{B}\right\rangle \\
\mathrm{K}\end{array}$ & $\begin{array}{c}\mathrm{E}_{\mathrm{a}} \\
\times 10^{-20} \mathrm{~J}\end{array}$ & $\begin{array}{c}\mathrm{K}_{e f} \\
\times 10^{5} \mathrm{~J} / \mathrm{m}^{3}\end{array}$ & $\begin{array}{c}T_{B}^{M A X} \\
\mathrm{~K}\end{array}$ & $\begin{array}{c}\mathrm{E}_{\mathrm{d}} \\
\times 10^{-20} \mathrm{~J}\end{array}$ & $\begin{array}{c}\mathrm{K}_{\mathrm{d}} \\
\times 10^{5} \mathrm{~J} / \mathrm{m}^{3}\end{array}$ \\
\hline & \multicolumn{2}{c}{$H_{k}$} & & $H_{C} v s T$ & & $-d\left(M_{F C W}-M_{\text {ZFC }}\right) / d T$ vs $T$ & & $\mathrm{ZFC}$ \\
\hline Ferrofluido & 0.148 & 1.44 & 32.57 & 1.12 & 10.87 & 37.04 & 1.27 & 12.32 & 117 & 4.04 & 39.22 \\
Pó & 0.16 & 1.56 & 51.09 & 1.76 & 17.08 & 121.05 & 4.17 & 39.99 & 152 & 5.24 & 50.87 \\
\hline
\end{tabular}

Observando a dependência térmica do campo coercivo na amostra de ferrofluido diluído e pó encontramos valores uma ordem de grandeza maior em relação a $H_{k}$, de fato esse comportamento é devido ao aumento da energia térmica do sistema que leva ao descongelamento dos spins de superfície e desbloqueio das nanopartículas menores. Comparando esses valores da dependência térmica de $\mathrm{H}_{\mathrm{C}}$ com os encontrados a partir do pico da derivada $-d\left(M_{F C W}-M_{Z F C}\right) / d T$ versus $T$, constatamos que as duas analises distintas encontram valores semelhantes da temperatura de bloqueio $T_{B}$ para amostra de ferrofluido diluído. Essas análises reforçam os resultados observados da dependência do exchange bias com a temperatura, que por volta de $30 \mathrm{~K}$ os valores encontrados são irrisórios.

Para o pó da amostra FPCo2 encontramos temperaturas de bloqueio bem distintas, isto se deve a influência do campo aplicado nas interações, com campo aplicados maiores conseguese desbloquear mais partículas em temperaturas menores, como observamos na Tabela 11 . Na dependência do campo coercivo é aplicado campos relativamente grandes para obter o ciclo de 
histerese, aqui usamos campos de $\pm 90 \mathrm{kOe}$, é de se supor que conseguimos vencer as interações com esse campo aplicado. Na análise do pico da derivada $-d\left(M_{F C W}-M_{Z F C}\right) / d T$ versus $T$, um campo relativamente pequeno aplicado na curva $\mathrm{FCW}, 50 \mathrm{Oe}$, auxilia a energia térmica a desbloquear as nanopartículas. Como efeito disso, uma temperatura um pouco menor que a obtida pela curva ZFC é encontrado. Apoiando essa afirmação os resultados da curva ZFC nos manifesta valores altos, na presença de um pequeno campo de prova aplicado, uma vez que existe o aumento da energia do sistema via temperatura. Assim as nanopartículas irão começar a desbloquear tardiamente e entram em estado superparamagnético em temperaturas elevadas.

\subsection{Desordem magnética em sistemas de NPs-CS com interações fracas e fortes.}

\subsubsection{Dependência térmica da magnetização em alto campo}

Utilizamos o protocolo de medida exposto no apêndice C.1 para investigar a influência da camada superficial SGL nas propriedades magnéticas das nanopartículas aqui estudadas. Escolhemos a amostra de ferrofluido diluído para este estudo, uma vez que estamos interessados em observar a contribuição da superfície num regime com interações mínimas. As interações intrapartículas mascaram o efeito da superfície, devido as interações dipolares entre partículas e de exchange entre os spins de superfície. Fornecendo informações imprecisas sobre a contribuição de superfície. Duas contribuições distintas são notadas na dependência térmica da magnetização para nanopartículas. Em altas temperaturas a magnetização obedece a Lei de Bloch uma vez que os spins de superfície estão flutuando, a curva da cor preta na Figura 36 mostra este comportamento. Uma segunda região em baixa temperatura em que os spins de superfície começam a congelar, influenciando nas propriedades magnéticas, visualizado na Figura 36Figura 36 no instante em que se inicia a diferença entre a curva de cor preta e a dos dados experimentais em círculos azuis, provocando um acréscimo na magnetização. As duas contribuições são descritas pela equação que considera a soma das contribuições (AQUINO et al., 2005) expresso pela equação 38. O primeiro termo é a lei de Bloch, com um expoente à ser determinado. Descreve o comportamento até o congelamento dos spins da camada SGL (casca) na temperatura de freezing.

O segundo termo $\Delta M_{S}(T)$ da equação (38) representa a contribuição magnética da superfície na magnetização total e é estritamente dependente a baixa temperatura, em 
consequência do progressivo congelamento dos spins da camada desordenada em uma estrutura do tipo SGL. Apresentamos a curva de magnetização em alto campo em função da temperatura para amostra de ferrofluido diluído, após a devida subtração da resposta diamagnética do liquido carreador na Figura 36.

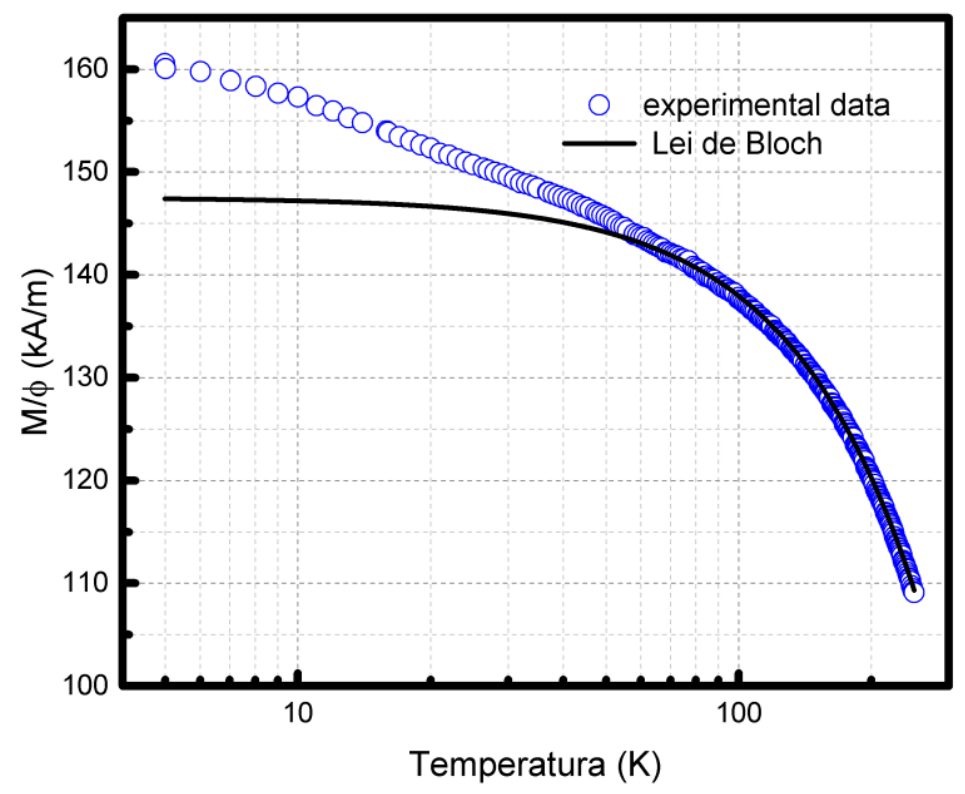

Figura 36: Magnetização da amostra de ferrofluido diluído congelado com variação de $5 \mathrm{~K}$ até $250 \mathrm{~K}$ com campo aplicado de $90 \mathrm{kOe}$.

O campo escolhido para os experimentos foi de $90 \mathrm{kOe}$, máximo fornecido pelo equipamento e o mesmo aplicado em outro trabalho com amostra e tamanho parecidos para comparação dos resultados. Determinamos o valor de $\alpha$ e $B$ da lei de Bloch pelo ajuste da curva com a expressão 29, a linha sólida da cor preta é o ajuste pela lei de Bloch para a amostra de ferrofluido diluído e $\alpha$ e $B$ encontrados foram de 1.4 e de $1.053 \times 10^{-4}$, respectivamente. Os parâmetros utilizados para tais ajustes são mostrados na Tabela 12. Podemos compara nossos resultados com os obtidos por Cabreira-Gomes et al. que investiga amostra com diâmetro ligeiramente maior de ferrita de cobalto, $3.15 \mathrm{~nm}$, onde encontram um $\alpha$ de 1.6 parecido com o nosso valor e um $B$ de $4.8 \times 10^{-5}$, aproximadamente metade do valor que encontramos. Aquino et al. encontra um valor de $\alpha=1.45$ para nanopartículas de $9 \mathrm{~nm}$ de $\mathrm{MnFe}_{2} \mathrm{O}_{4} @ \gamma-\mathrm{Fe}_{3} \mathrm{O}_{4}$ e $\alpha=$ 1.40 para nanopartículas de 10.4 nm de $\mathrm{CuFe}_{2} \mathrm{O}_{4} @ \gamma-\mathrm{Fe}_{3} \mathrm{O}_{4}$, obtidas pelo mesmo método utilizado nesta tese (AQUINO et al., 2005), esses resultados mostram que a anisotropia do núcleo influencia no valor do $\alpha$. 
Tabela 12: A tabela apresenta os valores encontrados nos ajustes, usando as equações (29) e (71). As colunas da tabela representam respectivamente: a fração volumétrica $(\phi)$, a magnetização de saturação (Ms), o expoente crítico $(\alpha)$, a constante de Bloch (B), a temperatura de congelamento $\left(T_{f}\right)$ e a constante de proporcionalidade $(\mathrm{A})$.

* Resultados extraídos de (CABREIRA-GOMES et al., 2014).

\begin{tabular}{|c|c|c|c|c|c|c|}
\hline \multirow[t]{2}{*}{ Amostra } & \multirow{2}{*}{$\begin{array}{c}\phi \\
(\%)\end{array}$} & $\begin{array}{l}\mathrm{Ms}(0) \\
(\mathrm{kA} / \mathrm{m})\end{array}$ & $\alpha$ & $\begin{array}{c}B \\
\left(\times 10^{-5}\right)\end{array}$ & $\begin{array}{c}T_{f} \\
(K)\end{array}$ & A \\
\hline & & \multicolumn{3}{|c|}{ Equação 29} & \multicolumn{2}{|c|}{ Equação 71} \\
\hline FPCo2 & 0.18 & 147.6 & $1.40 \pm 0.0017$ & 10.53 & $20.0 \pm 0.16$ & $1.23 \pm 0.01$ \\
\hline $\operatorname{Co} 3^{*}$ & 0.6 & 145 & $1.6 \pm 0.03$ & 4.8 & $21.0 \pm 0.29$ & $1.24 \pm 0.01$ \\
\hline
\end{tabular}

Contudo há ainda a contribuição da magnetização por parte da camada superficial que é quantificada pela relação:

$$
\frac{\Delta M_{S}(T)}{M_{S}(0)}=A \exp \left(-\frac{T}{T_{f}}\right)
$$

onde $A$ é uma constante de proporcionalidade e $T_{f}$ é a chamada temperatura de freezing (congelamento). A Figura 37 mostra a separação da contribuição superficial em baixas temperaturas $(\mathrm{T}<80 \mathrm{~K})$, onde a linha sólida representa o melhor ajuste aos dados pela equação 71, os resultados extraídos do ajuste estão organizados na Tabela 12. Comparando a valores encontrados em outras pesquisas do GFC que encontraram $T_{f}=20 \pm 0.5 \mathrm{~K}$ para ferritas coreshell de Mn e para Cu (AQUINO et al., 2005), de $18 \pm 0.5 \mathrm{~K}$, para amostras de ferritas de níquel (SOUSA et al., 2009), e um $T_{f}$ de $21 \pm 0.3 \mathrm{~K}$ para ferrita de cobalto (GOMES, 2015).

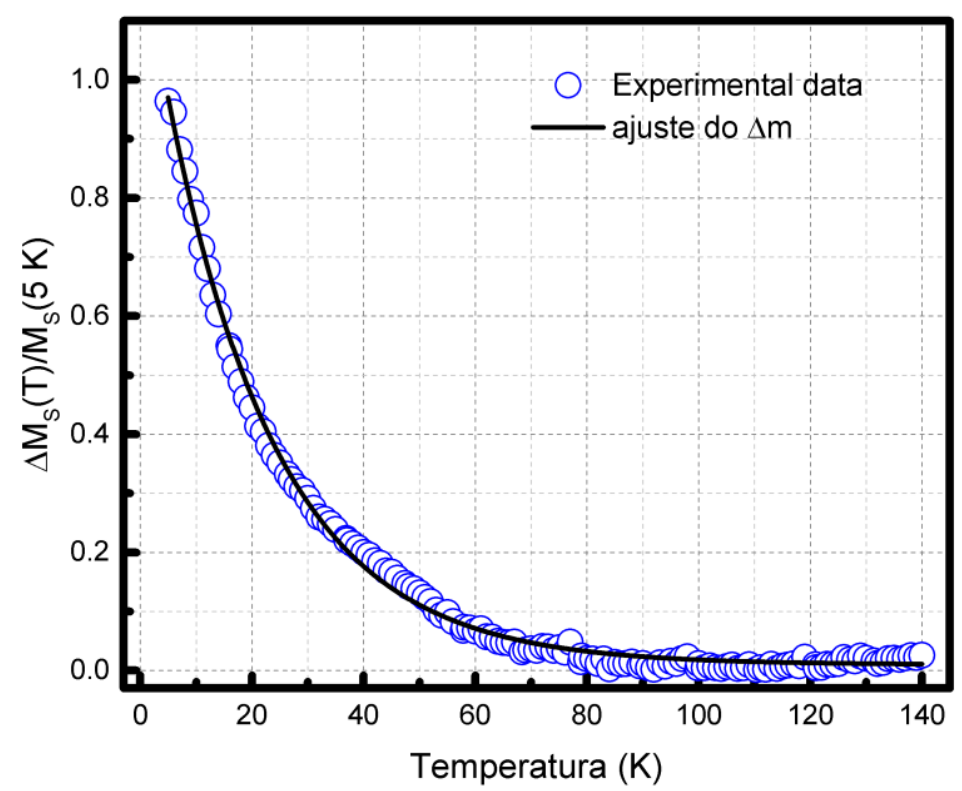

Figura 37: Variação da magnetização oriunda da camada de spins desordenados. A linha sólida representa o ajuste aplicado pela equação 71 . 
Reunimos na Tabela 12 os resultado obtidos para amostra Co3 de ferrita de cobalto com diâmetro de $3.15 \mathrm{~nm}$ investigada por Cabreira-Gomes et al. da dependência térmica da magnetização a alto campo (GOMES, 2015), a fim de fazermos uma comparação com os nossos resultados. Esta amostra foi sintetizada via coprecipitação hidrotérmica pelo professor Francisco Augusto Tourinho em 2002, o experimento feito por Cabreira-Gomes et al. da dependência térmica ocorreu em meados de 2013. Seguindo o mesmo protocolo de síntese, Priscilla Coppola obtém partículas com diâmetros ligeiramente menores de $2.7 \mathrm{~nm}$ no ano de 2015, nossos estudos foram feitos pouco tempo depois e são apresentados nessa seção. Os valores encontrados para amostra FPCo2 estão em bom acordo com os encontrados para amostra Co3 de ferrofluido diluído, mostrando a reprodutibilidade dos parâmetros e a estabilidade das amostras sintetizadas no Grupo de Fluidos Complexos.

Em resumo, esse incremento de magnetização em baixa temperatura é similar ao comportamento de um material paramagnético, onde o decréscimo da temperatura aumenta a magnetização devido ao aprimoramento do direcionamento dos spins. À frente mostraremos que esse incremento de magnetização surgido do processo de field cooling causa um efeito largamente conhecido na comunidade como exchange bias.

\subsubsection{Magnetização DC em baixo campo: memória e envelhecimento}

Resolvemos investigar a fase spin-glass-like que surge da quebra das ligações, defeitos e/ou vacâncias na rede cristalina, que acabam propagando uma desordem estrutural na superfície das NPs-CS aqui estudadas em regime diluído. No pó de nanopartículas a forte interação interpartículas induz uma estrutura de Superspin Glass (SSG), esta torna-se significativa, de modo que não pode ser desprezada, em comparação com a energia de anisotropia de cada partícula magnética (HIROI; KOMATSU; SATO, 2011). O efeito de memória magnética manifesta-se em sistemas com tais características e interpretado como uma inscrição magnética do sistema e está associado ao estado SG em baixas temperaturas (ZHENG et al., 2005). Em baixas temperaturas, a magnetização é rigorosamente idêntica, se o resfriamento é pausado e campo desligado o sistema vai entrar em equilíbrio. Com o religamento de ambos a magnetização do sistema tende a voltar ao estado de magnetização de referência. Em outras palavras o sistema memorizou informação, recuperando sua história térmica quando a temperatura é devolvida e campo ligado. Foram realizadas medidas de Efeito de Memória (EM) no protocolo de envelhecimento FC com magnetização DC, primeiramente 
reportadas por Sun et al. (SUN et al., 2003), discutido anteriormente na seção de protocolos no apêndice C.1. Os experimentos realizados para amostra de ferrofluido diluído e pó são apresentados na Figura 38 e 39, respectivamente.

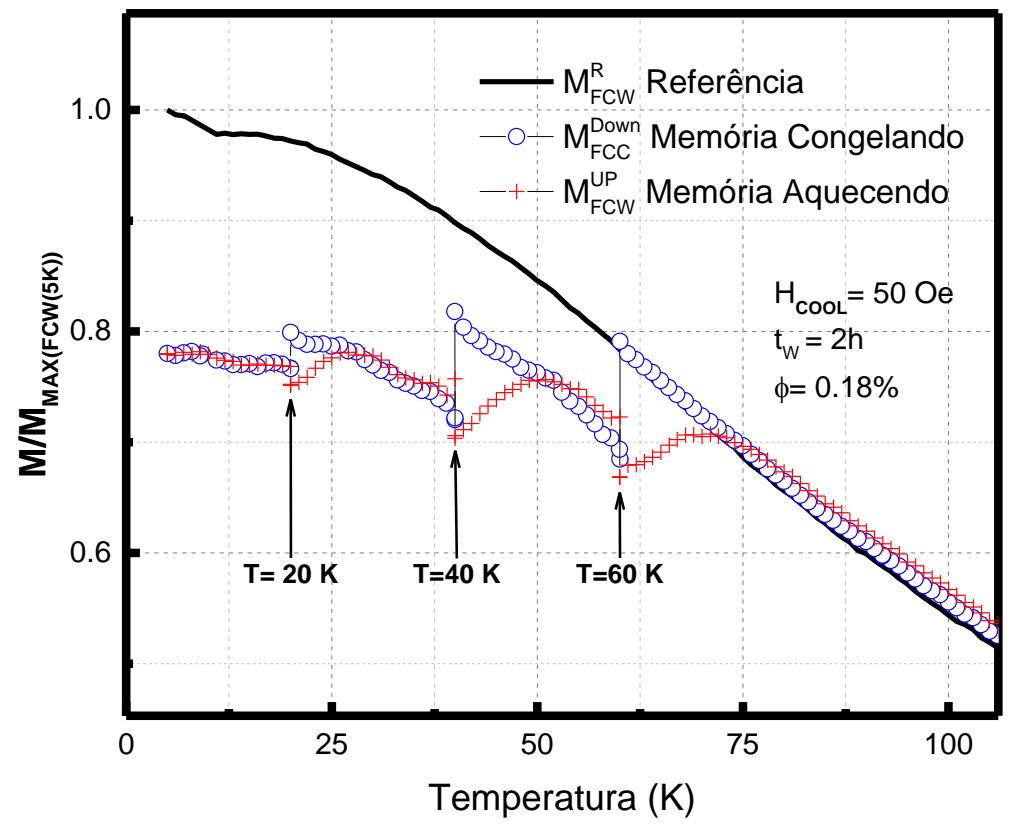

Figura 38: Efeito de memória para amostra de ferrofluido diluído congelado com paradas em 60, 40 e $20 \mathrm{~K}$ com tempo de paradas de 2 horas.

Nas curvas $M_{F C C}^{\text {Down }}$ de ambas amostras, uma queda na magnetização é observada até atingir o equilíbrio da magnetização em todos os steplike (degraus), no entanto, verifica-se que a quantidade de queda depende do estado magnético das nanopartículas. Na amostra de ferrofluido diluído os efeitos da dependência térmica da magnetização com fenômenos de envelhecimento são estudados para a fase spin-glass-like, a Figura 38 mostra que os degraus são menores uma vez que depende somente da fase $S G L$, depois do tempo de espera $\left(t_{w}\right)$, no tempo em que o campo e resfriamento é ligado a quantidade de recuperação da magnetização $\mathrm{M}(\mathrm{T})$ depende de quão rápido as nanopartículas se realinham com o campo aplicado.

Com os efeitos de interações dipolares mínimas para amostra de ferrofluido diluído, o processo de realinhamento das NPs-CS com o campo é acelerado. Assim, a temperaturas abaixo de $T_{B}^{M A X}$ e acima de $\left\langle T_{B}\right\rangle$ a queda da magnetização é considerável, nos degraus em $60 \mathrm{~K}$ e $40 \mathrm{~K}$ uma observação interessante na Figura 38 é vista. A curva $M_{F C C}^{\text {Down }}$ após retomar o arrefecimento se comporta quase paralelamente a curva de referência $M_{F C W}^{R}$ sem as paradas intermitentes. Na região abaixo da temperatura de congelamento dos spins da casca $\left\langle T_{B}\right\rangle$, nota-se que a $20 \mathrm{Ko}$ 
degrau é relativamente menor e rapidamente a magnetização entra em equilíbrio. Além disso, há uma recuperação insignificante da curva $M_{F C C}^{\text {Down }}$ abaixo de $20 \mathrm{~K}$. Na curva $M_{F C W}^{U p}$ a baixo de $30 \mathrm{~K}$ a dinâmica do sistema é extremamente lenta e observamos a tentativa ínfima de recuperar a magnetização. À temperatura um pouco maior que a do degrau a magnetização não

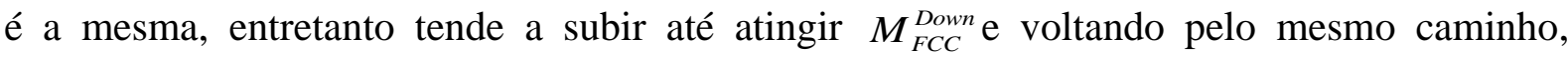
memorizando a magnetização. O comportamento da amostra de ferrofluido diluído é similar com as nanopartículas de permalloy $\left(\mathrm{Ni}_{81} \mathrm{Fe}_{19}\right)$ estudada por Sun et al. e está mais próxima de um estado superparamagnético devido à baixa fração volumétrica de partículas que leva ao regime de fracas interações. Ao observar a curva de referência $M_{F C W}^{R}$ abaixo de $10 \mathrm{~K}$, podemos observar um aumento abrupto da magnetização que é devido a contribuição superficial na magnetização, mesmo em baixo campo aplicado.

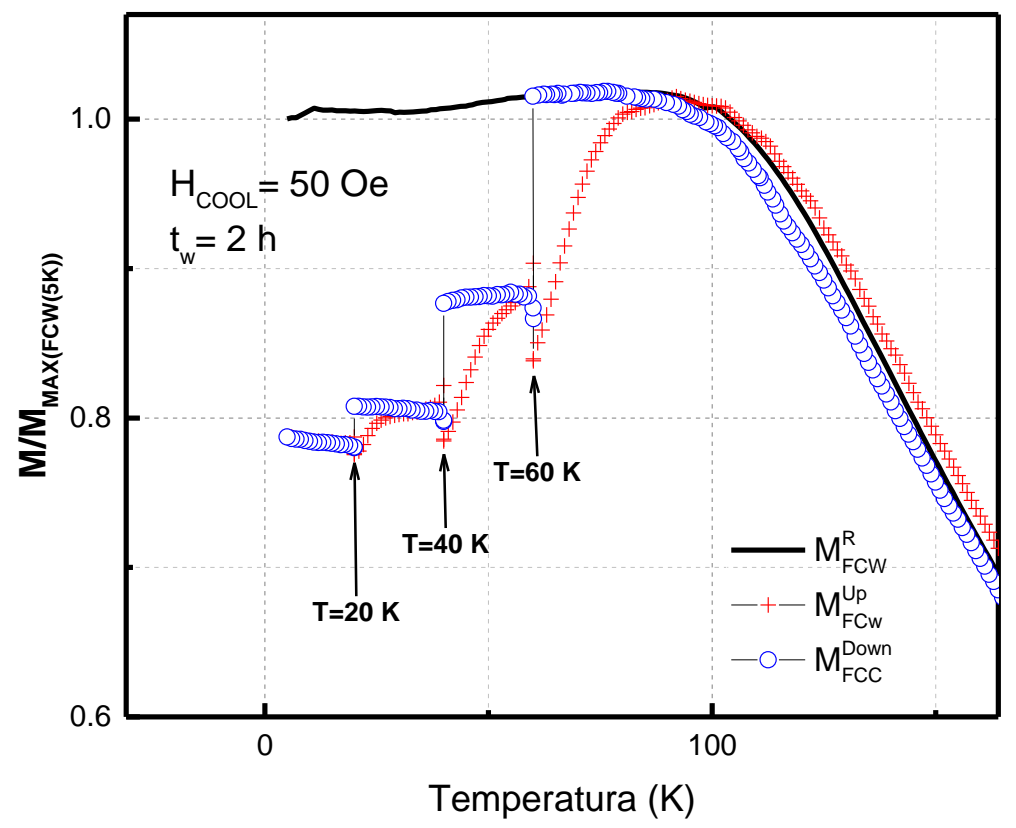

Figura 39: Efeito de memória para amostra pó de nanopartículas core-shell de ferrita de cobalto.

Os resultados para amostra pó são apresentados na Figura 39 seguindo o mesmo protocolo de medida. Nas paradas intermitentes do processo de FC enquanto o campo é desligado o valor da magnetização diminui relaxando para o estado de equilíbrio. O efeito de memória é mais pronunciado nesta amostra uma vez que as interações dificultam o

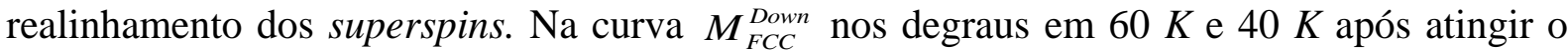
equilíbrio da magnetização posteriormente às paradas $t_{w}$, existe um pequeno aumento na 
magnetização e após apresenta um comportamento quase paralelo em $20 \mathrm{~K}$, em consequência do congelamento dos spins da casca e a dinâmica do sistema fica extremamente lenta.

No reaquecimento subsequente, o valor da magnetização no processo de arrefecimento anterior é recuperado, para cada paragem, a uma temperatura um pouco acima do que a parada. Nossos experimentos de efeito de memória estão análogos ao reportado por Sasaki et al. para pó de nanopartículas $\mathrm{Fe}_{3} \mathrm{~N}$ (SASAKI et al., 2005) e aos observados por Chandra et al. em nanopartículas core-shell de $\mathrm{Fe} / \gamma-\mathrm{Fe}_{2} \mathrm{O}_{3}$ (CHANDRA et al., 2012). Malik et al. obtém resultados parecidos para nanocompositos de $\mathrm{NiFe}_{2} \mathrm{O}_{4} /$ Polianilina (MALIK et al., 2014). Recentemente Gandhi et al. relata o mesmo tipo de comportamento para a magnetita $\left(\mathrm{Fe}_{3} \mathrm{O}_{4}\right)$ (GANDHI et al., 2015). Ambos sugerem que amostra na forma de pó apresenta o estado de superspins glass (SSG). Cador et al. coloca em suspensão nanopartículas de $\mathrm{ZnFe}_{2} \mathrm{O}_{4}$ e o efeito de memória desaparece sugerindo que as interações entre intrapartículas cria um estado de superspins glass (CADOR et al., 2004). Simulações feitas por Vasilakaki et al. para um conjunto de nanopartículas com estrutura core-shell FM/AFM apresentam o efeito de memória e se intensifica com a concentração. Seus resultados são comparados com curvas experimentais de nanopartículas Co incorporadas em uma matriz $\mathrm{Mn}$, neste sistema o acoplamento de troca da interface e as interações dipolares interpartículas contribuem para o comportamento dinâmico observado. Em particular, a interação de exchange da interface fornece uma fonte de aditivo para a frustração do sistema resultando num aumento do efeito de memória, confirmando o comportamento vítreo dos sistemas de nanopartículas investigados. (VASILAKAKI et al., 2013).

Atribuímos a casca com estrutura SGL, abaixo de $T_{g}$, existente nas NPs-CS de ferritas $\mathrm{CoFe}_{2} \mathrm{O}_{4} @ \gamma-\mathrm{Fe}_{2} \mathrm{O}_{3}$ como a origem intrínseca do efeito de memória na amostra de ferrofluido diluído e potencializado pelas interações interpartículas dipolares e de exchange na amostra de pó resultando em uma estrutura de vidro de superspins. Num relance, o efeito memória é qualitativamente o mesmo em ambas as amostras indicando uma origem semelhante do efeito, o estado de spin glass.

$\mathrm{O}$ exchange bias aumenta acentuadamente abaixo de $30 \mathrm{~K}$ devido ao aumento nas interações entre o core-shell (CHANDRA et al., 2012; CABREIRA-GOMES et al., 2014), enquanto o Efeito de Memória começa a desaparecer abaixo de 30 K (NADEEM; KRENN; SZABÓ, 2015). A profundidade dos degraus no efeito de memória diminui com a queda de temperatura e quase desaparece a $20 \mathrm{~K}$. No nosso caso, o colapso do degrau no efeito de 
memória ocorre na mesma região de temperatura na qual o exchange bias começa a se desenvolver. Os dois efeitos concorrentes coincidem perto de uma temperatura entre 20 - $30 \mathrm{~K}$.

\subsection{Exchange bias e efeito de treinamento induzido pelo shell}

\subsubsection{Exchange Bias}

Origem do exchange bias e sua dependência com o campo de cooling

Para o início da nossa investigação do exchange bias, estamos interessados em procurar a máxima resposta do exchange bias, para isso precisamos medir alguns ciclos de histerese magnética variando o campo de cooling. Resultados recentes de F.G Silva et al. para NPs-CS de ferrita mole de $\mathrm{MnFe}_{2} \mathrm{O}_{4} @ \gamma-\mathrm{Fe}_{2} \mathrm{O}_{3}$ (SILVA et al., 2013; SILVA, 2014) e Cabreira-Gomes et al. para ferrita dura de $\mathrm{CoFe}_{2} \mathrm{O}_{4} @ \gamma-\mathrm{Fe}_{2} \mathrm{O}_{3}$ (CABREIRA-GOMES et al., 2014; GOMES, 2015). Observam em nanopartículas com estrutura do tipo core-shell uma forte influência do campo de cooling $\left(H_{\text {cool }}\right)$ sobre o exchange bias. Para nossas amostras de $\mathrm{CoFe}_{2} \mathrm{O}_{4} @ \gamma-\mathrm{Fe}_{2} \mathrm{O}_{3}$ é esperado o mesmo comportamento. De acordo com o valor do $H_{\text {cool }}$ aplicado os momentos magnéticos do núcleo das NPs-CS se alinham na direção do campo aplicado (depende do valor do campo aplicador) e com a redução da temperatura, acima $T_{f}$ (temperatura de congelamento da superfície SGL), os spins do núcleo (fase ordenada) tendem a alinhar cada vez mais na direção do campo influenciando na magnetização. À medida que se diminui a temperatura através do $T_{f}$, uma configuração dos spins da casca (fase SGL) será selecionada através da interação complexa de exchange com o componente ordenada e partícula-partícula pelas interações dipolares. Assim, dependendo da intensidade de $H_{c o o l}$, a degenerescência do estado SGL pode ser reduzido. Na verdade, campos magnéticos fortes o suficiente pode destruir o estado SGL totalmente alinhando os spins na direção de $H_{\text {cool }}$ (DEL BIANCO et al., 2004; NIEBIESKIKWIAT; SALAMON, 2005). O valor do deslocamento é convencionalmente considerado como uma estimativa do campo do exchange bias $\left(H_{E X}\right)$ e determinado como:

$$
H_{E X}=\frac{1}{2}\left(H_{C}^{+}-H_{C}^{-}\right)
$$

$H_{C}^{+}$e $H_{C}^{-}$são os pontos onde o ciclo intercepta o eixo do campo magnético quando magnetização é zero. $\mathrm{O}$ deslocamento vertical $\delta \mathrm{M}$ é definido a partir das magnetizações remanentes positivas e negativas (VASILAKAKI; TROHIDOU, 2009) 


$$
\delta M=\left(M_{R}^{+}+M_{R}^{-}\right)
$$

$M_{R}^{+}$e $M_{R}^{-}$do ciclo de histerese (os pontos $H_{C}^{+}, H_{C}^{-}, M_{R}^{+}$e $M_{R}^{-}$no ciclo de histerese podem der visualizados na Figura 30). Apresentamos os resultados da dependência com campo de cooling para amostra pó na Figura 40.

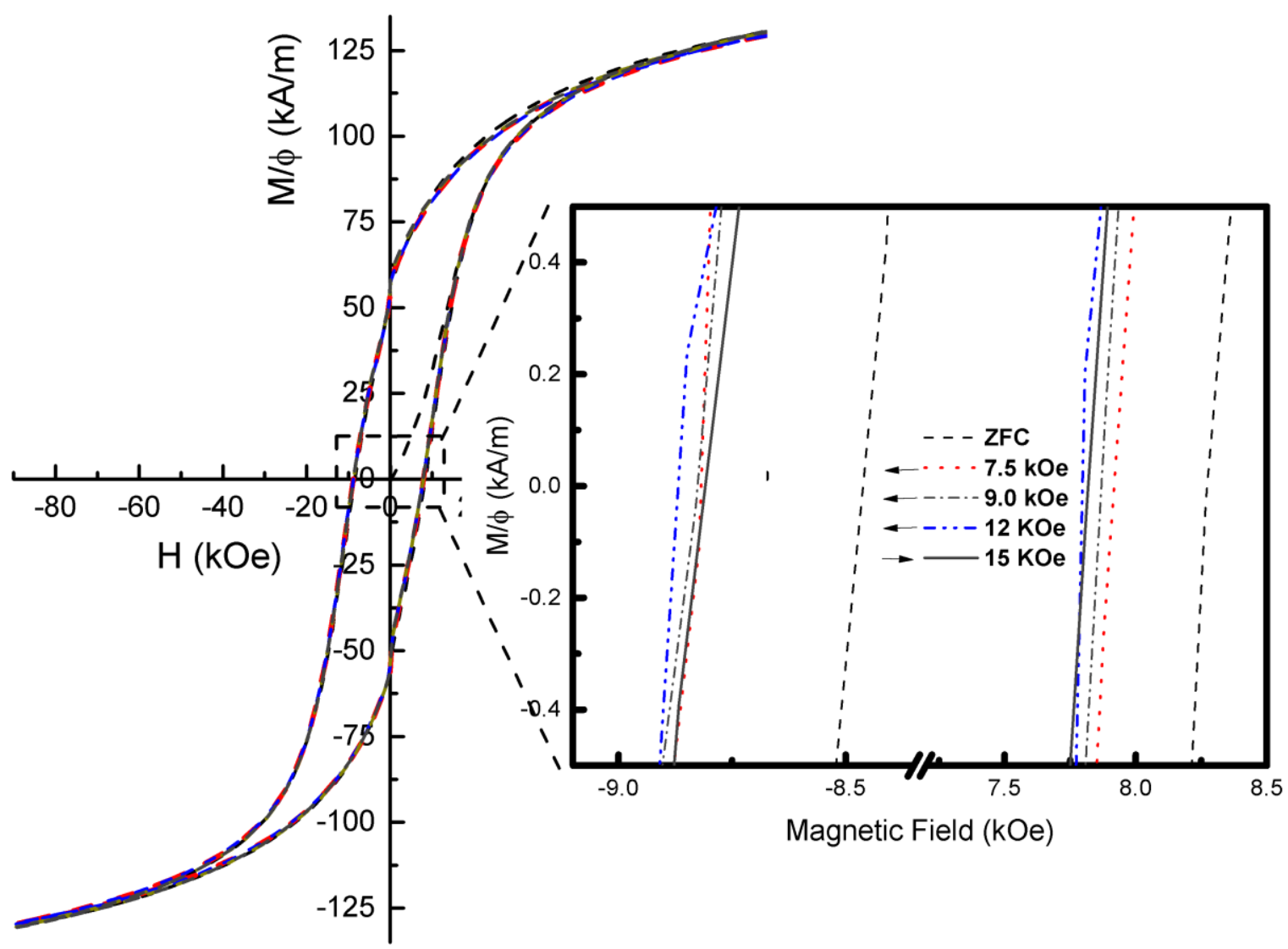

(a) Ciclos de histerese magnética

(b) centro dos ciclos de histerese

Figura 40: ciclos de histerese magnética com protocolo FC e ZFC a $5 \mathrm{~K}$ com variação do campo de cooling para amostra pó, as setas mostram a direção do deslocamento do ciclo a seta indica o sentido do deslocamento do exchange bias.

Os resultados de Cabreira-Gomes et. al para ferrita de $\mathrm{CoFe}_{2} \mathrm{O}_{4} @ \gamma-\mathrm{Fe}_{2} \mathrm{O}_{3}$ com diâmetro de $~ 3.15 \mathrm{~nm}$ encontram um valor $H_{C O O L}^{M A X} \sim 7.5$ kOe (CABREIRA-GOMES et al., 2014). Com diâmetro menor e campo de anisotropia maior encontrados para nossas amostras, esperamos achar um campo de cooling máximo $H_{C O O L}^{M A X} \sim H_{k} / 2$, anteriormente deduzimos o $H_{k} \sim 24$ kOe. A partir do $H_{C O O L}^{M A X}$ encontrado por Cabeira-Gomes et al. aumentamos o campo $H_{c o o l}$ até encontrar a máxima resposta do campo de exchange bias para nossas amostras. O $H_{E X}$ é definido utilizando a equação 72 . 
Note-se que a magnetização de saturação não muda para o pó de $130 \mathrm{kA} / \mathrm{m}$ exposto na Figura 41 (a) e para o ferrofluido diluído de $\sim 160 \mathrm{kA} / \mathrm{m}$, indicando que Ms é independente de $H_{\text {cool }}$.
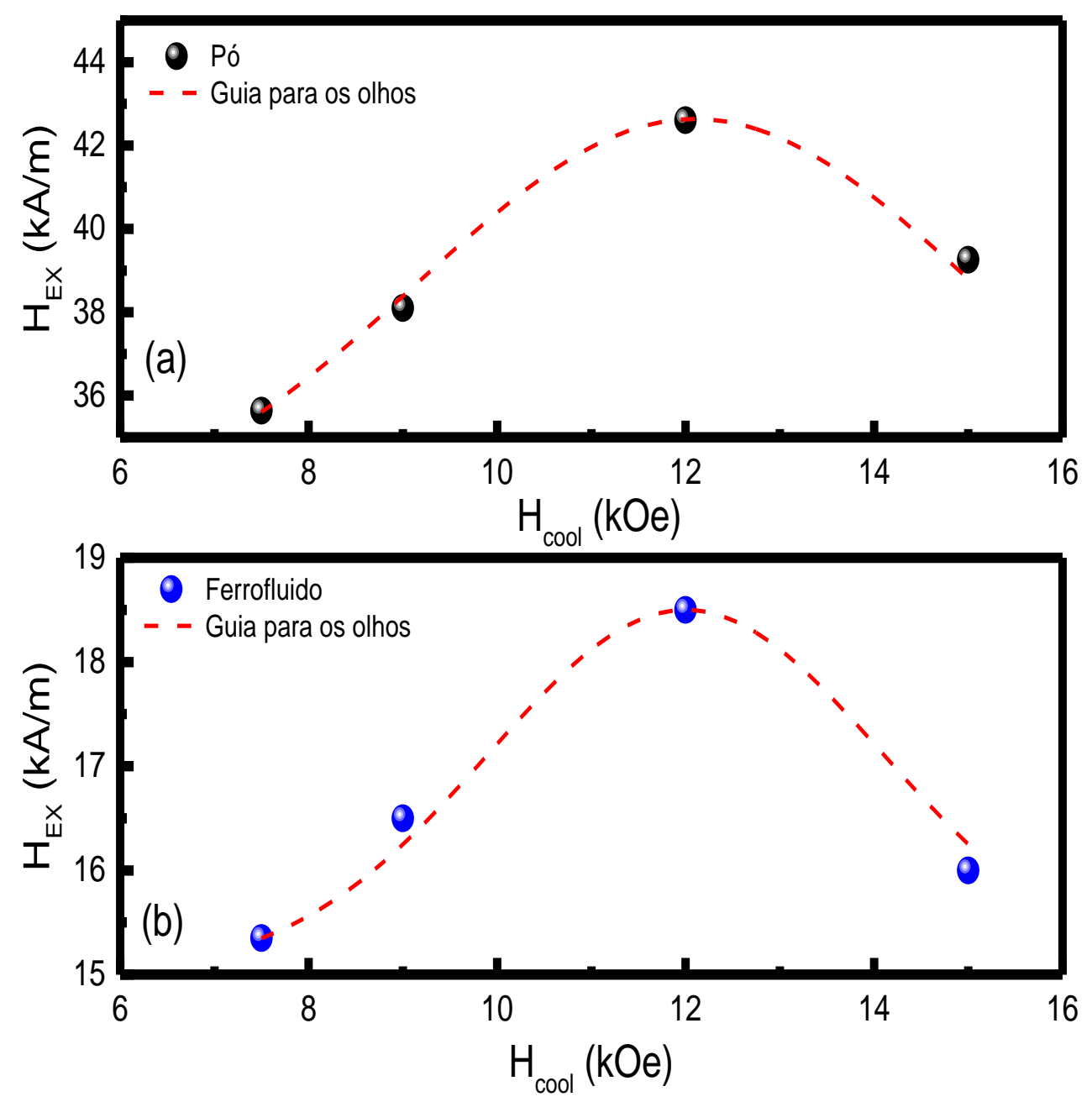

Figura 41: Dependência do campo de cooling de $H_{E X}$ para as amostras de (a) pó e (b) ferrofluido diluído.

Observamos uma intensa dependência do exchange bias medido a $\mathrm{T}=5 \mathrm{~K}$ com o $H_{\text {cool }}$ para 7.5, 9.0, 12 e 15 kOe e encontramos um $H_{\text {cool }}^{M A X}$ aproximado de $12 \mathrm{kOe}$ e $H_{E X}$ de 42.3 kA/m para amostra pó e $H_{E X}$ de $18.5 \mathrm{kA} / \mathrm{m}$ para amostra de ferrofluido diluído apresentado na Figura 41, valores superiores aos encontrados por Cabreira-Gomes et al. Atribuímos a potencialização do exchange bias com a redução do tamanho das nanopartículas uma vez que se aumenta a contribuição da superfície em relação ao volume da partícula.

Tais resultados são explicados em termos do acoplamento de troca entre o núcleo ferrimagnético (FI) e a superfície spin-glass-like (SGL), considerando a influencia do $H_{\text {cool }}$ para 
determinar o estado de magnetização máxima a $5 \mathrm{~K}$. Estes são similares aos observados por Del Bianco et al. (DEL BIANCO et al., 2004), nessa investigação os autores associaram o $H_{c o o l}^{M A X}$ a um limiar que divide os comportamentos, chamado por eles de depinning threshold, onde nessa região da curva é deflagrado um processo de desaprisionamento dos spins que estavam acoplados via interação de troca. Em outras palavras, é nessa região da curva que a energia Zeeman supera essas interações na interface, redirecionando esses spins com o campo de cooling.

Por outro lado, o comportamento de $H_{E X}$ em campos superiores a $H_{c o o l}^{M A X}$, é devido ao alinhamento dos spins da casca com o núcleo por meio da energia Zeeman, diminuindo a energia de troca entre as camadas, aumentando a magnetização. Ocasionando um deterioramento desse acoplamento na interface (SOUSA et al., 2009) e consequentemente decrescendo $H_{E X}$. É possível que esse processo de depinning threshold seja mediado por uma energia especial chamada de anisotropia rodável (DIAS et al., 2014). Os momentos magnéticos que possuem essa anisotropia não têm uma direção definida no espaço e dessa forma podem ter sua direção selecionada pela aplicação de um campo magnético suficientemente forte ou pelo momento magnético do material FI durante o processo de magnetização.

\section{Minor loops}

Minor loops (JACOBS; BEAN, 1963; SHUKLA, 2001), (NOGUÉS et al., 2005b) Têm sido amplamente estudados para avaliar a qualidade magnética de materiais ferromagnéticos bulk, bem como filmes finos ferromagnéticos (TAKAHASHI et al., 2006; KOBAYASHI et al., 2008, 2010). São basicamente ciclos de histereses magnéticos em que pelo menos um dos ramos foi medido até campos menores do que o campo de saturação (isto é, o campo necessário para ter todos os spins paralelo ao campo aplicado), rendendo uma mudança nos valores das magnetizações de remanência $\left(M_{R}\right)$, gerando um deslocamento vertical do ciclo de histerese (vertical shift). Simultaneamente o minor loop, cria um deslocamento horizontal para campos $H$ positivos (horizontal shift $-H_{\text {shift }}$ ) e apresentam também diferentes campos coercivos para os ramos crescentes e decrescentes dos laços de histerese.

Na verdade, esses deslocamentos são um efeito inerente a todos os materiais magnéticos quando não devidamente saturados, possuindo, consequentemente, nenhuma relação direta com o exchange bias, mas empregado para verificar a estabilidade do EB (SILVA et al., 2013; CABREIRA-GOMES et al., 2014). Este efeito pode ser especialmente importante para 
partículas pequenas e sistemas magnéticos duros, onde o campo de saturação pode ser bastante elevado e, portanto, difícil de alcançar com equipamentos convencionais (NOGUÉS et al., 2005b).

No caso de compostos nanocristalinos, ligas e óxidos, a magnetização a alto campo magnético (isto é, acima de $50 \mathrm{kOe}$ ), frequentemente não saturaram (GIRI; PATRA; MAJUMDAR, 2011). Em particular, os materiais que envolvem fases magnéticas desordenadas e/ou spin glass, configurações com spin canted ou sistemas com alta anisotropia não mostram uma tendência ainda saturante para a $\mathrm{H}>50 \mathrm{kOe}$. Assim, a escolha apropriada de campo máximo aplicado para a gravação de um ciclo de histerese magnética é importante. O campo saturante $\left(H_{\max }\right)$ é crucial para investigar o exchange bias, visto que pequenos $H_{\max }$ provocam o deslocamento do ciclo de histerese magnética mesmo para FM e substâncias magnéticas vítreas, atribuído aos processos irreversíveis da magnetização (GIRI; PATRA; MAJUMDAR, 2011).

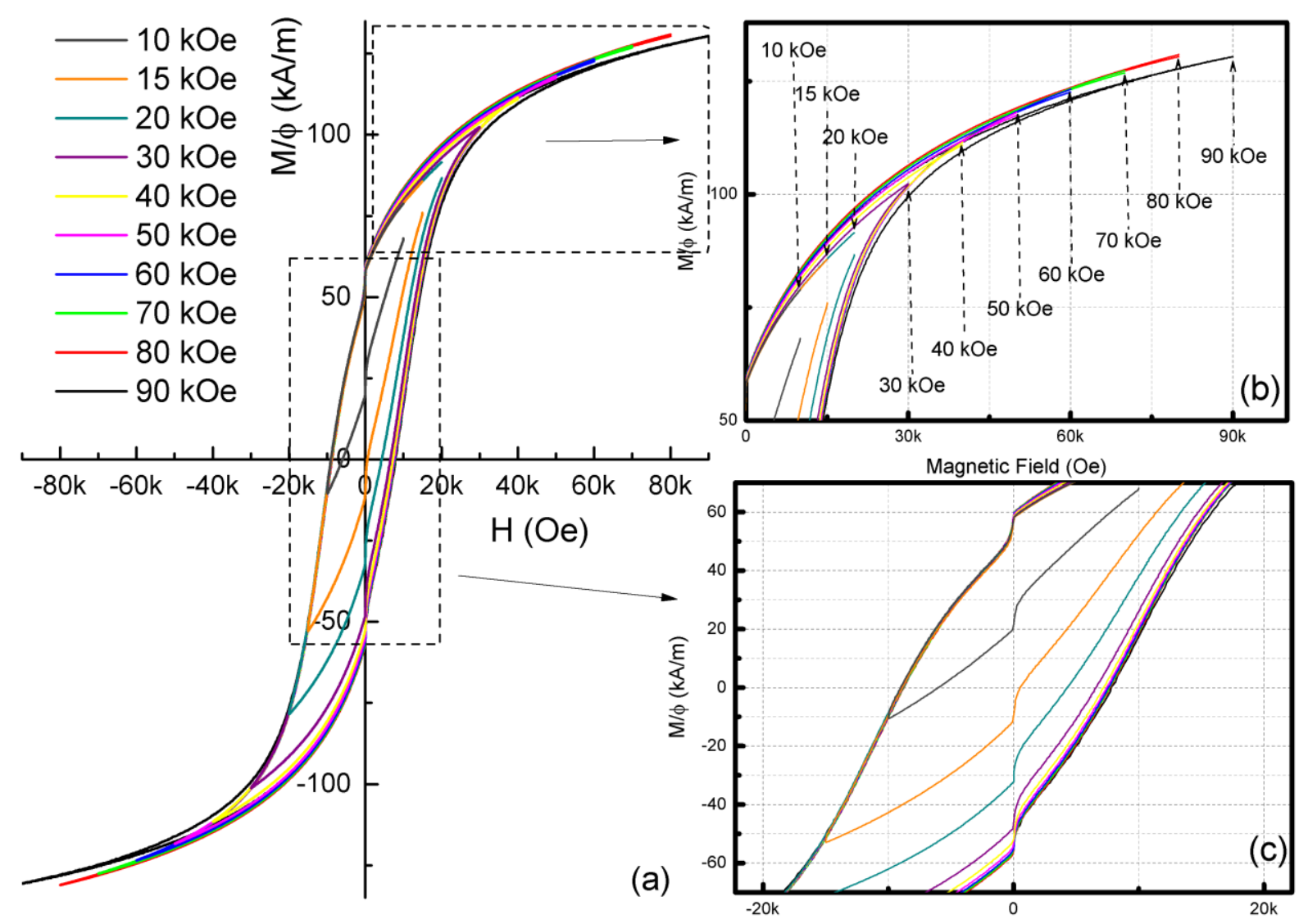

Figura 42: (a) Ciclos de histerese magnética medidos em diferentes entre $\pm H_{\max }$ são apresentados. Em (b) região de saturação, onde as setas representam os $H_{\max }$ utilizados nos experimentos realizados, os ciclos com $H_{\max }$ de 10 , 15 e 20 kOe não fecham as setas representam os campos magnéticos máximos utilizados em cada laço de histerese. (c) região central dos ciclos medidos mostrando o deslocamento dos ciclos para o primeiro quadrante com $H_{\text {max }}$. 
Para iniciar a investigação usamos a rotina do minor loops, o $H_{\max }$ pode ser escolhido de tal modo que $H_{\max }>H_{k}, H_{k}$ é o campo de anisotropia do sistema. A fim de evitar valores superestimados do exchange bias e da magnetização do exchange bias ( $\mathrm{M}_{\mathrm{E}}$ ) (GESHEV et al., 1990; GESHEV, 2008; PATRA et al., 2009). $H_{E X}$ e $\delta \mathrm{M}$ diminuem com o aumento $H_{\max }$ e tendem a estabilizar a valores altos (TANG; SUN; CHENG, 2006; SALAZAR-ALVAREZ et al., 2007; PATRA et al., 2009; YUAN et al., 2009). Utilizamos o protocolo de medida exposto no apêndice C.1 variando o campo saturante $H_{\max }$ de 10 - $90 \mathrm{kOe}$, afim de observar a estabilidade do exchange bias.

Na Figura 42 (a) visualizamos os ciclos de histereses obtidos com o protocolo do minor loops para a amostra FPCo2 pó com campo de cooling $12 \mathrm{kOe}$. Foram medidos dez ciclos, com valores baixos (10 kOe > -10 kOe, $15 \mathrm{kOe}>-15 \mathrm{kOe}$ e $20 \mathrm{kOe}>-20 \mathrm{kOe}$ ) simulando um estado em que o $H_{\max }$ não ultrapassa o campo de anisotropia $\left(H_{k}\right)$ de $24 \mathrm{kOe}$, encontrado na seção 4.2.1. E até o $H_{\max }$ limite suprido pelo equipamento $(9 \mathrm{kOe}>-9 \mathrm{kOe})$. Verificamos que quando $\mathrm{H}_{\max }$ é inferior ao campo de anisotropia do sistema, não atinge a saturação magnética Figura 42 (b).

Os ciclos de histereses magnéticas foram investigados analisando o deslocamento do horizontal shift quantificado pelas equações 66 e 72, aqui o $H_{E X}$ será chamando de $H_{\text {shift, e }}$ quanto o vertical shift pelas equações 67 e 73 . A Figura 43 exibe os valores de $M_{S}, H_{C}, H_{\text {shift, }}$ $M_{R}$ e $\delta M$ dependentes de $H_{m a x}$, provenientes da extração de dados do minor loops para amostra FPCo2 pó. Observamos que os ciclos adquiridos possuem comportamento semelhante acima do $H_{\max }>30$ kOe Figura 43 (a). Acima desse, os ramos ascendente e descendente dos ciclos de histereses coincidem em campos maiores que $H_{k}$ e em valores superiores a amostra pode ser considerada efetivamente saturada. Observamos que encontra a estabilidade acima de $80 \mathrm{kOe}$ como podemos visualizar na Figura 43 (a). Essa característica é confirmada na Figura 43 (b), que apresenta a região de saturação magnética, contudo, nos ciclos medidos onde $H_{\max }<<H_{k}$ (20 kOe, $15 \mathrm{kOe}$ e $10 \mathrm{kOe}$ ) o processo de medida torna-se insuficiente a ponto do ciclo de histerese não fechar.

Na Figura 43 (b) observa-se que o campo coercivo aumenta expressivamente até $40 \mathrm{kOe}$ e após uma região de valor constante, Figura 43 (c) os valores do $H_{\text {shift }}$ decaem de forma abrupta até $40 \mathrm{kOe}$ com aumento do $H_{\max }$. A partir de $40 \mathrm{kOe}$ estabiliza-se o deslocamento horizontal o que observamos em Figura 43 (b) e (c). Na Figura 43 (d) visualizamos o comportamento da magnetização remanente e do deslocamento vertical, também averiguamos que em $40 \mathrm{kOe}$ existe uma região de estabilidade. 

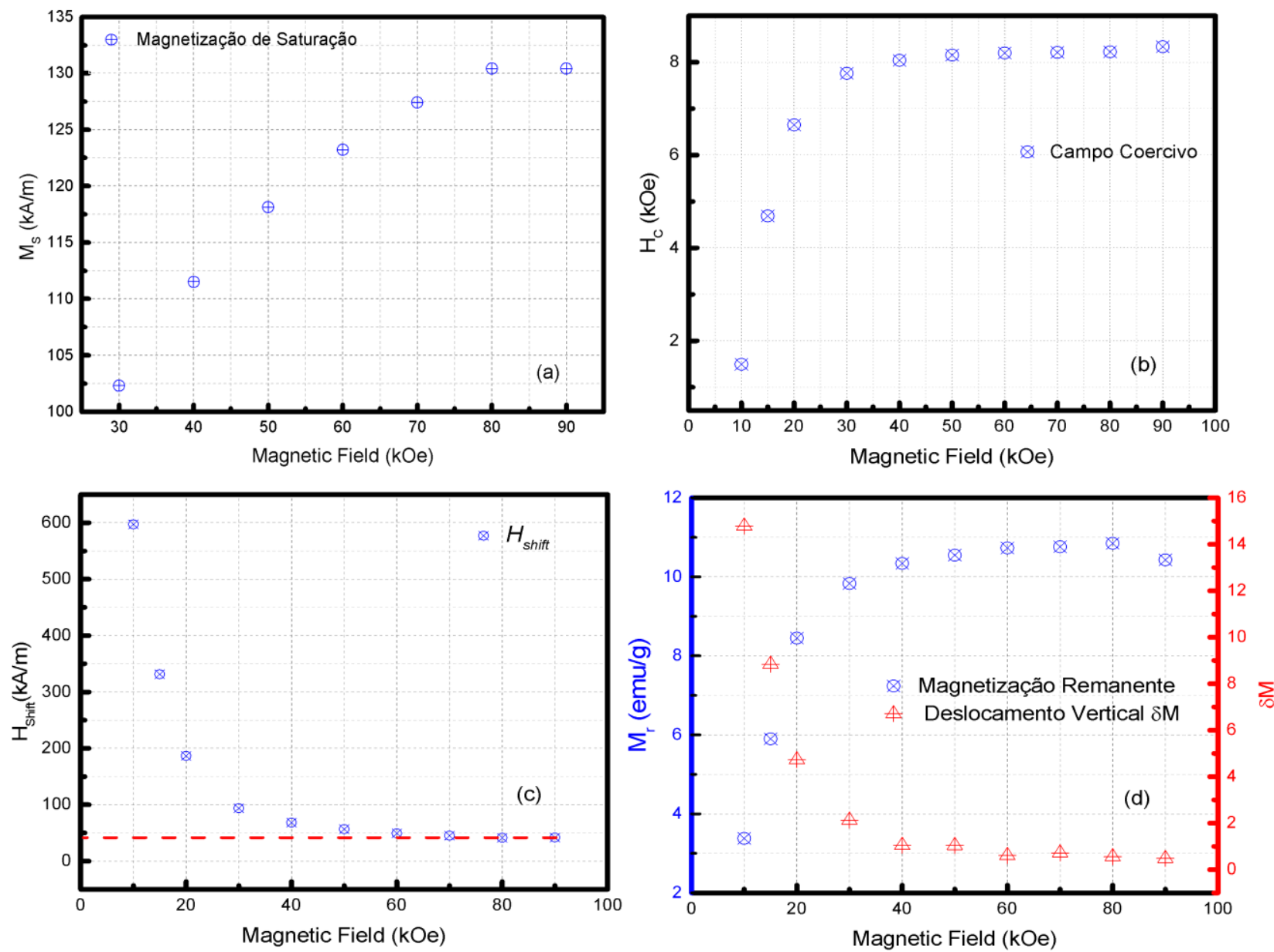

Figura 43: A figura (a) apresenta a magnetização de saturação dos ciclos obtidos de $30 \mathrm{kOe}$ até 90 kOe, abaixo de 30kOe o início e o final dos ramos superior e inferior dos ciclos não coincidem confirmando que estão abaixo de de $H_{k}$. (b) dependência do campo coercivo com $H_{\max }$ (c) dependência de $H_{\text {shift }}$ com $H_{\max }$. (d) Magnetização remanente e deslocamento vertical com dependência do $H_{\max }$.

À medida que $H_{\text {shift }}$ fica constante, ele torna-se $H_{\mathrm{EX}}$ e nos fornece o verdadeiro significado fenomenológico do campo de exchange bias. Por outro lado, as regiões de platô acima de 40 kOe em todas as análises, na Figura 43 (b), (c), (d) e a constância da magnetização de saturação acima de $H_{\max }=80 \mathrm{kOe}$ indica a região onde o campo magnético aplicado supera o campo de anisotropia $\left(H_{k}\right)$. Isso significa que a intensidade máxima de campo magnético externo $H_{\max } \pm 90 \mathrm{kOe}$ utilizado nas medidas alcança valores muito maiores que esse, eliminando qualquer desconfiança a cerca desse efeito indesejado.

\subsubsection{Dinâmica não linear do efeito de treinamento}

Pouco depois da descoberta do Exchange Bias, Paccard et al. (PACCARD et al., 1966) encontraram uma degradação gradual do campo EB durante consecutivo laços de histerese, Fenômeno conhecido como o efeito de treinamento, que é frequentemente observado pela 
redução no $H_{E X}$ e coercividade $\left(H_{C}\right)$. Nesta seção iremos apresentar os resultados do Efeito de Treinamento do Exchange Bias na amostra de ferrofluido diluído a base de NPs-CS, visto pela primeira vez aqui e pó compacto após evaporação do solvente. Observamos o fenômeno em relação a algumas características, regimes de interação fracas e fortes, relaxamento dos spins não compensados congelados e rotativos na interface, influência da temperatura e envelhecimento.

$\mathrm{Na}$ amostra de ferrofluido diluído, conseguimos sondar de forma individual as propriedades das nanopartículas em que a magnetização do núcleo é fixada pela camada desordenada com estrutura magnética de spin-glass-like (SGL) esta possui spins congelados que contribuem para o exchange bias e os rodáveis que influencia nas propriedades do exchange bias com a diminuição da temperatura. Na amostra pó compacto o exchange bias é potencializado pelo contato entre as superfícies das NPs-CS, nessa configuração as interações dipolares e de superexchange são os agentes da intensificação do exchange bias. As NPs-CS se organizam numa estrutura magnética do tipo superspins glass (SSG). Fenomenologicamente a energia, que controla o processo de relaxamento no efeito de treinamento, depende exclusivamente do desvio da magnetização da interface $S G L$, a partir do seu valor de equilíbrio para amostra da dispersão diluída e congelada e para pó é potencializada pelo estado SSG.

\section{Interações fracas e fortes no efeito de treinamento}

A Figura 44 retrata os ciclos de histerese magnética obtidos com aplicação do campo de cooling de 12 kOe em $5 \mathrm{~K}$ para amostras de (a) pó compacto e (b) ferrofluido diluído, os inserts mostram a região central dos ciclos. Foram medidos 7 ciclos sucessivos com tempo de parada entre os ciclos $t_{w}=0 s$ utilizando o protocolo apresentado no apêndice C.1, valores de $H_{E X}$ foram extraídos de todos os ciclos e estes não coincidem uns com os outros. Apontando a degradação do $H_{E X}$ para as amostras, devido o desprendimento de alguns spins congelados que se alinham com campo de congelamento e dos spins rodáveis que estão em estado metaestável de fácil alinhamento com campo, na interface entre o núcleo e a casca. Para amostra de FPCo2 em pó apresenta uma diminuição mais acentuada visualizado na Figura 44 (a). A diminuição de $H_{E X}$ é maior entre o primeiro e o segundo ciclo, posto que grande volume de spins se alinham com campo de congelamento, chamado de efeito de treinamento atérmico. Um segundo a partir do segundo ciclo em diante, à medida que o desprendimento e alinhamento dos spins influencia a interação de troca no exchange bias e segue uma lei de potência $H_{E X} \propto 1 / \sqrt{n}$ até atingir equilíbrio. 


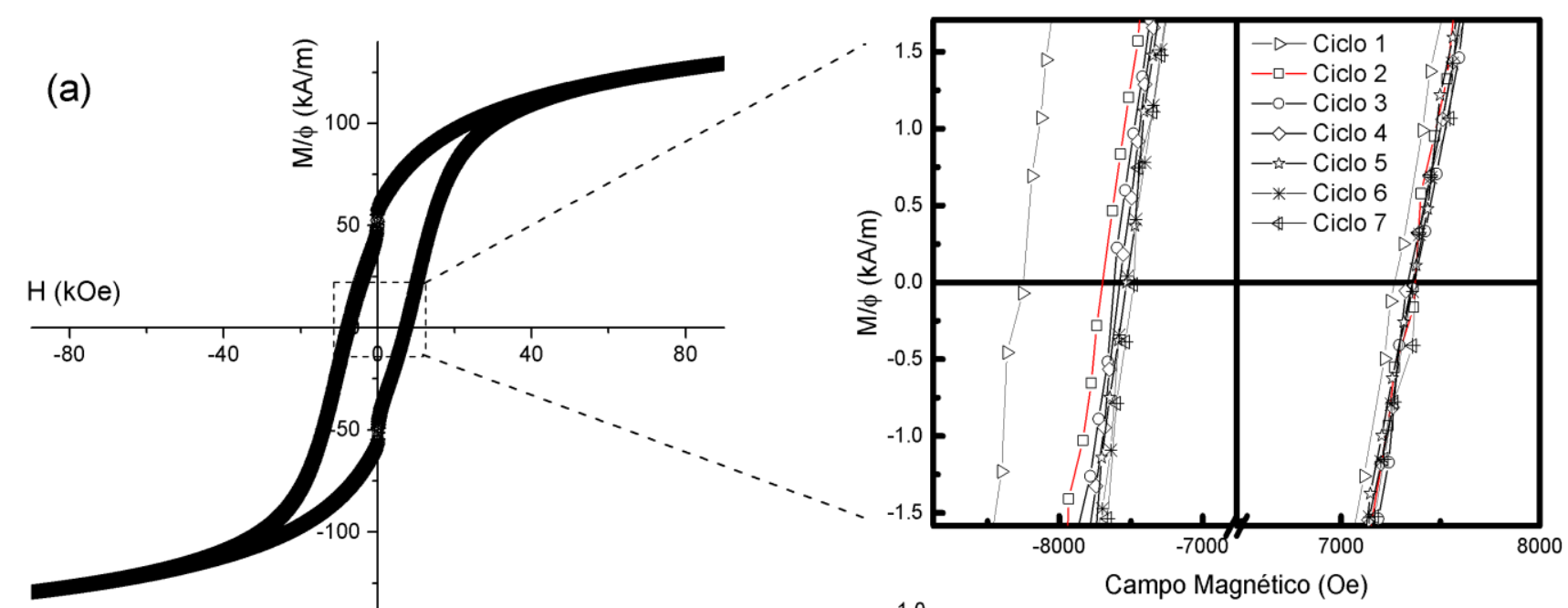

(b)

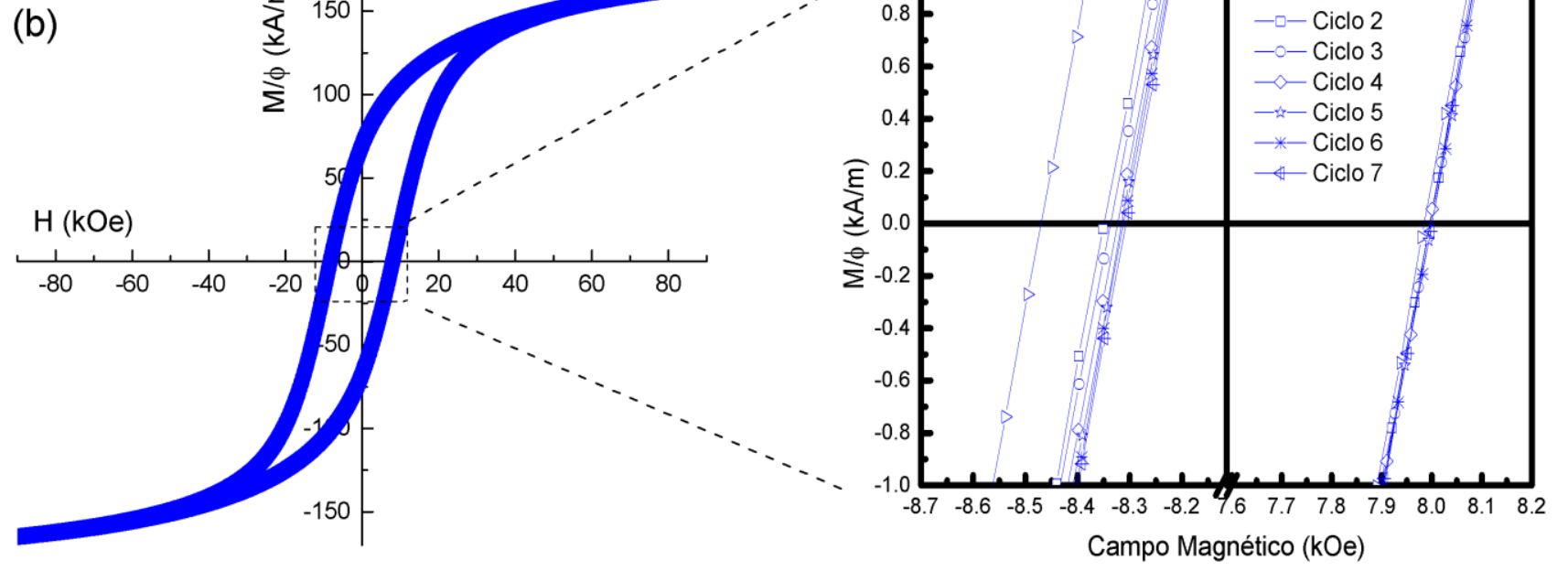

Figura 44: Ciclos de histerese magnética medidos consecutivos a $5 \mathrm{~K}$ para amostras de (a) pó e (b) ferrofluido diluído, os inserts mostram a região central dos ciclos de histerese.

Após determinamos o $H_{E X}$ pela equação 72 para cada ciclo medido, construímos o gráfico $H_{E X}$ versus $n$ para ambas as amostras exibidos na Figura 45. Ajustamos as curvas com a equação 39, do modelo de Paccard et al.(PACCARD et al., 1966; SCHLENKER; PACCARD, 1967). Esta expressão segue a dependência experimental do campo $H_{E X}$, para $n \geq 2$ visualizado na linha sólida vermelha. Conseguimos um bom ajuste com os pontos experimentais, mas quando o primeiro ponto é incluído na linha tracejada da cor preta, o ajuste é insatisfatório como observamos na Figura 45. 

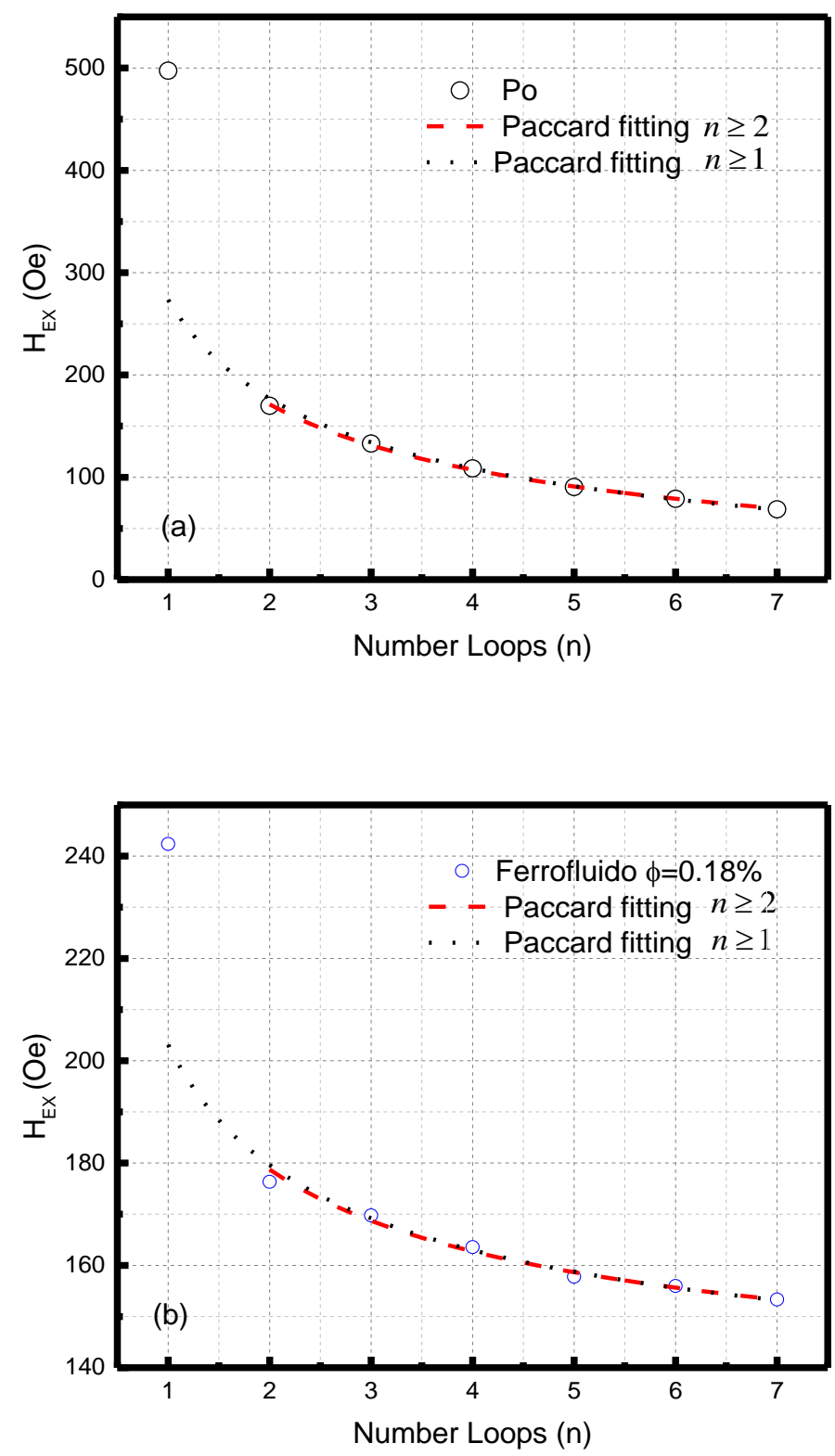

Figura 45: Dependência do Exchange Bias para amostras (a) pó e (b) ferrofluido diluído. Com o ajuste da curva com a equação 39 encontramos os valores de $k$ e $H_{E X}^{\infty}$ para as amostras de ferrofluidos diluído e pó compacto. Utilizamos o ajuste com $n \geq 2$ (linha solida vermelha) para servir de input, para $n \geq 1$ (linha tracejada em preto) o ajuste é insatisfatório.

A partir do ajuste dos dados experimentais com $H_{E X}-H_{E X}^{\infty}=k / \sqrt{n}$ encontramos os seguintes valores de $k=77.31$ Oe e $H_{E X}^{\infty}=127.07$ Oe para o ferrofluido diluído congelado com $\phi=0.18 \%$, e para o pó $k=308.92$ Oe e $H_{E X}^{\infty}=-47.12$ Oe, os resultados foram reunidos na Tabela 13. Em ambos os casos a equação 39 não pode explicar o relaxamento abrupto no treinamento atérmico para $\mathrm{n}=1$. Encontramos um valor negativo para o campo de exchange bias quando 
$H_{E X}$ se estabiliza no limite de infinitos ciclos para o pó $\left(H_{E X}^{\infty}\right)$. As interações dipolares intrapartículas e de exchange entre os spins de superfícies em contato e o tamanho reduzido das partículas possivelmente potencializam o efeito, uma vez que para o regime diluído o $H_{E X}^{\infty}$ se estabiliza num valor bem próximo do valor $H_{E X}$ inicial. Nos indica que o efeito visualizado, num sistema de partículas não interagentes, é devido as interações de exchange entre o núcleo e a casca no interior da NPs-CS. Esses resultados servirão de input para os demais modelos utilizados nas interpretações do fenômeno.
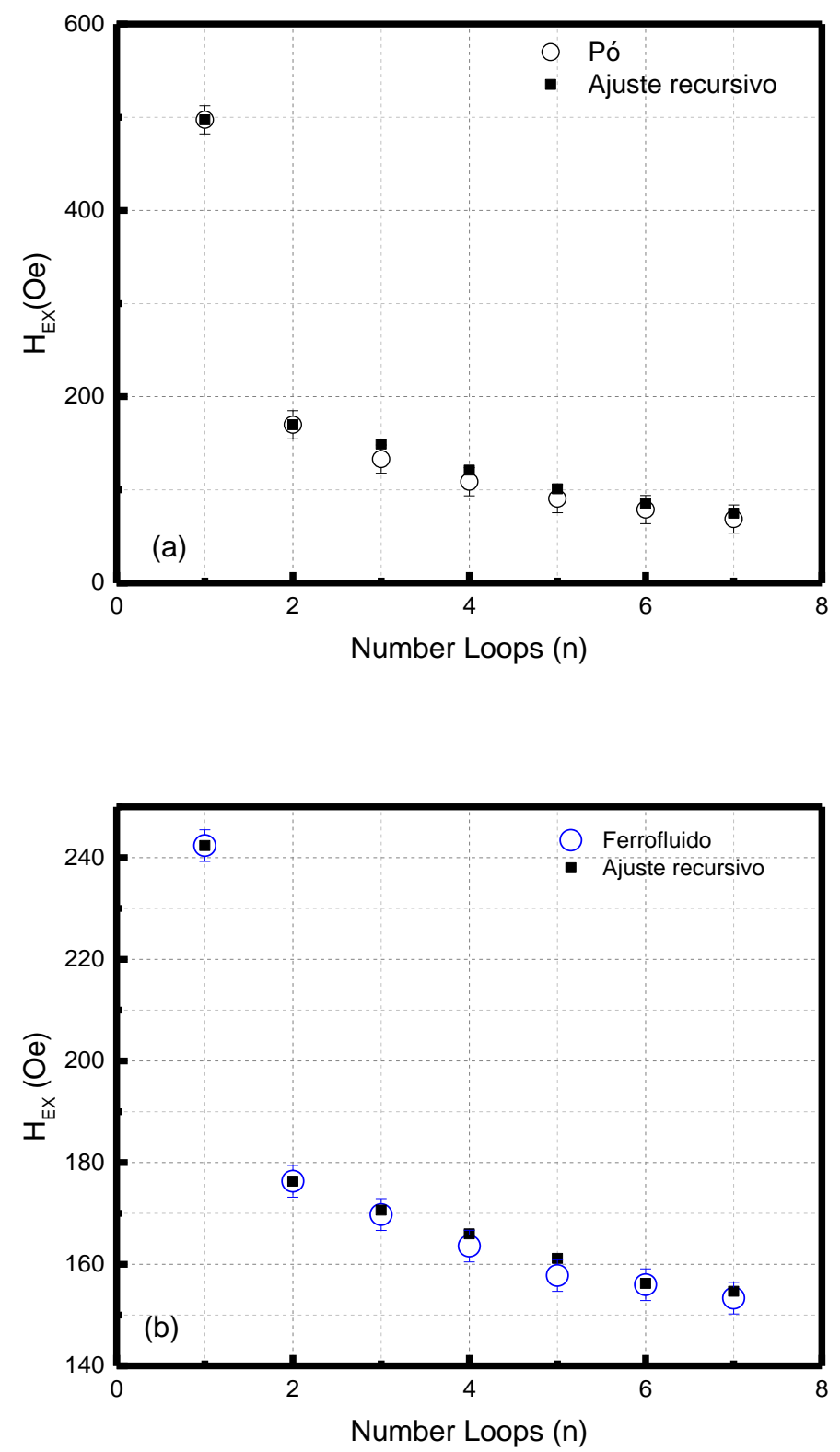

Figura 46: A figura reuni os dados extraídos dos ciclos de histerese magnética no protocolo $\mathrm{FC}$ e $\mathrm{H}_{E X} v s n$ (ciclos abertos) obtidos para o ferrofluido diluído (azul) e pó compacto (preto) da amostra de ferrita de cobalto. Quadrados da cor preta são o ajuste recursivo pelo modelo de Binek. 
Para descrever o fenômeno de relaxamento do exchange bias com ciclos sucessivos de forma completa utilizamos o modelo de Binek (BINEK, 2004) que utiliza os resultados do modelo de Paccard et al. como imput do seu modelo. O parâmetro $\gamma$ que descreve a força absoluta do efeito de treinamento, calculado a partir das informações extraídas do ajuste com o modelo de Paccard et al. na equação 41, o ajuste recursivo do modelo de Binek é calculado pela equação 40, os quadrados sólidos mostram o ajuste quando incluído n =1 na Figura 46 para ambas as amostras.

Os valores de $\gamma$ apresentados na Tabela 13, são obtidos de uma a duas ordens de grandeza menores do que relatado para bicamadas $\mathrm{Co} / \mathrm{CoO} \gamma=5 \times 10^{-4} \mathrm{Oe}^{-2}$ (ALI et al., 2012). Isto pode ser interpretado como sendo devido a existência de um acoplamento mais forte entre o núcleo (FI) e a casca (SGL) das nossas NPs-CS, sempre que observamos o ferrofluido diluído congelado sondamos a partícula de forma individual e o fenômeno observado é intrapartícula. Guo et al. investiga o efeito de treinamento em nanocompósitos de $\mathrm{Ni} / \mathrm{NiO}$ e encontra uma diminuição de $2.2 \mathrm{kOe}$ para o segundo $1.5 \mathrm{kOe}$. O parâmetro de relaxamento de $\gamma=1.46 \times 10^{-7} \mathrm{Oe}^{-2}, \gamma$ encontrado por Guo et al. é muito pequeno e nos mostra uma grande redução, 68\% entre o primeiro e segundo ciclo (GUO et al., 2010). Encontramos resultados com mesma característica para amostra pó que apresenta uma redução similar de $72 \%$.

Tabela 13: Resultados dos ajustes de Paccard et al. e Binek para as amostras de ferrofluido diluído e pó com tempo de espera entre os ciclos $t_{W}=0 s . T E_{n}(\%)$ entre o primeiro e segundo ciclo.

\begin{tabular}{ccccc}
\hline Amostra & $\begin{array}{c}H_{E X}^{\infty} \\
(\mathrm{Oe})\end{array}$ & $\begin{array}{c}k \\
(\mathrm{Oe})\end{array}$ & $\begin{array}{c}\gamma \\
\left(\times 10^{-6} \mathrm{Oe}^{-2}\right)\end{array}$ & $\begin{array}{c}T E_{n} \\
(\%)\end{array}$ \\
\hline \hline Ferrofluido & 124.07 & 77.31 & 39.9 & 72.8 \\
Pó & -47.12 & 308.92 & 2.02 & 34.2 \\
\hline
\end{tabular}

Proenca et al. investiga nanotubos de $\mathrm{Co} / \mathrm{CoO}$ com quatro e nove meses de oxidação natural que apresentam $\gamma \sim 2.3 \times 10^{-6} \mathrm{Oe}^{-2} \mathrm{e} \sim 1.7 \times 10^{-4} \mathrm{Oe}^{-2}$, respectivamente (PROENCA et al., 2013a). Os valores de $\gamma$ são proporcionais ao inverso do quadrado da constante de acoplamento entre as camadas FM/AFM $\gamma=\left(b / \sigma^{2} \xi^{\prime}\right)$. Portanto, o aumento observado de $\gamma$ com aumento da espessura $t_{A F M}$ para estrutura nanotubular FM/AFM pode ser interpretado como uma diminuição da constante de acoplamento entre a AFM e camadas de FM ao aumentar a espessura da camada de AFM. Para nosso caso, as interações de superexchange e dipolares presentes no pó fazem o papel de diminuir $\gamma$, aumentando a quantidade de metaestados dos spins da camada SGL. 
Observando a Figura 46 um decaimento acentuado após o ciclo 1 é visualidado e para o pó é mais intenso. Quantificamos essa diminuição relativa de $H_{E X}$ a partir do primeiro para o sétimo ciclo pela expressão (VENTURA et al., 2008; PROENCA et al., 2013a) por:

$$
T E_{n}(\%)=\left(1-\frac{\left(H_{E X}^{1}-H_{E X}^{n}\right)}{H_{E X}^{1}}\right) \times 100(\%) .
$$

Estudos atribuíram a forte diminuição $H_{E X}$ do primeiro para o segundo ciclo a um estado de não-equilíbrio ou um arranjo metaestável dos spins da camada AFM com o ciclismo do campo (SUESS et al., 2003; ALI et al., 2012; PROENCA et al., 2013b). Uma redução do exchange bias é observada em ambas as amostras utilizando a equação 74. Para ferrofluido líquido diluído encontramos $72.8 \%$ do total entre o primeiro e o segundo ciclo, observa-se, enquanto que para os ciclos subsequentes EB diminua 2\%, entre o segundo e sétimo ciclo de $63.25 \%$ do total. Para o pó compacto existe uma grande redução entre os ciclos 1 e o 2 para $34.2 \%$ do total, entre 2 e 3 de $7.46 \%, 3$ e 4 de $4.89 \%$, 4 e 5 de $3.66 \%, 5$ e 6 de $2.39 \%$ e entre 6 e 7 ciclos de $2 \%$. Com uma redução do efeito do treinamento de $86.21 \%$ entre o 1 e o 7 ciclo.

Peng et al. reporta que amostras de NPs-CS monodispersas de $\mathrm{Co} / \mathrm{CoO}$ com 6 nm que o efeito do treinamento e relaxamento magnético pode ser interpretado pela hipótese de distúrbios nos spins na camada interfacial entre o $\mathrm{CoO}$ antiferromagnético (casca) e o Co ferromagnético (núcleo) (PENG et al., 2000). A diminuição de $H_{E X}$ é maior para o segundo ciclo e então torna-se inalterada após mais números de ciclos de treinamento e chega a uma redução de $89 \%$ entre o primeiro e décimo quarto ciclo. Tian et al. investiga nanocompósitos $\mathrm{NiFe}_{2} \mathrm{O}_{4}(31 \mathrm{~nm}) / \mathrm{NiO}(12 \mathrm{~nm})$ com campo de cooling de $40 \mathrm{kOe}$ a $10 \mathrm{~K}$, e observa uma redução de $H_{E X}$ em cerca de 55\% do valor do primeiro ciclo para o nono ciclo (TIAN et al., 2009).

Observamos na amostra pó que após o segundo ciclo a diminuição não é constante. Acreditamos que ainda existam configurações metaestáveis na casca (SGL) induzidas pelo comportamento coletivo (interações dipolares e exchange entre spins de superfície de partículas em contato) do estado de vidro de superspins, que potencializam as interações de exchange na interface entre o núcleo e a casca. Na superfície SGL, defeitos estruturais e de substituição, dão origem a orientação privilegia de alguns spins presos (spins canted), assim, conduzindo a estruturas metaestáveis cuja evolução com o ciclismo do campo é responsável para o efeito treinamento (TE).

Utilizando o modelo de Zheng et al. para observar como os spins congelados se comportam na região de interface entre o núcleo e a superfície com ciclismo da histerese magnética em nossas amostras (ZHENG et al., 2004a), este leva em consideração a diferença 
de magnetização reduzida, em nosso casso utilizamos o campo de $9 \mathrm{~T}$ para nossos experimentos, $\Delta \mathrm{M}(9 \mathrm{~T}) / \mathrm{M}_{\mathrm{R}}(9 \mathrm{~T})$. Os desvios dos ciclos de histerese em ambas as direções horizontal e vertical estão relacionados com os spins congelados. $\mathrm{O}$ alinhamento dos spins congelados ao longo da direção do campo de cooling reduz a energia de pinning eficaz. Por isso ele diminui com o ciclismo de campo.

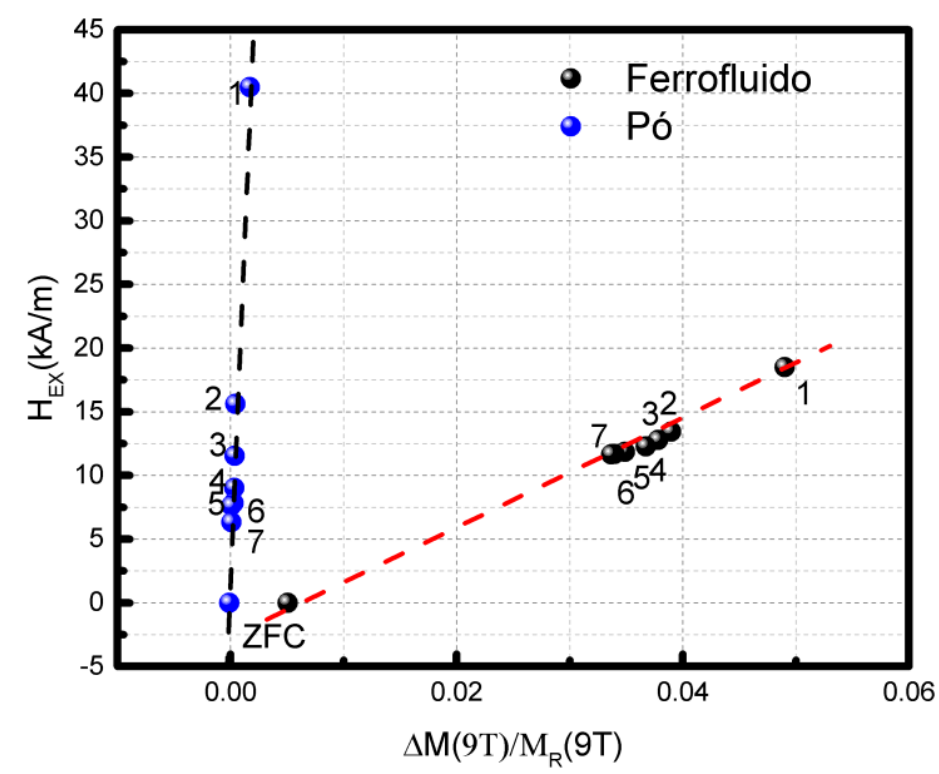

Figura 47: Dependência da magnetização reduzida com o exchange bias para as amostras pó e ferrofluido diluído, as linhas tracejadas são apenas guias para os olhos.

Extraímos a partir dos dados experimentais $H_{E X}, M_{S}$ e $M_{R}$ dos sete ciclos de histerese magnética, que possibilita a construção do gráfico da dependência $H_{E X} \operatorname{com} \Delta M(9 \mathrm{~T}) / M_{R}(9 \mathrm{~T})$ para os sete ciclos medidos com a expressão 48. Também utilizamos com os dados extraídos dos ciclos ZFC (Figura 30). Apresentamos na Figura 47 a dependência do $H_{E X}$ com a magnetização reduzida para as amostras de ferrofluido diluído e pó. A dependência quase linear manifesta o papel crucial dos spins congelados na determinação do exchange bias. Com o ciclismo alguns spins se desprendem se alinhando com os spins do núcleo reduzindo a energia de troca entre o núcleo e a casca.

Para ambas amostras observamos a tendência dos ciclos irem na direção do ciclo ZFC. $\mathrm{Na}$ amostra pó a magnetização reduzida diminui abruptamente aproximando-se rapidamente do ponto que representa o ciclo ZFC, por outro lado para amostra de ferrofluido diluído verificamos que precisaria medir mais ciclos para poder se aproximar do ciclo ZFC. Lembrando do valor do $H_{E X}^{\infty}=127.07$ Oe, de equilíbrio para o enésimo ciclo, concluímos que é impossível para esta amostra atingir o estado de magnetização do clico ZFC. Para o pó notamos que mais 
alguns ciclos medidos o estado seria atingido e possivelmente induzir o exchange bias positivo pelo efeito de treinamento na amostra, como o induzido por Mishra et al. para bicamadas de $\mathrm{NiFe} / \mathrm{IrMn}$ (MISHRA et al., 2009).

Observamos que efeito de treinamento para nossas amostras é bem explicado pelo modelo Stoner \& Wohlfarth modificado. Os desvios dos ciclos de histerese em ambas as direções horizontal e vertical pode estar relacionado com a fração de spins congelados, cujas alterações da configuração faz com que alguns spins se alinhem com campo de cooling com o ciclismo medido. A diminuição dos spins congelados ao longo da direção do campo de cooling reduz a energia de pinning eficaz. Por isso, ele diminui com o ciclismo de campo. Este modelo não leva em consideração os spins rodáveis que contribuem significativamente para o exchange bias.

A existência de uma região de interface entre as fases magnéticas moles e duras distintas para nossas NPs-CS é confirmada pelo forte efeito de exchange bias e os spins rodáveis são uma das principais causas da instabilidade magnéticas interfaciais. A dinâmica das rotações na interface irreversível/reversível é investigada aqui. Radu et al. (RADU; ZABEL, 2008a; MISHRA et al., 2009) sugerem que ambos as componentes relativas aos spins congelados e rodáveis são afetadas pelas inversões da magnetização do núcleo (FI). Além disso, as componentes mistas de acoplados FI e SGL contribuirão distintamente, através das diferentes taxas de relaxamento, para o efeito do treinamento, sendo impossível descrevê-lo por uma única exponencial.

Para este cenário Mishra et al. descreve o relaxamento de $H_{E X}$ em função do índice $n$ de ciclos agora considera um cenário misto, com duas contribuições importantes para a formação do exchange bias, as duas diferentes taxas de relaxamento para componentes de spins não compensados congelados e rodáveis na interface reescrevendo a equação (50) onde $f$ e $r$ denota a contribuição dos componentes spins congelados e rodáveis. Os parâmetros A têm dimensão do campo magnético, enquanto o parâmetro $\mathrm{P}$ tem dimensão adimensional e se assemelha a um tempo de relaxamento, onde a variável contínua é substituída por uma variável discreta, isto é, o índice $n$ do ciclismo da histerese magnética. Os parâmetros são derivados do ajuste equação (50) nos dados experimentais, ajustando-se perfeitamente em ambas amostras como visualizamos na Figura 48. Os parâmetros encontrados estão reunidos na Tabela 14. 

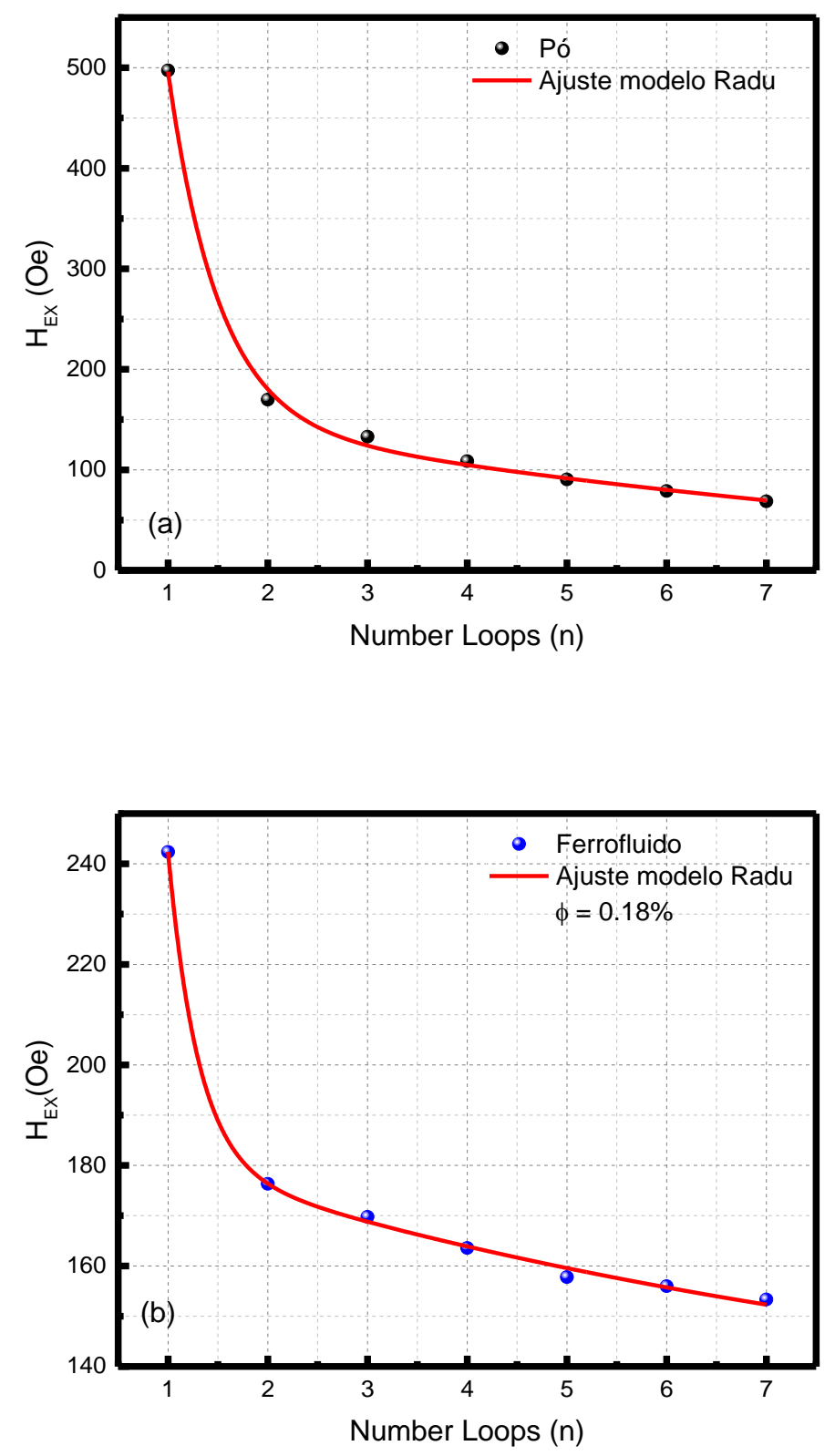

Figura 48: Efeito de treinamento das amostras aqui investigadas (a) pó e (b) ferrofluido. A linha sólida de cor vermelha é o ajuste com modelo Radu et al. que leva em consideração as contribuições dos spins congelados e rodáveis.

Para diminuir a incerteza dos valores dos ajustes, uma vez que possuímos cinco variáveis na expressão para ajustar, utilizamos o valor de equilíbrio do exchange bias $\left(H_{E X}^{\infty}\right)$ encontrado pelo modelo de Paccard et al. como input da expressão de Radu et al., já que esta é uma derivação da equação de Binek como vimos na seção 2.2.3. 
Tabela 14: Parâmetros encontrados do ajuste das curvas de efeito de treinamento utilizando o modelo de Radu et al.

\begin{tabular}{cccccc}
\hline Amostra & $\begin{array}{c}A_{f} \\
(\mathrm{Oe})\end{array}$ & $\begin{array}{c}A_{r} \\
(\mathrm{Oe})\end{array}$ & $P_{f}$ & $P_{r}$ & $P_{r} / P_{f}$ \\
\hline \hline Ferrofluido & 1718.86 & 62.96 & 0.301 & 8.72 & 28.96 \\
Pó & 2516.94 & 213.10 & 0.505 & 11.62 & 23.00 \\
\hline
\end{tabular}

A razão $P_{r} / P_{f}$ indica como os spins rotativos se reorganizam mais rapidamente do que os spins congelados (MAITY et al., 2013). Para amostra de ferrofluido diluído congelado encontramos $P_{r} / P_{f} \sim 29$ indicando que os spins rodáveis se reorganizam cerca de 29 vezes mais rapidamente do que os spins congelados, nesta amostra livre de interações dipolares os spins rodáveis possuem um grau de liberdade maior para mudar de direção. Para amostra pó $P_{r} / P_{f} \sim$ 23, houve uma clara diminuição da relação ao ferrofluido diluído, que pode ser explicado pelas interações dipolares e de exchange entre as NPs-CS que dificultam os spins rotativos de girar, já que precisa de uma energia maior para vencer o efeito das interações presentes.

Para bicamadas $\mathrm{CoO}(40 \AA) / \mathrm{Fe}(150 \AA) / \mathrm{Al}_{2} \mathrm{O}_{3}$ observa-se uma contribuição acentuada devido à baixa anisotropia dos spins AFM na interface e uma diminuição muito mais fracos do spins congelados não compensados (RADU; ZABEL, 2008a) encontram um valor de $P_{r} / P_{f} \sim$ 11.1. Para amostras de $\gamma-\mathrm{Fe}_{2} \mathrm{O}_{3}$ ocas de $14.8 \mathrm{~nm}$ foi encontrado um valor de $P_{r} / P_{f} \sim 7.02$ que indica que os spins reversíveis reorganizar 7 vezes mais rápido do que os spins irreversíveis a $10 \mathrm{~K}$ (KHURSHID et al., 2015). Para nanocompósitos de $\mathrm{BiFeO}_{3}(112 \mathrm{~nm}) / \mathrm{Bi}_{2} \mathrm{Fe}_{4} \mathrm{O}_{9}(19 \mathrm{~nm})$ a razão $P_{r} / P_{f} \sim 5$ os spins rodáveis se reorganizam cerca de 5 vezes mais rapidamente do que os spins congelados (MAITY et al., 2013). Em bicamadas de $\operatorname{NiFe}(7.5 \mathrm{~nm}) / \operatorname{IrMn}(3.5 \mathrm{~nm})$ distingue-se uma clara contribuição devido aos spins não compensadas na interface e uma diminuição muito mais fraco da spins congelados descompensados. A componente congeladas exibe uma relaxação 10 vezes mais lenta em comparação com a outra (MISHRA et al., 2009).

Comparando nossos resultados com alguns vistos na literatura, observamos que com a diminuição da estrutura magnética aumenta-se a razão entre as componentes $P_{r} / P_{f}$. Supomos que seja devido a menor energia para prender spins congelados. Consequentemente os spins de superfície de nossas amostras rotacionam mais rapidamente por consequência da espessura do da casca de $0.27 \mathrm{~nm}$.

\section{Dependência térmica do efeito de treinamento}

Resolvemos observar o efeito de treinamento a $30 \mathrm{~K}$, região um pouco abaixo da Temperatura de Bloqueio deduzida via as análises da dependência do campo coercivo $\left(T_{B i}\right)$ 
com a temperatura $(\sim 32 \mathrm{~K})$ e pelo $\left\langle T_{B}\right\rangle$ do pico da derivada $-d\left(M_{F C W}-M_{Z F C}\right) / d T$ versus $\mathrm{T}(\sim 37$ $\mathrm{K})$. O exchange bias e o efeito do treinamento desaparece necessariamente acima da Temperatura de Bloqueio $\left(T_{B}\right)$. A relação de EB com o aumento da temperatura é em regra destrutiva, isto é, ao passo que a temperatura é aumentada os spins da casca adquirem energia suficiente para se desacoplarem do núcleo (entrando num estado "paramagnético") não influenciando nas propriedades magnéticas da partícula (BINEK; HE; POLISETTY, 2005). Em $T_{B}$ a contribuição da magnetização da camada de pinning vai à zero.

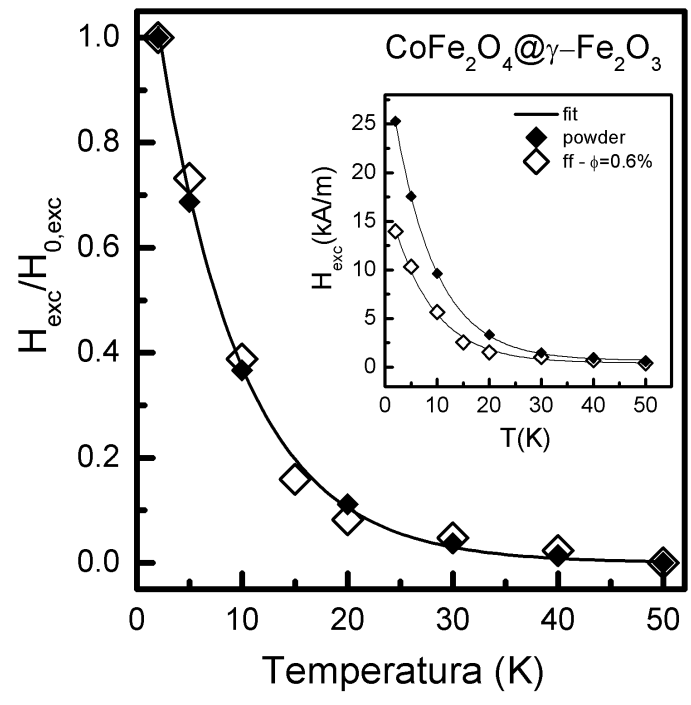

(a) dependência de $H_{E X} \times T$

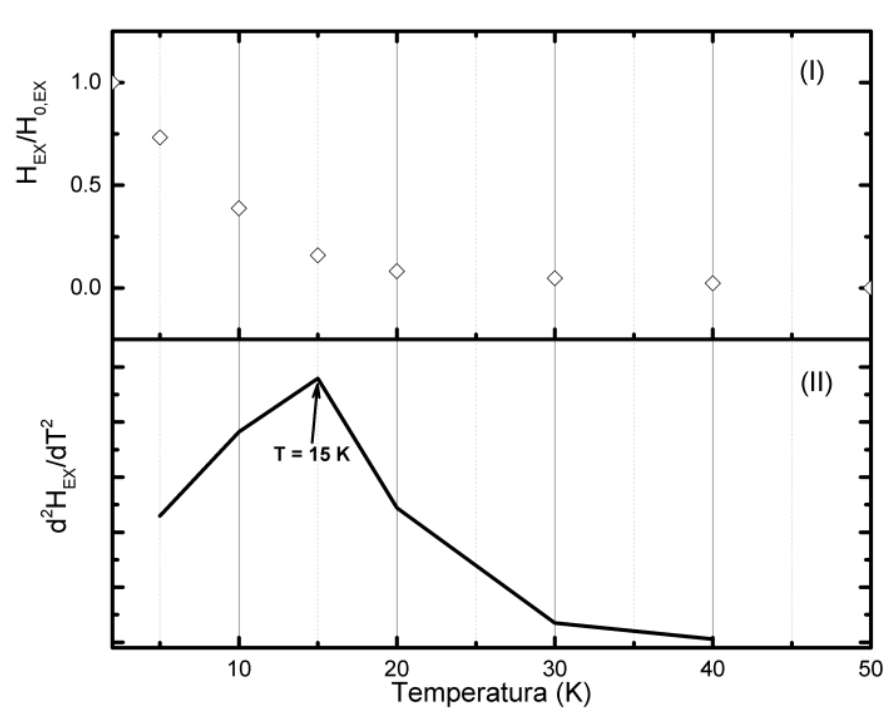

(b) ponto de inflexão

Figura 49: (a) apresenta a dependência de $H_{E X} \times T$, para amostras ultrapequenas de Ferrita de Cobalto normalizados pelo $H_{0, E X}$ quando $H_{e x}$ tende $0 \mathrm{~K}$ para pó e dispersão congelada da Co3. O insert apresenta os mesmos dados. As linhas sólidas são os melhores ajustes encontrados pela lei de resfriamento. Os dados da amostra Co3 foram gentilmente cedidos por R. Cabreira-Gomes. (b) em (I) apresenta curva $H_{E X} \times T$ para a amostra de ferrofluido diluída $\mathrm{Co} 3$ e (II) a segunda derivada da curva, evidenciando pela ponto de inflexão a temperatura em que o exchange bias tem um aumento acentuado.

Resultados da dependência do $H_{E X}$ com a temperatura (CABREIRA-GOMES et al., 2014) da amostra Co3 de cobalto com $d_{r x} \sim 3.15 \mathrm{~nm}$ indicam o total desaparecimento de $H_{E X}$, para ferrofluido diluído congelado e pó em $\mathrm{T}_{\mathrm{B}}$ resultados visualizado na Figura 49. Um decaimento monótono é observado em ambos os casos, esses são ajustados com um decaimento exponencial, lei de resfriamento típica, $H_{E X}=H(0)_{E X} \exp \left[-\left(T / T_{f}\right)\right], T_{f}$ é a temperatura característica onde todos os spins da casca estão congelados. O total desaparecimento de $H_{E X}$ acima de $T \approx 40 \mathrm{~K} \mathrm{em}$ ambas as séries de medidas, corrobora com o $T_{B}$ deduzido por $H_{C} v s T$. Outra característica importante é a temperatura de congelamento $T_{f} \sim 7.9 \mathrm{~K}$, nesta todos os 
spins estão congelados contribuindo para o exchange bias, mostrado na Figura 49 (a). Essas duas características confirmam que o $H_{E X}$ em pós e dispersões congeladas encontra sua origem no mesmo processo físico, ou seja, as interações de exchange na interface entre o núcleo e a superfície desordenada. Os resultados em temperatura estão em conformidade com os apresentados na Figura 49 (a), onde as amplitudes de $H_{E X}$ são maiores nos pós que nas dispersões em toda a variação de temperatura, confirmando a diferença entre os processos de interação inter e extrapartículas.

A Figura 49 (b) em (I) exibe a curva normalizada do ferrofluido diluído congelado e em (II) a derivada segunda $d^{2} H_{E X} / d T^{2} v s$ temperatura da amostra. $\mathrm{O}$ pico corresponde à temperatura a qual o exchange bias exibe um rápido aumento em $15 \mathrm{~K}$. Este rápido aumento de $H_{E X}$ ocorreu com campo de cooling de $7.5 \mathrm{kOe}$. A literatura atribui este pico como aumento exponencial de spins rotativos sendo congelados influenciando no exchange bias em NPs-CS (CHANDRA et al., 2012). Chandra et al. observam que em NPs-CS de Fe@ $\gamma$ - $\mathrm{Fe}_{2} \mathrm{O}_{3}$ a posição do pico tem uma variação insignificante com o campo de cooling, encontrando $21.5 \mathrm{~K}$ e $20 \mathrm{~K}$ com campos de cooling de $20 \mathrm{kOe}$ e $50 \mathrm{kOe}$, respectivamente. Eles atribuem esta temperatura como $T_{f}$ do shell $\left(T_{f-s h}\right)$. Inferior a $15 \mathrm{~K}$ a casca possui um acréscimo expressivo no congelamento dos spins, o número de centros de pinagem aumenta devido ao intercâmbio de acoplamento maior entre o núcleo e a casca. Este está atribuído ao aumento na densidade de ligações na interface FI/SGL do núcleo e a casca (ou seja, número de spins congelados na interface por unidade de área) e é consistente com os resultados de (EFTAXIAS; TROHIDOU, 2005; GIRI; PATRA; MAJUMDAR, 2011; ONG; LIN; WEI, 2011).

A $30 \mathrm{~K}$ o campo de exchange bias é mínimo para amostra de ferrofluido diluído como exibe a Figura 50, foi medido 7 ciclos de histerese magnética a $30 \mathrm{~K}$ e apresentam uma diminuição expressiva do campo coercivo, magnetização remanente e magnetização de saturação em relação as medidas a $5 \mathrm{~K}$. A partir da nossa discussão anterior, a $32 \mathrm{~K}$ (Temperatura de Bloqueio) o núcleo está congelado com os seus spins alinhados ao longo do campo, e o Shell começa a mostrar um comportamento de bloqueio. Devido à dinâmica lenta dos spins bloqueados $(<32 \mathrm{~K})$ na casca, eles se comportam como centros de imobilização (centros de pinning) levando ao desenvolvimento do exchange bias. Isto marca o início do $H_{E X}$ em NPs-CS. 


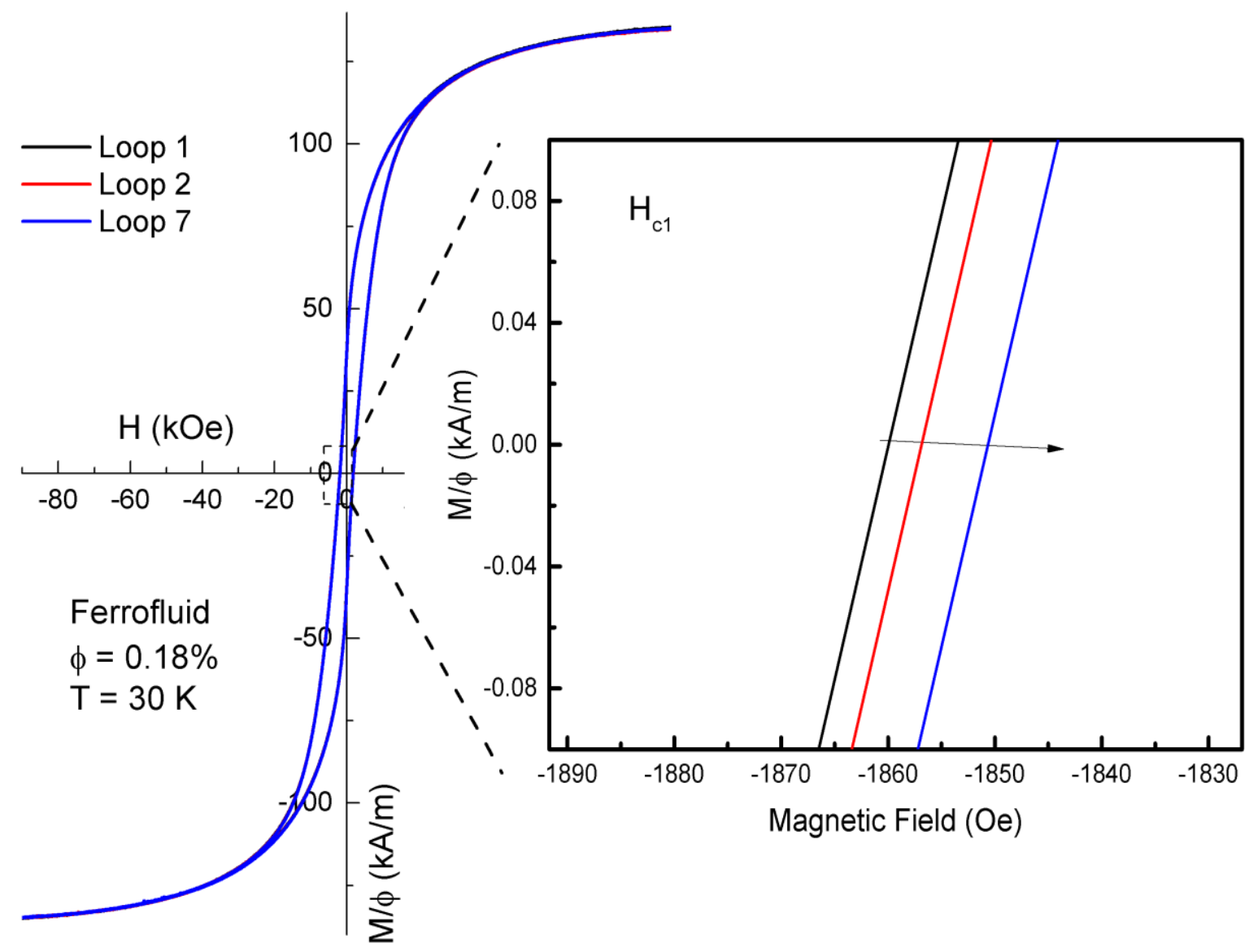

(a) Efeito de treinamento a $30 \mathrm{~K}$

(b) Contração do ciclos medidos

Figura 50: (a) ciclos de histerese magnética a $30 \mathrm{~K}$ da amostra de ferrofluido diluída. (b) exibe os ramos superiores dos ciclos 1,2 e 7 que possibilita visualizamos a contração dos ciclos.

Figura 50 (b) mostra a contração dos ciclos obtidos exibindo o efeito de treinamento nesta temperatura. $\mathrm{O}$ efeito de treinamento nesta temperatura não apresenta o relaxamento abrupto entre os o primeiro e segundo ciclo, Figura 51, diminuindo de modo aproximadamente linear. O efeito de treinamento atérmico, caracterizado por uma supressão abrupta de Hc e Hex entre o primeiro e o segundo ciclos consecutivos de medição, Hoffmann (HOFFMANN, 2004) propõem que o efeito do treinamento atérmico ocorre devido a um acoplamento spin-flop-like e que a configuração de spins inicial não pode ser restaurada. Próximo de $T_{B}$ existem apenas pequenos desvios do equilíbrio na interface de magnetização da casca (SGL) que afeta a energia livre que controla o processo de relaxamento. $\mathrm{O}$ equilíbrio é atingido mais rapidamente. Em temperaturas próximas do $T_{B}$ o efeito de treino atérmico desaparece. Apresentamos na Figura 51, a dependência do EB com número de ciclos para $30 \mathrm{~K}$ e comparamos com os resultados já apresentados com a temperatura de $5 \mathrm{~K}$. 


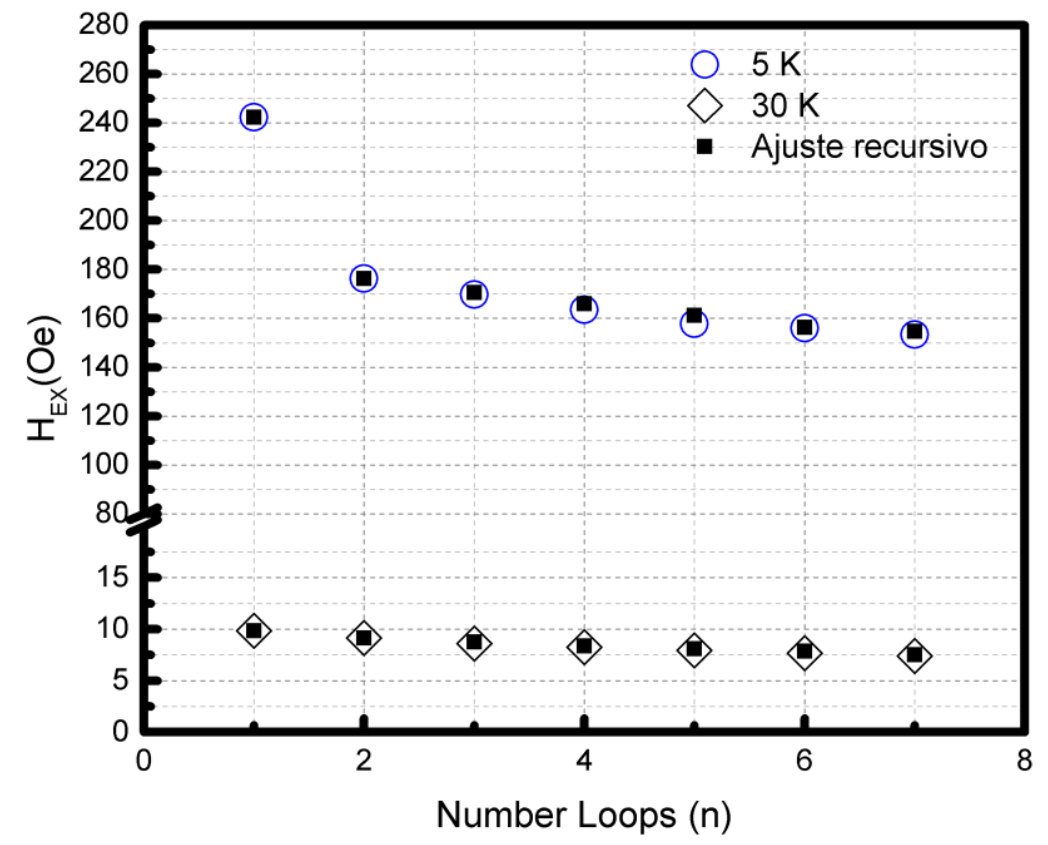

Figura 51: Dependência o EB com número de ciclos de histerese para as duas temperaturas, o quadrado sólido é o ajuste recursivo feito em ambas temperaturas.

A dependência de temperatura do efeito de treino do exchange bias nas duas temperaturas, 5 e $30 \mathrm{~K}$, é apresentado Figura 51. Usando o modelo de Binek, equação 40, encontramos $H_{E X}^{\infty}=6.12$ Oe e $\gamma=1.36 \times 10^{-2} \mathrm{Oe}^{-2}$ para a temperatura de $30 \mathrm{~K}$, TE $1(\%)$ entre o primeiro e o segundo é de $92 \%$. A dependência da temperatura no efeito de treino está de bom acordo entre os resultados experimentais com o modelo de Binek e indica a precisão qualitativa do modelo de relaxamento dos spins da camada de pinning utilizado nestes sistemas até aqui. A Temperatura de Bloqueio aqui obtido é perfeitamente compatível com os nossos dados e o efeito do treinamento há $30 \mathrm{~K}$ é ínfimo. A 30K o exchange bias é reduzido, e a sua formação não é bem descrito pelo modelo de Radu et al. ou mais modelos lei de potência de decaimento convencionais, mas sim diminui de forma aproximadamente linear.

\section{Influencia do envelhecimento do efeito de treinamento}

O efeito de envelhecimento influencia nas propriedades magnéticas da camada de pinning que induz o exchange bias. Dependendo do tempo de espera $\left(t_{w}\right)$ alguns spins congelados e rodáveis conseguem se desprender e rotacionar na direção do campo de cooling aplicado, influenciando no exchange bias medido. Del Bianco et al. observam uma estreita ligação exchange bias com o efeito de envelhecimento em nanopartículas de Fe dispersas numa 
matriz de óxido de Fe. Verificam um aumento do exchange bias com tempo de parada $\left(t_{w}\right)$ com campo ligado onde se inicia a medição do ciclo, atribuem como consequência a natureza vítrea da matriz do óxido (DEL BIANCO; FIORANI; TESTA, 2007). Binek prova que o tempo de parada entre os ciclos não influência nas propriedades dos ciclos, mas sim a configuração inicial da camada de pinning antes da obtenção do primeiro ciclo (BINEK, 2004). À vista disso propomos observar os efeitos de envelhecimento no efeito de treinamento seguindo os protocolos de medida apresentados no apêndice C.1 para amostra pó e ferrofluido diluído.

O Intuito desde experimento é tentar desprender alguns spins congelados juntamente com os rodáveis da casca com o envelhecimento (tempo de parada com campo ligado), antes e depois do primeiro ciclo medido e observar se as propriedades dos ciclos variam em relação ao processo sem paradas $\left(t_{w}=0 \mathrm{~s}\right)$. A Figura 52 apresenta a dependência do exchange bias em função dos ciclos medidos para amostra pó com tempos de parada entre cada ciclo de 0, 600 e $6000 s$ feitos após a medição do primeiro ciclo, $\mathrm{n}>1$.

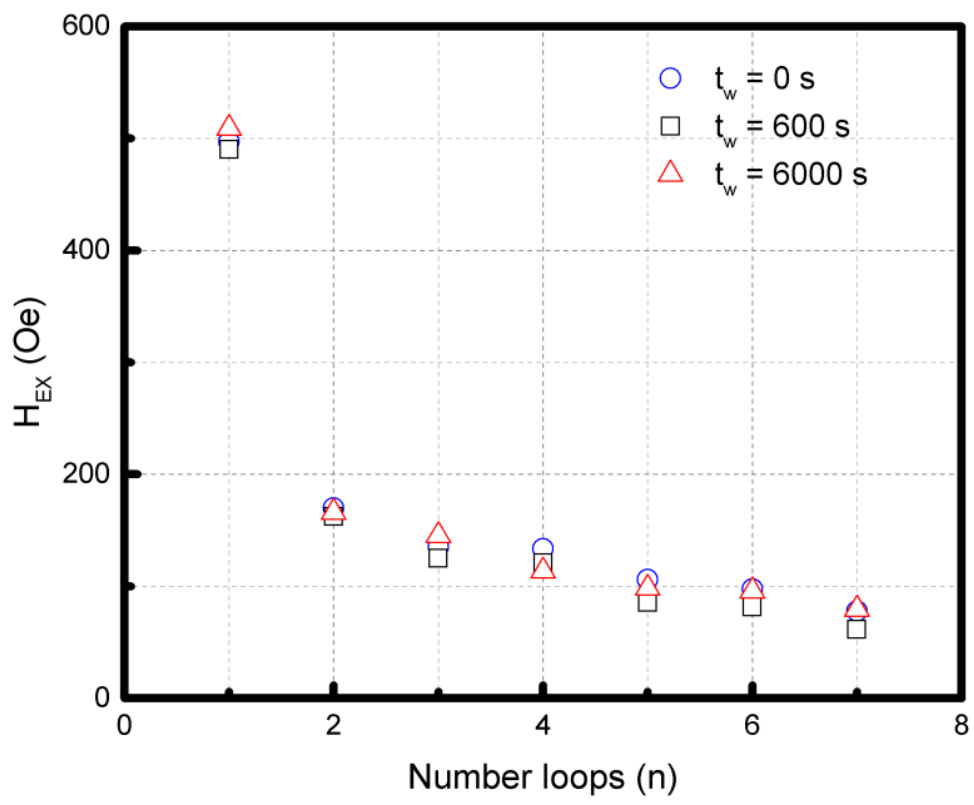

Figura 52: Efeito de treinamento para amostra pó com tempos de parada diferentes após o primeiro ciclo.

Claramente observamos que o envelhecimento após o primeiro ciclo medido não influência na dinâmica não linear do efeito de treinamento, uma vez que a configuração da camada de pinning inicial não foi alterada, corroborando com as afirmações de Binek. Com o ajuste do modelo de Binek extraímos os parâmetros das curvas e reunidos na Tabela 15 (BINEK, 2004). Os parâmetros apresentam uma variação insignificante, revelando que o sistema "memorizou" o estado dos spins da casca (camada de pinning) no primeiro ciclo e 
transmitindo, independentemente do tempo de parada entre os ciclos, para os demais ciclos medidos. Não alterando a dinâmica não linear do sistema no efeito de treinamento.

Tabela 15: Parâmetros extraídos do modelo de Binek para amostra pó com protocolo de envelhecimento com tempos de parada $\left(t_{w}\right)$ diferentes.

\begin{tabular}{cccccc}
\hline Amostra & $\begin{array}{c}t_{w} \\
(\mathrm{~s})\end{array}$ & $\begin{array}{c}H_{E X}^{\infty} \\
(\mathrm{Oe})\end{array}$ & $\begin{array}{c}k \\
(\mathrm{Oe})\end{array}$ & $\begin{array}{c}\gamma \\
\left(\times 10^{-6} \mathrm{Oe}^{-2}\right)\end{array}$ & $\begin{array}{c}T E_{n} \\
(\%)\end{array}$ \\
\hline \hline \multirow{4}{*}{ Pó } & 0 & -47.12 & 308.92 & 2.02 & 34.2 \\
& 600 & -49.07 & 309.15 & 2.09 & 33.11 \\
& 6000 & -48.09 & 311.48 & 2.01 & 32.64 \\
\hline
\end{tabular}

$\mathrm{Na}$ amostra de ferrofluido diluído resolvemos investigar o fenômeno com paradas com campo ligando em $+90 \mathrm{kOe}$ de $6000 \mathrm{~s}$ antes de todos os ciclos de histerese medidos. Escolhemos esta amostra para o experimento para examinar o comportamento na interface FI/SGL das NPsCS sem a influência das interações interpartículas. A ideia desse experimento é forçar o alinhamento de alguns spins em alto campo por um determinado tempo, não muito curto para que dê tempo dos spins congelados e rodáveis rotacionarem da direção do campo de cooling. A Figura 53 (a) e (b) revela que existe uma diminuição do exchange bias medido no primeiro ciclo com $t_{w} 6000 \mathrm{~s}$ (a) e da magnetização reduzida (b) como observamos na região tracejada na cor vermelha da Figura 53 (a) e (b)). Consequência do alinhamento de alguns spins da casca na direção do campo de cooling antes de iniciar o primeiro ciclo, reduzindo o acoplamento de troca entre o núcleo e a casca, resultando na diminuição do exchange bias.
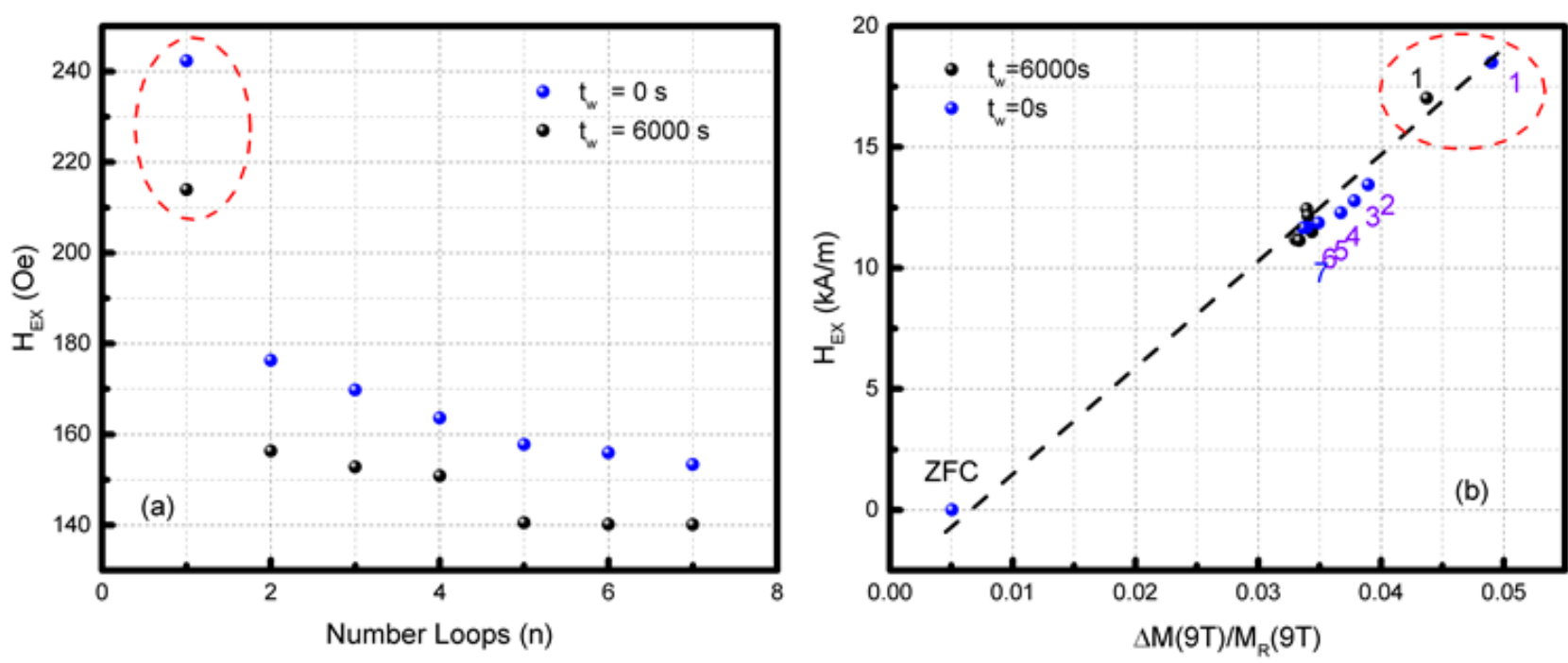

Figura 53: Efeito de treinamento amostra de ferrofluido diluído com parada em +90kOe de $6000 \mathrm{~s}$ antes de todos os ciclos de histerese medidos (a) Dependência do exchange bias com número de ciclos medidos. (b) dependência exchange bias com a magnetização reduzida do modelo de Zheng et al. 
Também apresentamos o ajuste feito com o modelo de Radu et al. na Figura 54 e reunimos os valores dos ajustes na Tabela 16.

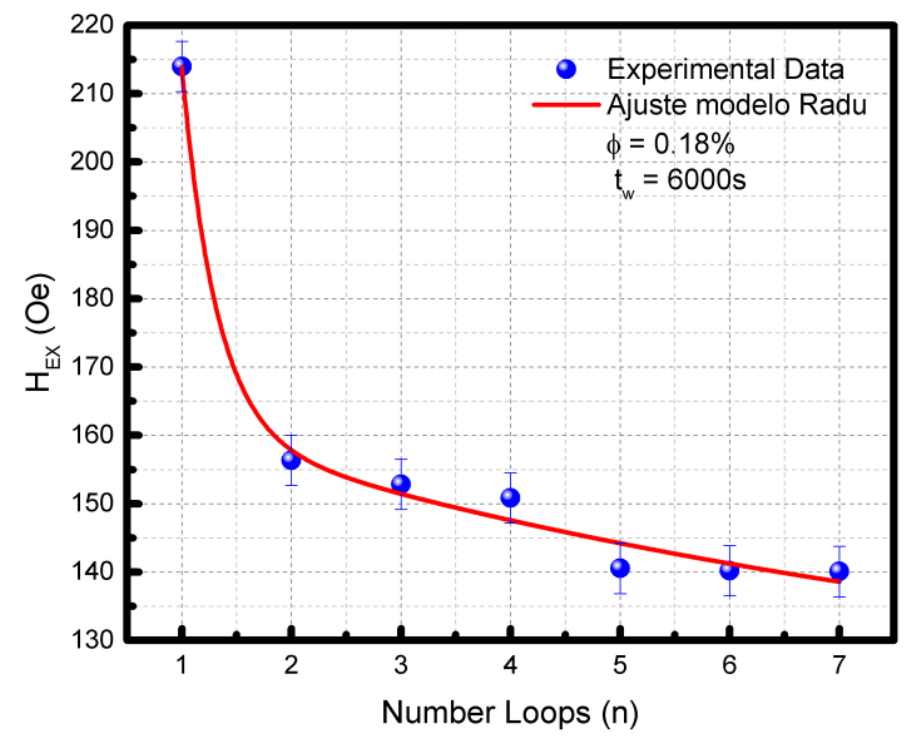

Figura 54: Efeito de treinamento com protocolo de envelhecimento para amostra diluída com ajuste com modelo de Radu et al.

Tabela 16: Resultados extraídos dos modelos de Binek e Radu et al. para amostra de ferrofluido diluído com protocolo de envelhecimento.

\begin{tabular}{ccccccccccc}
\hline \multicolumn{1}{c}{ Modelo de Binek } & \multicolumn{5}{c}{ Modelo de Radu et al. } \\
\hline \hline \multirow{2}{*}{ Amostra } & $\begin{array}{c}t_{W} \\
(\mathrm{~s})\end{array}$ & $\begin{array}{c}H_{E X}^{\infty} \\
(\mathrm{Oe})\end{array}$ & $k$ & $\begin{array}{c}\gamma \\
\left(\times 10^{-5} \mathrm{Oe}^{-2}\right)\end{array}$ & $\begin{array}{c}T E_{n} \\
(\%)\end{array}$ & $\begin{array}{c}A_{f} \\
(\mathrm{Oe})\end{array}$ & $\begin{array}{c}A_{r} \\
(\mathrm{Oe})\end{array}$ & $P_{f}$ & $P_{r}$ & $P_{r} / P_{f}$ \\
\hline \hline \multirow{2}{*}{ Ferrofluido } & 0 & 124.07 & 77.31 & 3.99 & 72.8 & 1718.86 & 62.96 & 0.301 & 8.72 & 28.96 \\
& 6000 & 117.44 & 56.29 & 6.40 & 63.1 & 1267.66 & 48.33 & 0.315 & 8.46 & 26.81 \\
\hline
\end{tabular}

Nossos experimentos vão de encontro aos resultados obtidos por Del Bianco et al. no sistema investigado o $H_{E X}$ aumenta devido à espessura da camada AFM que dificulta os spins de rotacionar (DEL BIANCO; FIORANI; TESTA, 2007). Devido à natureza diferente da camada de pinning de nossas nanopartículas, uma camada superficial SGL muito fina com o campo ligado por $t_{w}=6000 \mathrm{~s}$, alguns spins irão se alinhar progressivamente com campo aplicado devido ao rearranjo da configuração da interface de spins. Em nossos experimentos, o envelhecimento antes de medir o primeiro ciclo modifica a configuração da camada de pinning SGL da casca e esse efeito é transmitido entre todos os ciclos no efeito de treinamento do exchange bias. Com o modelo de Binek extraímos os seguintes parâmetros para amostra com $t_{w}=6000 \mathrm{~s}$ e comparamos com $t_{w}=0 \mathrm{~s}$ reunidos na Tabela 16. Com o envelhecimento no efeito 
de treinamento encontramos exchange bias no equilibrio $\left(H_{E X}^{\infty}\right)$ de 117.44 Oe uma diminuição em torno de $5 \%$ em relação ao medido com $t_{w}=0 \mathrm{~s}$. Enquanto o parâmetro $\gamma$ deduzido é de $6.40 \times 10^{-5} \mathrm{Oe}^{-2}$ com um aumento de $60 \%$, este valor observado de $\gamma$ pode ser interpretado como uma diminuição da constante de acoplamento entre o shell SGL e o core FI ao envelhecer o sistema mostrando o alinhamento de alguns spins. Utilizamos o modelo de Zheng et al. (ZHENG et al., 2004a) para observar o efeito de envelhecimento, os resultados exibidos na Figura 53 (b). Constatamos uma diminuição dos spins congelados ao longo da direção do campo de cooling que reduz a energia pinning eficaz. Por isso ele diminui com o ciclismo de campo. Com o envelhecimento do primeiro ciclo alguns spins se desprendem alinhando se com os spins do núcleo reduzindo a energia de troca entre o núcleo e a casca afetando a magnetização reduzida.

Investigando as contribuições dos spins rodáveis com o modelo proposto por Radu et al. (RADU; ZABEL, 2008a) exposto na Figura 54, equação 50, observamos que a componente dos spins congelados $P_{f}$ possui um aumento e encontramos $P_{r} / P_{f} \sim 26.8$ com um envelhecimento da amostra diluída, indicando uma diminuição da contribuição dos spins rodáveis de se reorganizar cerca de 2 vezes mais lentamente sem envelhecimento isto é explicado devido ao diminuição de spins rotativos que se alinharam com o campo visto em $P_{r}$.

Por fim reunimos todos os valores encontrados com os dois modelos para amostra pó e ferrofluido diluído na tabela 17.

Tabela 17: Valores extraídos dos modelos de Binek e Radu et al. as amostras com efeito de envelhecimento antes e após o primeiro ciclo de histerese magnética medido.

\begin{tabular}{|c|c|c|c|c|c|}
\hline \multirow[b]{3}{*}{$t_{w}$} & \multicolumn{2}{|c|}{ Ferrofluido } & \multicolumn{3}{|c|}{ Pó } \\
\hline & \multicolumn{2}{|c|}{ Antes do primeiro ciclo } & \multicolumn{3}{|c|}{ Após o segundo ciclo } \\
\hline & 0 & 6000 & 0 & 600 & 6000 \\
\hline & \multicolumn{5}{|c|}{ Modelo de Binek } \\
\hline$H_{E X}^{\infty}(\mathrm{Oe})$ & 124.07 & 117.44 & -47.12 & -49.07 & -48.09 \\
\hline$k$ & 77.31 & 56.29 & 308.92 & 309.15 & 311.48 \\
\hline$\gamma\left(\mathrm{Oe}^{-2}\right)$ & $3.99 \times 10^{-5}$ & $6.40 \times 10^{-5}$ & $2.02 \times 10^{-6}$ & $2.09 \times 10^{-6}$ & $2.01 \times 10^{-6}$ \\
\hline \multirow[t]{2}{*}{$T E_{n}(\%)$} & 72.8 & 63.13 & 34.2 & 33.11 & 32.64 \\
\hline & \multicolumn{5}{|c|}{ Modelo de Radu et al. } \\
\hline 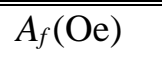 & 1718.86 & 1267.66 & 2516.94 & - & $\begin{array}{l}- \\
\end{array}$ \\
\hline$A_{r}(\mathrm{Oe})$ & 62.96 & 48.33 & 213.10 & - & - \\
\hline$P_{f}$ & 0.301 & 0.315 & 0.505 & - & - \\
\hline$P_{r}$ & 8.72 & 8.46 & 11.62 & - & - \\
\hline$P_{r} / P_{f}$ & 28.96 & 26.81 & 23.00 & - & - \\
\hline
\end{tabular}




\section{Considerações Finais}

As nanopartículas ultrapequenas aqui investigadas foram sintetizadas através do método coprecipitação hidrotérmica de fluidos magnéticos com dupla camada elétrica - EDL-MF, com intuito que as propriedades magnéticas fossem potencializadas pela redução do tamanho e aumento da contribuição superficial. O produto desta síntese resulta em nanopartículas de ferrita de cobalto $\left(\mathrm{CoFe}_{2} \mathrm{O}_{4}\right)$ recoberta por uma fina camada desordenada de maguemita $(\gamma$ $\left.\mathrm{Fe}_{2} \mathrm{O}_{3}\right), \mathrm{CoFe}_{2} \mathrm{O}_{4} @ \gamma-\mathrm{Fe}_{2} \mathrm{O}_{3}$, fruto do tratamento de nitrato de ferro de superfície. A amostra na forma de pó de NPs-CS é caracterizada por difração de raios X e verificamos que são compostas de nanopartículas com tamanho mediano de $2.7 \mathrm{~nm}$. Encontramos uma correspondência com a ficha No. 22-1086 do PDF-2 para $\mathrm{CoFe}_{2} \mathrm{O}_{4}$ que confirma que a estrutura do cristal é o tipo espinélio e pertencente ao grupo espacial $F d 3 m$ e não contém quaisquer outras fases cristalinas.

Determinamos quantitativamente a presença de metais nas partículas utilizando a técnica de Espectrometria de Absorção Atômica (AAS). Empregamos o modelo do core-shell químico para determinar heterogeneidade causada pelo enriquecimento de ferro das superfícies das nanopartículas magnética, encontramos uma fração de metal divalente $\chi_{M}$ de 0.16 , menor que 0.33 que mostra o enriquecimento superficial de ferro. A partir do modelo core-shell conseguimos calcular a espessura da casca de $0.27 \mathrm{~nm}$, equivalente a $52 \%$ da partícula. Diluímos o ferrofluido para obtermos uma amostra com um regime de interações fracas com $\phi$ de $0.18 \%$, essa usada em todos experimentos de magnetização. Em medidas de densidade do ferrofluido diluído encontramos um valor de $1.0051 \mathrm{~g} / \mathrm{cm}^{3}$ a partir do qual conseguimos estimar, via densidade, um $\phi$ de $0.1817 \%$ em total concordância com o resultado da dosagem química feita por AAS.

Para investigar a morfologia e avaliar a distribuição de tamanho as nanopartículas utilizamos a técnica de Microscopia Eletrônica de Transmissão (MET) em conjunto com técnicas auxiliares. Por Espectroscopia de Dispersão de energia de Raios X (EDS) construímos um espectro relativo ao número de contagens em função da energia possibilitando assim identificar os elementos presentes na amostra. Os picos detectados no espectro indicam os elementos presentes de Fe e Co da amostra FPCo2, não havendo contaminantes. O histograma de distribuição de tamanho foi obtido através da contagem individual de aproximadamente 500 nanopartículas, o histograma foi ajustado por uma lei de distribuição do tipo log-normal e encontramos um diâmetro médio de $2.67 \mathrm{~nm}$, ligeiramente menor que o obtido pelo formalismo de Sherrer, e uma polidispersão $\sigma=0.26$. Imagem de HRTEM de uma nanopartícula 
selecionada do conjunto de imagens da amostra evidencia alta cristalinidade das NPs (monocristalinas) onde podemos visualizar os planos atômicos e possibilita medir a distância interplanar. Encontramos um valor da ordem de 2.6 Å correspondente ao índice de Miller [311] para a ferrita de cobalto. Em conjunto com análise da imagem usando Fast Fourier Transform - FFT observamos pontos brilhantes que correspondem as distâncias interplanares, o ponto 0.28 nm corresponde ao índice de Miller [220] e o ponto $0.26 \mathrm{~nm}$ corresponde ao índice [311].

Do comportamento da magnetização à temperatura ambiente para a amostra FPCo2 diluída observamos que curva é simétrica em ambas direções do campo aplicado, também é uma função crescente do campo devido ao seu tamanho reduzido com tendência de não saturação. Do ajuste com o formalismo de Langevin obtém-se um diâmetro médio das partículas de $3 \mathrm{~nm}$ e da polidispersão $\sigma=0.35$. Ao comparar com os resultados de MET e $\mathrm{d}_{\mathrm{rx}}$, observamos um diâmetro e uma polidispersão ligeiramente maiores, isso é devido ao ajuste não conseguir ajustar na região de alto campo. Da análise em alto campo na região de linearidade da curva extrapolado $1 / H \rightarrow 0$, encontramos um $M_{S}$ de $115 \mathrm{kA} / \mathrm{m}$. Do experimento susceptibilidade magnética em baixo campo obtivemos um valor de $\chi_{0}$, que possibilitou deduzir o valor de referência $\Psi_{d d} 2.323$ em $300 \mathrm{~K}$ e deste parâmetro de interação dipolar $\lambda$ de $3.32 \times 10^{-4}$ para a amostra de ferrofluido diluído. Quando $\lambda \ll 1$ as interações dipolares magnéticas são consideradas desprezíveis. Há $5 \mathrm{~K}$ elas possuem um papel não desprezível para amostra de ferrofluido diluído calculamos $\lambda$ uma ordem de grandeza maior de $69.54 \times 10^{-4}$, para o pó devido à proximidade das partículas que faz com que as interações dipolares e de superexchange entre os spins de superfície induzam um regime de fortes interações. Caracterizando as interações fracas e fortes nos regimes estudados.

Dos ciclos de histerese magnética a $5 \mathrm{~K}$ com protocolo ZFC obtidos, observamos um acréscimo do $\mathrm{H}_{\mathrm{C}}$ da amostra pó em relação com a dispersão diluída congelada, devido as interações dipolares e de exchange entre os spins de superfície em contato que aumenta a dificuldade de reduzir a zero a magnetização remanente. A magnetização remanente tem uma diminuição devido ao aumento das interações dipolares que são altamente desmagnetizantes. Para observar o comportamento das interações presentes nas amostras investigadas, resolvemos utilizar a abordagem proposta por Thamm e Hesse, utilizamos o ramo superior $m_{\text {sup }}$, inferior $m_{\text {inf }}$ do primeiro quadrante e a curva de primeira magnetização inicial dos ciclos a $5 \mathrm{~K}$ para a avaliação. Ambas possuem um desvio negativo o que nos releva que a interação dipolar é predominante. Para a amostra de ferrofluido diluído observamos que existe um regime de interação fraca em relação a amostra pó. As curvas $\Delta m$ apresentam um perfil semelhante com 
amostras estudas em outros trabalhos feitos no GFC-UnB pelo método de Henkel Plot. Especialmente as obtidas Vieira et al. ao investigar ferrita de cobalto com diâmetro similar à investigada nesta Tese, encontramos uma posição do pico em consonância com seus os resultados.

Para amostra de ferrofluido diluído encontram valores semelhantes da temperatura de bloqueio $T_{B}$, deduzidos via dependência térmica do campo coercivo (alto campo aplicado) e do pico da derivada $-d\left(M_{F C W}-M_{Z F C}\right) / d T$ versus $T-\left\langle T_{B}\right\rangle$ (baixo campo) da ordem de $30 \mathrm{~K} .\left\langle T_{B}\right\rangle$ é ligeiramente maior, visto que é necessária uma energia maior para as partículas começarem a desbloquear em baixo campo. Para o pó da amostra de NPs encontramos temperaturas de bloqueio bem distintas, isto se deve a influência do campo aplicado nas interações. Com campo aplicados maiores, consegue-se desbloquear mais partículas em temperaturas menores. Apoiando essa afirmação os resultados das curvas ZFC de ambas amostras nos mostra valores altos, o campo aplicado é muito pequeno e grande parcela do aumento da energia do sistema é devido a temperatura.

Investigamos os efeitos que surgem com a desordem de spins de superfície em relação a dependência térmica em alto campo, em baixas temperaturas as propriedades magnéticas das NPs-CS evidenciam vários fenômenos, uma vez que anisotropia magnética apresenta uma forte contribuição da superfície a magnetização das nanopartículas é fortemente influenciada pela desordem de superfície. Observamos um desvio da Lei de Bloch em baixa temperatura responsável pelo congelamento dos spins de superfície em camada desordenada do tipo spinsglass-like, influenciando nas propriedades magnética e criando uma interface FI/SGL nas nanopartículas. Determinamos os valores do ajuste da Lei de Bloch para curva experimental da amostra de ferrofluido diluído e quantificamos a contribuição da casca por uma lei de resfriamento típica. Os valores encontrados dos ajustes estão de acordo com a amostra Co3 de ferrofluido diluído investigada por Cabreira-Gomes et al., mostrando a reprodutibilidade dos parâmetros e a estabilidade das amostras sintetizadas no Grupo de Fluidos Complexos. Em baixo campo investigamos o efeito de memória magnética com protocolo de envelhecimento DC. Nas curvas $M_{F C C}^{\text {Down }}$ de ambas amostras, uma queda na magnetização é observada até atingir o equilíbrio da magnetização em todos os degraus, no entanto, verifica-se que a quantidade de queda depende do regime de interações magnéticas da nanopartículas. Atribuímos à casca (spins-glass-like) existente nas NPs-CS de ferritas $\mathrm{CoFe}_{2} \mathrm{O}_{4} @ \gamma-\mathrm{Fe}_{2} \mathrm{O}_{3}$ como a origem intrínseca do efeito de memória e potencializado pelo comportamento coletivo, devido as interações 
interpartículas dipolares e de exchange resultando num estado SSG. Destas análises em alto e baixo campo podemos definir a interface FI/SGL das nanopartículas aqui investigadas.

Em temperaturas muito baixas a interface FI/SGL quando congelada na presença de campo induz o exchange bias $\left(H_{E X}\right)$. Está associado a um exchange de troca entre os spins desordenados da camada superficial e os do núcleo ordenado, alinhados na direção do campo aplicado. Esta depende intimamente em relação ao campo de congelamento $H_{c o o l}$. $H_{E X}$ cresce em função do campo de cooling, conforme acontece o alinhamento progressivo dos spins do core na direção do campo aplicado. Esse incremento de $H_{E X}$ acontece até atingir um máximo e depois uma redução é observada, associada ao acoplamento Zeeman entre os spins da casca e o campo externo. Esse máximo do campo de exchange está associado a um limiar de desbloqueio dos spins da superfície, que estavam ancorados fortemente pelo efeito da interface e passam a se acoplar progressivamente ao campo aplicado e em consequência a isso o campo $H_{E X}$ diminui. Encontramos um máximo $12 \mathrm{kOe}$ para $\boldsymbol{H}_{\text {cool }}^{\text {MAX }}$ e $H_{E X}$ de $42.3 \mathrm{kA} / \mathrm{m}$ para amostra pó e $H_{E X}$ de $18.5 \mathrm{kA} / \mathrm{m}$ para amostra de ferrofluido diluído, valores superiores aos encontrados por CabreiraGomes et al., atribuímos a potencialização do exchange bias com a redução do tamanho das nanopartículas. Investigando a estabilidade usando o protocolo de minor loops, verificamos que quando $H_{\max }$ é inferior ao campo de anisotropia do sistema não atinge a saturação magnética e $H_{\max }$ aplicado é maior que $60 \mathrm{kOe}$. Os valores encontrados para $H_{\text {shift }}$ encontrados ficam constantes e $H_{\text {shift }}$ se torna $H_{E X}$, nos fornecendo o verdadeiro significado fenomenológico do campo de exchange bias.

Pela primeira vez o efeito de treinamento do exchange bias em ferrofluidos à base de NPs-CS é visto. Investigamos em relação a algumas características: regime de interações fracas e fortes, relaxamento dos spins não compensados congelados e rotativos na interface FI/SGL e influência da temperatura e envelhecimento. Observamos que as interações interpartículas tem um papel crucial nas propriedades do fenômeno. Ao se estudar o regime diluído com fracas interações observamos como o ciclismo do exchange bias atinge um equilíbrio $\left(H_{E X}^{\infty}\right)$ em 124.07 Oe não muito longe do estado inicial de 240 Oe e um $\gamma$ de $3.99 \times 10^{-5} \mathrm{Oe}^{-2}$, para amostra pó o $H_{E X}^{\infty}-47.12$ Oe e o $H_{E X}$ de 540 Oe e $\gamma$ de $2.02 \times 10^{-6} \mathrm{Oe}^{-2}$, mostrando que as interações potencializam o efeito visualizado. Uma vez que para o regime diluído o $H_{E X}$ se estabiliza em um valor bem próximo do $H_{E X}$ inicial, nos indica que o efeito visualizado, num sistema de partícula não interagentes, ocorre devido as interações de exchange entre o núcleo e a casca no interior da NPs-CS. Esses resultados estão de acordo com os da literatura e a intensidade do efeito de treinamento é mais fraca para grande valor de $\gamma$ como observamos para amostra de 
ferrofluido líquido. Para ambas amostras observamos a tendência de os ciclos irem na direção do ciclo ZFC. Na amostra pó a magnetização reduzida diminui abruptamente aproximando-se rapidamente do ZFC, por outro lado para amostra de ferrofluido diluído verificamos que precisaria medir mais ciclos para poder se aproximar do ZFC. Concluímos que é impossível para esta amostra atingir o estado de magnetização do clico ZFC. Para o pó notamos que em mais alguns ciclos medidos o estado seria atingido e possivelmente a induzir o exchange bias positivo pelo efeito de treinamento na amostra. Para amostra de ferrofluido diluído congelado encontramos $P_{r} / P_{f} \sim 29$ indicando que os spins rotativos se reorganizam cerca de 29 vezes mais rapidamente do que os spins congelados, nesta amostra livre de interações dipolares os spins rodáveis têm um grau de liberdade maior para mudar de direção. Para amostra pó $P_{r} / P_{f} \sim 23$, houve uma clara diminuição da relação ao ferrofluido diluído, que pode ser explicado pelas interações dipolares e de exchange entre as NPs-CS que dificultam os spins rotativos de girar, já que é necessária uma energia maior para vencer o efeito das interações presentes.

Em $30 \mathrm{~K}$ o campo de exchange bias é mínimo para amostra de ferrofluido diluída e apresenta uma diminuição expressiva do campo coercivo, magnetização remanente e magnetização de saturação em relação as medidas a $5 \mathrm{~K}$. O efeito de treinamento nesta temperatura não apresenta o relaxamento abrupto entre os o primeiro e segundo ciclo, diminuindo de um modo aproximadamente linear. Próximo de $T_{B}$ existe apenas pequenos desvios do equilíbrio na interface de magnetização da casca (SGL) que afeta a energia livre que controla o processo de relaxamento. O equilíbrio é atingido mais rapidamente. Em temperaturas próximas do $T_{B}$ o efeito de treino atérmico desaparece. A dependência da temperatura no efeito de treinamento está de bom acordo com o modelo de Binek e indica a precisão qualitativa do modelo de relaxamento dos spins da camada de pinning utilizado nestes sistemas até aqui. A Temperatura de Bloqueio aqui obtido é perfeitamente compatível com os nossos dados e o efeito do treinamento a $30 \mathrm{~K}$ é ínfimo. A 30K o exchange bias é reduzido, e a sua formação não é bem descrito pelo modelo de Radu et al. ou mais modelos lei de potência de decaimento convencionais, mas sim diminui de forma aproximadamente linear.

O efeito de envelhecimento influencia nas propriedades magnéticas da camada de pinning que induz o exchange bias. Para amostra pó o tempo de parada ( $\left.t_{w}\right)$ é medido depois do primeiro ciclo. Os parâmetros apresentam uma variação insignificante, revelando que o sistema "memorizou" o estado dos spins da casca (camada de pinning) no primeiro ciclo e transmitindo, independentemente do tempo de parada entre os ciclos, para os demais ciclos medidos, não alterando a dinâmica não linear do sistema no efeito de treinamento. Na amostra de ferrofluido 
diluído com paradas antes do primeiro ciclo revela que existe uma diminuição do exchange bias medido no primeiro ciclo com $t_{w}$. Consequência do alinhamento de alguns spins da casca na direção do campo de cooling antes de iniciar o primeiro ciclo, reduzindo o acoplamento de troca entre o núcleo e a casca, resultando na diminuição do exchange bias. No experimento de envelhecimento no efeito de treinamento encontramos o exchange bias no equilibrio de ciclos infinitos $\left(H_{E X}^{\infty}\right)$ de 117.44 Oe, observamos uma diminuição em torno de $5 \%$ em relação ao medido com $t_{w}=0 \mathrm{~s}$. Enquanto o parâmetro $\gamma$ deduzido é de $6.40 \times 10^{-5} \mathrm{Oe}^{-2}$, um aumento de $60 \%$, este valor observado de $\gamma$ pode ser interpretado como uma diminuição da constante de acoplamento entre a casca (SGL) e o núcleo (FI) ao envelhecer o sistema, mostrando que houve o alinhamento de alguns spins da casca. Constatamos uma diminuição dos spins congelados ao longo da direção do campo de cooling que reduz a energia pinning eficaz. Por isso ele diminui com o ciclismo de campo. Com o envelhecimento do primeiro ciclo alguns spins se desprendem alinhando-se com os spins do núcleo reduzindo a energia de troca entre o núcleo e a casca afetando a magnetização reduzida. Investigando as contribuições dos spins rodáveis com o modelo proposto por Radu et al. observamos que a componente dos spins congelados $P_{f}$ possui um aumento e $P_{r} / P_{f}$ é $~ 26.8$ com o envelhecimento da amostra diluída, indicando uma diminuição da contribuição dos spins rodáveis de se reorganizar cerca de 2 vezes mais lentamente sem envelhecimento. Isto é explicado devido a diminuição de spins rotativos que se alinharam com o campo visto em $P_{r}$.

Em resumo, utilizando a abordagem proposta por Thamm e Hesse caracterizamos as interações interpartículas em ferrofluido diluído e pó compactado. Mostramos que estas são associadas a regimes de interações fracas e fortes, respectivamente. Investigamos o efeito de memória magnética nos dois sistemas e os resultados mostram que o efeito é potencializado pelas interações interpartículas. No ferrofluido o comportamento do efeito de memória é governado pela camada de spins desordenados do tipo SGL. No pó compactado o efeito de memória é característico de um sistema SSG em consequências das interações interpartículas.

Investigamos o efeito de exchange bias e de treinamento nos dois sistemas. Os principais resultados mostram que:

- As interações aumentam a taxa de decrescimento do EB com aplicação de sucessivos ciclos;

- Os spins desordenados se alinham mais rapidamente no pó em relação ao ferrofluido. A razão $P_{r} / P_{f}$ indica como os spins rodáveis se reorganizam mais rapidamente do que os spins presos; 
- Em $30 \mathrm{~K}$ os spins rodáveis já não participam mais no efeito de treinamento;

- O acoplamento entre as camadas diminui em $30 \mathrm{~K}$, influenciando no valor do $\gamma$;

- Com o envelhecimento após primeiro ciclo na amostra pó, os resultados mostram uma "memorização" da configuração da casca (SGL) em regime de interações fortes;

- Com o envelhecimento antes do primeiro ciclo no Ferrofluido diluído, alguns spins rodáveis se alinham com o campo de $9 \mathrm{~T}$ diminuindo a constante de acoplamento entre o núcleo e a casca durante a primeira reversão.

Os fenômenos visualizados merecem ser testados mais amplamente. A interpretação, porém, é bastante complicada, já que inúmeros fatores cooperam para o comportamento. $\mathrm{O}$ estudo descrito no presente documento precisa ser continuado, para que as interpretações sugeridas sejam aplicadas em partículas de composição diferentes e em fluidos concentrados, neste último as interações dipolares são tradicionalmente desmagnetizantes, como já visto em trabalhos anteriores do GFC, e os efeitos de memória e treinamento do exchange bias podem ser fortemente influenciados. 


\section{Apêndices}

\section{A. Unidades de medida em magnetismo 9}

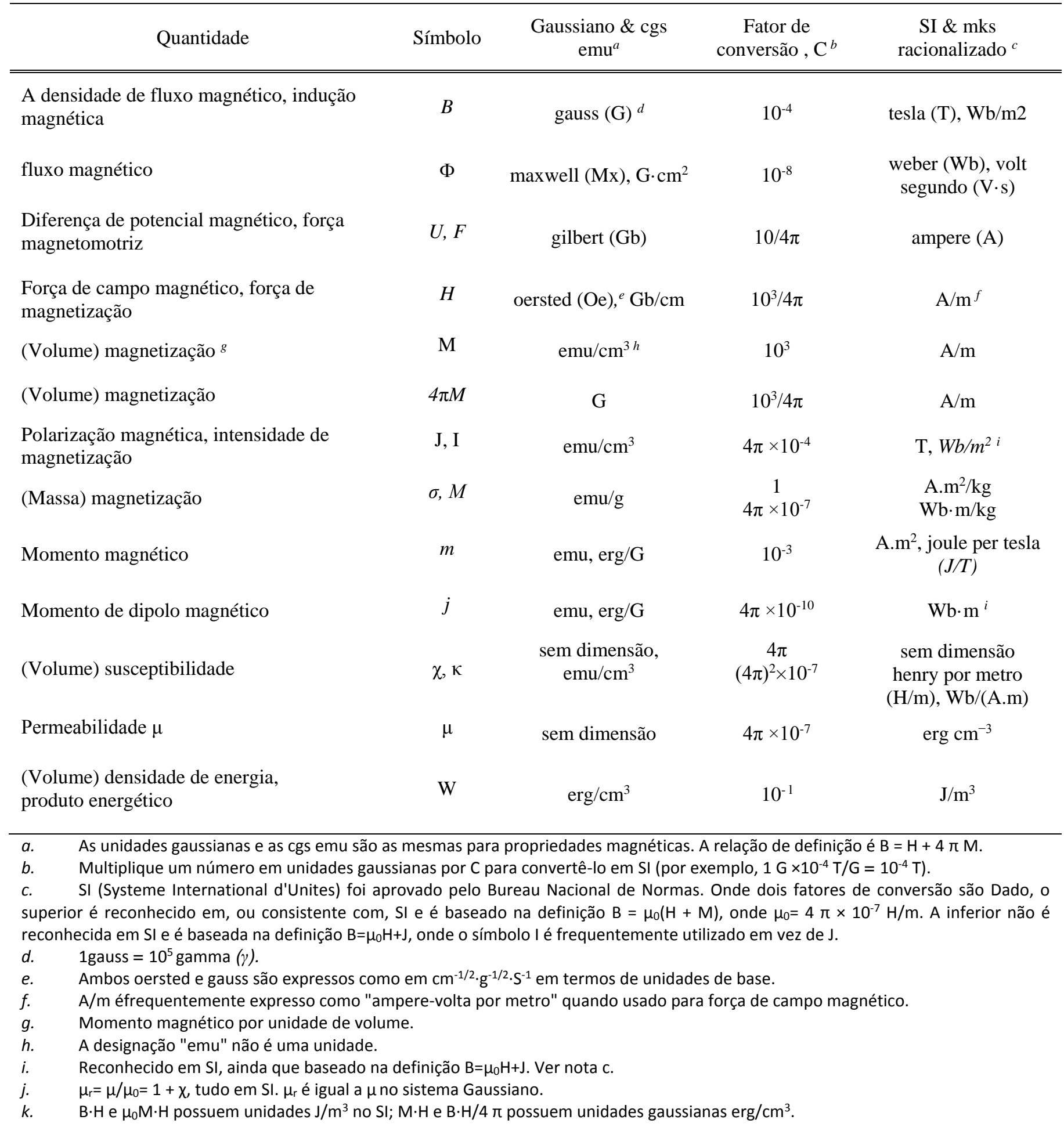

\footnotetext{
${ }^{9}$ R. B. Goldfarb and F. R. Fickett, U.S. Department of Commerce, National Bureau of Standards, Boulder, Colorado 80303, March 1985 NBS Special Publication 696 For sale by the Superintendent of Documents, U.S. Government Printing Office, Washington, DC 20402
} 


\section{B. Magnetismo - Aspectos gerais}

O magnetismo é a capacidade da matéria de responder, Indução Magnética (B), a um campo magnético externo $(\mathrm{H})$, onde todas as substâncias sejam elas sólidas, líquidas ou gasosas mostram alguma característica magnética em todas as temperaturas. Essa propriedade da matéria surge essencialmente por duas razões: (i) capacidade que toda corrente elétrica tem de produzir um campo magnético (Lei de Biot-Savat) e (ii) dos momentos magnéticos dos $\operatorname{spins}^{10}$. Classicamente, o momento magnético dos spins surge do movimento do spin em torno de seu próprio eixo, representado graficamente por uma seta, que possui duas configurações possíveis $\uparrow$ up (para cima) e $\downarrow$ down (para baixo) que se combinam em pares opostos dentro de um orbital. Obedecendo ao princípio de exclusão de Pauli e a regra de Hund anulam-se em decorrência disso, dependendo da configuração eletrônica dos átomos de um material podem existir orbitais parcialmente preenchidos tendo certo número de spins que contribuem para magnetização resultante. Na Teoria quântica um átomo com um elétron possui um momento magnético de spin (ou simplesmente spin), $\mu_{s}$, na direção do campo aplicado H que é $\mu_{s}=e \hbar / 2 m$, onde $e$ é a carga do elétron, $m$ a massa do elétron e $\hbar$ a constante de Planck. Esse valor é definido como unidade fundamental do momento magnético e denominado de magnéton de Bohr ${ }^{11}$ em homenagem ao seu descobridor e escrito como $\mu_{B}=e \hbar / 2 m$ (MORRISH, 1965; BERTOTTI, 1998; CULLITY; GRAHAM, 2011).

A resposta da matéria frente a campos magnéticos externos se denomina Magnetização (M). Quando se imerge um material qualquer numa região onde há um campo magnético esse tende a alinhar os momentos magnéticos dentro do material, a estrutura responde imediatamente produzindo um campo magnético próprio cuja intensidade e orientação dependem do campo externo denominado de indução magnética (B). Podemos relacionar o campo externo aplicado, a indução e a magnetização é expressa por:

$$
B=\mu_{0}(H+M)
$$

$\mu_{0}$ é a permeabilidade do vácuo. Diz-se então que o material se encontra magnetizado. A magnetização é definida como a somatória de todos os momentos magnéticos elementares (dipolo magnético) por unidade de volume, $M=\mu_{\text {total }} / V$. A temperatura do sistema é um fator

\footnotetext{
${ }^{10} \mathrm{O}$ termo Spin (em inglês "girar") associa-se, sem rigor, às possíveis orientações que partículas subatômicas carregadas como prótons ou elétrons e alguns núcleos atômicos podem apresentar quando imersas em um campo magnético.

${ }^{11}$ No Sistema Internacional de medidas S.I. tem valor de $9.274 \cdot 10^{-24} \mathrm{~J} \cdot \mathrm{T}^{-1}$ e de $9.274 \cdot 10^{-21} \mathrm{erg} \cdot \mathrm{G}^{-1}$ no Sistema CGS (centímetro-grama-segundo).
} 
primordial, visto que quanto maior a temperatura, maior a energia térmica dos spins que dificulta o alinhamento desses com o campo aplicado.

Precisamos conhecer mais alguns princípios básicos para classificar os tipos de materiais. Definida pelo quociente $\chi_{m}=M / H$ e denominada de susceptibilidade magnética do meio, esta grandeza adimensional no Sistema Internacional de Medidas (S.I.) mede a função resposta correspondente da relação entre o campo aplicado $(\mathrm{H})$ não muito intenso e a magnetização $(\mathrm{M})$. A magnetização é proporcional à estimulação magnética induzida pelo campo e quando se remove o campo magnético a magnetização destes materiais esvanece. Outra propriedade que precisamos conhecer é a permeabilidade magnética do meio $(\mu)$, que mensura o campo magnético no interior de um material - devido ao campo magnetizante $\mathrm{H}$ préexistente na região onde o material é colocado bem como à magnetização por este induzida no material, expresso por $\mu=B / H$. Substituindo ambos os conceitos de susceptibilidade magnética e permeabilidade magnética na equação B.1 temos:

$$
\frac{\mu_{\text {total }}}{\mu_{0}}=\chi_{m}+1
$$

$\mu_{0}$ é a permeabilidade magnética do vácuo ${ }^{12}$. Relacionando as grandezas adimensionais $\mu$ e $\chi_{\mathrm{m}}$ podemos classificar os materiais de acordo com sua resposta magnética e sua magnetização conforme expresso na Tabela 18 e visualizado na Figura A.1.

Tabela 18: Reúne classificação dos materiais com os principais tipos de comportamentos magnéticos conhecidos em relação à susceptibilidade magnética e a permeabilidade magnética relativa (MATTIS, 2012).

\begin{tabular}{cccc}
\hline & Material & $\chi_{m}$ & $\mu / \mu_{0}$ \\
\hline \hline Magnetismo & Diamagnético & $<0$ & $<1$ \\
Atômico & Paramagnético & $>0$ & $>1$ \\
\hline \multirow{2}{*}{ Magnetismo } & Ferromagnético & $>>0$ & $>>1$ \\
Cooperativo & Ferrimagnético & $>>0$ & $>>1$ \\
& Antiferromagnético & $>0$ & $>1$ \\
\hline
\end{tabular}

O magnetismo pode ser dividido de acordo com a resposta magnética em duas classes: o magnetismo atômico e o magnetismo cooperativo. No magnetismo atômico não existe qualquer interação entre os momentos individuais dos átomos e cada momento magnético age de forma independente uns dos outros, exemplo desse comportamento é o diamagnetismo e o paramagnetismo. No magnetismo cooperativo os spins estão acoplados uns aos outros formando estados magneticamente ordenados e com momentos em paralelos (ferromagnético)

${ }^{12} \mu_{0}=4 \pi \times 10^{-7} \mathrm{~N} / \mathrm{A}^{2}=4 \pi \times 10^{-7} \mathrm{H} / \mathrm{m}, \approx 1.2566 \times 10^{-6} \mathrm{H} / \mathrm{m}(\mathrm{ou} \mathrm{T} \cdot \mathrm{m} / \mathrm{A})$. 
ou antiparalelos (antiferromagnético e ferrimagnético). A Figura A.1 exibe uma comparação simplificada do comportamento da permeabilidade magnética para os principais tipos de comportamento magnético. Outros comportamentos como vidros de spins abordaremos com uma riqueza maior de detalhes a posteriori.

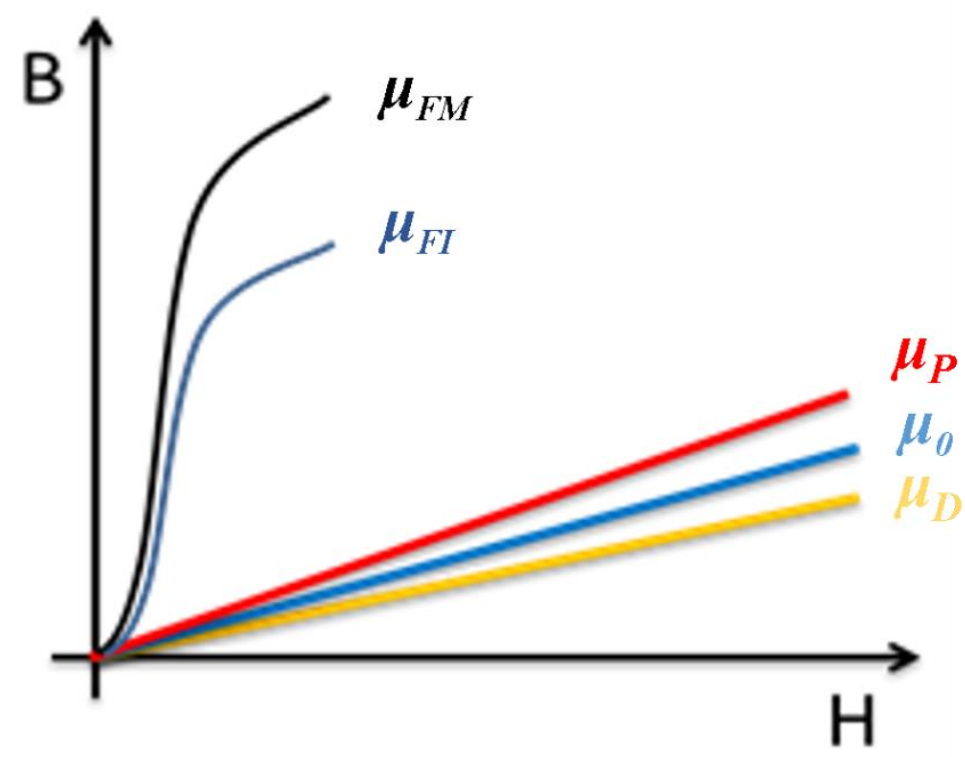

Figura A.1: Comparação simplificada da permeabilidade para: Ferromagnetismo $\left(\mu_{F M}\right)$, Ferrimagnetismo $\left(\mu_{F I}\right)$, Paramagnetismo $\left(\mu_{P}\right)$, o vácuo $\left(\mu_{0}\right)$ e Diamagnetismo $\left(\mu_{D}\right)$.

\section{B.1 Diamagnetismo}

Essa é uma propriedade magnética que todos os materiais estão sujeitos na presença de um campo externo, tão fraco que normalmente não pode ser observado quando o material possui uma das outras propriedades (Ferromagnetismo e Ferrimagnetismo) que se sobressaem. O Diamagnetismo é caracterizado por uma pequena susceptibilidade magnética negativa e apresentam valores reduzidos e negativos para a susceptibilidade magnética, na ordem de $\chi_{m}$ $=-9 \times 10^{-6}$ para água por exemplo, ou seja, a magnetização induzida por um campo externo é inversamente proporcional ao campo aplicado.

Temos como exemplo deste comportamento os gases nobres e os sólidos iônicos cujos átomos perderam alguns elétrons, transformando-se em íons que possuem subníveis eletrônicos completos, fazendo com que os momentos fiquem emparelhados e se anulem. Podemos citar $\mathrm{NaCl}$ como exemplo de sólido iônico que apresenta o diamagnetismo. Nos materiais covalentes a camada externa é somente parcialmente preenchida devido à ausência de elétrons, espera-se que esses exibam um momento magnético diferente de zero. Entretanto, toda ligação covalente é composta por um par de elétrons com spins opostos e o momento angular orbital total é nulo. 
citamos as moléculas de $\mathrm{H}_{2}, \mathrm{~N}_{2}$ e $\mathrm{H}_{2} \mathrm{O}$ que possuem um momento magnético nulo mesmo que os átomos que compõem tenham momento magnético não nulo (CULLITY; GRAHAM, 2011).

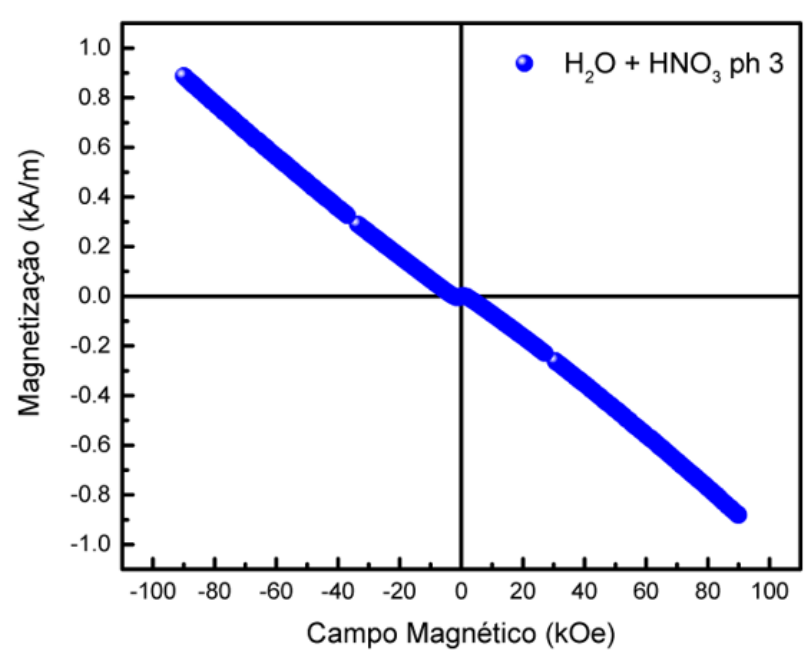

(a) Medida a $5 \mathrm{~K}$

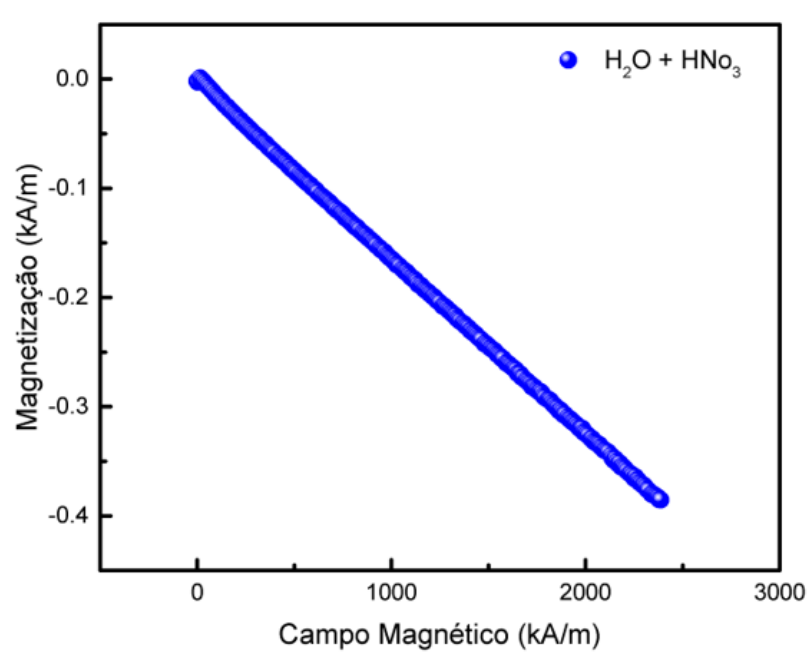

(b) Medida $300 \mathrm{~K}$

Figura A.2: (a) Ciclo de histerese a $5 \mathrm{~K}$ com variação de campo aplicado de $\pm 90 \mathrm{kOe}$ e (b) susceptibilidade a baixo campo $300 \mathrm{~K}$ de $\mathrm{H}_{2} \mathrm{O}+\mathrm{HNO}_{3}$ com ph 3 utilizada para subtração da resposta diamagnética do líquido carreador das amostras investigadas nesta Tese.

O comportamento diamagnético do eletrólito $\mathrm{H}_{2} \mathrm{O}+\mathrm{HNO}_{3}$ utilizado para dispersar as NPs magnéticas nos ferrofluidos investigados nesse trabalho é apresentado na Figura A.2. Essas curvas foram utilizadas para subtração da resposta diamagnética da amostra de ferrofluido diluída em alto campo $\pm 90 \mathrm{kOe}$ a $5 \mathrm{~K}$ em (a) e a baixo campo a $300 \mathrm{~K}$ (b) na Figura A.2 exemplificando o comportamento diamagnético.

\section{B.2 Paramagnetismo}

Os materiais paramagnéticos são constituídos de átomos que apresentam momento magnético intrínseco resultante dos momentos dos spins, contudo não interagem entre si. Esses possuem elétrons desemparelhados (elétrons livres), ou seja, orbitais atômicos ou moleculares com apenas um elétron. As interações de troca entre momentos de dipolo magnético vizinhos não são relevantes e podem ser negligenciadas em uma primeira aproximação, a susceptibilidade magnética destes materiais varia na ordem de $\sim 10^{-5}<\chi_{m}<10^{-3}$. (DE LACHEISSERIE; GIGNOUX; SCHLENKER, 1999). 
Um elétron desemparelhado na ausência de um campo magnético aplicado alinha seu momento magnético de forma aleatória, um sistema com grande número de elétrons livres desemparelhados não consegue reter magnetização por causa do movimento térmico randomizado das orientações dos spins, assim sua magnetização resultante é zero. Na presença de um campo magnético os spins tendem a se alinhar na mesma direção do campo magnético externo, mas apenas uma pequena magnetização é induzida, porque apenas uma pequena fração dos spins será orientada pelo campo. Essa fração é proporcional à força do campo e explica a dependência linear $M=\chi_{m} H$ e com a retirada do campo a magnetização cai para zero.

Em condições usuais de temperatura e baixo campo aplicado o paramagnetismo apresenta uma dependência com a temperatura na forma $1 / T$, esse comportamento foi descoberto experimentalmente por Pierre Curie em 1895 e expresso por:

$$
\chi_{m}=\frac{C}{T},
$$

C é a constante de Curie e é uma característica intrínseca do material. Esta lei é válida em regime de baixa magnetização, $\mu_{B} H \lesssim k_{B} T$. No regime de alto campo e baixa temperatura não se aplica a expressão, visto que a saturação da magnetização acontece $\mu_{B} H \gtrsim k_{B} T$ e todos os spins estão alinhados com o campo magnético aplicado, mesmo aumentando o campo externo não aumentará a magnetização total, uma vez que não aumentará alinhamento dos spins. A constante de Curie para um íon paramagnético está relacionada com os momentos magnéticos dos íons individuais com momento angular ( $\mathrm{J})$ e expresso por:

$$
C=\frac{N}{3 k_{B}} \mu_{e f f}^{2},
$$

$N$ é o número de átomos (ou moléculas magnéticas) por unidade de volume, $\mu_{\text {eff }}=g \mu_{B} \sqrt{J(J+1)}$ é o momento magnético efetivo por íon ou átomo paramagnético, g é o fator de Landé. Com a Lei de Curie pode-se obter experimentalmente o momento efetivo dos átomos, ou o número efetivo de magnétons de Bohr (CHIKAZUMI; GRAHAM, 2009). Na presença de campo a agitação térmica de um material paramagnético se opõe à tendência dos elétrons desemparelhados de se alinhar com o campo aplicado mantendo os momentos atômicos aleatoriamente orientados. O resultado é um alinhamento parcial na direção do campo. Outra característica importante é devido ao aumento da temperatura, o efeito randômico da agitação térmica faz com que a susceptibilidade magnética do material diminua (BLUNDELL; THOULESS, 2001). 


\section{B.3 Ferromagnetismo}

Determinados materiais podem apresentar um comportamento paramagnético que surge acima da Temperatura de Curie $\left(T_{C}\right)$. Em baixas temperaturas os momentos magnéticos tendem a se ordenar e o ponto de Curie $T_{C}$ é visto como uma transição de fase entre um ferromagneto e um paramagneto. A dependência da temperatura requer uma versão alterada da lei de Curie para explicar o ferromagnetismo. P. Weiss foi o primeiro a tentar entender e estabelecer a primeira teoria para o ferromagnetismo. Postulou a existência de um campo interno $H_{W}$ proporcional à Magnetização $H_{W}=\lambda M$, chamada de teoria do campo molecular. Essa teoria leva em consideração as interações de cada momento magnético atômico com todos os outros vizinhos, substituindo-as por um campo médio de origem "molecular" $(\lambda)$ (WEISS, 1907). O campo magnético total pela teoria de Weiss é escrito como $B+\lambda M$, aplicando o conceito na lei de Curie temos:

$$
\chi_{C}=\frac{M}{H} \rightarrow \frac{M}{B+\lambda M}=\frac{C}{T} .
$$

Encontramos a conhecida como a lei de Curie-Weiss:

$$
\chi_{C W}=\frac{C}{T-C \lambda},
$$

$C \lambda$ é uma constante com dimensão de temperatura e definida como $T_{C}$. O termo descreve a interação de troca que está presente ainda que superado pelo movimento térmico e o sinal de $T_{C}$ depende do tipo de interações ferro ou antiferromagnéticas. O materiais ferromagnéticos apresentam algumas características (CULLITY; GRAHAM, 2011):

- Relação M-H não linear, caracterizado por ciclos de Histerese;

- Dependência da susceptibilidade com a temperatura obedecendo à lei de CurieWeiss;

- Dependência da magnetização com a temperatura satisfazendo a Lei de Bloch;

- Formação de domínios magnéticos e paredes de domínio.

Com a miniaturização algumas propriedades do material podem ser alteradas. A lei de Bloch, por exemplo, pode apresentar um acréscimo em temperaturas muito baixas e a abaixo de um diâmetro crítico do material há a formação de monodomínios. 


\section{B.4 Antiferromagnetismo}

Substâncias antiferromagnéticas possuem uma pequena susceptibilidade positiva em

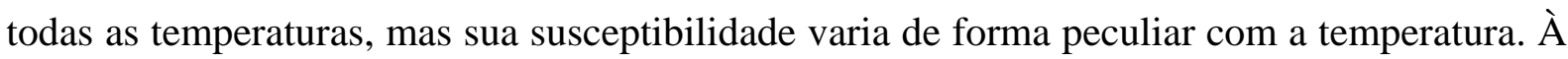
primeira vista, eles podem ser considerados como paramagnetos anômalos. No entanto, um estudo mais minucioso mostrou que a sua estrutura magnética é completamente diferente e que merecem uma classificação separada. A teoria do antiferromagnetismo foi desenvolvido por Néel em uma série de artigos, começando em 1932, no qual ele aplicou a teoria do campo molecular Weiss para o interpretar o fenômeno (NÉEL, 1932). Apresenta uma tendência de alinhamento antiparalelo dos spins vizinhos, contrário ao que acontece com o Ferromagnetismo. É possível ainda obter a susceptibilidade magnética, através de uma teoria do campo molecular de Weiss (WEISS, 1907), encontrando assim o seguinte resultado:

$$
\chi_{C W}=\frac{C}{T+T_{N}},
$$

onde $T_{N}$ é denominada de temperatura de Néel.

O material antiferromagnético não apresenta uma magnetização espontânea macroscópica a baixas temperaturas, abaixo da temperatura critica $T_{N}$ a magnetização e a susceptibilidade diminuem com a temperatura tendendo à zero, $\mathrm{T} \rightarrow 0$. Acima de $T_{N} \mathrm{o}$ comportamento é de um paramagneto com uma temperatura de Curie-Weiss negativa. Este comportamento foi previsto por Néel, e resultante de um acoplamento antiparalelo dos momentos magnéticos iguais e vizinhos.

Os materiais antiferromagnetos e interações antiferromagnéticas podem se acoplar a materiais FM e fixar a magnetização dos ferromagnetos, por exemplo, através de um mecanismo conhecido como exchange bias (MEIKLEJOHN; BEAN, 1956). Quando um filme ferromagnético é crescido sobre um antiferromagneto ou annealing (cozimento) na presença de um campo magnético os spins da superfície do ferromagneto se alinham com os spins da superfície do antiferromagneto. Isto proporciona a capacidade de "pinned"(fixar) que é a orientação da camada de spins ferromagnética. Esses materiais bicamadas com essas propriedades magnéticas são utilizados no desenvolvimento das válvulas de spins (OHLDAG et al., 2003) e construção de cabeças de leitura de discos rígidos (KOOLS, 1996). A temperatura igual ou acima do qual uma camada antiferromagnética perde a sua capacidade de fixar é chamada temperatura de bloqueio dessa camada e é geralmente inferior à temperatura de Néel. 


\section{B.5 Ferrimagnetismo}

O artigo publicado em 1948 por Néel (NÉEL, 1948) forneceu a chave para a compreensão teórica das ferritas, a palavra ferrimagnetismo é devido a elas. Substâncias ferrimagnéticas exibem uma magnetização espontânea substancial à temperatura ambiente e abaixo de uma temperatura crítica como ferromagnetos. Esses materiais não correspondem à magnetização de saturação esperada para os íons paramagnéticos constituintes, correspondendo ao alinhamento paralelo destes quando $\mathrm{T} \rightarrow 0$.

Exemplo mais comum são as ferritas compostas por óxidos de ferro (magnetita e maguemita) e óxidos duplos de metais de transição (M) representado por $\mathrm{MFe}_{2} \mathrm{O}_{4}, \mathrm{M}$ pode ser metais de transição como o cobalto, níquel, manganês, cobre e zinco ou combinação destes elementos. Nesta classe de material os íons de $\mathrm{Fe}^{3+}$ são divididos em sítios tetraédricos e octaédricos e os íons de $\mathrm{Fe}^{2+}$ ocupam os sítios octaédricos, apresentando interações de superexchange entre os pares de íons nos diferentes sítios com natureza antiferromagnética. Outra constatação do comportamento ferrimagnético é observada ao se investigar a dependência térmica da magnetização das ferritas onde encontra-se uma temperatura de CurieWeiss negativa. O resultado negativo indica uma interação dominante AFM, isto sugere que os dois $\mathrm{Fe}^{3+}$ se acoplam antiparalelamente entre si e os $\mathrm{Fe}^{2+}$ paralelamente, devido ao arranjo geométrico da estrutura. Resultando num momento magnético em uma dessas direções maior do que na outra, devido as subredes do material consistirem de diferentes átomos (ou íons).

Substâncias ferrimagnéticos exibem uma magnetização espontânea substancial à temperatura ambiente, assim como ferromagnéticos:

- Exibem os fenômenos de saturação magnética e histerese;

- Sua magnetização espontânea desaparece acima de uma temperatura crítica $T_{N}$;

- Há formação de domínios magnéticos e paredes de domínio acima de um diâmetro crítico do cristal.

Só em 1948 os materiais ferrimagnéticos foram reconhecidos como a formação de uma classe distinta magnética e são materiais essenciais em algumas aplicações e estas características já os tornam industrialmente importantes (CULLITY; GRAHAM, 2011). 


\section{B.6 Interações de Exchange}

No magnetismo cooperativo a magnetização depende de como os spins estão acoplados e como estes interagem, a interação de Exchange ${ }^{13}$ ou interação de troca surge na sobreposição de elétrons em conjunto e da interação de Coulomb, obedecendo o princípio de exclusão de Pauli. Foi descoberta de forma independentemente por Dirac e Heisenberg em 1926 (BLUNDELL; THOULESS, 2001). Heisenberg mostrou que a interação de troca é fundamental para o entendimento do ferromagnetismo, considerando-se simetrias cristalinas e interações do tipo spin-órbita é possível deduzir um Hamiltoniano de Heisenberg. Se dois átomos $i$ e $j$ possuem momentos angulares, respectivamente, então a Hamiltoniana da interação de troca entre os elétrons é:

$$
H=-2 J_{i j} \vec{S}_{i} \vec{S}_{j} \cos \phi,
$$

$J_{i j}$ é a integral de troca. Teremos o ferromagnetismo quando a Hamiltoniana tem valor mínimo que resulta quando os spins estão em paralelos $\phi=0^{\circ}(\cos \phi=1)$ e quando $J_{i j}>0$. Se $H$ é máximo os spins assumem a configuração antiparalela $\phi=180^{\circ} \quad(\cos \phi=-1)$ levando ao antiferromagnetismo, esse também surge quando $J_{i j}<0$ e o estado de menor energia é atingido, levando a configuração de spins antiparalelos. A interação de troca entre os íons magnéticos vizinhos forçará o alinhamento dos momentos individuais com seus vizinhos de acordo com a distância. Conhecemos três tipos de Exchange: i) Exchange direto, ii) Exchange indireto e iii) Superexchange.

i) Exchange direto atua entre momentos magnéticos, quando estes estão próximos o suficiente há uma sobreposição das suas funções de onda dos elétrons e os elétrons são obrigados a estar no mesmo local no espaço, ao mesmo tempo, obrigatoriamente irão possuir rotações opostas. De acordo com Bethe e Slater os elétrons passam a maior parte de seu tempo entre átomos vizinhos, efeito causado pela distância interatômica pequena, originando um alinhamento antiparalelo e o exchange é negativo. Característica desse comportamento é uma estrutura antiferromagnética como mostrado na Figura A.3 (a). Caso os átomos estejam distantes, os elétrons permanecerão longes uns dos outros a fim de minimizar a repulsão elétronelétron, dando origem a um alinhamento paralelo ou troca positiva (ferromagnetismo) visualizamos em (b). A Figura A.3 (c) mostra a variação da integral de troca com a proporção $r_{a} / r_{3 d}, r_{a}$ é o raio atômico e $r_{3 d}$ o raio da camada eletrônica $3 d$. A curva representa a magnitude

\footnotetext{
${ }^{13}$ Interação de Exchange é um efeito quântico que só ocorre entre partículas idênticas, neste caso interações entre os elétrons.
} 
da integral de troca em função da distância interplanar, o cobalto está situado perto do pico da curva, enquanto o crômio e o manganês estão no lado negativo. O ferro com o sinal da integral de troca dependendo das estruturas cristalinas se encontra em torno do ponto de transição da curva (CULLITY; GRAHAM, 2011).

(a)
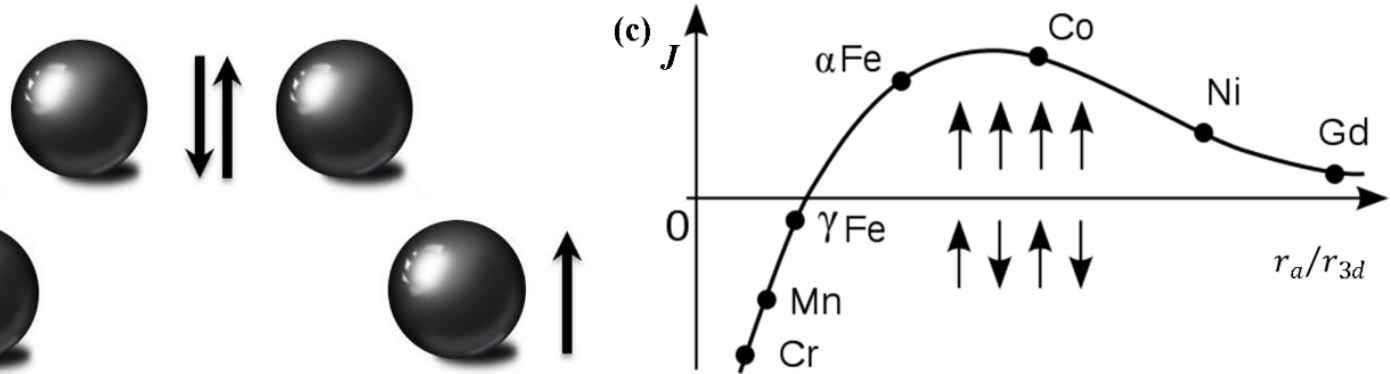

(b)
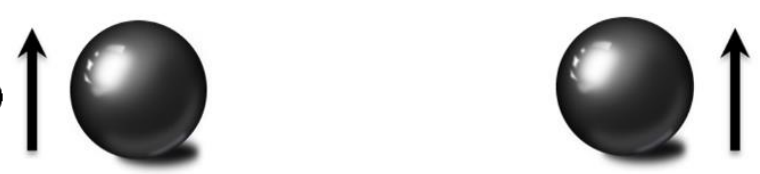

Figura A.3: Representação pictográfica do comportamento das interações (a) exchange direto (b) exchange indireto. (c) curva de Bethe e Slater mostra que o sinal da integral $J$ muda com o raio dos átomos e assim mudando o tipo de acoplamento, J positivo alinhamento paralelo e $J$ negativo alinhamento antiparalelo. Figura extraída e adaptada da ref. (CULLITY; GRAHAM, 2011).

ii) Exchange Indireto é o mecanismo de acoplamento de momentos magnéticos dos spins localizados na camada $d$ ou $f$ de um metal e a interação acontece por meio de um agente intermediário, os elétrons de condução (elétrons itinerantes), em que há pouca ou nenhuma sobreposição direta entre elétrons vizinhos. Este tipo de intercâmbio é mais conhecido como interação RKKY nomeado em homenagem Ruderman, Kittel, Kasuya e Yoshida. A integral de troca $J$ oscila de positivo para negativo com a distância interatômica $r$, dependendo da distância entre os vizinhos podemos ter interações FM ou AFM (RUDERMAN; KITTEL, 1954; KASUYA, 1956; YOSIDA, 1957). A interação de troca resultante é de longo alcance e tem um valor oscilante amortecido como é visualizado na Figura A.4.

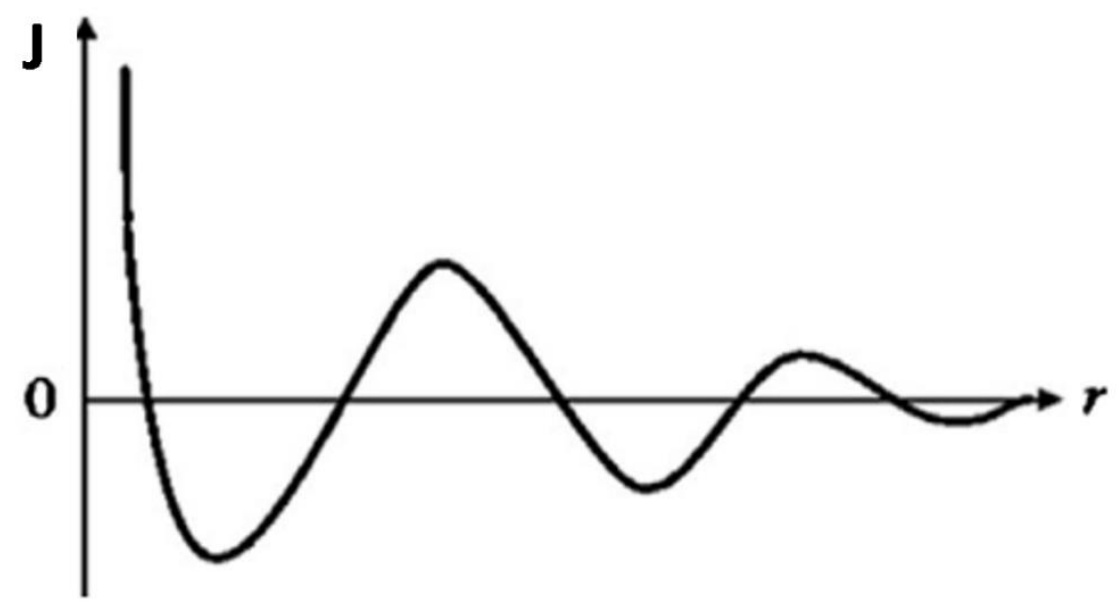

Figura A.4: O coeficiente de exchange indireto (RKKY) versus o espaçamento interatômica $r$ extraído de (SENGUPTA; SARKAR, 2015). 


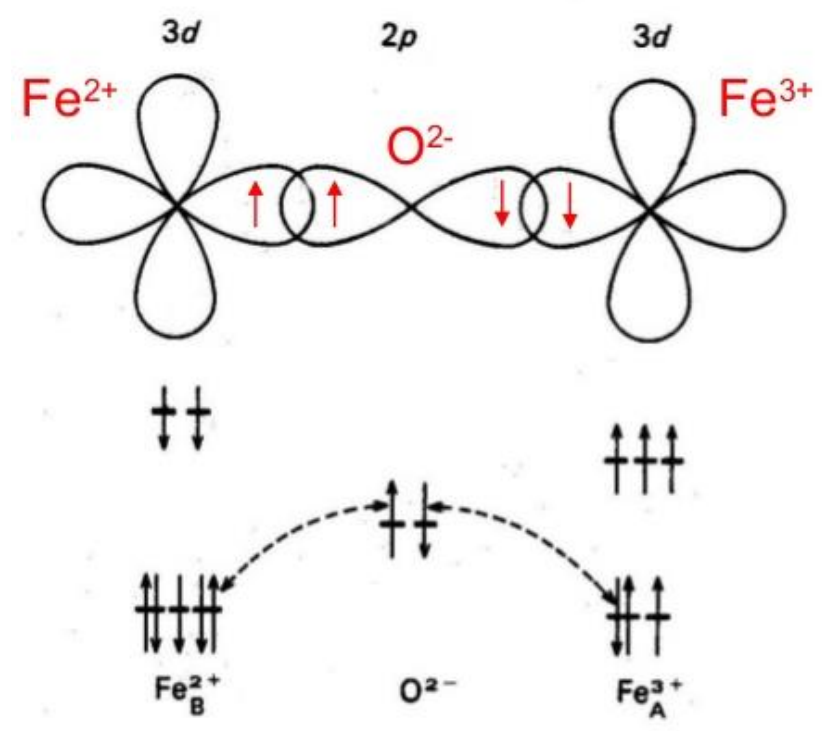

Figura A.5: Representação do acoplamento de superexchange da magnetita $\left(\mathrm{Fe}_{3} \mathrm{O}_{4}\right)$, as setas representam os spins dos átomos.

iii) Superexchange descreve acoplamento entre íons que se encontram distantes que podem ser ligados por um exchange direto, mas acoplado por uma distância relativamente longa através de um material não-magnético. Basicamente, o Princípio de exclusão de Pauli rege o acoplamento de superexchange. Quando dois íons magnéticos estão com orbitais com metade preenchida, se acoplam por meio de um íon não magnético intermediário (por exemplo, $\mathrm{O}^{2-}$ ) e o superexchange será fortemente antiferromagnético. Enquanto o acoplamento entre um íon com um orbital cheio e um com um orbital semi-completo será ferromagnético. Outra possibilidade de acoplamento é a de um íon com o orbital semi-completo ou completo e um íon com orbital vazio, esse acoplamento poderá ser Anti ou Ferro, mas o comportamento Ferromagnético é beneficiado (ANDERSON, 1950). A Figura A.5 exemplifica o comportamento da magnetita $\left(\mathrm{Fe}_{3} \mathrm{O}_{4}\right)$. Em sistemas nanoparticulados, geralmente, encontramos estruturas desordenadas que é impossível de determinar a direção de um spin levando a frustação.

\section{B.7 Frustração e Vidros de Spins}

Nesta seção, discutiremos brevemente as características de um spins glass (vidros de spins) em relação a um material bulk. Um sistema magnético correlacionado nem sempre satisfaz todas as interações de troca, há uma distribuição aleatória de interações de troca devido aos sinais da integral de troca, quando este é positivo ele possui comportamento ferromagnético 
e se negativo antiferromagnético. A frustração magnética num material é desenvolvida devido aos spins descompensados ou da competição entre spins vizinhos não tão próximos e interações de vizinhos bem mais próximos, que acabam provocando uma competição energética entre todos. Nesse caso diz-se que o sistema está frustrado. Ilustra-se um caso de uma rede antiferromagnética que possui um ordenamento e de frustração na Figura A.6 (a).

$\mathrm{Na}$ Figura A.6 (b) mostramos uma rede triangular antiferromagnética que está intrinsecamente frustrada, energeticamente a orientação do spin superior é indistinguível. Por isso existe a degenerescência no estado fundamental de energia e o sistema se torna magneticamente frustrado. Num outro cenário, introduzindo impurezas magnéticas num material não-magnético, o posicionamento aleatório dos átomos magnéticos gera interações com forças variadas resultando num sistema magneticamente desordenado.

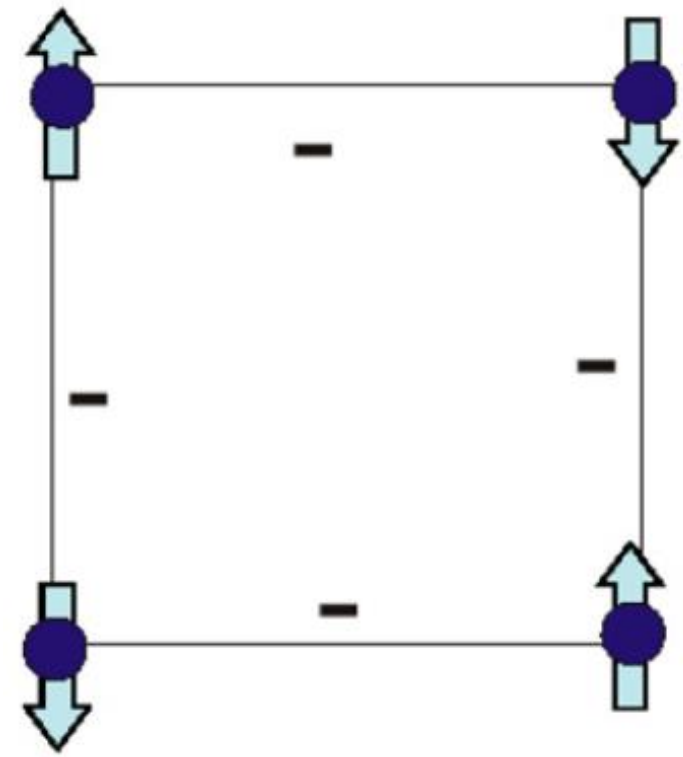

(a) Não Frustrada

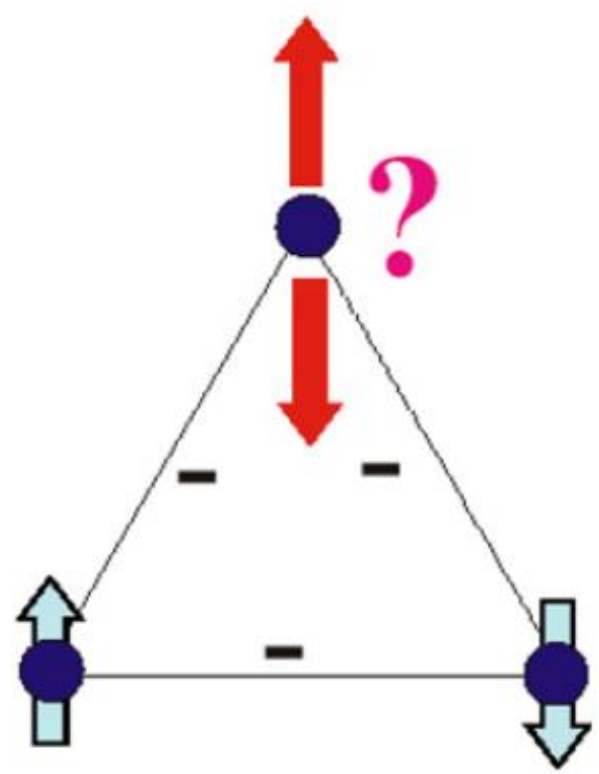

(b) Frustrada

Figura A.6: (a) rede quadrada de vizinhos mais próximos antiferromagnética não frustrada. (b) rede triangular de vizinhos mais próximos antiferromagnética frustrada extraída de (BEDANTA; KLEEMANN, 2009).

Vidros de spins são estruturas magnéticas com estado metaestável onde a frustração é o processo dominante, tendo como resultado uma magnetização média nula, ou seja, $\left\langle\sum_{i} S_{i}^{z}\right\rangle=0$, mas com valor quadrático médio $\left\langle\left(S_{i}^{z}\right)^{2}\right\rangle$ não nulo. Esse fenômeno surge quando há um congelamento desordenado dos momentos magnéticos elementares abaixo de uma temperatura crítica $T_{g}$, chamada de temperatura de transição vítrea dos spins. Em outras palavras, ao passo que o congelamento vai acontecendo, ocorre uma competição entre interações e consequentemente uma frustração dessas (TOULOUSE, 1987). Diminuindo-se a temperatura 
de um sistema desordenado é observado que abaixo de uma certa temperatura os spins entram num estado irreversível (frozen) $T_{f}$. Isto é, a dinâmica da magnetização torna-se criticamente lenta com o resfriamento e associado com o comportamento cooperativo dos spins no congelamento. (TOULOUSE, 1987).

\section{Tipos de Vidros de Spins}

Spins glass é divido principalmente em três tipos, (i) spins glass canônico, (ii) spins glass cluster, e (iii) spins glass de superfície ou spin-glass-like (como vidros de spin).

(i) Vidro de spins canônico é geralmente formado por metais nobres ( $\mathrm{Au}, \mathrm{Ag}, \mathrm{Pt}, \mathrm{Cu}$ ) que são fracamente dopados com íons de metais de transição $3 d$, tais como Fe ou Mn, uma vez que as impurezas magnéticas são colocadas dentro de uma matriz a interação magnética é geralmente tipo RKKY (BLÜGEL, 1995). Como resultado os spins (distribuídos aleatoriamente) dentro do metal hospedeiro, apresentam algumas interações spin-spin positivas (favorecendo o exchange direto), enquanto outras podem ser negativos conduzindo a um exchange indireto, levando a uma frustração magnética do sistema.

(ii) Para materiais que possuem separação de fases magnéticas, como por exemplo aglomerados FM dentro de uma matriz AFM os domínios FM interagem de forma correlacionada uns com os outros levando a um estado vítreo que é chamado de tipo de spins glass cluster (vidro de spin de aglomerado). A dinâmica de sistemas com fases spin glass é sensível ao diâmetro dos clusters de FM, que por sua vez depende da temperatura e do campo magnético externo.

(iii) Em nanoestruturas os efeitos de superfície se tornam significativos devido a razão superfície/volume. A frustração magnética surge devido à quebra de simetria dos spins de superfície, defeitos e/ou vacâncias na rede cristalina que propagam uma desordem estrutural na superfície chamado em spin-glass-like ou spins glass de superfície (MØRUP et al., 1995). A interação de troca entre os spins da superfície e os momentos centrais (abaixo da temperatura $T_{f}$ ) de nanoestruturas pode provocar o efeito de exchange bias que é investigado nesta Tese. 


\section{Medidas de Magnetização}

A medida é conseguida através da oscilação da amostra próximo de uma bobina de detecção, que recolhe de forma sincronizada a voltagem induzida. Usando um gradiômetro de primeira ordem, que consiste em duas bobinas enroladas opostamente, com uma relativamente grande amplitude de oscilação ( $2 \mathrm{~mm}$ de pico e uma variação de $0.1 \mathrm{~mm}-5 \mathrm{~mm}$ ) e uma frequência de $40 \mathrm{~Hz}$, o sistema possui uma sensibilidade capaz de observar as mudanças de magnetização da ordem de $10^{-10} \mathrm{~A} / \mathrm{m}^{2}$, equivalente a $10^{-7} \mathrm{emu}$. Uma bobina supercondutora, localizado no Dewar ${ }^{14}$, opera desde $400 \mathrm{~K}$ até temperatura de $1.9 \mathrm{~K}$ e pode gerar um campo homogêneo de até 16 T. Esse aparelhamento é bem versátil, no modo Oven Module com forno acoplado no VSM chega a temperaturas de até $1000 \mathrm{~K}$, possibilitando realizar experimentos de Calor Específico, Eletro-Transporte e Magnetometria. Além de permitir o uso de um modo alternativo de refrigeração o Helium-3 Refrigerator Option é capaz de atingir temperaturas ainda mais baixas, de até $0.5 \mathrm{~K}$.
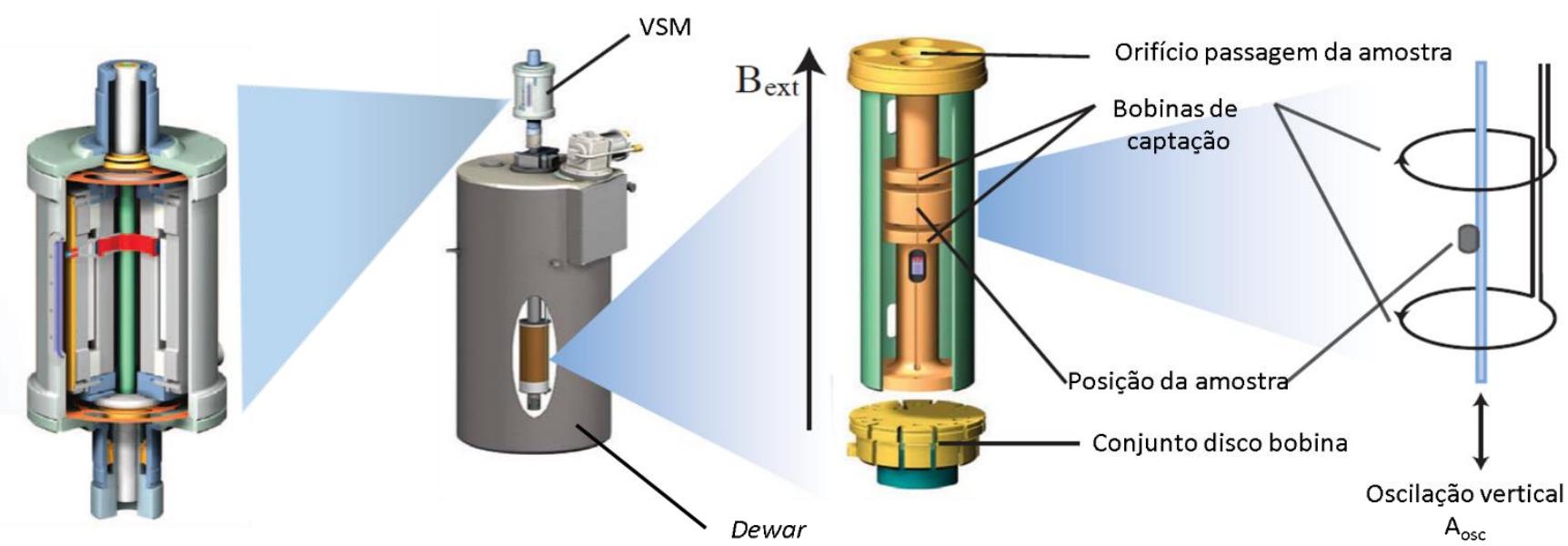

Figura A.7: Representação pictográfica do PPMS com opção VSM.

Uma representação pictográfica do PPMS com opção VSM é visualizado na Figura A.7. O princípio básico de funcionamento de um VSM é que um fluxo magnético variável irá provocar uma tensão nas bobinas de captação. A definição do fluxo magnético é dada por

$$
d \phi=\vec{B}_{S} \cdot \vec{d} n=B_{S} \cdot A \cos \alpha,
$$

onde $\vec{B}_{S}$ é o campo magnético produzido pela amostra, e $\vec{d} n$ é o vetor perpendicular à área da amostra A. Para a posição da amostra senoidalmente oscilante e $\vec{B}$ paralelo ao $\vec{d} n$, o fluxo magnético se torna

\footnotetext{
${ }^{14}$ Recipiente projetado para fornecer um isolamento térmico quase perfeito, dificultando as trocas de calor com o meio externo.
} 


$$
d \phi=\underbrace{C m A_{o s} \cos \omega t}_{B_{S}} \cdot A,
$$

onde C é uma constante de acoplamento, o símbolo $m$ representa o momento magnético da amostra, $A_{\text {osc }}$ é a amplitude de oscilação e $\omega=2 \pi f$ é a frequência angular de oscilação. Aplicando a lei de Faraday da indução $U_{\text {ind }}=-\phi$, verifica-se que a tensão induzida nas bobinas de captação é dada por:

$$
U_{\text {ind }}=\omega C m S A_{o s c} \sin \omega t .
$$

A aquisição de medição dos momentos magnéticos envolve a medição do coeficiente de resposta da tensão sinusoidal a partir das bobinas de detecção. Por exemplo, um ciclo de histerese consiste em medir o momento magnético $\mathrm{m}$ em função do campo aplicado externamente $B_{\text {ext }}$ gerado por uma bobina supercondutora.

\section{C.1 Protocolos experimentais das medidas magnéticas}

Uma explanação dos processos de medidas utilizados nesta Tese é apresentada, bem como as denominações para alguns protocolos e nomenclaturas adotadas serão descritos a seguir.

\section{Magnetização versus Temperatura}

Além da técnica básica de aplicação de campo externo (ciclo de histerese), a caracterização da dependência da magnetização nos fornece informações para evidenciar propriedades superparamagnéticas de conjuntos de nanopartículas. Nesses experimentos a baixo campo e na ausência de campo, a separação entre as curvas ZFC e FC em uma dada temperatura, juntamente com um pico na curva ZFC normalmente definida como temperatura de bloqueio $\left(T_{B}\right)$, é uma assinatura da anisotropia magnética das partículas. Este pico corresponde à transição de um estado bloqueado para estado superparamagnético. Essas medidas são amplamente utilizadas, pois fornecem informações sobre a energia anisotropica magnética de nanopartículas. A seguir apresentamos os protocolos de medida usados nessa Tese.

ZFC (Zero Field Cooling - Resfriado a Campo Zero), amostra é resfriada de uma temperatura inicial acima da temperatura de Bloqueio (transição magnética) com ausência de campo magnético aplicado até a temperatura mais baixa do experimento, nesta é aplicado um 
campo de prova e os dados são obtidos durante o processo de aumento da temperatura da medida.

Um processo FC ou FCC (Field Cooling ou Field Cooled Cooling - Resfriamento com Campo Aplicado) é geralmente efetuado imediatamente após o protocolo ZFC: inicia-se a medida com a diminuição da temperatura em presença de campo DC de baixa intensidade (50 Oe) até chegar a temperatura mais baixa do experimento.

Em um processo FCW ou FH (Field Cooled Warming ou Heating - Aquecendo com Campo de Congelamento Aplicado), a amostra é aquecida após resfriamento em presença de com campo DC de baixa intensidade.

Para observar a dependência térmica da magnetização a alto campo, Lei de Bloch, utilizamos o seguinte protocolo de medida. Inicialmente, as amostras investigadas são resfriadas com protocolo ZFC. Esse processo de resfriamento fixa os eixos de fácil magnetização das partículas orientados de modo aleatório. Em $5 \mathrm{~K}$ aplica-se um campo de 90 kOe, varia-se a temperatura até $250 \mathrm{~K}$ e registra-se a magnetização de saturação (Ms) em função da temperatura.

Apresentamos aqui o protocolo de medida para o efeito de memória DC utilizado nessa Tese com base nos experimentos de Sun et al. (SUN et al., 2003). Em primeiro lugar, a amostra é resfriada em campo magnético pequeno, a uma taxa de resfriamento constante, então aquecêlo de volta continuamente à mesma taxa e registar a magnetização $M_{F C W}^{R}$. Essa curva será a referência para comparação com as outras curvas e visualizamos na Figura A.8 (I). Em seguida, resfriar-se a amostra com a mesma taxa e novamente registra a magnetização com resfriamento, agora com paradas temporarias $\left(t_{w}\right)$, como é visualizado na Figura A.8 (II). Em (a) o campo é cortado para deixar a magnetização relaxar decrescentemente e depois de um tempo de espera $t_{w}$ o campo é ligado em (b), entre (b)-(c) a temperatura é diminuída a uma taxa de resfriamento constante. Entre (c)-(d) uma nova parada é feita e após diminui-se a temperatura até (e) e o campo novamente cortado e feita uma nova parada entre (e)-(f). Após a parada diminui-se a temperatura até chegar a temperatura de base em $(\mathrm{g})$. Este procedimento produz uma curva de resfriamento com steplike (degraus) $M_{F C C}^{\text {Down }}$. Depois de atingir a temperatura de base em (g) na Figura A.8 (II) e (III) imediatamente a temperatura é elevada continuamente e a magnetização é registrada $M_{F C W}^{U_{p}}$ novamente com steplike entre (h)-(i), (j)-(k) e (l)-(m) com o mesmo tempo de parada usado no resfriamento. 

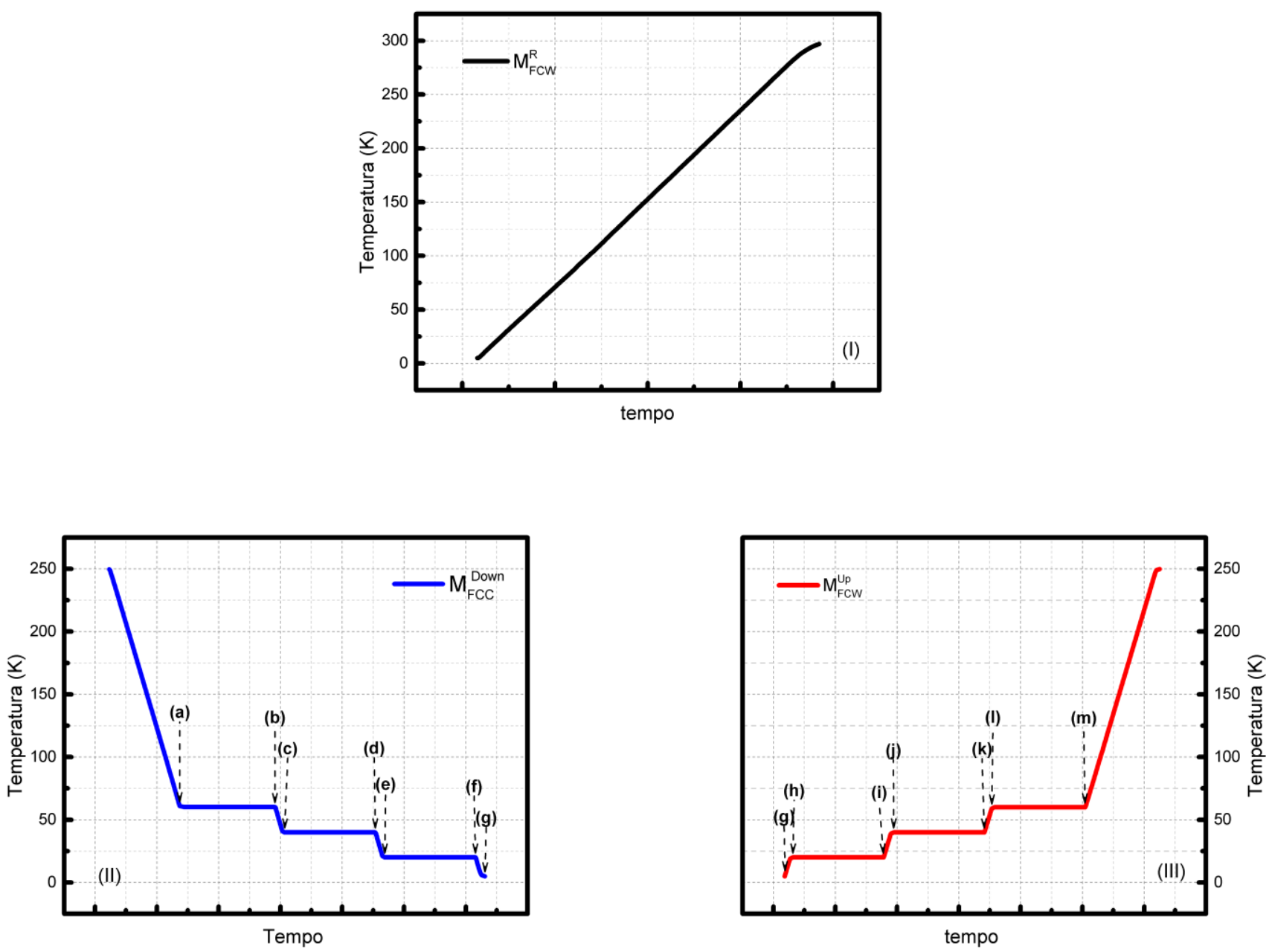

Figura A.8: Protocolo de medida do efeito de memória com magnetização DC. (I) linha sólida na cor preta é a medida com aquecimento a uma velocidade constante de $2 \mathrm{~K} / \mathrm{min}$ com protocolo FC e campo de cooling de 50 Oe (curva de referência) $M_{F C W}^{R}$. (II) protocolo de resfriamento com paradas programadas $M_{F C C}^{\text {Down }}$ e em (III) protocolo de medida com aquecimento $M_{F C W}^{U p}$. (II) e (III) as curvas foram feitas com paradas de 2 horas de duração, a 60 , 40 e $20 \mathrm{~K}$. O campo é cortado durante cada paragem.

\section{Magnetização versus Campo Magnético Aplicado}

Nesta seção apresentamos o método empregado para a aquisição dos ciclos de histerese magnética, isto é, o seu momento magnético em função do campo magnético aplicado. Os parâmetros magnéticos mais importantes que caracterizam um material magnético são aqueles relacionados ao seu ciclo de histerese magnética. A forma de um laço de histerese pode ser utilizada para determinar a utilidade de um material para uma aplicação particular. Além do mais, os valores da magnetização de saturação $\left(\mathrm{M}_{\mathrm{S}}\right)$, a coercividade $\left(\mathrm{H}_{\mathrm{C}}\right)$, remanência $\left(\mathrm{M}_{\mathrm{R}}\right)$ e susceptibilidade $(\chi)$ podem ser deduzidos. Podemos medir os ciclos de histerese magnética utilizando protocolos ZFC e FC. 
ZFC (Zero Field Cooling - Resfriado com Campo Zero) a temperatura ambiente se aplica uma rotina para desmagnetizar a amostra, que consiste em aplicar campo em sentidos opostos e diminuindo a intensidade até chegar a zero. Após se reduz a temperatura até a desejada, nesta registra-se a magnetização com o aumento do campo até o campo máximo positivo, em seguida diminui-se o campo até o campo máximo negativo e por fim aumenta-se o campo até o campo máximo positivo do experimento. As curvas de diminuição do campo, $\mathrm{H}(+) \rightarrow \mathrm{H}(-)$, denomina-se ramo superior e com aumento do campo $\mathrm{H}(-) \rightarrow \mathrm{H}(+)$ denomina-se ramo inferior, essas são diferentes abaixo da temperatura de bloqueio do material. A curva traçada pela soma dos ramos superior e inferior é chamada de ciclo de histerese magnética $\mathrm{H}(+) \rightarrow \mathrm{H}(-) \rightarrow \mathrm{H}(+)$.

FC (Field Cooling-Resfriado com Campo), aplica-se um campo magnético externo e amostra é resfriada até a temperatura desejada do experimento e um ciclo de histerese completo é medido. Comparando os dois protocolos ZFC e FC em materiais constituídos por multicamadas podemos observar o deslocamento do ciclo de histerese magnética para esquerda, fenômeno conhecido como exchange bias.

Para a investigação da dependência do exchange bias $\left(H_{E X}\right)$ em função do campo de cooling $\left(H_{\text {cool }}\right)$. Após a rotina de desmagnetização em temperatura de $\mathrm{T}=250 \mathrm{~K}$, aplica-se $H_{\text {cool }}$ para alinhar os momentos das NPs-CS na direção do campo aplicado, após reduzida a temperatura progressivamente até $5 \mathrm{~K}$. Então o campo é aumentado de $H_{\text {cool }}$ até $H=+90 \mathrm{kOe}$ e a medição do ciclo de histerese magnética começa. Entre uma medida e outra a temperatura é aumentada até $250 \mathrm{~K}$ e uma rotina para desmagnetizar a amostra é aplicada e só após se inicia a medida do próximo ciclo.

Para o estudo da estabilidade do exchange bias utilizamos a rotina do minor loops (laços menores) que consiste em aplicar um campo de cooling de $12 \mathrm{kOe}$ na temperatura $250 \mathrm{~K}$, depois a temperatura é diminuida de $250 \mathrm{~K}$ até $5 \mathrm{~K}$ e quando a temperatura está estabilizada, o campo é aumentado de $H_{\text {cool }}$ até $H=+90 \mathrm{kOe}$, os ciclos histereses magnéticas são medidos. Entre os sucessivos ciclos, as amostras foram aquecidas e uma rotina de desmagnetização é executada em 250 K. Variamos o campo saturante $\mathrm{H}_{\max }$ de 10 - 90 kOe.

Após o estudo minucioso da dependência do exchange bias com o campo de cooling e de estabilidade via minor loops, apresentados anteriormente, podemos estudar a dinâmica não linear do exchange bias (o efeito de treinamento) nas nossas amostras. Utilizamos os seguintes protocolos de medida para investigar o efeito de treinamento do exchange bias e o campo de 
cooling aplicado em todas os experimentos é $H_{\text {cool }}^{M A X} 12 \mathrm{kOe}$, valor máximo encontrado no estudo da dependência do exchange bias com o campo de cooling.

- Para amostra de pó compacto realizamos o seguinte protocolo: Resfriamos a amostra com $H_{C O O L}^{M A X}$ até $5 \mathrm{~K}$, imediatamente $\left(\mathrm{t}_{\mathrm{w}}=0 \mathrm{~s}\right)$ inicia-se o primeiro ciclo de histerese até \pm 90 kOe, com a conclusão deste é medido seis ciclos de histerese com tempos de parada diferentes $\mathrm{t}_{\mathrm{w}}=0,600$ e $6000 \mathrm{~s}$ entre cada ciclo.

- Para amostra de ferrofluido diluído, realizamos dois protocolos de medida. Resfriamos a amostra com $H_{C O O L}^{M A X}$ até 5 e $30 \mathrm{~K}$. Inicia-se o primeiro ciclo de histerese, com a conclusão deste é medido seis ciclos de histerese com tempo de parada $t_{w}=0 \mathrm{~s}$ entre cada ciclo. Com o protocolo de envelhecimento descemos a temperatura com $H_{C O O L}^{M A X}$ até $5 \mathrm{~K}$ subimos o campo até $\pm 90 \mathrm{kOe}$ e aguardamos $t_{w}=6000 \mathrm{~s}$ antes de iniciar todos os ciclos medidos. 


\section{Referências Bibliográficas}

ALI, S. R.; GHADIMI, M. R.; FECIORU-MORARIU, M.; BESCHOTEN, B.; GÜNTHERODT, G. Training effect of the exchange bias in $\mathrm{Co} / \mathrm{CoO}$ bilayers originates from the irreversible thermoremanent magnetization of the magnetically diluted antiferromagnet. Physical Review B - Condensed Matter and Materials Physics, v. 85, n. 1, p. 1-4, 2012.

ANDERSON, P. W. Antiferromagnetism. Theory of superexchange interaction. Physical Review, v. 79, n. 2, p. 350, 1950.

AQUINO, R.; DEPEYROT, J.; SOUSA, M. H.; TOURINHO, F. A.; DUBOIS, E.; PERZYNSKI, R. Magnetization temperature dependence and freezing of surface spins in magnetic fluids based on ferrite nanoparticles. Physical Review B, v. 72, n. 18, p. 184435, 2005.

AQUINO, R.; TOURINHO, F. A.; ITRI, R.; E LARA, M.; DEPEYROT, J. Size control of $\mathrm{MnFe} 2 \mathrm{O} 4$ nanoparticles in electric double layered magnetic fluid synthesis. Journal of magnetism and magnetic materials, v. 252, p. 23-25, 2002.

ASKELAND, D. R.; PHULÉ, P. P. The science and engineering of materials. 2003.

BACRI, J. C.; PERZYNSKI, R.; SALIN, D. Magnetic and thermal behaviour of $\gamma$-Fe2O3 fine grains. Journal of magnetism and magnetic materials, v. 71, n. 3, p. 246-254, 1988.

BATLLE, X.; LABARTA, A. Finite-size effects in fine particles: magnetic and transport properties. Journal of Physics D: Applied Physics, v. 35, n. 6, p. R15, 2002.

BEAN, C. P.; LIVINGSTON, J. D. Superparamagnetism. Journal of Applied Physics, v. 30, n. 4, p. S120-S129, 1959.

BEDANTA, S.; KLEEMANN, W. Supermagnetism. Journal of Physics D: Applied Physics, v. 42, n. 1, p. 13001, 2009.

BERTOTTI, G. Hysteresis in Magnetism: For Physicists, Materials Scientists, and Engineers, 1998. .

BINEK, C. Training of the exchange-bias effect: A simple analytic approach. Physical Review B, v. 70, n. 1, p. 14421, 2004.

BINEK, C.; HE, X.; POLISETTY, S. Temperature dependence of the training effect in a $\mathrm{Co}$ CoO exchange-bias layer. Physical Review B, v. 72, n. 5, p. 54408, ago. 2005.

BITTER, F. Experiments on the nature of ferromagnetism. Physical Review, v. 41, n. 4, p. 507-515, 1932.

BLÜGEL, S. Magnetism of 4d and 5d transition metal adlayers on Ag (001): Dependence on the adlayer thickness. Physical Review B, v. 51, n. 3, p. 2025, 1995.

BLUNDELL, S.; THOULESS, D. Magnetism in condensed matter. [s.1.] Oxford university press New York, 2001. v. 18

BØDKER, F.; MØRUP, S.; LINDEROTH, S. Surface effects in metallic iron nanoparticles. Physical Review Letters, v. 72, n. 2, p. 282, 1994.

BRAGG, W. H.; BRAGG, W. L. The reflection of X-rays by crystals. Proceedings of the Royal Society of London. Series A, Containing Papers of a Mathematical and Physical 
Character, v. 88, n. 605, p. 428-438, 1913.

CABREIRA-GOMES, R.; SILVA, F. G.; AQUINO, R.; BONVILLE, P.; TOURINHO, F. A.; PERZYNSKI, R.; DEPEYROT, J. Exchange bias of MnFe2O4@ $\gamma-\mathrm{Fe} 2 \mathrm{O} 3$ and CoFe2O4@ $\gamma$ $\mathrm{Fe} 2 \mathrm{O} 3$ core/shell nanoparticles. Journal of Magnetism and Magnetic Materials, v. 368, p. 409-414, 2014.

CADOR, O.; GRASSET, F.; HANEDA, H.; ETOURNEAU, J. Memory effect and super-spinglass ordering in an aggregated nanoparticle sample. Journal of Magnetism and Magnetic Materials, v. 268, n. 1-2, p. 232-236, 2004.

CANNAS, C.; MUSINU, A.; PICCALUGA, G.; FIORANI, D.; PEDDIS, D.; RASMUSSEN, H. K.; MØRUP, S. Magnetic properties of cobalt ferrite-silica nanocomposites prepared by a sol-gel autocombustion technique. Journal of Chemical Physics, v. 125, n. 16, 2006.

CARTA, D.; CASUlA, M. F.; FLORIS, P.; FALQUI, A.; MOUNTJOY, G.; BONI, A.; SANGREGORIO, C.; CORRIAS, A. Synthesis and microstructure of manganese ferrite colloidal nanocrystals. Physical Chemistry Chemical Physics, v. 12, n. 19, p. 5074-5083, 2010 .

CHANDRA, S.; KHURSHID, H.; LI, W.; HADJIPANAYIS, G. C.; PHAN, M. H.; SRIKANTH, H. Spin dynamics and criteria for onset of exchange bias in superspin glass $\mathrm{Fe} / \gamma-$ Fe 2 O 3 core-shell nanoparticles. Physical Review B, v. 86, n. 1, p. 14426, 2012.

CHAUDHURI, R. G.; PARIA, S. Core/Shell Nanoparticles : Classes, Properties, Synthesis Mechanisms , Characterization, and Applications. Chemical Reviews, v. 112, p. 2373-2433, 2012.

CHEN, X.; SAHOO, S.; KLEEMANN, W.; CARDOSO, S.; FREITAS, P. P. Universal and scaled relaxation of interacting magnetic nanoparticles. Physical Review B, v. 70, n. 17, p. 172411, 2004.

CHIKAZUMI, S.; GRAHAM, C. D. Physics of ferromagnetism 2e. [s.1.] Oxford University Press on Demand, 2009.

COEY, J. M. D. Noncollinear spin arrangement in ultrafine ferrimagnetic crystallites. Physical Review Letters, v. 27, n. 17, p. 1140, 1971.

CULLITY, B. D. Elements of X-ray Diffraction. 2001.

CULLITY, B. D.; GRAHAM, C. D. Introduction to magnetic materials. [s.1.] John Wiley \& Sons, 2011.

DE LACHEISSERIE, E. T.; GIGNOUX, D.; SCHLENKER, M. Magnétisme, Collection Grenoble Sciences. Ch18, p. 213-235, 1999.

DEL BIANCO, L.; FIORANI, D.; TESTA, A. M. Aging in an exchange biased Fe/FeOxide nanogranular system. Journal of Magnetism and Magnetic Materials, v. 310, n. 2, p. 2289 2291, 2007.

DEL BIANCO, L.; FIORANI, D.; TESTA, A. M.; BONETTI, E.; SAVINI, L.; SIGNORETTI, $\mathrm{S}$. Magnetic properties of the $\mathrm{Fe} / \mathrm{Fe}$ oxide granular system. Journal of Magnetism and Magnetic Materials, v. 262, n. 1, p. 128-131, 2003.

DEL BIANCO, L.; FIORANI, D.; TESTA, A. M.; BONETTI, E.; SIGNORINI, L. Fieldcooling dependence of exchange bias in a granular system of Fe nanoparticles embedded in an Fe oxide matrix. Physical Review B, v. 70, n. 5, p. 52401, 2004.

DENARDIN, J. C.; BRANDL, A. L.; KNOBEL, M.; PANISSOD, P.; PAKHOMOV, A. B.; 
LIU, H.; ZHANG, X. X. Thermoremanence and zero-field-cooled/field-cooled magnetization study of Co x (SiO 2) 1- x granular films. Physical Review B, v. 65, n. 6, p. 64422, 2002.

DIAS, T.; MENÉNDEZ, E.; LIU, H.; VAN HAESENDONCK, C.; VANTOMME, A.; TEMST, K.; SCHMIDT, J. E.; GIULIAN, R.; GESHEV, J. Rotatable anisotropy driven training effects in exchange biased Co/CoO films. Journal of Applied Physics, v. 115, n. 24, 2014.

DORMANN, J. L. Le phénomène de superparamagnétisme. Revue de Physique Appliquée, v. 16, n. 6, p. 275-301, 1981.

ECKERT, M. Disputed discovery: the beginnings of X-ray diffraction in crystals in 1912 and its repercussions. Acta Crystallographica Section A: Foundations of Crystallography, v. 68, n. 1, p. 30-39, 2012.

EFTAXIAS, E.; TROHIDOU, K. N. Numerical study of the exchange bias effects in magnetic nanoparticles with core/shell morphology. Physical Review B, v. 71, n. 13, p. 134406, 2005.

FARADAY, M. The Bakerian lecture: experimental relations of gold (and other metals) to light. Philosophical Transactions of the Royal Society of London, v. 147, p. 145-181, 1857.

FERNÁNDEZ-PACHECO, R.; MARQUINA, C.; VALDIVIA, J. G.; GUTIÉRREZ, M.; ROMERO, M. S.; CORNUDELlA, R.; LABORDA, A.; VILORIA, A.; HIGUERA, T.; GARCÍA, A. Magnetic nanoparticles for local drug delivery using magnetic implants. Journal of Magnetism and Magnetic Materials, v. 311, n. 1, p. 318-322, 2007.

FEYNMAN, R. P. There's plenty of room at the bottom. Engineering and science, v. 23, n. 5, p. 22-36, 1960.

FIORANI, D. Surface effects in magnetic nanoparticles. [s.1.] Springer Science \& Business Media, 2005.

FIORANI, D.; PEDDIS, D. Understanding dynamics of interacting magnetic nanoparticles: from the weak interaction regime to the collective superspin glass state. Journal of Physics: Conference Series, v. 521, n. 1, p. 12006, 2014.

FIORANI, D.; TESTA, A. M.; LUCARI, F.; D'ORAZIO, F.; ROMERO, H. Magnetic properties of maghemite nanoparticle systems: Surface anisotropy and interparticle interaction effects. Physica B: Condensed Matter, v. 320, n. 1-4, p. 122-126, 2002.

FRIEDRICH, W.; KNIPPING, P.; LAUE, M. Interferenzerscheinungen bei Röntgenstrahlen. Annalen der Physik, v. 346, n. 10, p. 971-988, 1913.

FULCOMER, E.; CHARAP, S. H. Thermal fluctuation aftereffect model for some systems with ferromagnetic-antiferromagnetic coupling. Journal of Applied Physics, v. 43, n. 10, p. 41904199, 1972.

GANDHI, A. C.; REDDY, P. M.; CHAN, T.-S.; HO, Y.-P.; WU, S. Y. Memory effect in weakly-interacting $\mathrm{Fe}_{3} \mathrm{O}_{4}$ nanoparticles. RSC Adv., v. 5, n. 103, p. 84782-84789, 2015.

GAO, R.; CHEN, W.; ZHANG, J.; FONG, W.; LI, W.; LI, X. Intergrain interaction, coercivity and Henkel plot for NdFeB magnets. Cailiao Kexue Yu Jishu(Journal of Materials Science \& Technology)(China)(USA), v. 17, 2001.

GARCÍA-OTERO, J.; PORTO, M.; RIVAS, J.; BUNDE, A. Influence of dipolar interaction on magnetic properties of ultrafine ferromagnetic particles. Physical review letters, v. 84, n. 1, p. 167, 2000.

GAWANDE, M. B.; GOSWAMI, A.; ASEFA, T.; GUO, H.; BIRADAR, A. V; PENG, D.-L.; ZBORIL, R.; VARMA, R. S. Core-shell nanoparticles: synthesis and applications in catalysis 
and electrocatalysis. Chemical Society Reviews, v. 44, n. 21, p. 7540-7590, 2015.

GAZEAU, F.; DUBOIS, E.; BACRI, J.-C.; BOUÉ, F.; CEBERS, A.; PERZYNSKI, R. Anisotropy of the structure factor of magnetic fluids under a field probed by small-angle neutron scattering. Physical Review E, v. 65, n. 3, p. 31403, 2002.

GESHEV, J. Comment on:"Exchange bias and vertical shift in CoFe2O4 nanoparticles"[J. Magn. Magn. Mater. 313 (2007) 266]. Journal of Magnetism and Magnetic Materials, v. 320 , n. 3, p. 600-602, 2008.

GESHEV, J.; POPOV, O.; MASHEVA, V.; MIKHOV, M. Thermomagnetic curves for a disordered system of single-domain ferromagnetic particles with cubic anisotropy. Journal of magnetism and magnetic materials, v. 92, n. 2, p. 185-190, 1990.

GIRI, S.; PATRA, M.; MAJUMDAR, S. Exchange bias effect in alloys and compounds. Journal of Physics: Condensed Matter, v. 23, n. 7, p. 73201, 2011.

GITTLEMAN, J. I.; ABELES, B.; BOZOWSKI, S. Superparamagnetism and relaxation effects in granular Ni-Si O 2 and Ni-Al 2 O 3 films. Physical review B, v. 9, n. 9, p. 3891, 1974.

GOMES, J. de A.; SOUSA, M. H.; TOURINHO, F. A.; AQUINO, R.; DA SILVA, G. J.; DEPEYROT, J.; DUBOIS, E.; PERZYNSKI, R. Synthesis of core-shell ferrite nanoparticles for ferrofluids: chemical and magnetic analysis. The Journal of Physical Chemistry C, v. 112, n. 16, p. 6220-6227, 2008.

GOMES, R. C. Dispersões de nanopartículas magnéticas do tipo core-shell: propriedades magnéticas e termodifusivas. 2015.

GOMIDE, G. S. Propriedades magnéticas intrínsecas e coletivas de nanopartículas de ferritas mistas de Zn-Mn. 2013.

GUO, S.; LIU, W.; MENG, H.; LIU, X. H.; GONG, W. J.; HAN, Z.; ZHANG, Z. D. Exchange bias and its training effect in $\mathrm{Ni} / \mathrm{NiO}$ nanocomposites. Journal of Alloys and Compounds, v. 497, n. 1, p. 10-13, 2010.

HALO, T. L.; MCMAHON, K. M.; ANGELONI, N. L.; XU, Y.; WANG, W.; CHINEN, A. B.; MALIN, D.; STREKALOVA, E.; CRYNS, V. L.; CHENG, C. NanoFlares for the detection, isolation, and culture of live tumor cells from human blood. Proceedings of the National Academy of Sciences, v. 111, n. 48, p. 17104-17109, 2014.

HAMMOND, C.; HAMMOND, C. The basics of crystallography and diffraction. [s.l.] Oxford University Press Oxford, 2009. v. 12

HARRES, A.; GESHEV, J. Athermal training due to exchange and dipolar coupling within a granular model for exchange bias. Journal of Physics: Condensed Matter, v. 23, n. 21, p. 216003, 2011

HENKEL, O. Remanenzverhalten und Wechselwirkungen in hartmagnetischen Teilchenkollektiven. physica status solidi (b), v. 7, n. 3, p. 919-929, 1964.

HIROI, K.; KOMATSU, K.; SATO, T. Superspin glass originating from dipolar interaction with controlled interparticle distance among $\gamma$-Fe2O3 nanoparticles with silica shells. Physical Review B - Condensed Matter and Materials Physics, v. 83, n. 22, p. 1-9, 2011.

HOFFMANN, A. Symmetry driven irreversibilities at ferromagnetic-antiferromagnetic interfaces. Physical review letters, v. 93, n. 9, p. 97203, 2004.

IGLESIAS, Ò.; BATLLE, X.; LABARTA, A. Microscopic origin of exchange bias in core/shell nanoparticles. Physical Review B, v. 72, n. 21, p. 212401, 2005. 
IGLESIAS, Ò.; LABARTA, A. Influence of surface anisotropy on the hysteresis of magnetic nanoparticles. Journal of magnetism and magnetic materials, v. 290, p. 738-741, 2005.

IGLESIAS, O.; LABARTA, A.; BATLLE, X. Exchange bias phenomenology and models of core/shell nanoparticles. Journal of nanoscience and nanotechnology, v. 8, n. 6, p. 27612780, 2008.

JACOBS, I. S.; BEAN, C. P. Magnetism, Vol. 3 (GT Rado and H. Suhl, eds.)Academic Press, New York, , 1963. .

JÖNSSON, P.; HANSEN, M. F.; NORDBLAD, P. Nonequilibrium dynamics in an interacting Fe-C nanoparticle system. Physical Review B, v. 61, n. 2, p. 1261, 2000.

JONSSON, T.; MATTSSON, J.; DJURBERG, C.; KHAN, F. A.; NORDBLAD, P.; SVEDLINDH, P. Aging in a magnetic particle system. Physical review letters, v. 75, n. 22, p. 4138, 1995.

JONSSON, T.; SVEDLINDH, P.; HANSEN, M. F. Static scaling on an interacting magnetic nanoparticle system. Physical review letters, v. 81, n. 18, p. 3976, 1998.

KACHKACHI, H.; EZZIR, A.; NOGUES, M.; TRONC, E. Surface effects in nanoparticles: application to maghemite-Fe O. The European Physical Journal B-Condensed Matter and Complex Systems, v. 14, n. 4, p. 681-689, 2000.

KASUYA, T. A theory of metallic ferro-and antiferromagnetism on Zener's model. Progress of theoretical physics, v. 16, n. 1, p. 45-57, 1956.

KECHRAKOS, D.; TROHIDOU, K. N. Magnetic properties of dipolar interacting singledomain particles. Physical Review B, v. 58, n. 18, p. 12169, 1998.

KHURSHID, H.; LAMPEN-KELLEY, P.; IGLESIAS, Ò.; ALONSO, J.; PHAN, H.; SUN, C.; SABOUNGI, M.; SRIKANTH, H. Spin-glass-like freezing of inner and outer surface layers in hollow $\gamma$-Fe 2 O 3 nanoparticles. Nature Publishing Group, n. 500, p. 1-13, 2015.

KNELLER, E. F.; LUBORSKY, F. E. Particle size dependence of coercivity and remanence of single-domain particles. Journal of Applied Physics, v. 34, n. 3, p. 656-658, 1963.

KNOBEL, M.; NUNES, W. C.; SOCOLOVSKY, L. M.; DE BIASI, E.; VARGAS, J. M.; DENARDIN, J. C. Superparamagnetism and other magnetic features in granular materials: a review on ideal and real systems. Journal of nanoscience and nanotechnology, v. 8, n. 6, p. 2836-2857, 2008.

KOBAYASHI, S.; KIMURA, T.; TAKAHASHI, S.; KAMADA, Y.; KIKUCHI, H. Quantitative evaluation of dislocation density using minor-loop scaling relations. Journal of Magnetism and Magnetic Materials, v. 320, n. 20, p. 551-555, 2008.

KOBAYASHI, S.; TAKAHASHI, S.; KAMADA, Y.; KIKUCHI, H. A low-field scaling rule of minor hysteresis loops in plastically deformed steels. IEEE Transactions on Magnetics, v. 46, n. 2, p. 191-194, 2010.

KODAMA, R. H. Magnetic nanoparticles. Journal of Magnetism and Magnetic Materials, v. 200, n. 1, p. 359-372, 1999.

KODAMA, R. H.; BERKOWITZ, A. E.; MCNIFF JR, E. J.; FONER, S. Surface spin disorder in NiFe 2 O 4 nanoparticles. Physical Review Letters, v. 77, n. 2, p. 394, 1996.

KODAMA, R. H.; BERKOWITZ, a. E.; MCNIFF JR., E. J.; FONER, S. Surface Spin Disorder in Ferrite Nanoparticles. Materials Science Forum, v. 235-238, p. 643-650, 1997. 
KOOLS, J. C. S. Exchange-biased spin-valves for magnetic storage. IEEE transactions on magnetics, v. 32, n. 4, p. 3165-3184, 1996.

LEDERMAN, D.; NOGUÉS, J.; SCHULLER, I. K. Exchange anisotropy and the antiferromagnetic surface order parameter. Physical Review B, v. 56, n. 5, p. 2332, 1997.

LEE, J.-J.; JEONG, K. J.; HASHIMOTO, M.; KWON, A. H.; RWEI, A.; SHANKARAPPA, S. A.; TSUI, J. H.; KOHANE, D. S. Synthetic ligand-coated magnetic nanoparticles for microfluidic bacterial separation from blood. Nano letters, v. 14, n. 1, p. 1-5, 2013.

LEITE, R. C. Coercividade e anisotropia magnética e matgneto-óticas em nanocolóides magnéticos. 2011.

LIN, P.-C.; CHEN, S.-H.; WANG, K.-Y.; CHEN, M.-L.; ADAK, A. K.; HWU, J.-R. R.; CHEN, Y.-J.; LIN, C.-C. Fabrication of oriented antibody-conjugated magnetic nanoprobes and their immunoaffinity application. Analytical chemistry, v. 81, n. 21, p. 8774-8782, 2009.

LU, J.; MA, S.; SUN, J.; XIA, C.; LIU, C.; WANG, Z.; ZHAO, X.; GAO, F.; GONG, Q.; SONG, B. Manganese ferrite nanoparticle micellar nanocomposites as MRI contrast agent for liver imaging. Biomaterials, v. 30, n. 15, p. 2919-2928, 2009.

LUO, W.; NAGEL, S. R.; ROSENBAUM, T. F.; ROSENSWEIG, R. E. Dipole interactions with random anisotropy in a frozen ferrofluid. Physical review letters, v. 67, n. 19, p. 2721, 1991.

MAHMOODI, N. M. Manganese ferrite nanoparticle: Synthesis, characterization, and photocatalytic dye degradation ability. Desalination and Water Treatment, v. 53, n. 1, p. 8490, 2015.

MAITY, T.; GOSWAMI, S.; BHATTACHARYA, D.; ROY, S. Superspin glass mediated giant spontaneous exchange bias in a nanocomposite of $\mathrm{BiFeO} 3-\mathrm{Bi} 2 \mathrm{Fe} 4 \mathrm{O} 9$. Physical Review Letters, v. 110, n. 10, p. 1-5, 2013.

MALIK, R.; SEHDEV, N.; LAMBA, S.; SHARMA, P.; MAKINO, A.; ANNAPOORNI, S. Magnetic memory effects in nickel ferrite/polymer nanocomposites. Applied Physics Letters, v. 104, n. 12, p. 1-6, 2014.

MAMIYA, H.; NAKATANI, I.; FURUBAYASHI, T. Slow dynamics for spin-glass-like phase of a ferromagnetic fine particle system. Physical review letters, v. 82, n. 21, p. 4332, 1999.

MARINHO, E. P. SÍNTESE, CARACTERIZAÇÃO FÍSICO-QUÍMICA E. ELETROQUÍMICA.UNIVERSIDADE DE BRASÍLIA, , 2011. .

MARTINEZ-HUERTA, J. M.; MEDINA, J. D. L. T.; PIRAUX, L.; ENCINAS, A. Configuration dependent demagnetizing field in assemblies of interacting magnetic particles. Journal of Physics: Condensed Matter, v. 25, n. 22, p. 226003, 2013.

MASSART, R. Preparation of aqueous magnetic liquids in alkaline and acidic media. IEEE transactions on magnetics, v. 17, n. 2, p. 1247-1248, 1981.

MATTIS, D. C. The theory of magnetism i: statics and dynamics. [s.1.] Springer Science \& Business Media, 2012. v. 17

MEIKLEJOHN, W. H.; BEAN, C. P. New magnetic anisotropy. Physical review, v. 102, n. 5, p. 1413, 1956.

MÉRIGUET, G.; WANDERSMAN, E.; DUBOIS, E.; CEBERS, A.; DE ANDRADE GOMES, J.; DEMOUCHY, G.; DEPEYROT, J.; ROBERT, A.; PERZYNSKI, R. Magnetic fluids with tunable interparticle interaction: monitoring the under-field local structure. 
Magnetohydrodynamics, v. 48, n. 2, p. 415-425, 2012.

MICHELE, O.; HESSE, J.; BREMERS, H. Magnetization measurements on frozen ferrofluids: an attempt to separate interaction and anisotropy influences. Journal of Physics: Condensed Matter, v. 18, n. 20, p. 4921, 2006.

MISHRA, S. K.; RADU, F.; DÜRR, H. A.; EBERHARDT, W. Training-induced positive exchange bias in NiFe/IrMn bilayers. Physical review letters, v. 102, n. 17, p. 177208, 2009.

MORRISH, A. H. The Physical Principles of Magnetism, Wiley Series on the Science and Technology of Materials. 1965.

MØRUP, S.; BØDKER, F.; HENDRIKSEN, P. V.; LINDEROTH, S. Spin-glass-like ordering of the magnetic moments of interacting nanosized maghemite particles. Physical Review $\mathbf{B}$ Condensed Matter, v. 52, n. 1, p. 287-294, 1995.

NADEEM, K.; KRENN, H.; SZABÓ, D. V. Memory effect versus exchange bias for maghemite nanoparticles. Journal of Magnetism and Magnetic Materials, v. 393, p. 239$242,2015$.

NAKAMAE, S.; CRAUSTE-THIBIERGE, C.; KOMATSU, K.; L'HO^TE, D.; TAHRI, Y.; VINCENT, E.; DUBOIS, E.; DUPUIS, V.; PERZYNSKI, R. Superspin glass aging behavior in textured and nontextured frozen ferrofluid. Journal of Applied Physics, v. 107, n. 9, p. 09E135, 2010a.

NAKAMAE, S.; CRAUSTE-THIBIERGE, C.; KOMATSU, K.; L'HÔTE, D.; VINCENT, E.; DUBOIS, E.; DUPUIS, V.; PERZYNSKI, R. Anisotropy-axis orientation effect on the magnetization of $\gamma$-Fe 2 O 3 frozen ferrofluid. Journal of Physics D: Applied Physics, v. 43, n. 47, p. 474001, 2010b.

NAKAMAE, S.; CRAUSTE-THIBIERGE, C.; L'HÔTE, D.; VINCENT, E.; DUBOIS, E.; DUPUIS, V.; PERZYNSKI, R. Dynamic correlation length growth in superspin glass: Bridging experiments and simulations. Applied Physics Letters, v. 101, n. 24, p. 2010-2014, 2012.

NÉEL, L. Influence des fluctuations du champ moléculaire sur les propriétés magnétiques des corps... [s.1.] Masson, 1932.

NÉEL, L. La loi d'approche en a: H et une nouvelle théorie de la dureté magnétique. J. phys. radium, v. 9, n. 5, p. 184-192, 1948.

NÉEL, L. Théorie du trâ̂nage magnétique des ferromagnétiques en grains fins avec applications aux terres cuites. Ann. Géophys, v. 5, p. 99-136, 1949.

NÉEL, L.; CHASTEL, R.; BESSET, C.; HOROWITZ, J.; MESSIAH, A.; WINTER, J.; PAQUETTE, G.; BAYET, M.; HOYAUX, M.; BERNAS, R. Magnetic surface anisotropy and superlattice formation by orientation. Anisotropie magnétique superficielle et surstructures d'orientation p. 225. Journal de Physique et le Radium, v. 15, n. 4, 1954.

NIEBIESKIKWIAT, D.; SALAMON, M. B. Intrinsic interface exchange coupling of ferromagnetic nanodomains in a charge ordered manganite. Physical Review B, v. 72, n. 17, p. $174422,2005$.

NOGUÉS, J.; SCHULlER, I. K. Exchange bias. Journal of Magnetism and Magnetic Materials, v. 192, n. 2, p. 203-232, 1999.

NOGUÉS, J.; SORT, J.; LANGLAIS, V.; SKUMRYEV, V.; SURINACH, S.; MUNOZ, J. S.; BARÓ, M. D. Exchange bias in nanostructures. Physics Reports, v. 422, n. 3, p. 65-117, 2005a. 
NOGUÉS, J.; SORT, J.; LANGLAIS, V.; SKUMRYEV, V.; SURIÑACH, S.; MUÑOZ, J. S.; BARÓ, M. D. Exchange bias in nanostructures. Physics Reports, v. 422, n. 3, p. 65-117, 2005 b.

NUNES, W. C.; SOCOLOVSKY, L. M.; DENARDIN, J. C.; CEBOLLADA, F.; BRANDL, A. L.; KNOBEL, M. Role of magnetic interparticle coupling on the field dependence of the superparamagnetic relaxation time. Physical Review B, v. 72, n. 21, p. 212413, 2005.

OHLDAG, H.; SCHOLL, A.; NOLTING, F.; ARENHOLZ, E.; MAAT, S.; YOUNG, A. T.; CAREY, M.; STÖHR, J. Correlation between exchange bias and pinned interfacial spins. Physical review letters, v. 91, n. 1, p. 17203, 2003.

ONG, Q. K.; LIN, X.-M.; WEI, A. Role of Frozen Spins in the Exchange Anisotropy of CoreShell Fe@ $\mathrm{Fe}_{3} \mathrm{O}_{4}$ Nanoparticles. The Journal of Physical Chemistry C, v. 115, n. 6, p. 2665 2672, 2011.

PACCARD, D.; SCHLENKER, C.; MASSENET, O.; MONTMORY, R.; YELON, A. A New Property of Ferromagnetic-Antiferromagnetic Coupling. physica status solidi (b), v. 16, n. 1, p. 301-311, 1966.

PATRA, M.; THAKUR, M.; DE, K.; MAJUMDAR, S.; GIRI, S. Reply to comment on "Particle size dependent exchange bias and cluster-glass states in LaMn0. 7Fe0. 3O3". Journal of Physics: Condensed Matter, v. 21, n. 7, p. 78002, 2009.

PEDDIS, D.; CANNAS, C.; MUSINU, A.; PICCALUGA, G. Coexistence of superparmagnetism and spin-glass like magnetic ordering phenomena in a $\mathrm{CoFe}_{2} \mathrm{O}_{4}-\mathrm{SiO}_{2}$ nanocomposite. Journal of Physical Chemistry C, v. 112, n. 13, p. 5141-5147, 2008.

PENG, D. L.; SUMIYAMA, K.; HIHARA, T.; YAMAMURO, S.; KONNO, T. J. Magnetic properties of monodispersed Co/CoO clusters. Physical Review B, v. 61, n. 4, p. 3103, 2000.

PROENCA, M. P.; VENTURA, J.; SOUSA, C. T.; VAZQUEZ, M.; ARAUJO, J. P. Temperature dependence of the training effect in electrodeposited $\mathrm{Co} / \mathrm{CoO}$ nanotubes. Journal of Applied Physics, v. 114, n. 4, $2013 \mathrm{a}$.

PROENCA, M. P.; VENTURA, J.; SOUSA, C. T.; VAZQUEZ, M.; ARAUJO, J. P. Exchange bias, training effect, and bimodal distribution of blocking temperatures in electrodeposited coreshell nanotubes. Physical Review B - Condensed Matter and Materials Physics, v. 87, n. 13, p. 1-7, $2013 b$.

RADU, F.; ZABEL, H. Magnetic heterostructures. [s.l: s.n.]v. 227

RADU, F.; ZABEL, H. Exchange bias effect of ferro-/antiferromagnetic heterostructures. In: Magnetic heterostructures. [s.1.] Springer, 2008b. p. 97-184.

RAIKHER, Y. L.; SHLIOMIS, M. I. The effective field method in the orientational kinetics of magnetic fluids. Adv. Chem. Phys, v. 87, p. 595-751, 1994.

ROCO, M. C. The long view of nanotechnology development: the National Nanotechnology Initiative at 10 years. Journal of Nanoparticle Research, v. 13, n. 2, p. 427-445, 2011.

ROSENSWEIG, R. E. Ferrohydrodynamics. [s.1.] Courier Corporation, 2013.

RUDERMAN, M. A.; KITTEL, C. Indirect exchange coupling of nuclear magnetic moments by conduction electrons. Physical Review, v. 96, n. 1, p. 99, 1954.

SAHOO, S.; POLISETTY, S.; BINEK, C.; BERGER, A. Dynamic enhancement of the exchange bias training effect. Journal of Applied Physics, v. 101, n. 5, 2007a. 
SAHOO, S.; POLISETTY, S.; BINEK, C.; BERGER, A. Dynamic enhancement of the exchange bias training effect. Journal of Applied Physics, v. 101, n. 5, p. 53902, $2007 \mathrm{~b}$.

SALAZAR-ALVAREZ, G.; SORT, J.; SURINACH, S.; BARÓ, M. D.; NOGUÉS, J. Synthesis and size-dependent exchange bias in inverted core-shell $\mathrm{MnO} \mid \mathrm{Mn} 3 \mathrm{O} 4$ nanoparticles. Journal of the American Chemical Society, v. 129, n. 29, p. 9102-9108, 2007.

SASAKI, M.; JÖNSSON, P. E.; TAKAYAMA, H.; MAMIYA, H. Aging and memory effects in superparamagnets and superspin glasses. Physical Review B, v. 71, n. 10, p. 104405, 2005.

SCHERRER, P. Bestimmung der inneren Struktur und der Größe von Kolloidteilchen mittels Röntgenstrahlen. In: Kolloidchemie Ein Lehrbuch. [s.1.] Springer, 1912. p. 387-409.

SCHERRER, P. Estimation of the size and internal structure of colloidal particles by means of röntgen. Nachr. Ges. Wiss. Göttingen, v. 2, p. 96-100, 1918.

SCHLENKER, C.; PACCARD, D. Couplages ferromagnétiques-antiferromagnétiques: étude des contractions de cycles d'hystérésis à l'aide d'un traceur de cycle très basses fréquences. Journal de Physique, v. 28, n. 7, p. 611-616, 1967.

SCHWERTMANN, U.; CORNELL, R. M. Iron oxides in the laboratory: preparation and characterization. [s.1.] John Wiley \& Sons, 2008.

SENGUPTA, A.; SARKAR, C. K. Introduction to nano: basics to nanoscience and nanotechnology. [s.1.] Springer, 2015.

SERRELI, V.; LEE, C.-F.; KAY, E. R.; LEIGH, D. A. A molecular information ratchet. Nature, v. 445, n. 7127, p. 523-527, 2007.

SHLIOMIS, M. I. Magnetic fluids. Physics-Uspekhi, v. 17, n. 2, p. 153-169, 1974.

SHLIOMIS, M. I.; PSHENICHNIKOV, A. F.; MOROZOV, K. I.; SHURUBOR, I. Y. Magnetic properties of ferrocolloids. Journal of Magnetism and Magnetic Materials, v. 85, n. 1, p. 40-46, 1990.

SHUKLA, P. Exact expressions for minor hysteresis loops in the random field Ising model on a Bethe lattice at zero temperature. Physical Review E, v. 63, n. 2, p. 27102, 2001.

SILVA, F. G.; AQUINO, R.; TOURINHO, F. A.; STEPANOV, V. I.; RAIKHER, Y. L.; PERZYNSKI, R.; DEPEYROT, J. The role of magnetic interactions in exchange bias properties of $\mathrm{MnFe}_{2} \mathrm{O}_{4} @ \gamma-\mathrm{Fe}_{2} \mathrm{O}_{3}$ core/shell nanoparticles. Journal of Physics D: Applied Physics, v. 46, n. 28, p. 285003, 2013.

SILVA, F. G. da. Propriedades magnéticas, desordem de superfície e polarização por intercâmbio de nanopartículas magnéticas. 2014.

SMEDLEY, E. Encyclopaedia metropolitana; or, universal dictionary of knowledge, on an original plan: comprising the twofold advantage of a philosophical and an alphabetical arrangement, with appropriate engravings: edited by edw. smedley, hugh jam. rose, and h. john . [s.l.] B. Fellowes, Rivington, Ducan, Malcolm, Suttaby, Hodgson, 1845. v. 1

SOUSA, E. C.; RECHENBERG, H. R.; DEPEYROT, J.; GOMES, J. A.; AQUINO, R.; TOURINHO, F. A.; DUPUIS, V.; PERZYNSKI, R. In-field Mossbauer study of disordered surface spins in core/shell ferrite nanoparticles. Journal of Applied Physics, v. 106, n. 9, p. 93901, 2009.

STEPHEN, P. S. Low viscosity magnetic fluid obtained by the colloidal suspension of magnetic particlesGoogle Patents, , 2 nov. 1965. . 
STONER, E. C.; WOHLFARTH, E. P. A mechanism of magnetic hysteresis in heterogeneous alloys. Philosophical Transactions of the Royal Society of London A: Mathematical, Physical and Engineering Sciences, v. 240, n. 826, p. 599-642, 1948.

SUESS, D.; KIRSCHNER, M.; SCHREFL, T.; FIDLER, J.; STAMPS, R. L.; KIM, J.-V. Exchange bias of polycrystalline antiferromagnets with perfectly compensated interfaces. Physical Review B, v. 67, n. 5, p. 54419, 2003.

SUN, Y.; SALAMON, M. B.; GARNIER, K.; AVERBACK, R. S. Memory effects in an interacting magnetic nanoparticle system. Physical review letters, v. 91, n. 16, p. 167206, 2003.

TAKAHASHI, S.; KOBAYASHI, S.; KAMADA, Y.; KIKUCHI, H.; ZHANG, L.; ARA, K. Analysis of minor hysteresis loops and dislocations in Fe. Physica B: Condensed Matter, v. 372, n. 1-2, p. 190-193, 2006.

TANG, Y.; SUN, Y.; CHENG, Z. Exchange bias associated with phase separation in the perovskite cobaltite La 1- x Sr x CoO 3. Physical Review B, v. 73, n. 17, p. 174419, 2006.

THAMM, S.; HESSE, J. A simple plot indicating interactions between single-domain particles. Journal of Magnetism and Magnetic Materials, v. 154, n. 2, p. 254-262, 1996.

THAMM, S.; HESSE, J. The remanence of a Stoner-Wohlfarth particle ensemble as a function of the demagnetisation process. Journal of Magnetism and Magnetic Materials, v. 184, n. 2, p. 245-255, 1998.

TIAN, Z. M.; YUAN, S. L.; LIU, L.; YIN, S. Y.; JIA, L. C.; LI, P.; HUO, S. X.; LI, J. Q. Exchange bias training effect in $\mathrm{NiFe} 2 \mathrm{O} 4 / \mathrm{NiO}$ nanocomposites. Journal of Physics $\mathbf{D}$ : Applied Physics, v. 42, n. 3, p. 35008, 2009.

TOULOUSE, G. Theory of the frustration effect in spin glasses: I. SPIN GLASS THEORY AND BEYOND: AN INTRODUCTION TO THE REPLICA METHOD AND ITS APPLICATIONS. Edited by MEZARD M ET AL. Published by World Scientific Press, 1987. ISBN\# 9789812799371, pp. 99-103, p. 99-103, 1987.

TOURINHO, F. A. Thèse de Doctorat D’Etat ès Sciences Physiques. 1988.

TOURINHO, F. A.; FRANCK, R.; MASSART, R. Aqueous ferrofluids based on manganese and cobalt ferrites. Journal of Materials Science, v. 25, n. 7, p. 3249-3254, 1990.

TOURINHO, F.; FRANCK, R.; MASSART, R.; PERZYNSKI, R. Synthesis and mangeitc properties of managanese and cobalt ferrite ferrite ferrofluids. In: Trends in Colloid and Interface Science III. [s.1.] Springer, 1989. p. 128-134.

TROMSDORF, U. I.; BIGALL, N. C.; KAUL, M. G.; BRUNS, O. T.; NIKOLIC, M. S.; MOLLWITZ, B.; SPERLING, R. A.; REIMER, R.; HOHENBERG, H.; PARAK, W. J. Size and surface effects on the MRI relaxivity of manganese ferrite nanoparticle contrast agents. Nano letters, v. 7, n. 8, p. 2422-2427, 2007.

VASILAKAKI, M.; TROHIDOU, K. N. Numerical study of the exchange-bias effect in nanoparticles with ferromagnetic core/ferrimagnetic disordered shell morphology. Physical Review B, v. 79, n. 14, p. 144402, 2009.

VASILAKAKI, M.; TROHIDOU, K. N.; PEDDIS, D.; FIORANI, D.; MATHIEU, R.; HUDL, M.; NORDBLAD, P.; BINNS, C.; BAKER, S. Memory effects on the magnetic behavior of assemblies of nanoparticles with ferromagnetic core/antiferromagnetic shell morphology. Physical Review B - Condensed Matter and Materials Physics, v. 88, n. 14, p. 1-5, 2013. 
VÁZQUEZ-VÁZQUEZ, C.; LÓPEZ-QUINTELA, M. A.; BUJÁN-NÚÑEZ, M. C.; RIVAS, J. Finite size and surface effects on the magnetic properties of cobalt ferrite nanoparticles. Journal of Nanoparticle Research, v. 13, n. 4, p. 1663-1676, 2011.

VENTURA, J.; ARAUJO, J. P.; SOUSA, J. B.; VELOSO, A.; FREITAS, P. P. Training effect in specular spin valves. Physical Review B, v. 77, n. 18, p. 184404, 2008.

VIEIRA, C. A. de M. Efeitos das interações magnéticas entre partículas nas propriedades de bloqueio de nanocristais de ferrita de cobalto. 2013.

VIOLA, K. L.; SBARBORO, J.; SUREKA, R.; DE, M.; BICCA, M. A.; WANG, J.; VASAVADA, S.; SATPATHY, S.; WU, S.; JOSHI, H. Towards non-invasive diagnostic imaging of early-stage Alzheimer's disease. Nature nanotechnology, v. 10, n. 1, p. 91-98, 2015.

VIZDRIK, G.; DUCHARME, S.; FRIDKIN, V. M.; YUDIN, S. G. Kinetics of ferroelectric switching in ultrathin films. Physical Review B, v. 68, n. 9, p. 94113, 2003.

WARREN, B. E. X-ray diffraction. [s.1.] Courier Corporation, 1969.

WEISS, P. L'hypothèse du champ moléculaire et la propriété ferromagnétique. J. phys. theor. appl., v. 6, n. 1, p. 661-690, 1907.

WELO, L. A.; BAUDISOH, O. XXXIX. Studies on precipitated magnetite, with particular reference to hysteresis. The London, Edinburgh, and Dublin Philosophical Magazine and Journal of Science, v. 3, n. 14, p. 396-410, 1927.

WILSON, B. Account of Dr. Knight's Method of Making Artificial Loadstones. By Mr. Benjamin Wilson, FRS. Philosophical Transactions of the Royal Society of London, v. 69, p. 51-53, 1779.

WU, R.; QU, J. Removal of water-soluble azo dye by the magnetic material MnFe2O4. Journal of Chemical Technology and Biotechnology, v. 80, n. 1, p. 20-27, 2005.

YANES, R.; CHUBYKALO-FESENKO, O.; EVANS, R. F. L.; CHANTRELL, R. W. Temperature dependence of the effective anisotropies in magnetic nanoparticles with Néel surface anisotropy. Journal of Physics D: Applied Physics, v. 43, n. 47, p. 474009, 2010a.

YANES, R.; CHUBYKALO-FESENKO, O.; EVANS, R. F. L.; CHANTRELL, R. W. Temperature dependence of the effective anisotropies in magnetic nanoparticles with Néel surface anisotropy. Journal of Physics D: Applied Physics, v. 43, n. 47, p. 474009, 1 dez. 2010 b.

YANES, R.; CHUBYKALO-FESENKO, O.; KACHKACHI, H.; GARANIN, D. A.; EVANS, R.; CHANTRELL, R. W. Effective anisotropies and energy barriers of magnetic nanoparticles with Néel surface anisotropy. Physical review B, v. 76, n. 6, p. 64416, 2007.

YANG, H.; ZHANG, C.; SHI, X.; HU, H.; DU, X.; FANG, Y.; MA, Y.; WU, H.; YANG, S. Water-soluble superparamagnetic manganese ferrite nanoparticles for magnetic resonance imaging. Biomaterials, v. 31, n. 13, p. 3667-3673, 2010a.

YANG, J.; LIM, E.-K.; LEE, E.-S.; SUH, J.-S.; HAAM, S.; HUH, Y.-M. Magnetoplex based on $\mathrm{MnFe} 2 \mathrm{O} 4$ nanocrystals for magnetic labeling and MR imaging of human mesenchymal stem cells. Journal of Nanoparticle Research, v. 12, n. 4, p. 1275-1283, 2010 b.

YANG, P. Y.; ZENG, F.; PAN, F. Exchange bias and training effect in Ni/Ag-doped NiO bilayers. Journal of Magnetism and Magnetic Materials, v. 322, n. 5, p. 542-547, 2010.

YOSIDA, K. Magnetic properties of Cu-Mn alloys. Physical Review, v. 106, n. 5, p. 893, 1957. 
YUAN, S.; XU, K.; LI, Z.; YU, L.; KANG, B.; CAO, S. Exchange bias and spin glassy behavior in low doped La1- xSrxCoO3 cobaltites. Journal of Applied Physics, v. 105, n. 9, p. 93910, 2009.

ZHENG, R. K.; GU, H.; XU, B.; ZHANG, X. X. Memory effects in a nanoparticle system: Low-field magnetization and ac susceptibility measurements. Physical Review B, v. 72, n. 1, p. 14416, 2005.

ZHENG, R. K.; GU, H.; ZHANG, X. X. Comment on “Memory Effects in an Interacting Magnetic Nanoparticle System”. Physical Review Letters, v. 93, n. 13, p. 139702, 21 set. 2004.

ZHENG, R. K.; WEN, G. H.; FUNG, K. K.; ZHANG, X. X. Training effect of exchange bias in $\gamma$ - Fe 2 O 3 coated Fe nanoparticles. Physical Review B, v. 69, n. 21, p. 214431, 2004a.

ZHENG, R. K.; WEN, G. H.; FUNG, K. K.; ZHANG, X. X. Giant exchange bias and the vertical shifts of hysteresis loops in $\gamma$-Fe2O3-coated Fe nanoparticles. Journal of Applied Physics, v. 95, n. 9, p. 5244-5246, 2004b.

ZYSLER, R. D.; DE BIASI, E.; RAMOS, C. A.; FIORANI, D.; ROMERO, H. Surface and interparticle effects in amorphous magnetic nanoparticles. In: Surface Effects in Magnetic Nanoparticles. [s.1.] Springer, 2005. p. 239-261. 